\title{
Cognitive aging and health-related factors
}

Citation for published version (APA):

Houx, P. J. (1991). Cognitive aging and health-related factors. [Doctoral Thesis, Maastricht University]. Rijksuniversiteit Limburg. https://doi.org/10.26481/dis.19911017ph

Document status and date:

Published: 01/01/1991

DOI:

10.26481/dis.19911017ph

Document Version:

Publisher's PDF, also known as Version of record

\section{Please check the document version of this publication:}

- A submitted manuscript is the version of the article upon submission and before peer-review. There can be important differences between the submitted version and the official published version of record.

People interested in the research are advised to contact the author for the final version of the publication, or visit the DOI to the publisher's website.

- The final author version and the galley proof are versions of the publication after peer review.

- The final published version features the final layout of the paper including the volume, issue and page numbers.

Link to publication

\footnotetext{
General rights rights.

- You may freely distribute the URL identifying the publication in the public portal. please follow below link for the End User Agreement:

www.umlib.nl/taverne-license

Take down policy

If you believe that this document breaches copyright please contact us at:

repository@maastrichtuniversity.nl

providing details and we will investigate your claim.
}

Copyright and moral rights for the publications made accessible in the public portal are retained by the authors and/or other copyright owners and it is a condition of accessing publications that users recognise and abide by the legal requirements associated with these

- Users may download and print one copy of any publication from the public portal for the purpose of private study or research.

- You may not further distribute the material or use it for any profit-making activity or commercial gain

If the publication is distributed under the terms of Article $25 \mathrm{fa}$ of the Dutch Copyright Act, indicated by the "Taverne" license above, 
COGNITIVE AGING AND HEALTH-RELATED FACTORS 


\section{COGNITIVE AGING AND HEALTH-RELATED FACTORS}

\section{PROEFSCHRIFT}

ter verkrijging van de graad van doctor aan de Rijksuniversiteit Limburg te Maastricht, op gezag van de Rector Magnificus, prof. mr. M.J. Cohen, volgens het besluit van het College van Dekanen, in het openbaar te verdedigen op

donderdag, 17 oktober 1991 om 16.00 uur

door

PETRUS JACOBUS HOUX

geboren op 9 maart 1958 te 's-Gravenhage 
PROMOTOR:

Prof. Dr. J. Jolles

BEOORDELINGSCOMMISSIE:

Prof. Dr. M. A. van den Hout (voorzitter)

Prof. Dr. A. P. W. M. Appels

Prof. Dr. A. Kok (Universiteit van Amsterdam)

Dr. J. Lodder

Dr. J. J. F. Schroots (ERGO)

ISBN 90-9004338-1 
voor mijn ouders

\section{aan mijn oma's}


NAJAARSMIST

Het landschap dat, nu stilte en avond dalen,

In lage, lichte nevelen verdwijnt,

Is als de hemel, waar de herfstmaan schijnt

Door de wolken heen, waarachter de sterren stralen.

De duistre hoeven, door het land verspreid,

En langs den kouden weg de lege bomen

Gaan in den mist teloor. De harten stromen

Vol van het najaar en zijn eenzaamheid. 
Chapter 1 - Introduction and rationale

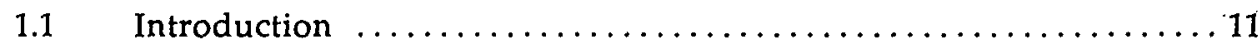

1.2 Important questions in cognitive gerontology $\ldots \ldots \ldots \ldots \ldots \ldots \ldots 13$

1.3 Methodological issues in (cognitive) aging research $\ldots \ldots \ldots \ldots \ldots 16$

1.4 Health-related factors in the normal population; biological life events (BLE) introduced $\ldots \ldots \ldots \ldots \ldots \ldots \ldots \ldots \ldots \ldots$ i9

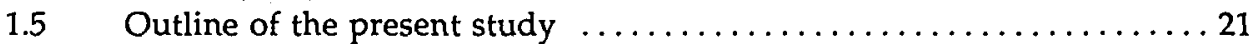

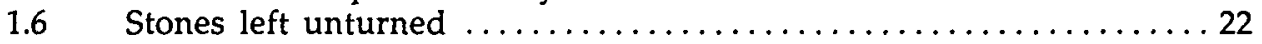

Chapter 2 - Some cognitive functions and methods to assess them

2.1 Theoretical constructs of cognitive functions $\ldots \ldots \ldots \ldots \ldots \ldots \ldots 25$

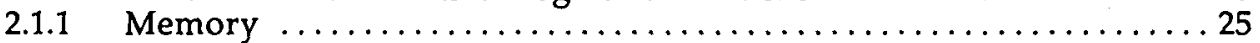

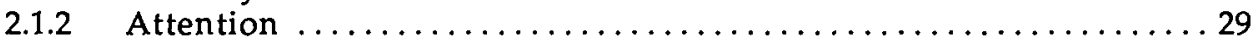

2.2 Different approaches to neuropsychological assessment $\ldots \ldots \ldots \ldots 30$

2.2.1 Psychometrics .................................... 31

2.2.2 Tasks derived from the information processing paradigm $\ldots \ldots \ldots \ldots 32$

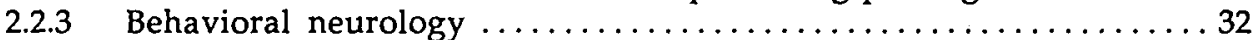

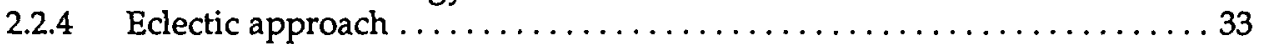

2.3 The issue of optimal assessment methods $\ldots \ldots \ldots \ldots \ldots \ldots \ldots \ldots 33$

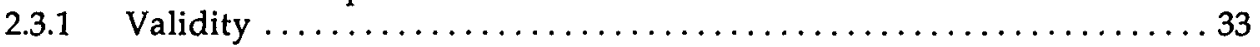

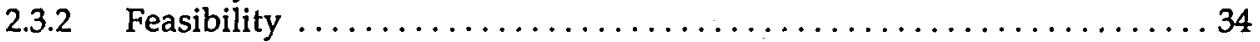

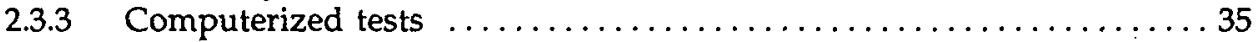

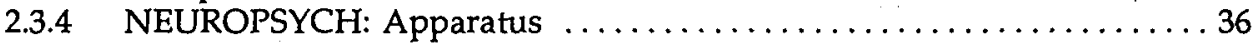

2.4 The choice of tests for the present research $\ldots \ldots \ldots \ldots \ldots \ldots \ldots 37$

Chapter 3 - Subjects and procedure

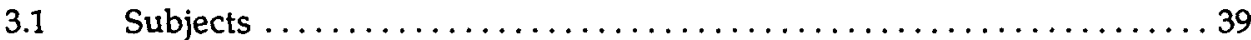

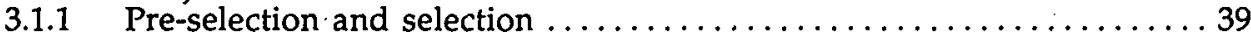

3.1.2 Education .................................... 40

3.1.3 Assignment to groups with and without biological life events (BLE) . 40

3.1.4 Biological Life Events and scoring $\ldots \ldots \ldots \ldots \ldots \ldots \ldots \ldots \ldots \ldots 1$

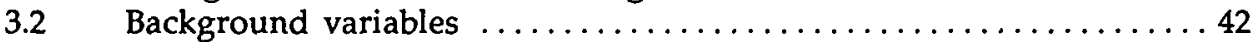

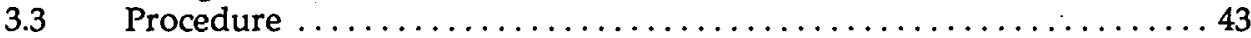

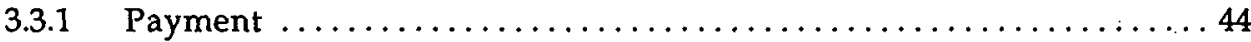

Chapter 4 - Biological Life Events and background variables in the present sample

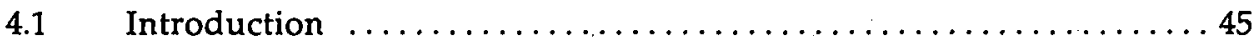

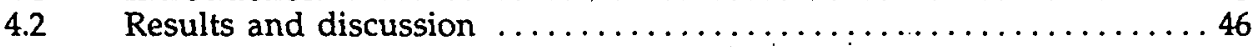

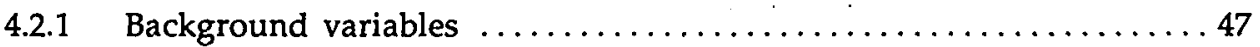

Chapter 5 - Primary memory: Digit \& Block Span Tests

$5.1 \quad$ Introduction: Measurement of short-term memory span $\ldots \ldots \ldots \ldots 51$

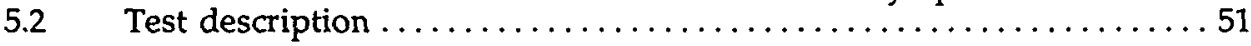




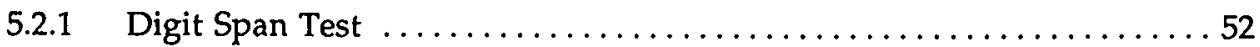

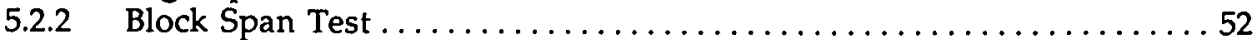

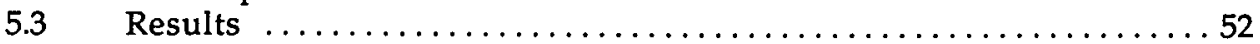

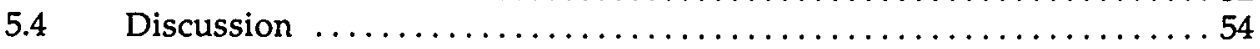

Chapter 6 - Speed of memory processing I: Computerized Memory Scanning Test

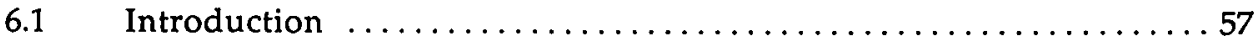

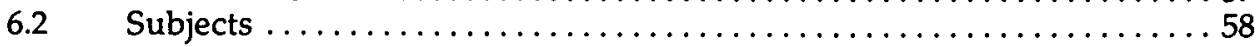

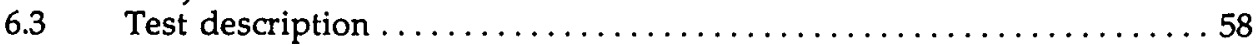

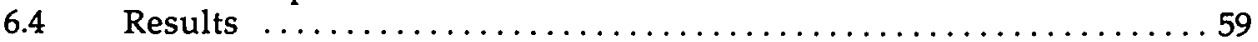

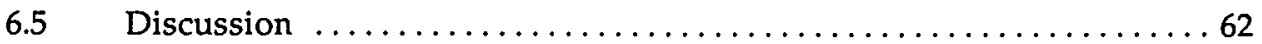

Chapter 7 - Speed of memory processing II: Paper-and-Pencil Memory Scanning Test

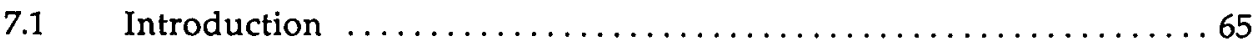

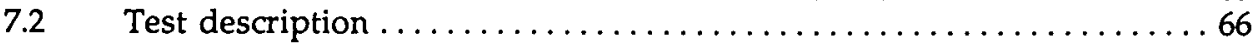

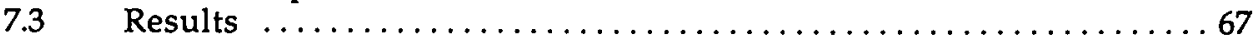

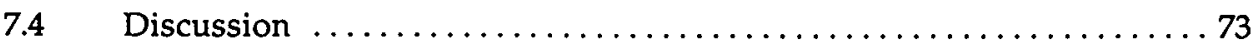

Chapter 8 - Secondary memory performance: Visual Verbal Learning Test

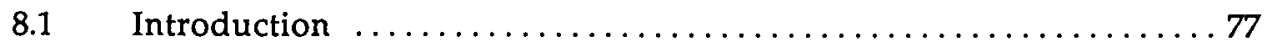

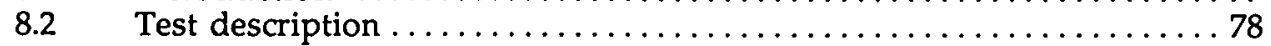

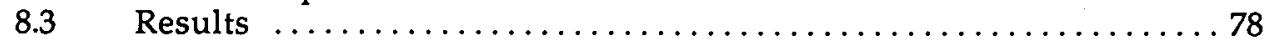

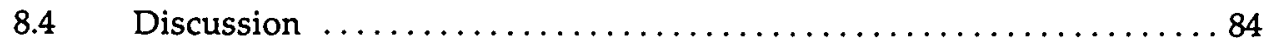

Chapter 9 - Interference susceptibility: Stroop Color Word Test

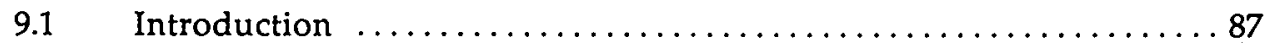

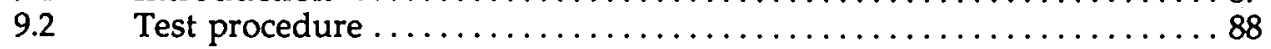

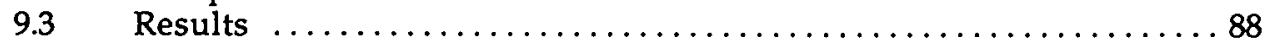

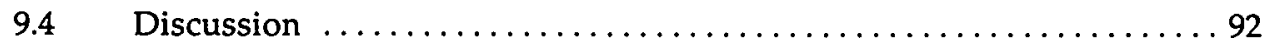

Chapter 10 - Concept shifting ability: Revised Trail Making Test and Concept Shifting Test

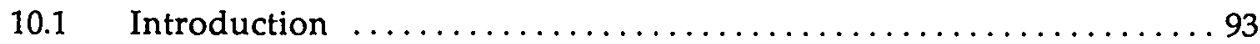

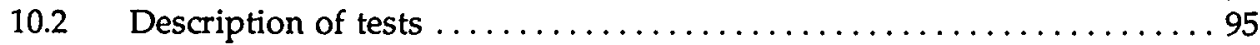

10.2.1 Revised Trail Making Test (R-TMT) ..................... 95

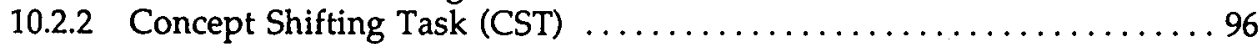

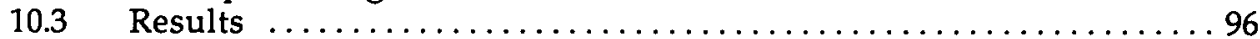

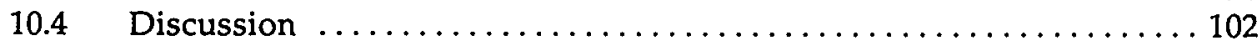


Chapter 11 - Psychomotor Performance I: Continuous

Performance Tapping Test

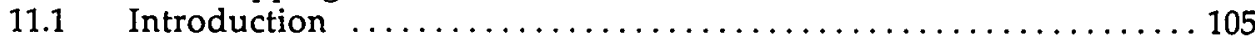

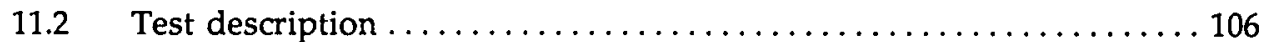

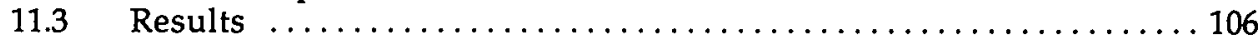

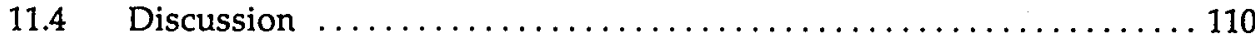

Chapter 12 - Psychomotor performance II: Motor Choice Reaction Test

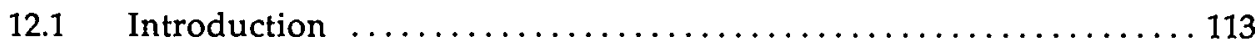

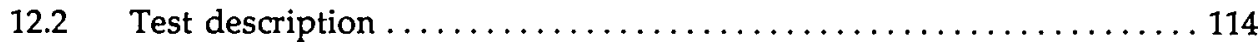

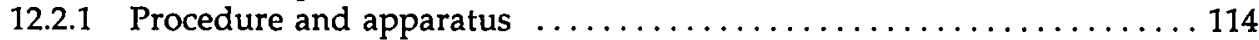

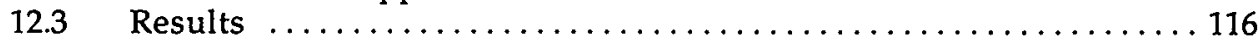

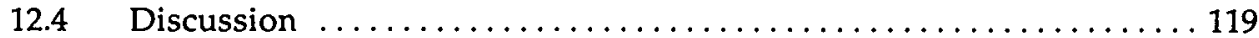

Chapter 13 - Relations between test outcomes:

Beyond the single test paradigm

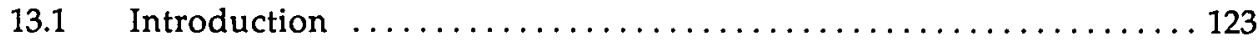

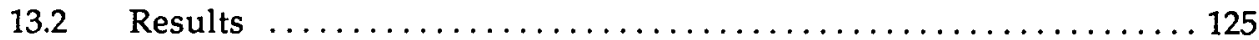

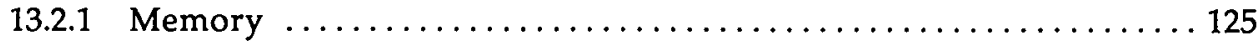

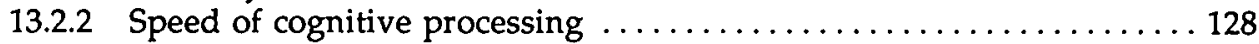

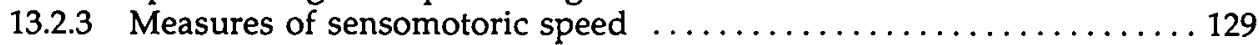

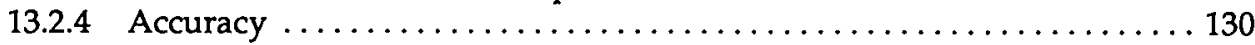

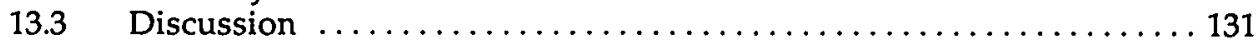

Chapter 14 - General discussion and concluding remarks

$14.1 \quad$ Age-associated memory impairment $\ldots \ldots \ldots \ldots \ldots \ldots \ldots \ldots \ldots \ldots$

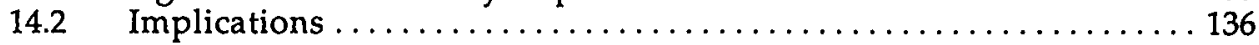

14.2.1 Research of aging and dementia ....................... 137

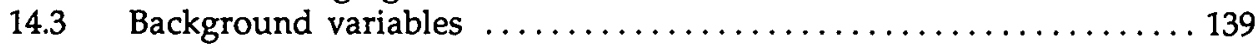

14.4 Longitudinal follow-up $\ldots \ldots \ldots \ldots \ldots \ldots \ldots \ldots \ldots \ldots \ldots \ldots \ldots$

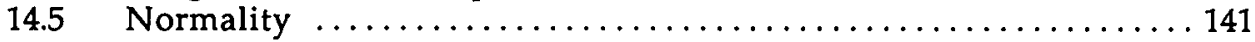

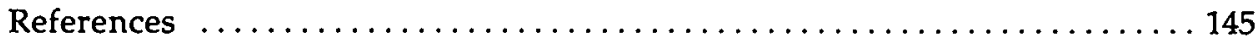

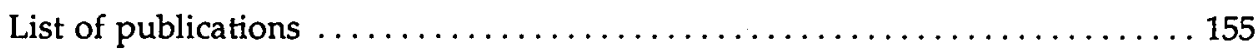

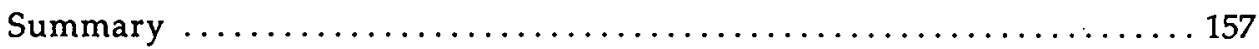

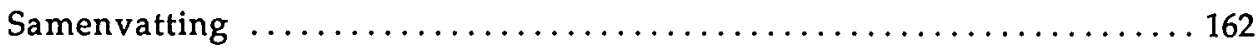

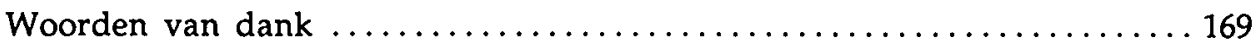

Curriculum Vitae ................................... 171

Appendix I : Instructions for test administration $\ldots \ldots \ldots \ldots \ldots \ldots \ldots \ldots 173$

Appendix II : Norm tables ................................ 181 


\section{INTRODUCTION AND RATIONALE}

\subsection{Introduction}

It is quite firmly established that virtually all aspects of cognitive functioning deteriorate with age. The literature on age effects on cognitive performance is immense, and it is expanding rapidly. Recently appeared journals (e.g., the APAjournal 'Psychology and Aging') are dedicated exclusively to psychological aspects of adult development and aging. Also, several authoritative handbooks (e.g., Charness, 1985; Birren and Schaie, 1985; 1990; Botwinick, 1984; Salthouse, 1986) constitute rich sources of information on most conceivable realms of cognitive aging. As for cognitive functions, the general picture that emerges from all this, is that nearly all aspects of cognitive performance decline as age advances, and that this is true for all individuals, including normal and healthy subjects. We also know, however, that not all individuals decline at the same rate: the variability of the performance in cognitive tests increases with age. As yet, there is little cohesion in the field of studies on cognitive aging, probably due to the immense complexity of the matter.

Not only the number of publications on aging is rising. During the last decades, The Netherlands and other Western European and North American countries have seen a sharp increase in the absolute number as well as the proportion of aged individuals in the whole population (CBS, 1991). The term double aging (dubbele vergrijzing) has been used to refer to the rapid increase in the number of aged persons due to both increased life expectancy since World War II and the "birth boom" of the post-war years. The double aging will manifest itself especially in the beginning of the 21st century. However, already in the period 1990-2000, there will be an increase in the number of middle-aged subjects.

The expected increase in the number of middle-aged and elderly subjects in the years to come draws attention to the topic of cognitive aging or cognitive gerontology (e.g., Rabbitt, 1990), one of the main issues of the present thesis. After the great amount of research that has been performed in recent decades, it is now generally agreed upon that several aspects of cognitive functioning decline in healthy individuals during the later decades of adult life (Birren and Schaie, 1985; Charness, 1985; Poon, 1986). The acquisition of new information is less efficient, which, coupled by a diminished retention of that information for later use, results in substantially poorer memory performance (Jolles, 1986). Planning of new activities, problem solving, and complex decision making, as well as flexibility is noticeably diminished (Reese and Rodeheaver, 1985). In addition, attentional processes appear to be invariably poorer in old subjects (Plude and Hoyer, 1985). Over a third of all individuals aged over sixty years complain of problems with sleeping (Woodruff, 1985). Sleeping is closely related to arousal, which is also impaired in old age. In addition, there appears to be a general slowness, especially in the performance of tasks that have to be carried out under 
time pressure and/or in demanding situations. At the root of this slowness, in turn, may be a general slowing down of central nervous system (CNS) functioning (Botwinick, 1984). A fruitful model for this slowing is provided by the notion of resources and resource reduction, as discussed by Salthouse (1988). Briefly, any cognitive activity requires resources, that can be viewed as time, space, or energy. Reduction of resources results in a diminished capacity to process information. In the present chapter, no in-depth review is given of the relation between aging and cognition. For a thorough overview of the evidence on this issue, the reader is referred to one of the excellent surveys mentioned above, especially the one by Birren and Schaie (1985).

While it is quite clearly established that the deterioration in cognitive functioning -or cognitive efficiency-is present in elderly subjects (i.e., after 65 years of age), there is evidence that the performance of even normal, healthy subjects already deteriorates in middle age (above 40 years), at least in some categories of individuals (Houx, Vreeling, and Jolles, 1991a; Rabbitt, 1990). Ageassociated cognitive decline may lay dormant for decades, and only become gradually or suddenly apparent as the subject realizes that some aspect of his or her functioning is no longer what it used to be. Recent evidence points out that loss of CNS neurones may occur as early as the fourth decade (Haug, 1985). Finally, emotional changes may occur in the elderly, either due to social or material losses, or as a consequence of the knowledge that many faculties have been lost or diminished (Botwinick, 1984).

The impact of cognitive aging is manyfold and impressive, both for the individual and for society (Schroots, Birren, and Svanborg, 1988). Elderly people have much spare time because of their increased life expectancy. At the same time, many aging individuals experience the decline of functions and abilities as a handicap for activities to which they may still be motivated. Reduced cognitive abilities have a profound influence on the experienced quality of life. Moreover, cognitive aging and the decline of memory and other functions by which aging is accompanied, may herald pathological conditions such as dementia. Many people live in fear of an approaching dementia, which afflicts $5 \%$ of all subjects over 65 and $40 \%$ of all those over 85 years of age. Such a fear of forgetting may affect the quality of life of many individuals in its own right.

Cognitive aging places enormous burdens on society, the first and foremost of which lies in the realm of health-care (Van der Maas, 1988). The impact of dementia for our society is enormous, both in view of the burden on the family, on social and medical systems and in view of the finances which are necessary for diagnosis, treatment and care. Increased knowledge about normal/healthy cognitive aging is a prerequisite for the study of dementia, as knowledge about normality is necessary for assessing deviations from the norm. Cognitive aging already appears to have an impact on middle-aged people, more than is recognized to date (Houx et al., 1991c). Problems that persons aged 40-60 experience may have to do with the fact that cognitive functions and abilities deteriorate. These problems often arise in their jobs and can cause problems in family and other relations, increased use of the social security system, and of 
health-care facilities and drugs. This in turn, gives rise to complaints of defective memory functions, decrease of cognitive energy, especially in demanding situations, and lack of concentration and attention. To date, the problems in work or social relations in the middle-aged have been ascribed to social causes, but they might also be the consequence of decreased cognitive functioning.

A final effect of cognitive aging is secondary to the rapid technological changes that have appeared in the course of the last decades. The elderly are less apt to cope with the new technical tools and with information technology (e.g., Teletext). It may even be the case that the procedures presently used to convey information via brochures, manuals, traffic information, television (e.g., subtitles) and route descriptions in hospitals, railway stations, etc. are not optimal for the elderly.

\subsection{Important questions in cognitive gerontology}

The quest for knowledge about the processes of aging of cognitive functions has been termed cognitive gerontology. This discipline tries to bridge the gaps between various other disciplines such as social gerontology, psychogerontology and medical gerontology. Rabbitt (1990) formulated the objectives of cognitive gerontology:

"The main research goals for Applied Cognitive Gerontology are deceptively simple: when do age changes in cognition first appear? How fast do they proceed? Are changes "global" so that all cognitive systems and the skills that they support change at similar rates and to the same extent, or does ageing affect some independent "modules" and their "domain specific" skills before others? We may ask parallel questions about variations in the rates of ageing between individuals: are there marked individual differences in the ages of onset and in the rates of progression of cognitive ageing? Do all individuals experience the same patterns of cognitive change with age or are there a variety of distinct patterns with characteristic time-scales and aetiologies? These last questions imply the most interesting issue of all for applied cognitive psychologists: Can we slow or abolish cognitive aging?".

The simplicity of these goals is indeed deceptive: attaining only one of them may well be a life's work, or more. To illustrate this, the questions concisely formulated, have to be spun out somewhat:

Can a distinct point be assigned in the individual life-span at which cognitive changes first emerge?

It is not known when cognitive changes appear and once the change begins, at what rate it proceeds. Does the decline start early in life and gradually go on or accelerate with age (the continuous decline hypothesis) or does it manifest itself abruptly (the terminal drop hypothesis (Riegel and Riegel, 1967; 1972). Terminal drop may occur after a major event, e.g., related to physical health, such as an 
infective disease, resulting in a sharp decrease in cognitive performance. Of course, terminal drop is more likely to occur in the second half of the life span, but with the life expectancy having become much higher during the last century, this period can extend over the fourth to the ninth decade of life. Unfortunately, the majority of experimental cognitive aging research performed up till now has focused on performance differences between young adults (mostly students) and elderly subjects. By consequence, information on cognitive deterioration in the middle ages is lacking. Yet, studying the ages between 30 and 60 is essential to gain insight into functional development during all adulthood and knowledge about which functions decline when. The question when decline occurs, is closely related to the issue to be discussed in the next section.

\section{At what rate do cognitive functions decline?}

As the bulk of studies on cognitive aging was cross-sectional (i.e., studying two or several age groups at one point in time), the distinct possibility exists that studies reporting gradual cognitive decline are an artefact of the fact that older age groups merely contain more poorly performing subjects (Rabbitt, 1990). This could be the result of more elderly subjects who find themselves in the period between their terminal drop and death. This number increases with group age, causing the average group performance to be poorer. Incidentally, this would also result in higher group variance, a phenomenon often encountered in crosssectional research. Individual age-performance trajectories, as Rabbitt (1986) put it, may differ widely, and yet result in a tidily declining overall trajectory.

Another, intuitively appealing possibility is that most individuals do indeed show a gradual decline with age, perhaps as a result of the accumulation of effects of minor brain dysfunction. At first, these minor pathologies may have little impact, but, as they accumulate, or as age advances, their amassed effects result in perceivable cognitive deficits. Terminal drop would then only occur as a result of some major pathology. This latter possibility is clearly the more optimistic one, as it paves the way for adding life to the years. As yet, we do not know which of either possibilities, or some combination, might apply.

\section{Which cognitive functions are most vulnerable to age?}

Does continuous decline or terminal drop exist to a comparable extent for all different cognitive functions? This is unlikely, as it is known that not even memory is a unitary function and particular aspects of memory -e.g., recognition memory-appear to remain at least relatively intact up to later in life (Geffen, Moar, O'Hanlon, Clark, and Geffen, 1990). The decline of sensory and perceptual performance (Verillo and Verillo, 1985) and physical performance (Stones and Kozma, 1985) can have great impact on general cognitive functions, but there need not be any direct or causal relation to cognitive performance. Any loss of memory may well lag very much behind with perceptual loss, or not occur at all. Another well-known example of differential age effects is the dissociation between crystallized and fluid intelligence, originally put forward by Cattell 
(1963). In this dichotomy, the former denotes those cognitive processes and skills that are more or less independent of age (such as retrieval of long-stored information), the latter concerns processes that show age-related decline (such as attentional processes or spatial reasoning). White and Cunningham (1988) showed that the terminal drop phenomenon mentioned above may be limited to crystallized abilities. However, much about the fluidity of cognitive functions is unknown. In any case, we must be wary of confusing general decline from a very hypothetical common aetiology.

\section{Which individuals show age-related decline?}

There is a great lack of information as to whether general cognitive decline is something that all aging subjects are up against. In other words, is cognitive aging an inherent aspect of physiological aging or are additional factors -i.e., biological and/or psychosocial factors- also responsible for cognitive aging? There is a shortage of data on individual patterns of cognitive aging. Information regarding determinants of both healthy and pathological cognitive aging is lacking. It is important to get more information on individual trajectories and patterns of cognitive aging and their determinants (Rabbitt, 1986). This is especially true because several studies have shown that some of the elderly are not inferior in cognitive performance compared to normal young adults. This leaves us the question what determines this successful cognitive aging or, conversely, what causes the majority of individual aging patterns to be less successful? What causes the usual aging to be distinguishable from successful cognitive aging (Rowe and Kahn, 1987)?

Up till now, the majority of the research performed in the realm of memory and aging has been based upon the premise that the changes in memory with age are a corollary of the physiological aging process. Several terms have been proposed to define the condition in subjects who complain of memory and memoryrelated functions. Kral (1962) introduced the terms Benign and Malignant Senescent Forgetfulness (BSF and MSF, resp.). MSF would point to severe and progressive pathology such as dementia, whereas BSF would reflect forgetfulness often encountered in old age. Nevertheless BSF is thought be pathological to some extent. More recently, Crook et al. (1986) defined a condition named AgeAssociated Memory Impairment (AAMI). They proposed diagnostic criteria, that would also serve research purposes. A subject meeting these criteria would be characterized by -among other things- an absence of medical conditions involving the brain.

\section{Age norms for cognitive functions and test performance}

Tests that have been developed for neuropsychological assessment are often used to measure cognitive functions in experimental settings, especially in elderly subjects. Although a great many tests are presently used in neuropsychology, there is a nearly absolute lack of norms for the majority of the relevant tests, let alone norms subdivided for age. Of course, the well-known tests for intelligence 
(such as the Wechsler Adult Intelligence Score; WAIS; see Lezak, 1983) have wellestablished age-graded norms. Also some neuropsychological tests and batteries are provided with age norms (e.g., the Halstead-Reitan battery, or the Auditory Verbal Learning Test; Lezak, 1983). For most tests, however, clinicians and experimenters base their judgment about a patient or subject on a general notion about how the test should be performed. This may have some practical validity, but it is not sufficient in the long run. Often, some test norms are available, but no age norms are provided based on adequately large numbers of healthy subjects of various ages. Many experimental data on the performance of a welldefined sample of patients are used as norms for clinical populations. Normative data taking health-related factors into account are as yet non-existent.

In order to differentiate normal age-related functional decline from pathological functional aging, we have to know how healthy adults of all ages ideally perform at the test used to evaluate the function. Furthermore, as there may be interactions in effects on performance between age on the one hand, and sex, education, and health variables on the other, age norms should ideally be based on data obtained from various subgroups within a given age category.

\subsection{Methodological issues in (cognitive) aging research}

One of the major problems in interpreting and generalizing the results of gerontological research is that the vast majority of studies are cross-sectional. Subjects assigned to the different age groups (often only two) vary in more than just their calendar age. Thus, without further knowledge about the subjects who constitute the age groups, it is virtually impossible to tell true age effects from cohort effects. Charness (1985, p. XVI) cites a very illustrative anecdote:

"A researcher goes into a neighborhood, speaks to some young people, and finds that they speak fluent English; he speaks next to middle-aged people (their parent's generation) and hears English with a slight Italian accent. He speaks finally to older people (in their grandparent's generation) and hears a pronounced Italian accent. He then 'concludes' that as you grow older you develop an Italian accent".

Isolating the effect of age alone from that of other events that are embedded in time, is troublesome in yet another way. For instance, in the life of an 80-year old, problems with social relations at the age of 20 are a minor part of his total life experience; since that time he has had 60 more years in which he was exposed to life events of all kinds (divorce, falls, smoke, alcohol, etc.). Which of the differences between him and a twenty-year-old should be attributed to the passage of time and which to other variables?

Given the relative lack of longitudinal studies on cognition, confounding effects of cohort (and of time of measurement) are of serious concern (Schaie, 1986): that is, the role of generational changes and differential environmental stimulation. Cohort effects are generally understood as common experiences to those born in 
a historical epoch and as such they are external factors that potentially invalidate the findings of cross-sectional studies. Society having become increasingly complex and elderly subjects having had less access to technology, could place elderly individuals at a disadvantage when presented with cognitive tasks (cohort effect). Furthermore, impact of technology is extended over some period of time, during which time of measurement is another confounding variable. Schaie and Labouvie-Vief (1974) showed clearly that cohort effects do exist. After having found marked cross-sectional performance differences on several aspects of adult intelligence, their subjects were followed for as much as fourteen years, only to show that most of the subtest scores had remained stable or even improved in nearly all original age groups. It is thus very likely that the original age differences that were found were largely due to other factors than aging per se and that these factors could be identified as cohort effects. Schaie and Labouvie even concluded that

"most of the adult life span is characterized by an absence of decisive intellectual decrements. In times of rapid cultural and technological change it is primarily in relation to younger populations that the aged can be described as deficient, and it is erroneous to interpret such cross-sectional age differences as indicating ontogenic change patterns".

It must be stated, however, that Schaie and Labouvie-Vief's longitudinal study had been performed with initial age groups from 25 to 70 , that the older age groups did in fact show declining performance, and finally, that their samples became increasingly selective (Labouvie-Vief, 1985). This raises another problem, inherent to longitudinal studies: the danger of selective attrition must be dealt with. People who survive long enough to remain in a longitudinal study for many years are likely to be healthier and better educated, and better off from a social-economic point of view, and will therefore not be very representative of the whole aging population.

In short, whereas cross-sectional studies overestimate age-related decline, longitudinal research underestimates it. Even the last approach is not free from other confounds. In a longitudinal study of health by means of measuring blood pressure or cholesterol level, age is probably hard to distinguish from time of measurement in an epoch characterized by a rise in consumption of 'junk food'. Then there is the problem of practice effects and procedure learning. Being exposed to some test of cognitive performance, whether it be an IQ test or assessing technique of memory or motor reaction speed, makes a subject 'testsophisticate'. This may even occur if the test trials are widely spaced. 'You can't step into the same river twice'. Schaie's paper (1986) aims at breaking this methodological impasse by proposing a revised general developmental model, but, to date, there is no evidence of any studies having followed his suggestions.

Experimental designs that combine the advantages of longitudinal and crosssectional approaches, also have to deal with the problems inherent to both. Yet, authors like Nesselroade and Labouvie (1985) or Schaie (1965; 1986) feel such a sophisticated sequential design is the method of choice, other things being equal. In this vein, cross-sectional age differences can be checked after some time, 
thereby distinguishing between true age effects as predicted by cross-sectional differences observed at the first measurement, and cohort effects. At the same time, some correction for time of measurement can be carried out. Schaie and Labouvie-Vief (1974) describe a study carried out following this design.

Irrespective of the experimental setup, there are still other methodological problems complicating the collection of meaningful data on the development of cognitive functions during adulthood. There is a lack of agreement upon the definition of terms used to describe age-related dysfunctions. For instance, cognitive functions and dysfunctions have not been systematically investigated in middle-aged and elderly subjects who have no known somatic disease.

Furthermore, criteria for subject selection used by different researchers are not the same. Consequently, it is difficult to compare the results of various studies that use "healthy volunteers", but in which the health-assessment has not been standardized. Finally, cognitive tests administered to adults of different ages or capacities may not tap the same faculties. It is conceivable that elderly or less educated subjects opt for other strategies to accomplish a task. For instance, there is a persistent notion that, as age increases, so does cautiousness and conservatism (see Botwinick, 1984, pp. 166-184, for discussion). In tasks requiring speed, rather than precision, this may result in too great an emphasis on accuracy, when the experiment is carried out to test maximum speed.

One other important issue should be mentioned here. Most studies on aging are only concerned with one aspect of cognition. This is unfortunate because simultaneous analysis of different processes -both cognitive and purely sensoric or motoric- in relation to age could prove extremely informative about the nature of age-related changes in general functioning. Salthouse (1990) and Shimamura (1990) recently argued for the investigation of aging effects in different domains of functioning. Age-related changes in different aspects of cognition may have independent causes which should be unravelled. Moreover, age-effects found in different domains of cognition may share the same cause or set of causes, which can only be identified by studying an array of functions in the same set of aging individuals. However, these studies have been quite rare until the present day (Salthouse, 1990).

There are, in sum, a host of factors that can thwart the interpretation of aging research, either experimental or epidemiological, be it cross-sectional, or longitudinal. Researchers of aging apparently can do no better than pull themselves out of this morass by their bootstraps. This would certainly imply opting for longitudinal and sequential designs, in spite of difficulties attached to this approach, as it seems the only way to study intra-individual change. Another prerequisite to study cognitive functions as they change with increasing age, is at least one well worked-out theoretical model of the function concerned. Some of these models will be discussed in chapter 2 . 
1.4 Health-related factors in the normal population; Biological Life Events (BLE) introduced

It is only recently that some interest arose in health-related factors in relation to cognitive aging. Up till a few years ago, there have been no published reports on the possibility that subtle health-related factors might influence cognition, and that this health effect might aggravate the age-related cognitive decline. Of course, cognitive dysfunctions in relation to well established disease-states such as moderate to severe brain trauma, depression and chronic alcoholism are well documented. However, the issue at stake is whether conditions with unknown or ambiguous relation to cognitive (dys)function -such as very mild closed head injury ( $\mathrm{CHI}$ ), social drinking, increased blood pressure, anesthesia or diabetes mellitus- have some influence on cognitive functioning.

Recently, the term biological life events (BLE) was proposed (Houx et al., 1989; $1990 ; 1991 \mathrm{~b})$ to define "those factors which are related to physical or mental health, experienced at any point in life and thought to be related to brain dysfunctioning, other than grossly impairing conditions like dementia and brain trauma". These factors were taken into account in a number of cognitive aging studies, following data presented by Haxby et al. (1986), who found age effects of visual memory that were much smaller than usually reported in the literature in a sample of subjects who had passed a "rigorous health screening". Not all studies agree on this matter. Salthouse, Kausler, and Saults (1990) for instance, did not find a relationship between health (crudely assessed by means of a selfrating scale) and cognitive performance. Several other researchers however, found indications for such a relationship. Elias and coworkers (e.g., Elias, Robbins, Schultz, and Pierce, 1990), found main effects of hypertension on performance on a neuropsychological test battery. These effects interacted with age. Therefore, hypertension or anti-hypertensive medication can be regarded as BLE.

With respect to general anesthesia, Hartman (1988) reviews reports on the neuropsychological side effects of several anesthetics. It appears that evidence as for long-term performance decrements in aging subjects is inconclusive. Jones et al. (1990) found no significant effects at three months after operation. Their methods of testing, however, can be said to be rather insensitive. The same is true for the results of Chung et al. (1990) who concluded that "postoperative mental deterioration is no greater in elderly than in young patients".

Regarding mild brain trauma, or closed head injury ( $\mathrm{CHI}$ ), an increasing number of reports is suggestive of mild interactions with cognitive functioning (Binder, 1986). Little is known however, about interactions with the effects of aging. A similar issue pertains to the effects of mild to moderate alcohol consumption, i.e., individuals who can not be assumed to be an alcoholic (e.g., Hartman, 1988).

A wide variety of systemic diseases (see e.g., Knoefel and Albert, 1985) can lead to dementia. If they do not, or not permanently, the patient is thought to have recovered or not experiencing any complications. However, it is likely that the 
brain has suffered at least functional damage, which cannot be diagnosed.

Medication, or exposure to neurotoxic agents (Hartman, 1988) constitute another important area of possibly brain-damaging factors. Many elderly subjects receive sleep medication as soon as they complain about insomnia. Yet, these factors are rarely considered in usual cognitive aging research.

It can be concluded that subtle health-related factors are potentially of great importance for the issue of cognitive aging. These factors can be assumed not severe enough to cause any acute or perceivable trouble for the individual, but still have some impact on brain functioning. Self-ratings of health status seem too crude to be used to detect these factors, as can be concluded from several contributions to a special issue of the Journal of Gerontology (July, 1990) which was dedicated to health and cognitive aging. For instance, Salthouse et al. (1990) found indications that age trends were independent of health status. However, these authors deemed it premature to draw any conclusions, as their way of health screening was -as they put it- "extremely crude and insensitive": they let the subjects rate their own health on a five-point scale, whether they had been treated for high blood pressure or diabetes, and how many treatments they had received. The authors cite evidence that self-assessed health would reliably correlate with several medical problems. Perlmutter and Nyquist (1990) found only modest relationships between various self-reported physical health measures. Evidence about reliability of self-reports is not conclusive. It is conceivable, for instance, that subjects with long-lasting impaired health are used to their handicaps and therefore more inclined to underestimate their medical problems. Rabbitt (1990) states that the self-rating questionnaires, although well-

Table 1.1 Factors associated with brain dysfunctions and/or cognitive decline: Biological Life Events (BLE; adapted from Houx, Vreeling \& Jolles, 1991c)

1. Present or past treatment by a neurologist for TIA, epilepsy, migraine, meningitis, encephalitis, brain trauma etc.;

- 2. Present or past treatment for diseases with possible repercussions on the brain (e.g., renal dysfunction, diabetes mellitus, thyroid dysfunction). Hypertension not included;

3. More than 3 concussions, or 1 with a PTA of more than 1 hour;

4. General anesthesia more than 3 times a or 1 time for more than 3 hours;

5 . Use of medication that affects driving ability or consciousness;

6. Alcohol abuse (i.e. more then 35/21 glasses per week for men and women resp.);

07. Other neurotoxic factors, such as exposure to organic solvents or substance abuse;

8. Present (or less than 5 years past) treatment by a psychiatrist;

9. Complications at birth or developmental problems in early childhood. 
standardized have proved to be rather poor guides to actual cognitive competence. Moreover, correlations between self-reported health on a five-point scale and number of medications and medical treatments were usually insignificant and were never higher than 0.57. Studies into cognitive aging in which some objective health measure has been involved, are mysteriously lacking. This is understandable, as obtaining these measures can be impractical, costly, time-consuming, or even unethical. Yet, as can be inferred from the paragraph above, health can not be considered as some random error source, that can be expected to level out given large enough numbers of subjects. If health indeed plays a causative role in Rowe's and Kahn's (1987) concept of successful aging, it is inextricable from all aging research. Table 1.1 summarizes the healthrelated factors that were proposed by Houx et al. (1991c). They will be discussed in detail in chapter 3 .

\subsection{Outline of the present study}

In the preceding paragraphs, some important topics in gerontology have been discussed. The study presented in the thesis at hand was aimed at finding some at least tentative- answers to some of the general questions raised in section 1.2, thereby circumventing some of the methodological problems sketched out in section 1.3.

Early 1987, a study into cognitive aging was started, carried out by the author (neuropsychologist), Fred W. Vreeling (neurologist), and Jellemer Jolles (neuropsychologist). In section 1.3, it was stated that the sequential approach was the method of choice. Therefore, we chose for a cross-sectional design, to be repeated after some years, to make it cross-sequential. As only general notions existed -and still exist- about what functions decline when, and in which individuals, the study was an exploration of the very large field of more or less successful cognitive aging. By consequence, no specific research questions were formulated beforehand, apart from the more generally defined boundaries described below.

We were interested in -among other things- when in a human lifetime cognitive functions start to decline demonstrably. For this reason, and because of the fact that functions probably do not deteriorate at the same rate, subjects were to be recruited from all age groups from early adulthood on throughout the whole life span. Seven discontinuous age groups were used.

To answer the third general question (which functions are most vulnerable to age), a broad range of cognitive functions were to be investigated: many aspects of primary and secondary memory, attention, the ability to deal with several things at a time (shifting concepts), and some facets of psychomotor performance. To cover all these functions, a test battery was compiled, drawn from a large set of 
neuropsychological tests that are often used for clinical purposes and are based on theoretical models of cognitive functioning (Jolles, 1985; 1986; Brand, 1987).

The fourth question to be answered (which individuals are most likely to show age-related cognitive decline) is probably the most important one within the present thesis. Therefore, much attention was given to the recruitment of the subjects. Within each age group, attention was to be paid at least to sex, differences between subjects who had received high or low formal education, and optimal health of the subjects. Recruitment of subjects was to be continued until a fixed minimal number of optimally healthy subjects per age $x \operatorname{sex} x$ education class was reached. This number was set at five per cell, which resulted in a sample of at least 140 normal, healthy subjects for the whole study, allowing for statistical evaluation of interactions between age and other factors.

It can be stated here that this number was greatly exceeded because many subjects who had volunteered to participate as 'normal and healthy' proved not to be all that healthy at close inspection. After having passed the usual selection criteria ubiquitously used in studies into normal aging, they reported a host of events or health related factors of which is presently assumed that they are associated with brain dysfunction: biological life events (BLE). BLE were treated as exclusion factor for the optimally healthy group. These subjects were also examined, and considered a separate group.

The final issue of interest for the present study was that of gathering normative data for the neuropsychological tests of which the battery was compiled and reference material for case-control studies. This determined the choice of the tests to some extent because day-to-day clinical practice was to be taken into account. However, as the set of cognitive functions evaluated in different settings are largely identical, this constraint was not too severe. For most of the tests used in the present study, no detailed age norms are available, and if they are, no subdivision is made for sex or education, let alone health differences. For a number of tests used in the present study, this was inevitable, as they were newly constructed. In addition, the corpus of data obtained from the subjects should also allow treatment as a number of single case descriptions, to provide historical norms for contrasting patient groups with matched healthy controls. For this purpose, a large number of personal background variables was to be scored. Thus, post-hoc analyses can be carried out taking other factors than age, sex, or education into account.

\subsection{Stones left unturned}

In the section above, a brief description was given about what the present study is about. Some lines must be devoted to very important questions regarding 
cognitive aging not to be answered in this thesis. To some of these questions, a tentative answer might be given, based on the data discussed in this study. However, this would require considerable effort, statistical analyses, and space to discuss them, which would be far beyond the scope of the thesis. These issues will be discussed in other publications, presently in preparation.

The general questions raised in section 1.2 (which functions are most vulnerable to age? and which individuals are most vulnerable?) can be combined in the issue of individual patterns of cognitive aging. Conceivably, in some subjects memory is the first domain of cognitive functioning to be impaired as age advances, whereas in others deficits in attention or problem solving prevail. The scope of the present study is to narrow for this question: far from all cognitive functions have been covered and theorizing about most functions has been insufficiently developed. Furthermore, it is virtually impossible to distil any knowledge about these individual age-cognition trajectories (Rabbitt, 1990) from a set of cross-sectional data. Possibly, after the first follow-up measurement, some hypothesis can be formulated on this issue.

The health-related factors that were determined as exclusion criteria prior to the recruitment of subjects, were supposed to have some impact on the optimal functioning of the brain, or at least to be associated with suboptimal functioning (BLE). If, based on BLE, demonstrable differences in cognitive performance can be observed, it is very likely that different BLE are associated with different cognitive dysfunctions. For instance, some toxic substances are known to affect some regions in the brain more than others. Neuropsychologically speaking therefore, exposure to neurotoxic factors can be assumed to yield effects that can be distinguished from those of head trauma or stroke. However, to establish these dissociations requires very much more subjects per BLE, than have been recruited for the present study. This question remains to be answered, therefore, by future research, such as 'The Netherlands Memory \& Aging Programme 19911995' (Jolles, 1991).

It would be very interesting to arrive at some hypotheses why some individuals age very successfully (Rowe and Kahn, 1987), and to arrive at some wellestablished risk factors for unsuccessful aging. Again, this would require very large data sets, gathered on a multi-center basis. However, with sophisticated statistical models some conjectures could be done, as for each subject a host of background variables is available, in accordance with the work of Salthouse et al. (1988). This in turn would necessitate much data processing and additional statistical analysis, the discussion of which would perhaps justify another doctoral thesis. A distinct possibility for instance, is that there are some 'protective' factors against age-associated decline. Candidates for such factors could be -among other things- diet, sports, engaging in cognitively demanding activities such as music, reading, brain teasers, chess, or study. 
A final important issue that is not dealt with in this thesis, is that of the epidemiology of BLE. The procedure that was followed for the recruitment of the subjects prohibits this. As stated above, recruitment was continued for a given age $x \operatorname{sex} x$ education group until there were enough healthy subjects who had not experienced any BLE. By consequence the number of BLE was not controlled for in the subjects who had sustained BLE. Moreover, no claim can be made that the recruitment procedure was representative of the whole population. The validity of all statements about BLE is therefore limited to the sample of subjects recruited for the present study. 


\section{SOME COGNITIVE FUNCTIONS AND METHODS TO ASSESS THEM}

In this chapter, theoretical constructs of cognitive functioning are discussed (section 2.1), and some specific aspects thereof. In section 2.2, different approaches to neuropsychological assessment of cognitive dysfunctions associated with aging or dementia are discussed. Section 2.3 relates on some important issues on neurocognitive testing.

\subsection{Theoretical constructs of cognitive functions}

Higher cognitive functions like memory or attention are never observed, but always inferred. For a neuropsychologist, it is a basic assumption that all cognition emerges from the brain, as does blood circulation from the hart. It remains, however, an assumption. By consequence, our notion of cognition must be the reflection of a set of theoretical models. Whereas circulation is an observable and quantifiable function of the hart, the physiology of which is welldescribed, no such description exists for cognitive functions: memory, for instance, cannot be pin-pointed to some distinct part of the brain. Knowledge of representation of functions in the brain is still rather sketchy. At best, one or more cortical or subcortical areas or structures are known -or generally thoughtto be involved in a given function. Rather than relating cognition to the cerebral substrate, which is the airn of neuropsychological models (e.g., Luria's, 1973), the psychology of cognitive aging typically studies the adult development, change and decline of cognitive performance, and therefore uses functional models, largely unrelated to brain-behavior relationships. The following sections summarize some models of two of the cognitive functions that are studied in the present thesis: memory (and processing of information in memory) and attention. Thinking about the other functions, planning of behavior and psychomotor functioning has not been as detailed as about memory and attention, so that they can be dealt with in the chapters on experimental findings (chapters 10-12).

\subsubsection{Memory}

Kolb and Whishaw (1990) define memory as "a process that results in a relatively permanent change in behavior". Metaphors and models for this process have been coined at least as early as the time of the ancient Greeks. Many authors have since been engaged in the study of memory processes. Today, there is still no complete agreement upon the nature of the different types of memory. However, some intuitively appealing divisions have gained wide acceptance. 
The distinction between primary and secondary memory was first used by William James in 1890. In his definition, primary memory (PM) refers to the contents of consciousness and thus endures for only a brief time. By contrast, secondary memory (SM) denotes "the knowledge of a former state of mind after it has already once dropped from the consciousness" (James, 1890). This distinction still proves to be very useful (e.g., Poon, 1985). Primary memory is nowadays thought of as "an ephemeral, limited-capacity" (only $7 \pm 2$ unrelated items; Miller, 1956) store in which information is still "in mind", as it is being used. If the information is stored, it enters secondary memory, which is conceptualized as an unlimited, permanent store of newly acquired information. Some authors (e.g., Poon, 1983) mention tertiary memory, to denote what might be termed encyclopedic knowledge.

There is yet another type of memory which is thought to be modality-specific: sensory memory or sensory registration (SR), referred to as iconic memory for the visual system (VSR), and echoic memory (Neisser, 1967) for the auditory system (ASR). Logically, SR precedes PM as well as SM, because it is regarded as the very first stage of information flow. SR serves as buffer, information is preserved long enough there (less than a second in VSR; a few seconds in ASR) and codified to be accessible for the PM.

PM and SM have been referred to with several other terms, depending on the theoretical basic assumptions, and several other aspects of memory have been hypothesized and studied. In the distinction episodic/semantic memory (Tulving, 1972) for instance, episodic refers to memory for personally experienced events and activities, and semantic to memory contents that are shared by many individuals (cf. tertiary memory). Episodic and semantic memory can be categorized under SM.

Roughly equal to PM and SM are short-term and long-term memory, respectively (STM and LTM). Miller (1956) and Broadbent (1958) first used these now widely employed terms to describe the human memory as an information processing system. In the information processing approach, a processing unit controls the flow of information from SR to STM and from STM to LTM and vice versa. Broadbent's influential filter theory (1958) implies that selective attention is effective in an early stage of processing, by pre-analyzing all incoming information with regard to their physical properties, before the identification of the verbal content. This processing occurs in a parallel fashion, i.e., more than one feature at a time can be processed. Selective attention operates as a filter that completely blocks the analysis of information that does not have the selected feature. This blockade is necessary because of the limited processing capacity after the filter, which is thought to be strictly serial, i.e., one bit of information at a time.

Several aspects of information processing can be studied by measuring response 
times as a function of the manipulation of task requirements. Basic to this approach is the assumption that the processing that occurs between presentation of a stimulus and registration of a response is serial: all processing stages are thought to be additive. Sternberg (1969) elaborated this view, but it was first put forward by Donders in the nineteenth century (1868; see Koster, 1969) as the subtraction method. By subtracting the amount of extra time needed to respond to a stimulus when some aspect of the task conditions is varied, one can infer the separate processing stages and the extent to which they are influenced by task conditions.

As reaction time measurements are limited to the level of seconds or even milliseconds, information theory virtually limits itself to STM. Baddeley (1976) coined the term working memory to refer to the STM as a limited working space, controlled by processes such as rehearsal, coding, imaging, decision making and retrieval from LTM. Nowadays, 'working memory' is a widely used term, interchangeable with STM or PM, depending on the context in which the term is being used.

Information theory has proven to be one of the most fruitful paradigms of psychology in the last two decades, if only in the number of studies that were based upon it until the present day. Very influential were the models of Sternberg $(1969 ; 1975)$ and of Shiffrin and Schneider (1977). As they lie at the root of some of the methodology presented in this thesis (chapters 3,6, and 7), they are to be discussed in some detail.

Fundamental to the theory of Shiffrin and Schneider is the distinction between automatic and controlled (identical to effortful, as used by Hasher and Zacks, 1979) processing. Basic to this distinction is the assumption that operations vary in their attentional requirements (Kahneman, 1973). Operations that consume only minimal energy from the attentional mechanisms within the STM are called automatic. They do not interfere with other processes, function unintentionally at a constant level under all circumstances, and (once they have become automatic) do not improve with practice. Some automatic processes are more or less 'innate' (e.g., processing of temporal information), others develop through practice (e.g., reading or playing a piano). Automatic processing prevents the information processing system from becoming overloaded. In the view of Hasher and Zacks (1979) but also of others (e.g., MacLeod and Dunbar, 1988), there is no dichotomy between automatic and controlled. Rather, most activities are situated somewhere along an automatic-controlled continuum. Controlled processing, by contrast, requires considerable capacity (e.g., rehearsal or problem solving). Therefore, they can interfere with other capacity-demanding activities. They are subject to intention, and should improve with practice.

Which type of processing can occur automatically, and which requires attention, is assumed to vary between and within individuals, as a function of the varying 
attentional capacity. Fatigue, medication, or depression might thus affect the amount of operations that do not demand any attention. If almost all activities require cognitive effort, the system becomes overloaded, which is exactly the feeling that is expressed by many depressed or overstrained patients: "I always used to do many things at a time, but nowadays everything is too much for me"; "I no longer join in with a game of cards: it is all too fast for me". Of course, aging is another factor that may affect attentional capacity. This phenomenon can also be explained in terms of resource reduction (Salthouse, 1988): the individual is lacking capacity for the cognitive operations that are needed to participate in demanding activities.

The process of memory scanning as described by Sternberg is thought to be effortful. Scanning STM (which occurs in the process of telling an irrelevant stimulus from a set of well-memorized target stimuli) consists of several independent stages, the component latencies of which are supposed to be additive (Sternberg, 1969). These stages can be identified as: 1 . encoding; 2 . memory scanning; 3 . binary decision as to the nature of the response; 4 . response organization and execution. The memory scanning stage can be inferred from the slope of the reaction times (RTs) plotted as a function of memory load (set size). The other three stages are inferred from the intercept of this function. Theoretically, one can influence scanning and non-scanning stages differentially: the scanning stage by the set size, non-scanning stages by perceptual or motor constraints like stimulus legibility or stimulus-response compatibility (Frowein and Sanders, 1978). According to Logan (1978), most of the non-scanning stages do not require attention, and are therefore assumed to be automatic.

Models of forgetting are, of course, part of our thinking about memory. Remembering and forgetting are like the two sides of one coin. For different types of memory, generally, different types of forgetting are generally considered most important: the decay theory for STM, the interference theory for the LTM. Decay is defined as the result of time elapsed between item presentation and retention test (Broadbent, 1958). As early as 1900, Müller and Pilzecker first presented an interference theory of forgetting (see Luria, 1973). Interference is the disruption of a memory trace by other activities that are performed earlier (proactive), or later (retroactive; see Thomassen and Kempen, 1976, for a more detailed discussion).

Adherents of the hypothesis of decay in STM believe that a memory trace is only renewed by repetition, not strengthened. Autonomous decay is a function of the amount of time elapsed after repetition is stopped. Evidence for this line of thinking is necessarily indirect: it has to be inferred from memory loss after some interpolated task, that does not involve any learning (Broadbent, 1958). As one cannot exclude interaction between repetition of a memory trace and the interpolated task, 'pure' decay cannot be studied. Moreover, it is difficult to see how decay can explain the phenomenon that was described above by proactive 
interference. Thus, the controversy about decay or interference as the cause of forgetting in STM becomes rather academic.

For LTM too, decay and interference theories exist. Decay is thought of as some physiological process, irrespective of other cognitive activity, that increasingly affects memory traces and makes them fall apart. This is in sharp contrast with those models that do ascribe some disruptive role to any processing that occurs shortly before or after something is stored into the LTM, such as the interference model, very similar to the one described above for STM. Another such model is the so-called consolidation theory (Hebb, 1972): there is some neural activity making newly learned material 'sink in'. This activity starts within one second after information enters STM, and may require from a few minutes to one hour (Kolb and Whishaw, 1990, p. 529), during which other cognitive activity or physiological impacts such as brain trauma can disrupt the consolidation process. Interference of memory traces by other activity and disruption of the consolidation process do not seem to be mutually exclusive. Conceivably, they occur together.

The status of the different models is as yet unclear. Decay can surely not be the only explanation of forgetting in LTM because proactive effects can not be accounted for. The same goes for the disruption of consolidation. Thomassen and Kempen (1976) cite experimental evidence that is incompatible with the consolidation theory. It thus appears that the interference theory of forgetting seems to be the most empirically adequate.

\subsubsection{Attention}

Ever since attention became subject of psychological research, authors have had problems defining it, or even defining the fields of interest for the study of attention (Plude and Hoyer, 1985). As James (1892) put it: "It is a feeling which everyone knows, but which most people would call quite indescribable". His notion of "effortful" attention comes quite close to that of consciousness. $\mathrm{He}$ distinguished effortful attention (awareness of only one thing at a given moment) and the possibility of doing several habitual acts simultaneously. This distinction in turn, resembles the more recent notion of automatic and controlled processing as proposed by Shiffrin and Schneider (1977; discussed in the previous section).

Plude and Hoyer (1985) prefer to view attention as "the capacity or energy to support cognitive processing". Others equate attention with consciousness, and still others subscribe to a multiple-resource view (e.g., Wickens, 1980; Salthouse, 1988): there are various pools of capacity, each dedicated to their own component of information processing. Neither the unitary capacity models, nor the multiple resource model can account for all experimental evidence. For instance, Wickens' finding (1980) of absence of any performance tradeoff in dual-task 
situations cannot be accounted for in terms of a unitary capacity. However, by assuming that by practice and familiarity the demands on the central capacity are reduced (Shiffrin and Schneider, 1977), the functioning of the hypothetical unit that controls and coordinates capacity can be equated with selective attention. Yet, in addition to some global capacity, separate independent resources are assumed to be available for cognitive structures, as proposed by Kahneman (1973). These resources may even have their own, physiologically distinct substrates in the brain (Plude and Hoyer, 1985).

From this theoretical hairsplitting it can be deduced that much of the very many different notions on the different kinds of attention is formed on a rather intuitive basis. What has been described above can be roughly equated with selective (focused) attention. This is required for sustained attention, also termed vigilance, the power to concentrate for a long period of time on rarely occurring signals, and react appropriately. Conceptually different from this type of attention is divided attention, needed in situations where attention must be distributed over multiple sources of information (as encountered, for instance, in dichotic listening; Broadbent, 1958). It can be reasoned that allocation of attentional energy is switched between these sources (as would follow from the limited capacity view), or that multiple resources of energy are available to attend to all sources of information.

Finally, often constructs of modality specific attention are used for clinical purposes: auditory, visual, or even visuospatial attention (Lezak, 1983). This once again underlines the lack of conceptual cohesion concerning attention and the rather intuitive approach to the very complicated matter. The reader is referred to the multi-volume series Attention and Performance for more detailed information on the complex matter of attention (e.g., LaBerge, 1981).

\subsection{Different approaches to neuropsychological assessment}

Not all neuropsychologists adopt the same diagnostic methods. There are at least three different traditions or schools, each with their own objectives and areas of interest. This can be illustrated by shortly describing the different paradigms that have prevailed or still prevail.

Until the late 1950s the concept of "organicity", treating brain damage as a unitary phenomenon was taught to everyone who was concerned with patients suffering from brain damage or disease. With Goldstein (1959) many assumed that organicity was characterized by one central and therefore universal behavioral defect. Even nowadays, many psychologists talk of organicity as if it were some real and measurable entity. By consequence, many have sought 'the single best test', optimally sensitive to organicity: a neuropsychological litmus paper test 
(see Lezak, 1983, p. 17). This is stimulated by many a clinical referral by psychiatrists or neurologists, asking the neuropsychologist to find out 'whether or not organicity is at stake'. Quite understandably, the quest for the ideal organicity test has yielded nothing: no one test appeared to have sufficient sensitivity to detect brain injury and selectivity to detect only that. The widely heard cry for normative data, and the hesitation of many neuropsychologists to use some test before such data are available, can be understood as an aftermath of the organicity thinking. Current thinking in neuropsychology recognizes brain dysfunction as a multidimensional phenomenon that requires a multidimensional and even multidisciplinary approach (Luria, 1973; Jolles, 1985).

\subsubsection{Psychometrics}

The term psychometrics dates back to early decades of this century, when many American psychologists were engaged in the construction of intelligence tests (Vroon, 1980). This was an activity that was typically non-theoretical: test outcomes were compared to painstakingly gathered norms, and were not directly related to any theoretical construct, although some general ' $g$ ' factor was thought to underlie the intelligence quotients.

Tests stemming from the psychometric tradition have the advantage that they are standardized and that more or less well-established norms are generally available. They tend to have good reliability, in that subjects show roughly the same score when tested twice, and that subjects who perform subnormally do not show good test scores at another occasion, or vice versa. Also, they can often be modified for computer administration, which can have important advantages (see section 2.3.3).

The most important drawback of psychometric use of test scores is that it does not enable the identification of the cognitive deficits that underlie poor test performance. This is a consequence of the empirical nature of psychometrics, which was not developed for use with patients suffering from dementia or brain injury. As for aging, psychometrics will not yield insight into whether specific functions are affected in the aged, and what these functions are.

A practical problem of this approach is that psychometric testing usually involves very lengthy testing sessions to finish a whole battery of tests. Lezak's basic set of tests takes from three to six hours to complete. Although her procedure does not include only psychometric tests, most of it is taken up by a number subtests from the Wechsler Adult Intelligence Scale (WAIS; Lezak, 1983, pp. 106-107). If the patient's comprehension of the instructions or his performance is very slow, all of the testing may easily take more than a day. Therefore, the testing has to be spread over several sessions, preferably on different days, especially if the patient fatigues rapidly, which also can affect the reliability of the test outcomes very seriously. 


\subsubsection{Tasks derived from the information processing paradigm}

Theories of information processing have been discussed in section 2.1. They have been very productive in analyzing behavior in quantifiable components and qualitative patterns. Typically, in a test derived from information theory, one or more aspects of the test are varied, and differences in reaction time, or time needed to complete a subtest, is recorded as a function of this task variation.

Unfortunately, this very viable approach has not yet gained wide interest by neuropsychologists outside the psychological laboratory. Sternberg's memory scanning paradigm (1969), for instance, has been used for a wide variety of purposes (see Houx et al., 1991b), but very rarely for individual assessment. Many a task discussed in chapter 3 was directly derived from models of information processing, or modified in such a way that it allowed interpretation of test outcomes in terms of information processing.

Poon (1983) suggests a set of information processing tests for assessment of a variety of functions in the elderly: attention, decision making, primary, secondary and tertiary memory, and spatial processing. This approach may combine the advantages of psychometrics with a well worked-out theoretical framework. Furthermore, information processing tests can be of short duration (Jolles, 1985), and lend themselves very easily for computerized administration.

\subsubsection{Behavioral neurology}

The neuropsychologist Luria favored an approach that differs greatly from the strategies discussed above (Luria, 1973; 1980). He presented a very elaborate model of brain-behavior relationships, based on a lifetime of careful observation of behavioral disorders resulting from different brain injuries. His approach consists of a set of short procedures that systematically probe the various aspects of cognitive functioning. Christensen (1979) offered an adapted and translated version of his methods. Over 250 simple and short tasks can be administered, covering any cognition from basic perceptual and motor functions to abstract reasoning. Administration of the total set of tasks takes up to two hours, but this hardly ever happens: about half an hour suffices to gather a well-documented impression of a subject's abilities and disabilities. Luria's method aims at generating hypotheses on specific dysfunctions and their cerebral substrates, and testing these by a proper choice of small tests.

Luria's behavioral neurology is systematic and theoretical, but it can not be standardized. The Luria-Nebraska neuropsychological battery was meant to be a standardization of Luria's approach (Golden, 1981). However, as Spiers (1981; quoted by Lezak, 1983, p. 569) put it: "It is not these items, per se, but the manner in which Luria made use of them as a means of testing hypotheses concerning various abilities, deficits, or functions which is his method and his unique 
contribution to neuropsychological assessment. Consequently, the incorporation of items drawn from Luria's work into a standardized test should not be interpreted to mean that the test is an operationalization or standardization of Luria's method". In spite of attempts by his disciples, it does not appear possible to analyze test outcomes any further than merely tallying. The nearly absolute lack of quantitative data prohibits use of behavioral neurology in the assessment of subtle inter- and intra-individual differences as they are brought about by aging, medical treatment, or training.

\subsubsection{Eclectic approach}

An approach that integrates the advantages of the psychometric, information processing, and neurobehavioral approaches was described by Jolles (1985). For general clinical assessment a general impression is generated, provided by Luria's method, covering the whole range of cognitive functions, in order to provoke pathognomonic signs of disorders. If such a sign is indeed found, that area of functioning is further investigated, first by more neurobehavioral tests, then by psychometric and information processing tasks. In this vein, a complete neuropsychological assessment need not take longer than two to three hours, and can take place in one session. Most of the methods used for this eclectic approach are used in the study described in this book, with the exception of Luria's method, which does not lend itself for group comparisons.

\subsection{The issue of optimal assessment methods}

Many psychologists are not satisfied with the existing tools for neuropsychological assessment. They have the impression that the tests are not sensitive enough, or invalid, or impractical. For this reason, large amounts of effort are continuing to be invested in the construction of new, more valid, preferably computerized tests. Often, new tests are devised in order to agree with some new theoretical model of a cognitive function. Making tests for elderly subjects or patients constitutes some specific restraints on the test constructor. Some remarks on test construction seem appropriate at this place.

\subsubsection{Validity}

Neuropsychological tests must be valid, as should indeed all tests. Several types of validity can be invoked. Cook and Campbell (1979, chap. 2) identify at least internal and external validity. Internal validity refers to inference of cause between two variables, external validity to the generalization of the inferred cause to and across alternate measures of cause and effect, or situations. Internal 
validity is subdivided by Cook and Campbell into: 1 . statistical validity for conclusions about covariation based on statistical evidence; 2 . internal validity (mentioned above); 3 . construct validity referring to generalizations about higherorder constructs from the research operations. Lack of external validity can best be illustrated by the following. Most neuropsychological tests now available are quite abstract and bear little relevance to actual tasks of daily living. They do not assess practical aspects of cognitive performance. It is not clear, therefore, whether they have ecological validity (Neisser, 1988; Winograd, 1988), which is used to refer to tests which have the following characteristics: 1 . the test gives a reliable estimation of the nature or severity of everyday problems, 2 . the test contributes to the explanation of everyday problems and 3. the test contributes to development of valid intervention strategies. Finally, many tests lack yet another type of validity: face validity (Kausler, 1985), referring to the resemblance to daily life situations and activities.

Of course, any test that misses any of these types of validity, can offer problems as to the interpretability. The seriousness of these problems may vary. If statistical validity is lacking (e.g., in case of low test-retest reliability), any interpretation becomes irrelevant. However, some others feel that face validity is not allimportant, as long as "the processes mediating performance on a laboratory task approximate those mediating performance on the everyday counterpart" (Kausler, 1985). The assumption that this is the case with the tests presented in the chapters to follow, is basic to the present study. Both for clinical purposes and experimental studies like the present one, the tests are assumed to tap those functions they were meant to draw upon. Studies into the reliability of the operationalizations of functions have either been performed, and yielded positive results, or are currently being planned (Jolles, 1991).

\subsubsection{Feasibility}

Apart from being valid, a neuropsychological test must be practical. It must be of short duration and yet be as informative as possible as, during a clinical or experimental test session, time is limited: elderly subjects and patients fatigue easily. Resuming the test session at one or more other occasions can be a serious burden to the subject. In addition, longer or multiple test sessions can be very expensive when financial recompensation for participating in an experiment is required. Finally, having to retest a subject at a later date can have methodological disadvantages.

Tests have to be attractive and not too tedious. Subjects who are bored with some test, or think it is childish (which elderly subjects often do), are likely to perform poorly. Poor performance due to extrinsic factors threatens internal validity. Tests should be devised in such a way, that instructions can be kept simple. Elderly subjects often have poor attention spans, which prohibits lengthy or 
complicated explications about the procedure of a test. Especially memory tests should avoid interference of the complex instruction with the material to be memorized. Furthermore, as the complexity of the test instructions increases, so does the likelihood that subjects perform inadequately due to poor understanding, instead of due to the functional disorders the test was designed to draw upon. Tests, or even whole test sessions are often not carried out by an expert. For this reason, the procedure should preferably be unequivocal and the test easy to administer. Luria's methodology (see section 2.2.3) violates this rule, and should not be used by test assistants.

\subsubsection{Computerized tests}

It has become fashionable to implement many neuropsychological and other tests (like inventories) on a microcomputer. 'Behavior research methods, instrumentation, and computers' is a well-known journal, largely dedicated to this subject. The American Psychological Association is publishing directories of software for use in psychology (e.g., Stoloff and Couch, 1988). Computerizing tests has some evident advantages, both theoretical and practical: 1 . A computerized test is always administered in the same way, independent of the skill or mood of the neuropsychologist or test assistant, thereby contributing considerably to the internal validity of a test; 2 . Computer tests can save time: scoring and the most complex calculations can be performed automatically; 3 . A commonly used test can yield more useful information when administered by means of a computer. For instance, when administering paper-and-pencil tests, only total time and number of errors are available. The very same test, when administered by computer by means of a graphic digitizer (XY tablet; Houx, Brand, and Jolles, 1987), can tell the examiner what parts of the test were more difficult to the testee, because the pen dwelt longer at that spot; 4 . Some tests cannot be carried out, or only very laboriously, without computer. Examples are: reaction time tests or tests involving complex tachistoscopic stimulus presentation (Brand, 1987; Abbenhuis, Raaijmakers, and Raaijmakers, 1990).

Computer administration of tests can have important disadvantages, especially in neuropsychology (Houx and Jolles, 1988). First of all, some researchers want to computerize tests, for the sake of computerizing, to keep up with modern developments. Secondly, if a well-known and well-standardized test is adapted for computer administration, new norms have to be established, as it cannot be assumed that the two versions of the test are interchangeable. A third, more serious problem is that a computerized test does not necessarily tap exactly the same cognitive functions. Presentation of stimuli on a computer screen can essentially differ from auditory or paper-and-pencil administration. Fourthly, computer tests take very long to develop. They may keep many researchers from their proper work and are therefore very costly. Finally, for many adults, 
especially elderly subjects, a computer is a completely unknown tool, that may even frighten them. This may add to the general uneasiness often experienced during neuropsychological examination, and therefore influence the test outcomes. In conclusion, computerizing tests can be very advantageous, but clinicians have to think twice before they decide to purchase a computer or test programmes, and researchers should realize that it can be costly in several ways.

\subsubsection{NEUROPSYCH: Apparatus}

'NEUROPSYCH' (Brand, 1987) was developed for Apple-II (and compatible) microcomputers, as a tool for everyday neuropsychological practice as well as laboratory research. Almost all of the programming was in Applesoft BASIC (Poole, McNiff, and Cook, 1981), with the exception of some input and output routines with millisecond precision, which were programmed in machine language. Some peripheral hardware was developed:

1. A six-button keyboard for stimulus presentation, registering motor reaction time, and other motor processes;

2. Hand-held "Yes"/"No" buttons, for registering thumb presses;

3. Tachistoscopic slide presentation on a back-projection screen;

4. Interface between computer and peripherals.

The stimuli that were presented on a computer screen were $0.6 \mathrm{~cm}$ in height and were presented by means of the green standard computer-screen in ASCII-type characters and were viewed from approximately $60 \mathrm{~cm}$ distance, at an angle of approximately 15 degrees. Stimulus presentation and response registering could also occur via a graphic digitizer (XY-tablet), by administering paper-and-pencil tests by means of such a device (Houx, Brand, and Jolles, 1987). Test instruction could be done by means of a separate computer screen, or orally. NEUROPSYCH is presently being extended, and, in the latest version, now contains the following tests:

1. Visual verbal learning test (modification of AVLT, Lezak, 1983)

2. Memory scanning task, according to Sternberg (1969; Houx et al., 1991c)

3. Paper-and-pencil memory scanning task (Houx et al., 1987)

4. Sustained attention test (Brand, 1987)

5. Motor choice reaction test (Houx et al., 1991a)

6. Various tapping tests

7. Facial recognition test (Brand, 1987).

These tests are embedded in an over-head programme (shell), the flow of information between all separate software parts and test programmes. Most of the NEUROPSYCH tests are now re-programmed for IBM computers and compatibles. For these programmes, TurboPascal 6.0 is used. Peripheral hardware has been kept identical, in order to be able to compare data obtained by means of 
either system. In the near future, a similar shell as used for NEUROPSYCH is to be developed, with some extensions (Brand and Houx, 1989). Another possibility is a so-called test manager, a commercially available over-head programme, in which test programmes can be implemented.

\subsection{The choice of tests for the present research}

As was discussed above (section 1.5), the present study is an exploration of the very large field of normal aging. Furthermore, as was discussed in the previous chapter, age differences can be found in virtually all cognitive functions that have been examined so far. How these age differences lie to each other, is largely unclear however. Therefore, we chose to study some functions that are often found to be impaired in clinical neuropsychological practice as well as in normal, healthy aging (Jolles, 1986):

I. Primary memory;

II. Secondary memory;

III. Some measure of attention;

IV. Planning of behavior: shifting between concepts;

V. Psychomotor performance: peripheral and central.

We chose for a number of tests that were based on theoretical models concerning these five main areas of cognition. Furthermore, they are either regularly used or newly developed within our working group. Thus, the selection of tests was made on practical, as well as theoretical grounds. The 'test battery' consisted of:
I. Primary memory:
1. Digit Span test
2. Block Span test
3. Computerized Memory Scanning test
4. Paper-and-pencil Memory Scanning test
II. Secondary memory:
5. Visual Verbal Learning test
III. Attention:
6. Stroop Color-Word test;
IV. Planning of behavior:
7. Revised Trail Making test;
8. Concept Shifting test;

V. Psychomotor performance: 9. Continuous Performance Tapping test;

10. Motor Choice Reaction test.

For reasons of readability, these tests are discussed prior to the presentation of the outcomes, in chapters 5 through 12. 


\subsection{Subjects}

All subjects were recruited by means of advertisements in local newspapers, from a local brass band, sports club, or old people's home. Normal, healthy volunteers had explicitly been called up. Subjects were pre-selected over the telephone: only those applicants were provisionally admitted who regarded themselves as being healthy, normal, and not in need of any help.

\subsubsection{Pre-selection and selection}

It appeared that most applicants were unaware of possible or real threats to the healthy functioning of their brain: more than a hundred applicants were excluded who, on being asked, reported major brain damage by trauma, stroke, disease, or poisoning, or who reported a major psychiatric illness known to be characterized by cognitive deficits. Nonetheless, they judged themselves to be healthy and normal. (Conversely, some subjects were afraid they could not participate because they had caught a cold, and did not think themselves to be healthy.) Elderly people, especially those living in old people's homes, were overrepresented in the group of subjects who had experienced BLE.

For the purposes of subsequent statistical analysis, large enough numbers of subjects per age ( 7 levels) $x$ sex $x$ education cell ( 2 levels) were to be obtained. This meant that at least 140 subjects ( $\mathrm{N} \geq 5$ per cell) unaffected by any biological life event (BLE) had to be recruited. Therefore, recruitment and checking for BLE was to be continued until the fixed number of BLE-free subjects per cell was reached.

Two hundred and fifty-six subjects were eventually pre-selected and tested. Prior to the actual examination, the subjects were once again screened for evidence of brain damage. Nine additional subjects did not pass this screening: 6 subjects were mildly demented, as assessed by the Mini Mental State Examination (MMSE; Folstein, Folstein, and McHugh, 1975), with a score of less than 24, two subjects appeared to have had a major head injury resulting in persisting cognitive dysfunctions. One subject had been treated for brain tumor, which he had forgotten to mention at the pre-screening. If doubt existed about the accuracy about the subject's recollection of the events, their medical files could be consulted. Also, it was often possible to gather data provided by relatives to confirm the subject's statements. Thus, we had a large group of selected subjects $(n=247)$ without any a priori likelihood of brain dysfunction or cognitive dysfunctions attributable to a major neurological or psychiatric illness. The 
average physical and mental condition of the subjects can therefore be said to have been at least as good as that of any experiment reported in the literature.

\subsubsection{Education}

Care was taken to balance the level of education in each cohort and each subgroup. For this purpose, we used a dutch scoring system originally developed by Verhage (1964) and adapted in 1980: a 7-point scale, ranging from unfinished primary education (1) to master's degree (7). The advantage of this scoring system over counting the years of scholastic education is that qualitative aspects of education are also taken into account. For the present study the 7-point scale was condensed to two levels: 1-4 (less educated) and 5-7 (more educated). This was done to facilitate recruitment of a sufficient number of less and more educated subjects across all age groups.

\subsubsection{Assignment to groups without and with BLE}

At the time of the investigation, the 247 subjects were subjected to a semistructured and semi-quantitative interview (Houx et al., 1991C) by an experienced neurologist concerning BLE, prior to the actual testing. Each BLE was scored

Table 3.1 Composition of the various experimental groups with and without BLE: age and education

$\frac{20 \text { years }}{\text { age educ }} \frac{30 \text { years }}{\text { age educ }} \frac{40 \text { years }}{\text { age educ }} \frac{50 \text { years }}{\text { age educ }} \quad \frac{60 \text { years }}{\text { age educ }} \quad \frac{70 \text { years }}{\text { age educ }} \frac{80 \text { years }}{\text { age educ }}$

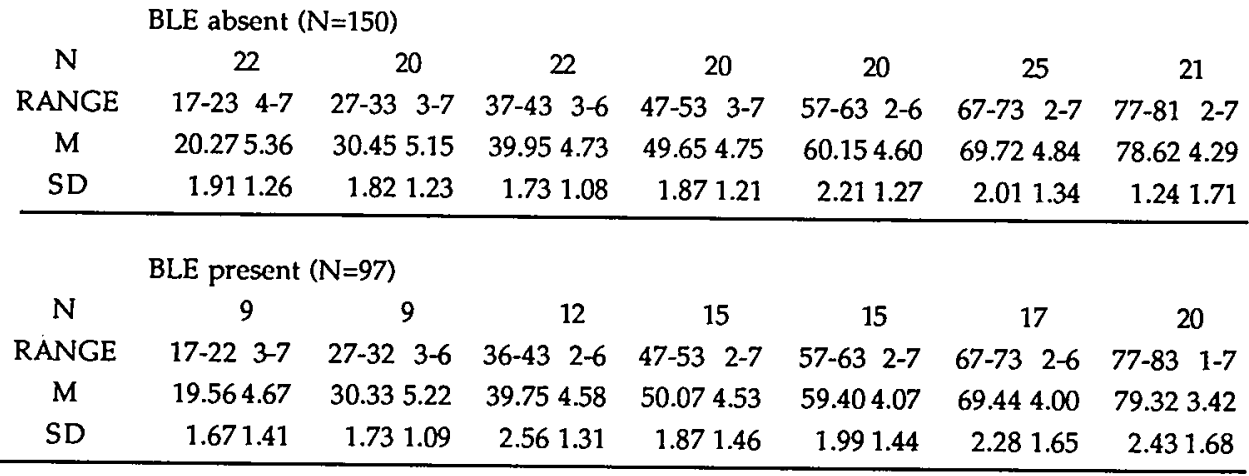

Note: age $=$ in years; educ $=$ education level $($ Verhage, 1964$)$. 
either present or absent. Subjects who were characterized by one or more BLE were assigned to one of seven BLE groups with mean ages ranging from 20 to 80 years. Subjects without any BLE were assigned to a corresponding optimally healthy age group. It appeared that of 31 subjects aged $20,9(=29 \%)$ subjects were characterized by BLE. This percentage roughly increased for every successive age group (see table 3.1 for the exact numbers of subjects). For the age groups of 70 and 80 years, the number of BLE-affected volunteers exceeded our testing capacity, so that an initial interview over the telephone about BLE had to take place prior to the testing. About another fifty volunteers were excluded at this stage.

\subsubsection{Biological Life Events (BLE) and scoring}

A neurologist administered the semi-structured interview about the subject's medical history to assess the existence and severity of the factors associated with brain dysfunction, and whether they should be scored as a biological life event (BLE). For the present study, BLE included the following factors (see also table 1.1 in chapter 1):

BLE 1, treatment by a neurologist concerning any brain disorder, was used to identify all subjects with a history of brain dysfunctioning (or consequences thereof) for which they had been treated, but of which they were said to have completely recovered. Cut-off criterion was presence or absence of past treatment.

The same applied for BLE 2, treatment for systemic diseases that are supposed to have a negative effect on the normal functioning of the brain (e.g., diabetes, renal, liver, or thyroid disease; see Knoefel and Albert, 1985).

BLE 3, closed head injuries, was scored present when a subject had sustained four or more mild head traumas or at least one with a post-traumatic amnesia (PTA) of more than one hour, which is moderate, according to Jennett (1976). For quantitative analysis, a weighted score was used: one point for every trauma, and in case of a PTA longer than one hour, four points.

For the purpose of the present study, the arbitrary criterion of anesthesia (BLE 4) on four or more occasions, or on one occasion lasting more than three hours, was applied. A similar quantitative score as used for traumas was applied: three points extra for each narcosis lasting longer than three hours.

For medication (BLE 5), the criterion was at least one drug marked by the pharmacist with a yellow sticker indicating its possible influence on driving ability (Dutch Medical Pharmaceutic Committee; 1988). Subjects were asked to bring all drugs they regularly or incidentally used with them. The number of different medications that were taken regularly was also recorded as quantified variable. 
Scoring of the presence of alcohol abuse (BLE 6) was based on data of a W.H.O. report (1980): maximum average consumption of five glasses a day for men, and three for women (irrespective of the nature of the refreshment). To compare alcohol consumption for the sexes, the intake of the women was multiplied by $5 / 3$.

There is still considerable dispute about the chronic neurotoxic effect of a number of other toxic factors (BLE 7), such as organic solvents or aromatic carbohydroxins (Ganzevles and Jolles, 1989). The same goes for abuse of psychotropic drugs (Hartman, 1988). This factor was scored present if the subject had (professionally) suffered intensive exposure for several years, or had sustained a single exposure to a very toxic substance (such as carbon monoxide inhalation with loss of consciousness).

Psychiatric disorders (BLE 8) such as mood disorders are known to be associated with cognitive dysfunctions (e.g., Weingartner, 1986). These disorders were scored as present when a subject had received psychiatric treatment within the past five years but was not receiving it at the time of the examination. For example, if a subject reported having suffered from depression during the last five years, but considered himself recovered, BLE 8 was scored present. If psychiatric treatment was being received at that time, the subject would not have passed the initial screening (section 3.1).

Perinatal complications or developmental problems in early childhood (BLE 9) constitute a whole array of factors associated with cognitive disorders later in life. Among these factors are: hypoxia at birth, M.B.D. and malnutrition during development (Kalverboer, 1988). These risk factors are the most difficult to score, especially in older adults. Unless positive information -anamnestic or of some other source- was available, the factor was scored 'not present'. Either presence or absence was scored.

Thus, for four factors, it had been possible to define some semi-quantitative measures, and cut-off criteria: anesthesia, medication, closed head injuries, and alcohol. The other factors were scored as 'present' when the subjects answered the questions positively. If any of these factors was scored positive, a subject was assigned to the risk group. As a result, subjects could have been affected by more than one BLE. The exact numbers of different BLE are given per age group in table 4.1 , in the following chapter.

\subsection{Background variables}

In the age groups of 60,70 , and 80 , a number of personal variables regarding daily activities were scored apart from the common demographical variables age, sex, education, and apart from the BLE. These included: time spent watching TV, 
reading, taking part in clubs or organizations, sports, 'mental' games such as brain teasers, crosswords, chess, or bridge, and other hobbies, not including the activities already mentioned. This was done following a suggestion by Salthouse et al. (1988) regarding interactions between the effects of age and background variables on cognitive performance. They did not find many of these interactions, nor did they find interactions of age by health-related factors, as was mentioned in chapter 1.

Salthouse et al. gave very precise measures of hours per week engaged in some activity. Unfortunately, no detailed information was provided as to how these measures were obtained: the subject completed a questionnaire. We found it virtually impossible to obtain reliable written self-estimated ratings about any subject variable. This was circumvented by providing the subject with some broader categories, and let him indicate in which of these his activities belonged. These six category ratings were used for subsequent analysis. To make the estimations easy for the subjects, they were asked to estimate how much time was spent per day (reading, TV, puzzles) or week (sports, club, hobbies). Ratings per day were multiplied by seven. The category boundaries were arbitrarily set, as, apart from anecdotal evidence, little is known about how older, communitydwelling people spend their time.

Hours per week spent

1. Reading (including newspapers)

2. Watching TV

3. Engaging in social activities: clubs, or other types of organizations

Category

4. Participating in sports, gymnastics, yoga, bicycling, or walking (for the very old)

$\begin{array}{cccc}0 & 1 & 2 & 3 \\ - & <3.5 & 3.5-14 & >14 \\ - & <3.5 & 3.5-14 & >14 \\ - & <0.5 & 0.5-2 & >2 \\ - & <0.5 & 0.5-2 & >2 \\ - & <0.5 & 0.5-2 & >2 \\ - & <0.5 & 0.5-2 & >2\end{array}$

5. On mental games (e.g., crosswords, brain teasers, chess, bridge)

6. Engaging in other hobbies, not including activities 1-5

\subsection{Procedure}

A neurologist administered the semi-structured interview about the subject's medical history to assess the existence and severity of the brain healththreatening factors, and whether they should be scored as BLE. This took about 20 minutes. 
All subjects were tested individually by the same examiners, and in the same order. The whole test session was divided into two halves, separated by a tenminute coffee or tea break. Each half took about 50 minutes. The first half of the complete examination was performed by a neurologist:

1. Introductory conversation during which information about the experiment was given and a general impression was gathered about the subject.

2. Semi-structured interview about BLE;

3. Short neurological examination;

4. Examination for pathological and primitive reflexes (Vreeling et al., 1991);

5. Stroop Color Word Test;

6. Revised Trail Making Test;

7. Concept Shifting Test.

The second half was carried out by a neuropsychologist:

1. Introductory conversation.

2. Computerized Visual Verbal Learning Test (VVLT);

3. Motor Choice Reaction Time Test;

4. Continuous Performance Tapping Test;

5. Delayed recall \& recognition trials of VVLT;

6. Computerized Memory Scanning Test (CMST);

7. Digit Span Test;

8. Block Span Test;

9. Paper \& Pencil Memory Scanning Test (P\&P-MST).

10. Payment and brief evaluation of the subject's performance, and some general information about the purpose of the study. Most subjects volunteered to participate in a follow-up study after five years.

As the test procedures of CMST and P\&P-MST much resembled one another (chapter 2), care was taken that the positive and negative memory sets were different in the two tests. As the elderly subjects needed much more time for the second half of the examination and total duration was to be kept at two hours, the CMST was omitted from the protocol for subjects aged over sixty.

\subsubsection{Payment}

All subjects received Dfl. 25,- as compensation for their participation in the study. 


\section{BIOLOGICAL LIFE EVENTS AND BACKGROUND VARIABLES IN THE PRESENT SAMPLE}

\subsection{Introduction}

In the vast majority of studies on cognitive aging, elderly individuals who volunteer for an experimental study, are assumed to be 'healthy and normal' subjects. Usually, the experimenters content themselves with asking their subjects whether they are healthy. Occasionally, researchers let their volunteers rate their own health status. For instance, Salthouse and Mitchell (1989) asked their subjects to rate their health on a five point scale: $98 \%$ reported themselves to be in at least average health. However, the present study also questions the premise that subjective health judgments are valid and accurate.

In chapter 1 and 3, it was shown that some health-related factors are associated with brain dysfunction (biological life events; BLE), and therefore can be assumed to affect cognitive functioning as well. In this chapter, it is attempted to investigate to what extent these BLE are present in a sample of subjects who can be characterized as normal and healthy. As was discussed in the previous chapter, this was done by recruiting as many subjects as needed to arrive at a sufficiently large group of subjects without any BLE. Therefore, the present study can only serve as a first approximation of the prevalence of BLE in the whole population.

The data do hold validity within the present study. Moreover they serve to illustrate several discussions in the chapters to follow. Finally, although probably not representative for the whole population, they clearly indicate the importance of a thorough health screening in studies involving supposedly normal and healthy subjects.

The method of subject recruitment was presented in chapter 3. Briefly, 256 subjects aged 20-80 served as volunteers, with ages centered around whole decades. Within every age group, a fixed minimal number of BLE-unaffected individuals was used. All subjects who appeared to be BLE-affected were assigned to a corresponding BLE group. Nine subjects appeared to be either mildly demented or to have sustained major brain damage. Thus, a group of 247 remaining subjects were healthy according to the standard of nearly all experimental aging research. 
Table 4.1 Numbers of BLE in the BLE-affected group

\begin{tabular}{lrrrrrrrr}
\hline & \multicolumn{7}{c}{ Age group } \\
\cline { 2 - 8 } BLE & 20 & 30 & 40 & 50 & 60 & 70 & 80 & All \\
\hline 1. Neurology & 1 & 4 & 2 & 6 & 7 & 9 & 5 & 34 \\
2. Systemic disease & 2 & 1 & 2 & 5 & 7 & 5 & 2 & 24 \\
3. Closed head injuries & 0 & 1 & 3 & 3 & 6 & 0 & 3 & 16 \\
4. Anesthesia & 1 & 2 & 6 & 7 & 13 & 8 & 9 & 46 \\
5. Medication & 2 & 2 & 4 & 3 & 7 & 9 & 9 & 36 \\
6. Alcohol & 3 & 2 & 4 & 1 & 6 & 2 & 1 & 19 \\
7. Neurotoxic factors & 1 & 3 & 1 & 0 & 2 & 3 & 2 & 12 \\
8. Psychiatry & 2 & 2 & 5 & 4 & 5 & 5 & 4 & 27 \\
9. Birth/developm. compl. & 3 & 4 & 3 & 4 & 4 & 1 & 3 & 22 \\
& & & & & & & & \\
Mcan N of BLE/subject & 1.7 & 2.3 & 2.5 & 2.2 & 3.8 & 2.5 & 1.9 & 2.4 \\
\hline Number of subjects & 31 & 29 & 34 & 35 & 35 & 42 & 41 & 247 \\
subjects with BLE & 9 & 9 & 12 & 15 & 15 & 17 & 20 & 97 \\
percentage of subjects with BLE & $29 \%$ & $31 \%$ & $35 \%$ & $43 \%$ & $43 \%$ & $40 \%$ & $49 \%$ & $39 \%$ \\
\hline
\end{tabular}

Note: Subjects can be characterized by the presence of more than one BLE. See sections 1.4 and 3.1.4, and table 1.1 for further information about each BLE.

\subsection{Results and discussion}

Table 4.1 summarizes the outcomes of the screening for biological life events that preceded each examination. At first glance, the table shows that no clear age trends were observed regarding any of the BLE. Within the BLE-group, there was no significant linear relationship between age and the number of BLE a subject had experienced. There seems to be an increase in the age groups until 60 years of age, and a decrease in the groups aged 70 or and 80 . Possibly, this is a 'survivor effect': older subjects who have sustained many subtle health factors, may have died, or have become demented, or be less likely to volunteer for some other reason connected to the BLE. This question cannot be answered by the present study. 
Table 4.2 Mean values of quantifiable BLE in the BLE-affected group

\begin{tabular}{lrrrrrrr}
\hline & \multicolumn{7}{c}{ Age group } \\
\cline { 2 - 7 } & 20 & 30 & 40 & 50 & 60 & 70 & 80 \\
\hline \#anesth & 3.0 & 2.1 & 3.1 & 4.7 & 5.0 & 3.2 & 2.9 \\
\#CHI & 0.2 & 0.9 & 1.0 & 1.1 & 1.9 & 0.2 & 0.7 \\
\#alcohol & 24.9 & 16.0 & 20.9 & 16.7 & 12.4 & 4.0 & 16.2 \\
\#medic & 0.3 & 0.6 & 0.7 & 0.5 & 0.9 & 3.0 & 2.2 \\
\hline
\end{tabular}

Note. \#anesth: weighed score of general anesthesia; \#CHI: weighed score of closed head injuries; \#alcohol: score of weekly alcohol consumption; \#medic: number of different medications taken regularly. See section 3.1.4 for information and scoring weights for these BLE.

The absence of any clear age differences also applies to the separate BLE. Of those BLE that could be quantified, three were significantly related to age: medication $(\mathrm{r}=.31, \mathrm{p}<.001)$; alcohol $(\mathrm{r}=-.28, \mathrm{p}<.001)$; $\mathrm{CHI}(\mathrm{r}=-.167, \mathrm{p}<.01)$. The other quantitative measure (anesthesia) was not related. Although these correlations are significant, age has little predictive value for the BLE: only very small proportions of variance are explained by age. The trends of alcohol and $\mathrm{CHI}$ appeared to be negatively correlated with age, supporting the 'survivor' hypothesis: conceivably, high alcohol consumption, or many head injuries are associated with a reduced (healthy) life span. If this is indeed the case, it might affect the number of elderly volunteers affected by these BLE.

In table 4.2, the mean values per age group of the quantifiable BLE are presented. For instance, the BLE-affected 20-year old subjects took an average of 0.3 different medications on a regular base, whereas subjects aged 70 in the same group took as much as 3 different types of medication. It can be observed that the occurrence of no single BLE appeared to be linearly related to age.

\subsubsection{Background variables}

Personal variables regarding daily activities in which some mental or physical exercise is required, were recorded from subjects of 60 years and older. These background variables could be thought of as some 'protective factor' against cognitive decline (section 3.2).

No age differences were observed in this subgroup of subjects. They are therefore treated as a homogenous group as for age. The BLE-affected subjects differed on some activities from their unaffected peers. This is shown in table 4.3. BLE- 
affected subjects spent significantly less time in sports, reading, puzzles, and hobbies. The other two variables, participation in clubs or organizations and watching TV showed no difference between the two groups.

At present, it cannot be stated whether there is any causal relationship between a lower level of activity and BLE, and whether BLE cause inactivity, or the other way around. This may only be determined by a longitudinal follow-up of the present study. If subjects who presently spend little time in demanding activities will have deteriorated with respect to cognitive performance more than individuals who are still very active, then it can be said that these background variables indeed represent a protective factor.

In chapter 13, some associations between test outcomes and background variables will be discussed. Some caution with the interpretation of the present data is warranted. As has been mentioned before, this study was not devised to estimate the prevalence of biological life events in the whole aging population. The numbers of subjects are too small, and recruitment has not been a-select: we continued to recruit new subjects of a given age group until the minimum number of subjects who had not experienced any BLE was reached. It is unlikely, therefore, that the proportion of subjects having experienced a particular BLE, or a number of $B L E$, reflects the true epidemiologic proportions. It is entirely possible that the true occurrence of a number of BLE is over-estimated by the pre-

Table 4.3 Background variables that were associated with BLE: frequencies.

\begin{tabular}{|c|c|c|c|c|c|c|c|c|c|}
\hline \multirow[b]{2}{*}{$\operatorname{BLE}(0 / 1)$ : } & \multicolumn{2}{|c|}{ Sports } & \multicolumn{2}{|c|}{ Reading } & \multicolumn{3}{|c|}{ Puzzles } & \multicolumn{2}{|c|}{ Hobbies } \\
\hline & 0 & 1 all & 0 & 1 all & 0 & 1 & all & 0 & 1 all \\
\hline
\end{tabular}

Time spent on activity

\begin{tabular}{lrrrrrrrrrrrr}
0 (none) & 15 & 22 & 37 & 2 & 2 & 4 & 6 & 19 & 25 & 6 & 8 & 14 \\
$1 \quad$ (little) & 10 & 16 & 26 & 10 & 21 & 31 & 8 & 9 & 17 & 5 & 14 & 19 \\
2 (average) & 12 & 8 & 20 & 17 & 16 & 33 & 18 & 11 & 29 & 9 & 11 & 20 \\
3 (much) & 29 & 6 & 35 & 37 & 13 & 50 & 45 & 19 & 64 & 33 & 12 & 45 \\
ALL & 66 & 52 & 118 & 66 & 52 & 118 & 66 & 52 & 118 & 66 & 52 & 188 \\
\hline $\mathrm{Chi}^{2}$ & $17.2, \mathrm{p}<.001$ & $13.99, \mathrm{p}<.01$ & $16.86, \mathrm{p}<.001$ & & $19.05, \mathrm{p}<.001$ \\
\hline
\end{tabular}

Note: BLE (0/1): BLE absent/present; Category: amount of time spent on activity (0: none at all, 3: much). See section 3.2 for a more precise description of the category boundaries. 
sent proportions. For instance, it is likely that subtle health-related factors are associated with unemployment or, in case of women, not having sought a job themselves. People without a job clearly have more spare time to participate in experiments than subjects who have to go to work during the day. Conversely, it might be that the proportions of BLE-affected subjects may underestimate the true frequencies. It is conceivable that BLE are associated with a tendency to stay at home and not to engage in unusual activities like coming to a neuropsychology clinic and participating in such a study. Undoubtedly, many arguments can be ventured, but as long as little is known about the epidemiology of BLE, interpreting the data above is somewhat speculative. Further-more, only longitudinal research can determine the predictive value of BLE for age-related decline, terminal drop, and death (Riegel and Riegel, 1973).

In summary then, analysis of the occurrence of BLE in the present sample showed that the likelihood of having experienced at least one BLE increased markedly with age. However, there was no clear relationship between age and the number of experienced BLE. Nevertheless, the usual implicit or explicit assumption that the health status of elderly volunteers is equal to that of young subjects was not confirmed by the present study. There was a relationship between the level of cognitive activity engaged in at a regular base and BLE in elderly subjects: those subjects who spent little time in cognitively demanding activities were significantly over-represented in the BLE-affected subjects. 



\section{PRIMARY MEMORY CAPACITY: DIGIT \& BLOCK SPAN*}

\subsection{Introduction: Measuring memory span}

The capacity of people's primary memory (PM; or short-term memory; STM; section 2.1.1) is usually measured with a test of the immediate memory span. Memory span is typically defined as the maximum number of verbal items a subject can correctly recall in the same order as they were presented, after one single presentation. This definition is followed for the purpose of the present chapter, although it must be stated that other definitions, as well as other ways of measuring exist. In this chapter, two forms of forward span measurement are presented, although other approaches to span testing can be used: for instance, reciting the items in backward order, or recalling one item that has not been mentioned in a recognition list (see, e.g., Thomassen and Kempen, 1976; or Lezak, 1983).

The immediate memory span is thought to be not very closely tied to general intellectual ability, and to show very little inter-individual and cross-cultural variation (Lezak, 1983, p. 88). This memory span also seems to be quite insensitive to aging (Botwinick and Storandt, 1974), and even patients with severe brain damage can show an unimpaired immediate memory span (Hamsher, Benton, and Digre, 1980). Accordingly, it was expected that our span measures would not be affected very much by the main factors used in the whole study: age, education, and BLE.

\subsection{Test description}

We used two different measures of memory span, which were, however identical as to the procedure. The Digit Span test is used in almost all studies involving neuropsychological assessment. This is a reason for inclusion in our

*A subset of the data presented here has been published elsewhere:

Houx, P. J., Vreeling, F. W., \& Jolles, J. (1990). Cognitieve veroudering wordt meer beinvloed door 'biological life events' dan door fysiologische veroudering [Cognitive aging is more influenced by biological life events than by physiological aging]. In C. P. M. Knipscheer, J. J. M. Michels, \& M. W. Ribbe (Eds.), Ouder worden nu' 90 [Aging now '90] (pp. 270-278). Almere, The Netherlands: Versluys.

Houx, P. J., Vreeling, F. W., \& Jolles, J. (1991). Age-associated cognitive decline is related to biological life events. In K. Iqbal, D. R. C. McLachlin, B. Winblad, \& H. M. Wisniewski (Eds.), Alzheimer's disease: Basic mechanisms, diagnosis and therapeutic strategies (pp. 353-358).

Chichester, UK: Wiley. 
study. The block span test is included because it is a memory span test for the visual modality and shares its procedure with the digit span test. Furthermore, although the two tests make use of different modalities, they are both devised to tap STM, which makes comparison of the performance in both tests interesting.

\subsubsection{Digit Span test}

The well-known Digit Span subtest used in the Wechsler tests (Wechsler Adult Intelligence Scale; Wechsler, 1955) was used to test the primary memory for auditorily presented items. The test is administered as follows: A sequence of 3 randomly chosen and unique digits (from 1 to 9 ) is slowly read aloud to the subject: "5-1-2". This is usually well reproduced, and a second set of 3 digits is presented. If this is also correctly reproduced, the examiner augments the set with one digit. If not, a third set of digits of equal size is presented. If the subject fails at both first two sequences, the memory span is assumed to be one item lower. For instance, a subject has correctly recalled two sequences of six digits, but fails at both presentations of seven items. His Digit Span score is then 6 . If only one sequence out of three of seven items is reproduced correctly, the score will be 6.5. The normal range for this test is $6 \pm 1$ (Lezak, 1973, p. 268). The Wechsler tests also contain a 'Digits Backward' test, in which the subject is to reproduce the sequences in exactly reversed order. This test was not administered in the present study.

\subsubsection{Block Span test}

Milner (1971) described Corsi's Block-tapping board: nine black $4 \mathrm{~cm}$. cubes in a random lay-out attached to a black board of about $35 \times 35 \mathrm{~cm}$. Each time the examiner taps the blocks in a fixed order, the subject is requested to tap the same blocks in the same order, after the examiner has finished the pattern. The original test served another purpose (incidental learning in brain-injured patients) and the procedure differed likewise. In our study the test was used as a visual memory span test, analogous to the Digit Span: the Block Span Test, it s procedure being identical to that of the Digit Span test.

\subsection{Results}

Scores of both tests are graphically summarized in figure 5.1. Means and standard deviations can be found in table 5.1.

Scores on the Digit Span Test showed significant effects of age $(F(6,216)=5.08$, $p<.001), \operatorname{BLE}(F(2,216)=4.57, p<.05)$, and education $(F(1,216)=12.15, p<.01)$, all effects in the obvious direction. There were no significant interaction effects. 

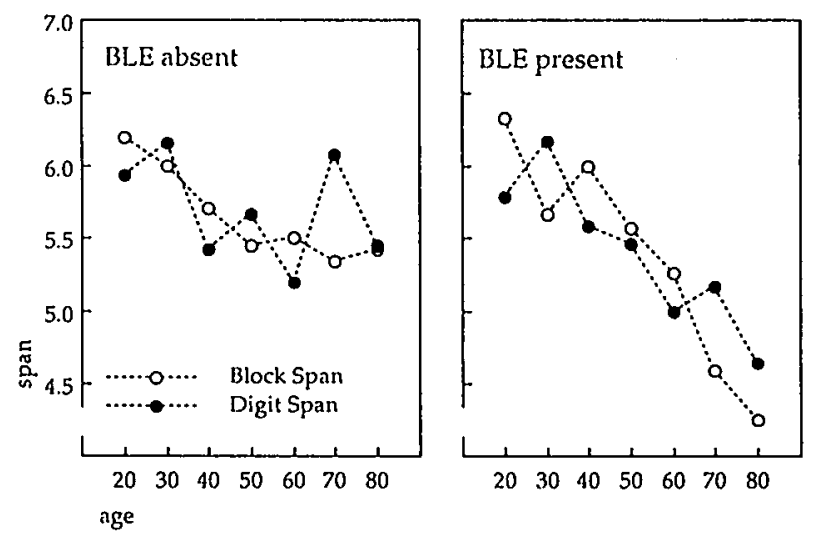

Figure 5.1 Mean scores on Digit and Block Span Test. Note that the $y$-axis has been cut.

Block Span was only affected by age $(F(6,216)=9.55, p<.001)$, and BLE $(F(1,216)=7.52$, $\mathrm{p}<.01)$, again in the obvious direction. One interaction effect was significant: age by $\operatorname{BLE}(F(6,216)=3.35, p<.01)$, indicating that older BLE-affected subjects performed more poorly, relative to young subjects.

In table 5.2, some Pearson's correlations are given between test scores and a number of subject variables. Age and education showed the strongest (but moderate) correlations. Number of experienced BLE appeared to correlate rather

Table 5.1 Mean scores of Digit and Block Span Tests (SD)

\begin{tabular}{|c|c|c|c|c|c|c|c|}
\hline & \multicolumn{7}{|c|}{ Age group } \\
\hline & 20 & 30 & 40 & 50 & 60 & 70 & 80 \\
\hline \multicolumn{8}{|c|}{ BLE absent } \\
\hline$N$ & 22 & 20 & 22 & 20 & 20 & 25 & 20 \\
\hline Digit span & $\begin{array}{c}6.0 \\
(0.9)\end{array}$ & $\begin{array}{c}6.2 \\
(0.9)\end{array}$ & $\begin{array}{c}5.5 \\
(1.0)\end{array}$ & $\begin{array}{c}5.7 \\
(1.1)\end{array}$ & $\begin{array}{c}5.2 \\
(1.0)\end{array}$ & $\begin{array}{c}6.3 \\
(1.1)\end{array}$ & $\begin{array}{r}5.6 \\
(0.8)\end{array}$ \\
\hline Block span & $\begin{array}{c}6.2 \\
(0.8) \\
\end{array}$ & $\begin{array}{r}6.0 \\
(0.6) \\
\end{array}$ & $\begin{array}{c}5.7 \\
(0.9) \\
\end{array}$ & $\begin{array}{r}5.5 \\
(0.9) \\
\end{array}$ & $\begin{array}{r}5.5 \\
(1.0) \\
\end{array}$ & $\begin{array}{c}5.5 \\
(0.8) \\
\end{array}$ & $\begin{array}{r}5.6 \\
(0.7) \\
\end{array}$ \\
\hline \multicolumn{8}{|c|}{ BLE present } \\
\hline$N$ & 9 & 9 & 12 & 15 & 17 & 17 & 20 \\
\hline Digit span & $\begin{array}{c}5.8 \\
(0.6)\end{array}$ & $\begin{array}{c}6.2 \\
(1.2)\end{array}$ & $\begin{array}{r}5.6 \\
(0.9)\end{array}$ & $\begin{array}{c}5.5 \\
(1.1)\end{array}$ & $\begin{array}{c}5.0 \\
(0.8)\end{array}$ & $\begin{array}{c}5.4 \\
(0.9)\end{array}$ & $\begin{array}{r}4.8 \\
(0.5)\end{array}$ \\
\hline Block span & $\begin{array}{c}6.3 \\
(0.8)\end{array}$ & $\begin{array}{c}5.7 \\
(0.8)\end{array}$ & $\begin{array}{c}6.0 \\
(0.7)\end{array}$ & $\begin{array}{c}5.6 \\
(0.6)\end{array}$ & $\begin{array}{c}5.3 \\
(0.8)\end{array}$ & $\begin{array}{r}4.6 \\
(0.6)\end{array}$ & $\begin{array}{r}4.3 \\
(0.8)\end{array}$ \\
\hline
\end{tabular}


Table 5.2 Correlations of test scores with Age and BLE

\begin{tabular}{lllllll}
\hline & Age & Educ & \#BLE & \#CHI & \#anest & \#alc/wk \\
\hline Digit Span & $-.22^{* *}$ & $.34^{* *}$ & $-.21^{* *}$ & .01 & $-.23^{* *}$ & .10 \\
Block Span & $-.45^{* *}$ & $.24^{* *}$ & $-.16^{*}$ & .00 & -.06 & .09 \\
\hline
\end{tabular}

Note: Educ: education, scored according to Verhagen (1964); \#BLE: number of BLE experienced by a subject; \#CHI: weighed score of the number of closed head injuries; \#anest: weighed score of general anesthesia; \#alc/wk: weighted score of alcohol consumption. ${ }^{*} \mathrm{p}<.05,{ }^{* *} \mathrm{p}<.01, \mathrm{t}$-test, two-tailed.

weakly, no stronger than the one single BLE that showed any correlation at all: the number of operations under general anesthesia.

Quite surprisingly, Digit and Block Span scores appeared to be only moderately correlated: $\mathrm{r}=.38, \mathrm{p}<.001$. Also, the amount of variance was quite high (see table 5.1 ): about $20 \%$ of the mean.

\subsection{Discussion}

Test performance appeared to be worse in older, less-educated and BLE-affected subjects. These effects did not interact (with the exception of age $\times$ BLE interaction as to Digit Span), so that they can be assumed to be parallel.

Some comments on the validity of the tests should be made (see section 2.3.1). As Lezak (1983; p. 268) states: "..it (Digit Span) appears to be primarily a measure of attention..". This is probably true, thereby seriously questioning the validity of these tests. Moreover, the necessarily very short duration of each set of items makes the tests more vulnerable to distraction, or temporary lapses of motivation or concentration. The tests do have face validity, and may have some ecological validity, because accurate short-term remembrance of short series of digits can be very useful in dialling telephone numbers, or writing down addresses or bank account numbers. This is why digit span is sometimes called 'telephone memory'.

The two measures of primary memory appeared to be not very closely related. Also, it is unclear whether this lack of high correlation is due to the difference of modality in which the items were presented, or whether the tests themselves are not very reliable. Unfortunately, test-retest reliability in aging subjects data are as 
yet unavailable. The moderate correlation between the two test outcomes makes it doubtful whether the tests measure the same type of memory, or place demands on the same type of attention. Furthermore, it is sometimes suggested that having to reproduce items from primary memory, and at the same time paying attention to the correct order of reproduction, is a dual task. Some future research should be aimed at the comparison of other tests of primary memory, of the accuracy items reproduction with and without the order constraint, and finally at the test-retest reliability. 


\section{SPEED OF MEMORY PROCESSING I: COMPUTERIZED MEMORY SCANNING TEST*}

In this chapter, data are discussed obtained with an abbreviated version of the original Sternberg task (Computerized Memory Scanning Test; CMST). Subjects constitute a subset of the sample population presented in the previous chapter (section 3.1), with age classes ranging from 17 to 63 years. Because the chapter in its present form was published as journal article, the analyses in that article are presented here.

\subsection{Introduction}

We describe data on the effects of aging and BLE on the speed of information processing, as measured with the CMST (a version of Sternberg's memory scanning task; Sternberg, 1975). This method is appropriate for research into agerelated memory impairments as it enables a closer examination of (dys)functions of short term memory and of discrete stages of information processing.

The processing that occurs in the memory scanning task consists of several independent stages, the component latencies of which are thought to be additive (Sternberg, 1975). These stages can be identified as: 1 . encoding of the stimulus; 2. serial memory scanning; 3 . binary decision about the nature of the response; 4 . response organization and execution. The time needed for the memory scanning stage can be inferred from the slope of the reaction times (RTs) as a function of memory load (set size). The three other stages are inferred from the intercept of this function. Theoretically, one can influence scanning and non-scanning stages differentially by varying different aspects of the task. During the last decade, this paradigm has become widely accepted, not only in experimental psychology, but also in other disciplines, such as neuropsychiatric research (e.g., Hart and Kwentus, 1987; Brand, 1987), drug research (e.g., Subhan and Hindmarch, 1984), and developmental psychology. For instance, Strayer, Wickens, and Cannon (1987) and Wickens, Braune, and Stokes (1987) found a substantial slowing with age of the non-scanning stages, and a less marked slowing of the speed of memory search in subjects aged 20-65.

*This chapter has been published as journal article:

Houx, P. J., Vreeling, F. W., \& Jolles, J. (1991). Rigorous health screening reduces age effect on Memory Scanning Task. Brain and Cognition, 15, 246-260. 


\subsection{Subjects}

The outcomes presented in this chapter are based on a subsample of the subjects recruited for the whole study (section 3.1; see table 6.1 for subject characteristics). No data are available from subjects older than 60 years: elderly subjects needed too much time to complete all tests. As the CMST took most time to complete, and yielded no more relevant information than the paper \& pencil version, the CMST was skipped in the adapted protocol for elderly subjects.

Table 6.1 Distribution (ranges, means, standard deviations) of age and level of education in a subsample of subjects described in chapter 3 .

\begin{tabular}{|c|c|c|c|c|c|c|c|c|c|c|}
\hline & \multicolumn{2}{|c|}{20 years } & \multicolumn{2}{|c|}{30 years } & \multicolumn{2}{|c|}{40 years } & \multicolumn{2}{|c|}{50 years } & \multicolumn{2}{|c|}{60 years } \\
\hline & age & educ & age & educ & age & educ & age & educ & age & educ \\
\hline \multicolumn{11}{|c|}{ BLE absent $(N=40)$} \\
\hline$\underline{\text { RANGE }}$ & $18-23$ & 3-7 & $27-31$ & $4-7$ & $37-42$ & 36 & $47-53$ & $3-6$ & $59-63$ & $3-5$ \\
\hline$\underline{M}$ & 20.75 & 4.88 & 29.75 & 4.75 & 39.75 & 4.63 & 49.75 & 4.50 & 61.38 & 4.38 \\
\hline$\underline{\mathrm{SD}}$ & 2.12 & 1.36 & 1.58 & 0.89 & 1.67 & 1.06 & 2.19 & 1.20 & 1.41 & 0.74 \\
\hline \multicolumn{3}{|c|}{ BLE present $(\mathrm{N}=40)$} & & & & & & & & \\
\hline RANGE & $17-22$ & 3-7 & $27-32$ & $3-6$ & $37-43$ & $2-6$ & $47-53$ & $2-6$ & $57-63$ & $2-7$ \\
\hline$\underline{\mathbf{M}}$ & 19.63 & 4.88 & 30.38 & 4.63 & 40.13 & 4.50 & 49.88 & 4.25 & 59.13 & 4.13 \\
\hline$\underline{\mathrm{SD}}$ & 1.77 & 1.55 & 1.92 & 1.06 & 2.64 & 1.31 & 2.42 & 1.28 & 2.10 & 1.73 \\
\hline
\end{tabular}

Note: age $=$ mean age in years; educ $=$ education level $($ Verhage, 1964$)$.

\subsection{Test description}

A Sternberg-type memory scanning task was used, as described by Brand (1987). The method of target and non-target selection was adapted from the method described by Logan (1978). The pool of possible stimuli consisted of the 21 consonants of the alphabet in capitals. The target set consisted of 9 different letters and there were 12 distractors or non-targets. Target items in one condition of the test never appeared as distractors in another condition.

Each stimulus was presented $1 \mathrm{sec}$. after the previous response (i.e. self-paced) and was displayed for a maximum of 1 sec. Response timing started at stimulus 
onset and stopped at the moment that a key was pressed. The subjects were instructed to memorize the items of a memory set consisting of $1,2,3$ or 4 letters presented for $5 \mathrm{sec}$. Thereafter, a series of letters was presented, one after another. The subject had to press the yes-button when a letter was presented that belonged to the memorized set and to press the no-button when it did not. Responses were to be as fast and as accurate as possible.

There were four equivalent conditions, corresponding to set sizes 1-4. Each consisted of at least 60 trials; there were 48 test trials, preceded by at least 12 practice trials. The test period started when there were no errors in the preceding 6 practice trials. There were 24 positive and 24 negative test trials, with equal probability of occurrence of the targets. The 12 non-targets were each presented twice in the test series, and the same non-target set was used throughout the whole test. Targets and non-targets were presented in the same semi-random order to each subject. No more than 3 targets or non-targets appeared in succession. The RT $x$ set size function was calculated, with the median of Rts ( $y-$ axis) per set size condition plotted against the size of the memory set ( $x$-axis). The most important parameters of this function were the slope (i.e. amount of extra time needed per item extra in memory) and the $(x=) 1$-intercept (i.e. the response latency with a memory load of only one item. The medians of the Rts of both positive and negative responses, and the number of errors per trial were analyzed. The main derivative variables were the 1-intercept, slope, and linearity of the RT $x$ set size function.

\subsection{Results}

The test results are shown in figures 1 and 2 . There was a significant over-all within subjects effect for the type of response $(F(1,70)=235.3, p<.001)$ : regardless of age or BLE, the mean 1-intercept of positive responses was $328.6 \mathrm{msec}$. and 348.2 msec. for the negative responses; the average slope of positive responses was less steep than that of the negative responses $(35.8 \mathrm{msec}$. and $42.5 \mathrm{msec}$. respectively; $F(1,79)=11.8, p=.001)$. This can be taken as evidence that positive decisions take less time than negative ones. The other within subjects factor (size of the memory set) also affected the response time: $F(3,210)=213.8$, $p<.001$, which can be taken to indicate that the size of the memory set is indeed positively related to the response latencies in all conditions. There was an over-all effect of age on response time (see fig. $1 \& 2$; between subjects effect $F(4,70)=13.3, p<.001$ ). 

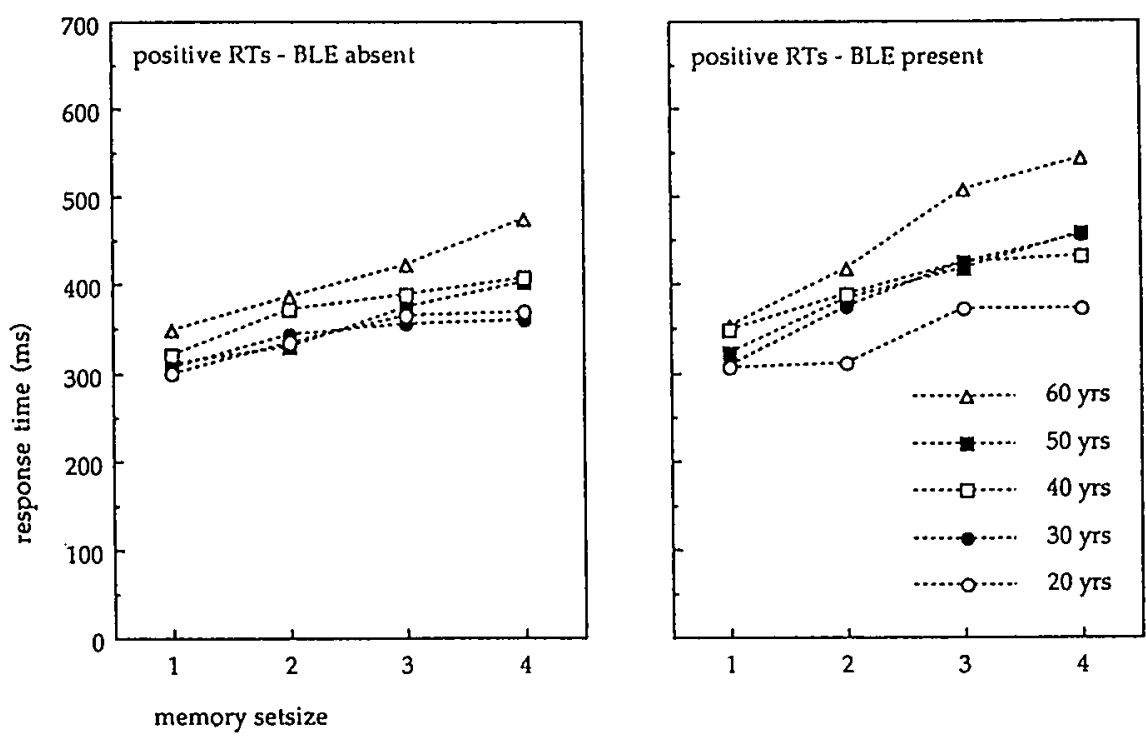

Figure 6.1 Average mean response time of positive responses as a function of set size, BLEunaffected (left) and BLE-affected subjects.

The same was true for the occurrence of BLE. The over-all effect of BLE on response times can readily be seen from the fan-shaped graphs and was statistically significant: $\mathrm{F}(1,70)=21.1, \mathrm{p}<.001)$. As a group, and regardless of any task variable, BLE-affected subjects (mean response time: $417.8 \mathrm{msec}$.) were slower than healthy volunteers $(373.9 \mathrm{msec}$.). There was no interaction between age and BLE on response time $(\mathrm{F}<1)$.

Regarding the derivative parameters (slope and 1-intercept of the RT $x$ set size functions), the slopes increased significantly with age (between subjects effect: $F(4,70)=7.6, p<.001)$. Age also significantly affected the 1-intercepts $(F(4,70)=4.8$, $\mathrm{p}<.01)$. For the memory scanning model, this suggests that both scanning and non-scanning stages are slower in the older age groups. Moreover, BLE affected both slopes and 1-intercepts: $F(1,70)=13.7, p<.001$ and $(F(1,70)=5.9, p<.05)$. Apparently, BLE can further delay memory processes. Concerning the slopes, age and BLE also showed significant statistical interaction: $F(4,70)=2.6, p<.05$, but not for the 1-intercept. This means that the effect of BLE on memory scanning speed, but not on the non-scanning stages, is more pronounced in subjects aged 40-60 than in young adults. This, in turn, indicates that the speed of memory search is more vulnerable to the joint influences of age and BLE than perceptual or motor processes. 

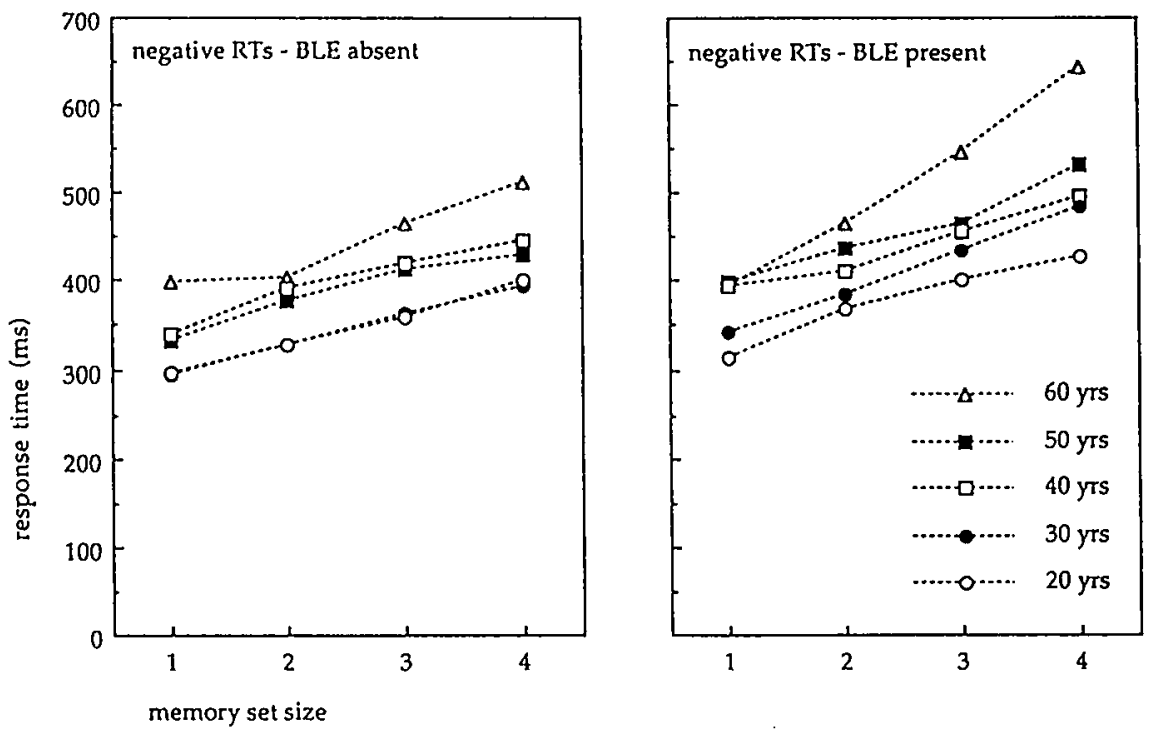

Figure 6.2 Average mean response time of negative responses as a function of set size, BLEunaffected (left) and BLE-affected subjects.

The number of BLE the subjects had been exposed to and the test performance of these subjects correlated significantly with the slopes of the positive and negative responses ( $r=.478$ and .507 , respectively; $p<.001)$, but regarding the 1 -intercepts no significant correlation was found ( $r=.073$ and $r=.121$, resp.).

The level of education of the subjects hardly affected any of the variables. The best correlation was that with the 1-intercept of the negative responses $(r=-.310$, $\mathrm{p}<.05$ ). This means that less than $10 \%$ of the total variance on this parameter could be explained by the educational level of the subjects. There was no correlation between the other variables and the educational level of the subjects.

Both the slopes and 1-intercepts of the positive and negative responses were significantly correlated $(r=.696$ and $r=.671$ respectively, $p<.001)$. This can be interpreted as evidence of a good internal consistency of the task used. With very few exceptions, the linearity of response time $x$ set size functions was quite high (overall mean $r=855$ ).

The overall mean number of errors was seldom greater than 1 per trial $x$ set size condition. There were far more false negative than false positive responses $(\mathrm{F}(1,79)=47.67, \mathrm{p}<.001)$. The number of errors was not affected by age, BLE or education (see table 6.2 for the mean number of errors per age $\times$ BLE group). 
Table 6.2 Mean number of negative and positive errors in healthy $(\mathrm{H})$ and BLE (B) groups.

\begin{tabular}{|c|c|c|c|c|c|c|c|c|c|c|c|c|c|c|c|c|}
\hline \multirow{3}{*}{ set size: } & \multicolumn{8}{|c|}{ False positives } & \multicolumn{8}{|c|}{ False negatives } \\
\hline & \multicolumn{2}{|c|}{1} & \multicolumn{2}{|r|}{2} & \multicolumn{2}{|r|}{3} & \multicolumn{2}{|r|}{4} & \multicolumn{2}{|r|}{1} & \multicolumn{2}{|r|}{2} & \multicolumn{2}{|r|}{3} & \multicolumn{2}{|c|}{4} \\
\hline & $\mathrm{H}$ & B & $\mathrm{H}$ & B & $\mathrm{H}$ & B & $\mathrm{H}$ & B & $\mathrm{H}$ & B & $\mathrm{H}$ & B & $\mathrm{H}$ & B & $\mathrm{H}$ & B \\
\hline \multicolumn{17}{|l|}{ age: } \\
\hline $20 \mathrm{y}: \underline{\mathrm{M}}$ & 1.00 & 0.75 & 0.75 & 0.63 & 1.00 & 0.13 & 0.38 & 0.88 & 1.13 & 0.25 & 0.38 & 0.00 & 0.25 & 0.38 & 0.13 & 0.25 \\
\hline$\underline{\text { SEM }}$ & 0.45 & 0.26 & 0.33 & 0.28 & 0.40 & 0.13 & 0.28 & 0.42 & 0.58 & 0.17 & 0.28 & 0.00 & 0.26 & 0.28 & 0.13 & 0.17 \\
\hline 30y: $\underline{M}$ & 0.63 & 0.25 & 0.38 & 1.63 & 0.88 & 1.38 & 0.25 & 1.00 & 0.25 & 0.63 & 0.13 & 0.88 & 0.25 & 0.13 & 0.38 & 0.25 \\
\hline$\underline{\text { SEM }}$ & 0.28 & 0.17 & 0.20 & 0.40 & 0.37 & 0.53 & 0.17 & 0.35 & 0.17 & 0.28 & 0.53 & 0.31 & 0.26 & 0.13 & 0.20 & 0.17 \\
\hline 40y: $\underline{M}$ & 0.38 & 1.00 & 1.00 & 0.88 & 0.63 & 0.50 & 0.25 & 0.38 & 0.88 & 0.38 & 0.25 & 0.50 & 0.13 & 0.25 & 0.50 & 0.00 \\
\hline$\underline{\text { SEM }}$ & 0.28 & 0.29 & 0.53 & 0.37 & 0.35 & 0.29 & 0.17 & 0.20 & 0.55 & 0.28 & 0.17 & 0.31 & 0.13 & 0.26 & 0.29 & 0.00 \\
\hline 50y: $\underline{\mathrm{M}}$ & 1.13 & 0.38 & 0.88 & 0.63 & 1.38 & 0.25 & 1.25 & 1.63 & 0.63 & 0.75 & 0.50 & 0.38 & 0.63 & 0.50 & 0.38 & 0.25 \\
\hline SEM & 0.37 & 0.20 & 0.37 & 0.28 & 0.45 & 0.17 & 0.37 & 0.63 & 0.40 & 0.17 & 0.29 & 0.20 & 0.20 & 0.31 & 0.20 & 0.17 \\
\hline $60 \mathrm{y}: \underline{M}$ & 1.13 & 0.13 & 1.13 & 0.63 & 0.63 & 0.75 & 1.25 & 0.50 & 0.38 & 0.25 & 0.13 & 0.13 & 0.25 & 0.38 & 0.75 & 0.00 \\
\hline$\underline{\text { SEM }}$ & 0.32 & 0.13 & 0.13 & 0.35 & 0.28 & 0.39 & 0.78 & 0.40 & 0.20 & 0.17 & 0.13 & 0.13 & 0.17 & 0.20 & 0.26 & 0.00 \\
\hline
\end{tabular}

\subsection{Discussion}

The results indicate that the Sternberg task has a fairly high internal consistency, which confirms the findings of Brand and Jolles (1987). Similarly, the almost invariably high linearity of the Rt $x$ set size functions further validates the use of the memory scanning paradigm in clinical settings. Furthermore, the lack of a significant correlation between any variable and educational level suggests that information processing, as measured by this task, is relatively independent of cultural factors.

There was a significant slowing with age of virtually all aspects of the memory scanning process. This was true for the actual memory search (reflected by the slopes of the Rt $x$ set size functions), as well as for perception and/or motor responses (reflected by the 1-intercept). BLE had similar effects in all age groups; thus, as far as the Sternberg task is concerned, it can be said that the existence of BLE for brain dysfunction aggravates the effects of aging even for subjects of 
about 60 years and younger. There was no systematic relationship between these main factors and the educational level of the subjects, neither was there a variable that could predict the number of errors made in the task used in the present study.

The negative responses were consistently slower and had steeper slopes than the positive responses. This is compatible with the assumption of serial selfterminating search, as a positive match should -in the long run- occur earlier in the scanning process than the conclusion that an item does not belong to the memory set. Sternberg (1975) discussed some limitations of self-terminating search as an alternative model to that of serial exhaustive search. In spite of Sternbergs' objections, it seems unclear how the finding of clear-cut differences in positive and negative Rts by the present study and by Strayer et al. (1987) could be explained in terms of exhaustive search.

The present results indicate that aging already affects the speed of information processing in middle-aged subjects (aged 40 to 50 ) as contrasted to healthy young adults aged 20 . Not only were the sensory and motor processes affected by age, as can be concluded from the increase in the intercept (which increased from 303 msec. at age 20 to $330 \mathrm{msec}$. at age 45), but in many instances memory scanning was also slower (the time needed per item extra in memory increased from 25.4 to $33.1 \mathrm{msec}$; see figures). The scanning speed is thought to be more central and therefore more relevant to the speed of overall cognitive functioning. These findings are in agreement with the data of Strayer et al. (1987) and Wickens et al. (1987): they found a marked overall increase from subjects aged 20 to 60, and a lesser age effect on scanning speed. Furthermore, the Rts in their studies were in the same range as those found in the present study, although the overall Rts were somewhat longer, and the slopes of Rt $\mathrm{x}$ set size functions tended to be steeper. This may be due to the fact that in their procedure, the stimulus presentation time was limited to $200 \mathrm{~ms}$, whereas in our procedure, stimuli were displayed for a maximum of $1 \mathrm{sec}$.

The apparent decrease with age in the speed of information processing could explain why elderly people who do not experience any significant perceptual or intellectual loss often have difficulties with processing all information that is presented to them. Even without subjective memory complaints, older individuals report that they can no longer keep up with all the new impressions and issues that pertain to their personal life. These worries may well originate from a general reduction in the speed of information processing, which already exists in earlier decades of life, but which only becomes manifest in the seventh or eighth decade. To quote Jensen (1982) as far as intelligence is concerned: "Seemingly small differences in speed of information processing (..), when multiplied by months or years of interaction with the environment can in part account for the large differences observed between individuals in vocabulary, general information, and other developed skills assessed by IQ tests". Taking IQ 
as an index of cognitive functioning, one might infer that a reduced speed of processing in middle-aged may eventually result in disorders of higher cognitive functions in elderly individuals.

The finding of more false negative than false positive responses can probably be explained by the different sizes of the positive and negative sets: in all conditions, there were 12 distractors and a maximum of only 4 targets. No significant change in the speed-accuracy trade-off (Fitts and Radford, 1966) was observed. This is inconsistent with the notion that people become slower but more cautious (i.e., more accurate) as they grow older (Botwinick, 1977). A possible explanation for the absence of evidence for such a shift in strategy might be found in the small number of errors and the large individual differences in the number of errors in all age groups. 


\section{SPEED OF PRIMARY MEMORY PROCESSING II: PAPER-AND-PENCIL MEMORY SCANNING TASK*}

Data are presented obtained with a paper-and-pencil memory scanning test (P\&PMST) that was derived from the paradigm that was originally proposed by Sternberg (1969), and was discussed in the previous chapter. The discussion of theoretical background (partly comparable to that of the abbreviated version of the orthodox Sternberg test discussed in the previous chapter) is specially directed to the P\&P-MST.

\subsection{Introduction}

To study the effect of age and the presence or absence of BLE on the speed of memory processes, we chose a well-known model of information processing. According to Poon (1985), general or process-specific age-related slowing of memory processes can be investigated in greater detail with tasks that are based upon an information processing model. By varying only one aspect of a task at a time, it is possible to obtain a more direct measure of the speed with which the information that is varied is being processed.

The processing that occurs in scanning the short term memory (recognizing a distractor stimulus from a set of well-memorized targets) consists of several independent stages, the component latencies of which are thought to be additive (Sternberg, 1969). These stages can be identified as: 1 . an encoding stage; 2 . a memory scanning stage; 3 . a stage of binary decision as to the nature of the response; 4. a response organization and execution stage. The memory scanning stage can be inferred from the slope of the reaction times (Rts) plotted as a function of memory load (set size). The other three stages are inferred from the

*This chapter is a condensed form of what has been submitted for publication as journal article:

Houx, P. J., \& Jolles, J. (1991). Biological life events accentuate age effects on performance in a paper \& pencil memory scanning task. Neuropsychologia (submitted).

A subset of the data presented here has been published elsewhere:

Houx, P. J., Vreeling, F. W., \& Jolles, J. (1990). Cognitieve veroudering wordt meer beïnvloed door biological life events' dan door fysiologische veroudering [Cognitive aging is more influenced by biological life events than by physiological aging]. In C. P. M. Knipscheer, J. J. M. Michels, \& M. W. Ribbe (Eds.), Ouder worden nu '90 [Aging now '90] (pp. 270-278). Almere, The Netherlands: Versluys.

Houx, P. J., Vreeling, F. W., \& Jolles, J. (1991). Age-associated cognitive decline is related to biological life events. In K. Iqbal, D. R. C. McLachlin, B. Winblad, \& H. M. Wisniewski (Eds.), Alzheimer's disease: Basic mechanisms, diagnosis and therapeutic strategies (pp. 353-358).

Chichester, UK: Wiley. 
intercept of this function. Theoretically, one can influence scanning and non-scanning stages differentially: the scanning stage by the set size, nonscanning stages by perceptual or motor constraints like stimulus legibility or stimulus-response compatibility (Frowein and Sanders, 1978).

During the last decade, this paradigm has become widely accepted, not only in experimental psychology, but also in other disciplines, such as neuropsychiatric research (e.g. Hart et al., 1986), drug research (e.g. Subhan and Hindmarch, 1984), and developmental psychology. For instance, Strayer, Wickens, and Cannon (1987) and Wickens, Braun, and Stokes (1987) found a substantial slowing of non-scanning stages with age (20 to 65 years), but a less marked slowing of the speed of memory search. Brand and Jolles (1987) found slowing of both scanning and non-scanning stages in unipolar depressive patients. For practical and theoretical reasons to be indicated in the next section, we used a newly developed paper-and-pencil task in this study.

\subsection{Test description}

Houx et al. (1991c) described a study on cognitive aging and BLE in which an orthodox version of Sternberg's paradigm was used. However, Jolles and Hijman (1983) have shown that the task can be adapted into a paper \& pencil version without any loss of reliability. Memory scanning can be assessed in clinical settings as opposed to the applications that are confined to laboratory settings. Moreover, by shortening the whole procedure and expanding the number of factors that are varied, it is possible to obtain additional information: the distinction between automatic and controlled processing (proposed by Shiffrin and Schneider, 1977; see section 2.1.1) is accessible for the clinical neuropsychologist. By making the target stimuli easily or categorically discernible from the distractor stimuli, memory scanning is made superfluous (Rabbitt, 1967). As a consequence, the slope of the (Rt) $x$ set size function is much less steep. Brand and Jolles (1987) showed that the paper \& pencil version using total times per test sheet $(\mathrm{Tt})$ yielded more reliable data, within one measurement (higher linearity of the $\mathrm{Tt} \times$ set size function) as well as in repeated measurements, for which different mapping of positive and negative items can be used.

The paper \& pencil memory scanning task (P\&P-MST; Brand and Jolles, 1987) consists of 9 different subtasks, each on a separate sheet of A4 paper, containing a matrix of $12 \times 12$ letters, digits or other characters. For each subtask, the subject was requested to memorize 1-4 target characters (the memory set) and to cross them out as quickly as possible, without making mistakes, each time they occurred on the test sheet. The method of target and distractor selection was adapted from Logan (1978). Attention was paid that the subject worked accurately 
and line by line, to prevent the subject from scanning a whole page for one target. This would make the task very similar to Neisser's (1963) visual search task. Non-targets (distractor characters) were always letters. Each test sheet contained 24 targets and 120 distractors. In the 9 successive subtasks, divided in three types, the targets were:

Subtask 1 and 9: the percentage sign ("\%"). The target saliently belongs to another category, making memory search unnecessary.

Subtask 2-4: 1, 2, or 4 different digits. The subject can detect that all targets belong to another category, and confine him/herself to looking for digits.

Subtask 5-8: 1, 2, 3 or 4 letters. Target and distractors belong to the same category, making necessary comparison with the memory set for each stimulus.

The total time needed by the subject to complete each subtask was timed with a stopwatch. Two individual total time $\mathrm{x}$ set size functions were calculated, one for the 3 digit subtasks, and one for the 4 letter subtasks. These functions were defined by the equation $\mathrm{Tt}=\mathrm{A}^{*} \mathrm{~S} s+\mathrm{B}$, in which $\mathrm{Tt}$ was the total time, $\mathrm{A}$ the slope of the function (i.e., the amount of extra time needed per item in the memory set), Ss the size of the memory set, and B the intercept with the $Y$-axis (in contrast to other studies, the $X=1$-intercept was calculated to avoid theoretical dispute). The linearity of the function was also calculated. Theoretically, the 1-intercepts for the digits and letter functions are the same, but the slope of the letters subtasks is markedly steeper than that of the digit subtasks, as the subject can adopt the strategy of crossing out all digits whatsoever, instead of paying attention to each separate character. In the latter case, it can be said that automatic cognitive processing occurs. The linearity $(r)$ of the time $x$ set size function can be taken as a measure of the consistency with which the subject completed the tasks. Usually, the correlation coefficient is quite high in the letters subtasks (well above 0.90; Brand and Jolles, 1987).

\subsection{Results}

The mean times needed per test sheet are summarized in figure 7.1. There were significant group effects of age on the speed with which all subtasks were completed: $F(6,229)=28.39$, $p<.001$ for the two "\%"-subtasks; $F(6,229)=31.92, p<.001$ for the three digits subtasks; and $F(6,229)=44.87$ for the four letters subtasks. Roughly, there was an increase with group age in time to finish any test part, although this increase was not monotonous.

BLE and educational level had the same group effects. The main effects of BLE were: $\mathrm{F}(1,229)=12.39, \mathrm{p}<.01$ ("\%"-subtasks); $\mathrm{F}(1,229)=23.25$, $\mathrm{p}<.001$ (digits-subtasks); $\mathrm{F}(1,229)=45.65, \mathrm{p}<.001$ (letters-subtasks). Thus, the group of subjects with BLE per- 

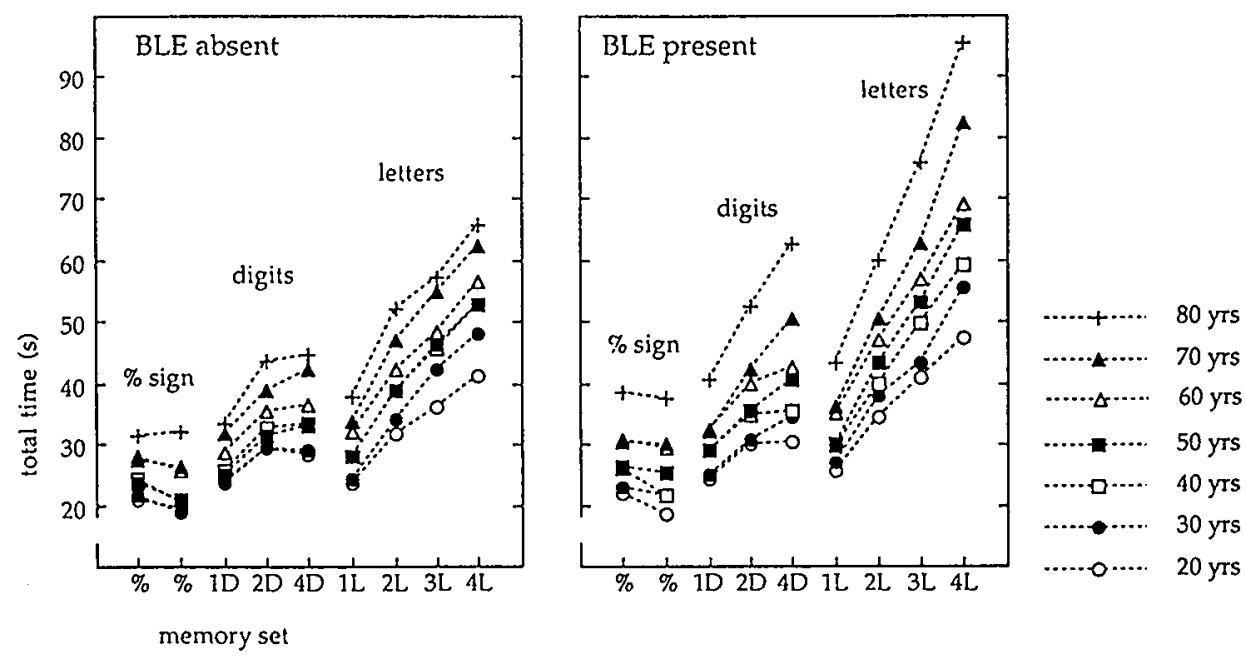

Figure 7.1 Mean total time per test sheet in all subtasks of the P\&P-MST, performed by subjects who are not affected by biological life events (BLE; left) and by subjects who are (right).

formed the task significantly more slowly than subjects without BLE (mean difference: 6.9 secs.). The main effects of educational level were: $F(1,229)=16.04$, $\mathrm{p}<.001$ ("\%"-subtasks); $F(1,229)=15.63, \mathrm{p}<.001$ (digits-subtasks); $F(1,229)=12.35$, $\mathrm{p}<.01$ (letters-subtasks). The subjects with a higher education were clearly somewhat faster than the other subjects (mean difference: 4.7 secs.). The only statistically significant interaction between group effects was that of age group by BLE on performance in the letters-subtask: $F(6,229)=2.564, p<.05$, indicating that age-related slowing was more pronounced in the BLE group.

The repeated measurement effect within the "\%"-subtasks $(F(1,229)=59.89$, $\mathrm{p}<.001)$, and the effect of set size in the digits-subtasks $(\mathrm{F}(2,458)=455.42, \mathrm{p}<.001)$, and letters-subtasks $(F(3,687)=1192.78, \mathrm{p}<.001)$ were very pronounced, as can be seen from the plots in figure 1 . The second measurement of the "\%"-subtask was generally performed faster, the total time for the digits- and letters-subtasks increased with the set size (see also tables 4 and 5). Moreover, several significant interactions between the effects of set size and other factors were observed. The older age groups needed more extra time when the set size was increased: $F(12,458)=8.40, p<.001$ (digits); $F(18,687)=9.15, p<.001$ (letters). BLE accounted for a similar pattern: $F(2,458)=15.61, p<.001$ (digits); $F(3,687)=43.12, p<.001$ (letters). The effects of age and BLE even appeared to interact within the effect of set size; the 
slopes of the $\mathrm{Tt} \times$ set size functions were steepest in elderly subjects in the BLE group: $F(12,458)=2.36, \mathrm{p}<.01$ (digits); $F(18,587)=3.70, \mathrm{p}<.001$ (letters).

Analysis of the linear regression parameters, 1-intercept and slope, revealed the same clear-cut differences. Tables 7.1 and 7.2 summarize the individual values for all age $x$ ble $x$ education groups.

The 1-intercept (the time needed to finish a test sheet with set size 1) differed very slightly -but consistently- over the two types of targets: $F(1,229)=12.15$, $\mathrm{p}<.001$. All main group effects were also statistically significant: age $(F(6,229)=27.93, p<.001), \operatorname{BLE}(F(1,229)=6.21, p<.05)$, and educational level $(F(1,229)=14.99, p<.001)$. This indicates that the basic speed of sensomotoric processing was affected by all the independent variables used in the present design. The extra time needed per extra item in the memory set (slope) showed the same main group effects, with the exception of educational level: age $(F(7,229)=18.90, p<.001)$ and $\operatorname{BLE}(F(1,229)=62.88, p<.001$. Moreover, age and BLE interacted in their effect on the slope: $F(6,229)=5.83, p<.001$. The within-subjects differences in the slope of the digits and letters subtasks were very large: overall means were 3.03 and 9.72 secs. respectively, $F(1,229)=939.54, p<.001$. This difference was greater in the older age groups: $F(6,229)=2.83, p<.05$. However, the interaction with BLE was much more pronounced: $F(1,229)=24.08, p<.001$. The only main group effect on the linearity of the $T t \times$ set size function was that of BLE: $F(1,229)=6.33, p<.05$. The letters subtasks showed a much more pronounced linear relationship (overall mean r-values were .959 versus .706). As stated in section 7.2, the time per test sheet in the digits subtasks should not increase linearly with set size.

Very few errors were made, especially by young and middle-aged subjects. The number of omissions was usually below 1 per subtask, and false positive responses (crossing out distractors) hardly ever occurred (see table 7.3). However, subjects older than 50 omitted significantly more targets in the letters subtasks: $F(6,229)=48.93$, p<.001. BLE greatly increased the number of omissions: $F(1,229)=16.43, p<.001$ (digits); $F(1,229)=13.93, p<.001$ (letters). Set size also affected the occurrence of omissions: $F(2,458)=9.86, p<.001$ (digits); $F(3,687)=35.79, p<.001$ (letters). Again, both age and BLE enhanced the effect of set size: $F(12,458)=2.55$, $\mathrm{p}<.01$ (age/digits); $\mathrm{F}(2,458)=5.67, \mathrm{p}<.01$ (risk/digits); $\mathrm{F}(18,687)=9.03, \mathrm{p}<.01$ (age/letters); $F(3,687)=4.26, p<.01$ (risk/letters). The false positive responses showed a similar pattern, although age did not affect the overall mean number in the letters subtasks, whereas BLE did: $F(1,229)=4.98, p<.05$.

It can be deduced from tables 7.1 and 7.2 that the within-group variation was markedly reduced when data from the subjects with BLE were omitted per age group. Moreover, within the BLE-free group, there was much less age-associated increase in the variation. 
Table 7.1 Mean scores (SD) of individual Tt $x$ size regression values; BLE absent

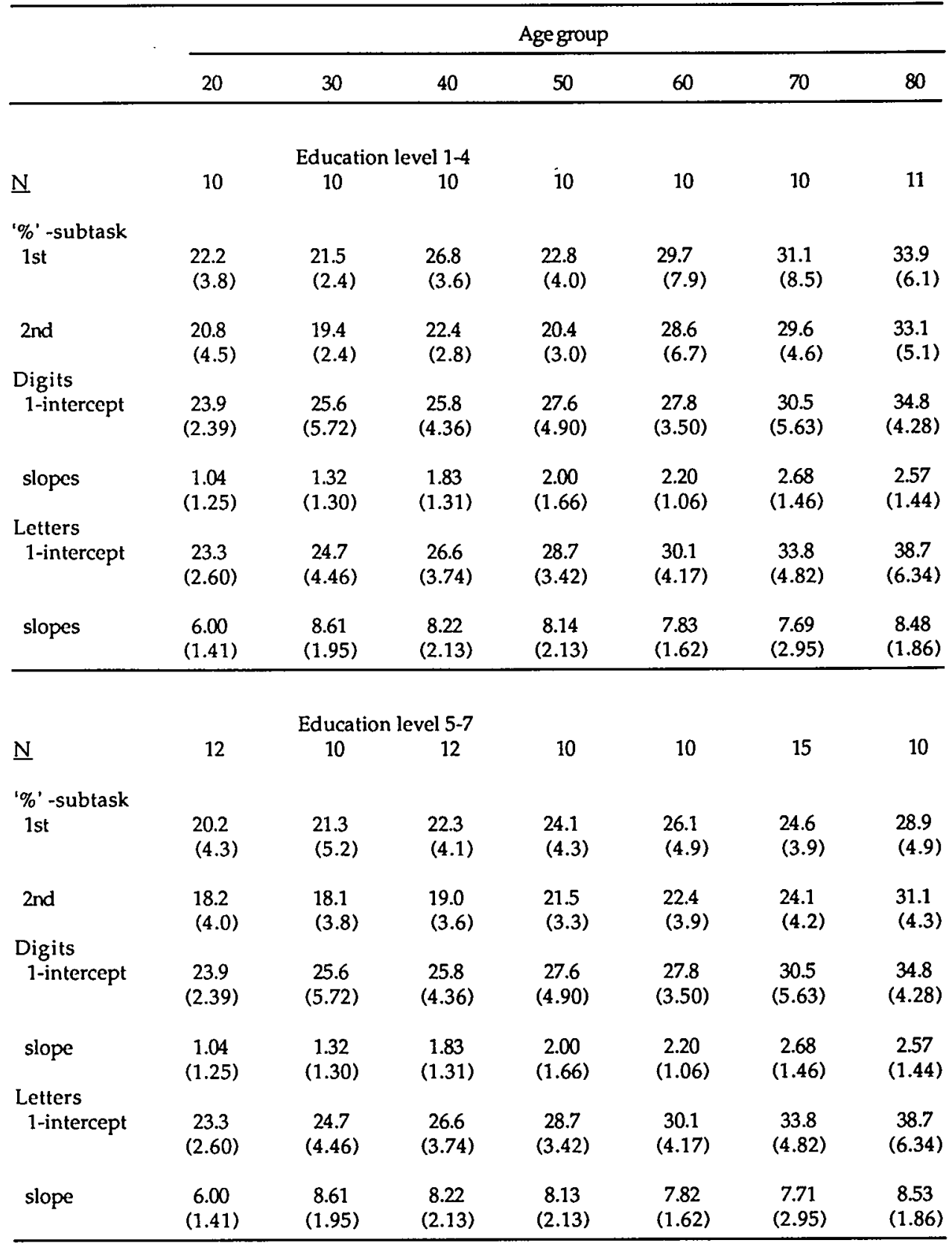


Table 7.2 Mean scores (SD) of individual Tt $\mathrm{x}$ size regression values; BLE present

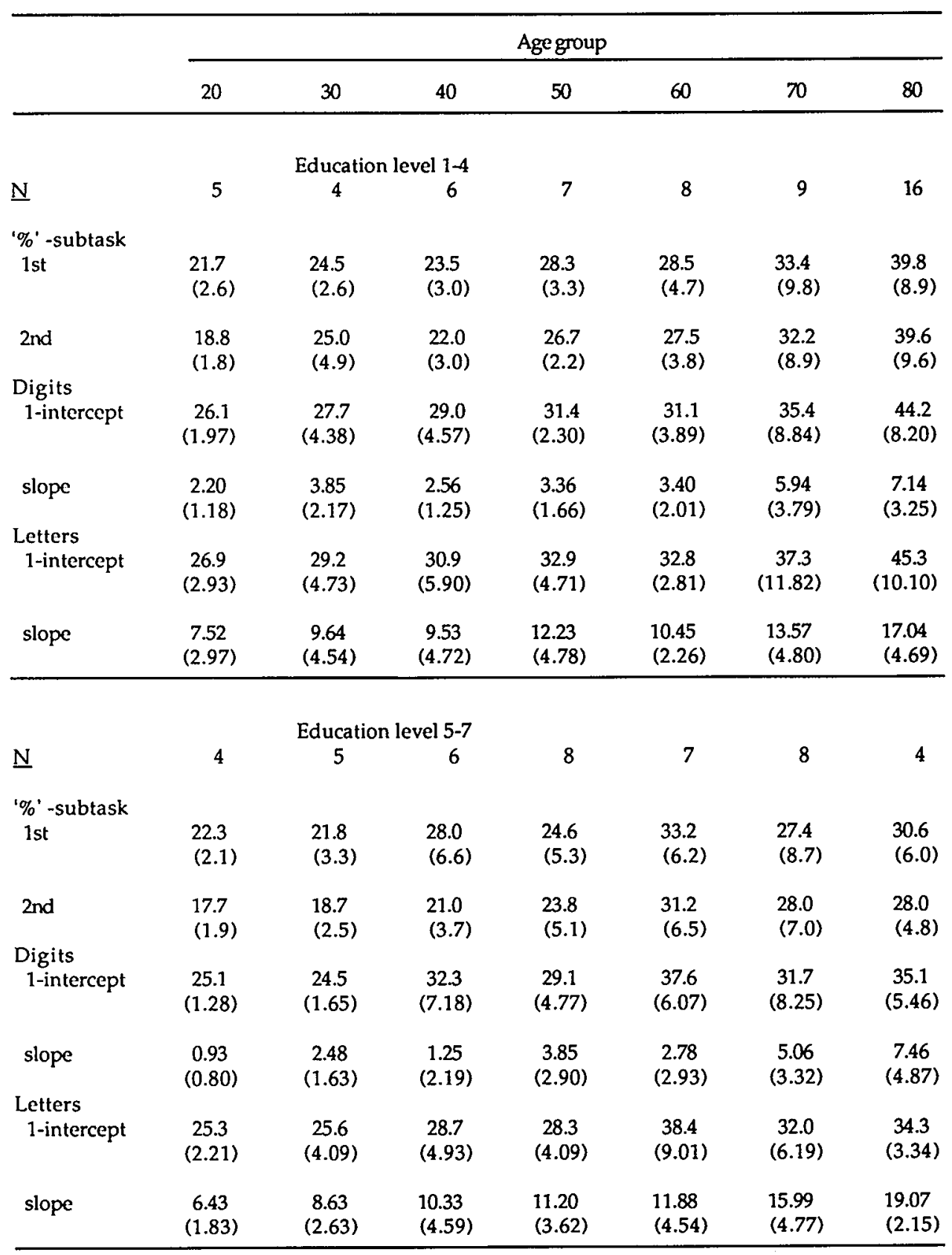


Table 7.3 Mean error numbers per subject, over all 9 subtasks (SD)

\begin{tabular}{|c|c|c|c|c|c|c|c|}
\hline & \multicolumn{7}{|c|}{ Age group } \\
\hline & 20 & 30 & 40 & 50 & 60 & 70 & 80 \\
\hline \multicolumn{8}{|c|}{ Omissions } \\
\hline BLE absent & & & & & & & \\
\hline Low education & $\begin{array}{c}3.2 \\
(3.2)\end{array}$ & $\begin{array}{c}5.4 \\
(3.2)\end{array}$ & $\begin{array}{c}5.2 \\
(2.5)\end{array}$ & $\begin{array}{c}6.9 \\
(4.3)\end{array}$ & $\begin{array}{c}6.1 \\
(3.1)\end{array}$ & $\begin{array}{l}10.0 \\
(5.2)\end{array}$ & $\begin{array}{c}9.7 \\
(5.7)\end{array}$ \\
\hline High education & $\begin{array}{c}4.6 \\
(2.7)\end{array}$ & $\begin{array}{c}5.4 \\
(3.1)\end{array}$ & $\begin{array}{l}3.6 \\
(1.8)\end{array}$ & $\begin{array}{c}4.7 \\
(3.5)\end{array}$ & $\begin{array}{c}5.3 \\
(2.5)\end{array}$ & $\begin{array}{c}8.4 \\
(8.0)\end{array}$ & $\begin{array}{l}8.3 \\
(5.1)\end{array}$ \\
\hline \multicolumn{8}{|l|}{ BLE present } \\
\hline Low education & $\begin{array}{c}4.3 \\
(3.8)\end{array}$ & $\begin{array}{l}10.5 \\
(6.7)\end{array}$ & $\begin{array}{l}6.3 \\
(3.1)\end{array}$ & $\begin{array}{l}9.0 \\
(4.3)\end{array}$ & $\begin{array}{l}8.0 \\
(5.0)\end{array}$ & $\begin{array}{c}23.2 \\
(10.9)\end{array}$ & $\begin{array}{c}17.3 \\
(11.9)\end{array}$ \\
\hline High education & $\begin{array}{c}2.3 \\
(2.1)\end{array}$ & $\begin{array}{l}6.8 \\
(3.1)\end{array}$ & $\begin{array}{l}6.5 \\
(6.7)\end{array}$ & $\begin{array}{c}8.9 \\
(2.2)\end{array}$ & $\begin{array}{c}6.9 \\
(4.3)\end{array}$ & $\begin{array}{c}16.1 \\
(10.8)\end{array}$ & $\begin{array}{l}13.3 \\
(4.1)\end{array}$ \\
\hline \multicolumn{8}{|c|}{ False positives } \\
\hline $\begin{array}{l}\text { BLE absent } \\
\text { low education }\end{array}$ & $\begin{array}{c}0.8 \\
(1.2)\end{array}$ & $\begin{array}{c}0.5 \\
(0.8)\end{array}$ & $\begin{array}{c}1.4 \\
(2.0)\end{array}$ & $\begin{array}{c}0.6 \\
(0.8)\end{array}$ & $\begin{array}{c}0.9 \\
(1.0)\end{array}$ & $\begin{array}{c}0.3 \\
(0.6)\end{array}$ & $\begin{array}{c}0.6 \\
(1.7)\end{array}$ \\
\hline high education & $\begin{array}{c}0.3 \\
(0.5)\end{array}$ & $\begin{array}{c}1.3 \\
(1.4)\end{array}$ & $\begin{array}{c}1.0 \\
(1.2)\end{array}$ & $\begin{array}{c}0.7 \\
(1.4)\end{array}$ & $\begin{array}{c}1.2 \\
(1.5)\end{array}$ & $\begin{array}{c}0.3 \\
(1.0)\end{array}$ & $\begin{array}{c}0.1 \\
(0.3)\end{array}$ \\
\hline \multicolumn{8}{|l|}{ BLE present } \\
\hline low education & $\begin{array}{c}1.3 \\
(1.6)\end{array}$ & $\begin{array}{l}3.0 \\
(2.5)\end{array}$ & $\begin{array}{c}1.0 \\
(1.4)\end{array}$ & $\begin{array}{c}2.9 \\
(4.7)\end{array}$ & $\begin{array}{c}2.8 \\
(2.0)\end{array}$ & $\begin{array}{c}0.7 \\
(1.9)\end{array}$ & $\begin{array}{c}1.0 \\
(2.9)\end{array}$ \\
\hline high education & $\begin{array}{c}1.3 \\
(0.5)\end{array}$ & $\begin{array}{c}3.4 \\
(4.8)\end{array}$ & $\begin{array}{c}2.2 \\
(1.8)\end{array}$ & $\begin{array}{c}1.4 \\
(1.9)\end{array}$ & $\begin{array}{c}1.7 \\
(1.2)\end{array}$ & $\begin{array}{c}1.8 \\
(2.9)\end{array}$ & $\begin{array}{c}0.8 \\
(1.3)\end{array}$ \\
\hline
\end{tabular}

The present study was not planned to investigate prospectively the effects of individual BLE on motor performance. By consequence, the prevalence of BLE can differ widely over the different age groups. However, correlations between test performance and age, level of education, and BLE can be compared. Spearman's rank order correlations between several measures of performance and age were usually about 0.50 ( $p<.01, t$-test). Table 7.4 gives correlations between test performance and age, education, number of experienced BLE, and some BLE. Although these values are statistically significant, both age and education leave a considerable amount of variation unaccounted for. The number of BLE the subjects had experienced during their lives appeared to correlate even weaker, with the exception of the slope of the letters subtasks. Correlations between performance and other BLE than given in table 7.4 seldom exceeded .10, and did not reach significance. 
Correlations between test performance on the P\&P-MST and the computerized version (CMST) discussed in the previous chapter were significant though small: the slope of the letters subtests showed a Pearson's $r$ of 0.257 with the slope of both negative and positive responses in the CMST $(t=2.35, \mathrm{df}=78, \mathrm{p}<.01)$. The 1intercept correlated 0.353 with the corresponding parameter of the positive responses in the CMST, and 0.385 with the negative responses.

Table 7.4 Spearman's rank order correlations of some test scores with age, education, number of experience BLE, and two separate BLE.

\begin{tabular}{llllll}
\hline & Age & Education & \#BLE & \#anest & \#medic \\
\hline $\begin{array}{l}\text { Digits } \\
\quad \text { 1-intercept }\end{array}$ & $0.57^{* *}$ & $-0.32^{* *}$ & $0.21^{* *}$ & $0.21^{* *}$ & $0.40^{* *}$ \\
$\quad$ Slope & $0.41^{* *}$ & $-0.23^{* *}$ & $0.25^{* *}$ & $0.16^{* *}$ & $0.25^{* *}$ \\
$\begin{array}{l}\text { Letters } \\
\quad \text { 1-intercept }\end{array}$ & $0.66^{* *}$ & $-0.35^{* *}$ & 0.11 & $0.17^{* *}$ & $0.41^{* *}$ \\
$\quad$ Slope & $0.44^{* *}$ & $-0.18^{* *}$ & $0.40^{* *}$ & $0.14^{*}$ & $0.36^{* *}$ \\
& $0.54^{* *}$ & $-0.33^{* *}$ & $0.23^{* *}$ & $0.23^{* *}$ & $0.42^{* *}$ \\
\hline '\%'-sign (1st meas.) & & & & &
\end{tabular}

Note: \#BLE: number of BLE (table 1) experienced by a subject; \#anest: weighed score of general anesthesia; \#medic: number of different medications, taken regularly.

${ }^{*} \mathrm{p}<.05,{ }^{* *} \mathrm{p}<.01, \mathrm{t}$-test, two-tailed.

\subsection{Discussion}

Subjects in older age groups needed more time for both scanning and nonscanning stages of memory search when performing the P\&P-MST; moreover, their overall accuracy decreased. Movements and scanning of the test sheets were slower, as was memory search. However, these age-related effects were significantly more pronounced in the subjects who were characterized by one or more biological life events. The most marked difference was the much steeper slope of the individual total time $x$ set size functions, irrespective of whether or not the task conditions were effort-demanding.

The present results suggest a very gradual age-related decline in performance in simple and complex cognitive speed tasks, with the decline starting as early as 
the third decade. The speed of information processing of middle-aged subjects already appeared to be markedly reduced compared with that of 20-year old people. A few t-tests comparing performance of 20- and 40-year old subjects may illustrate this point: 1 -intercept, digits: $\mathrm{t}=-2.86, \mathrm{df}=63, \mathrm{p}<.01$ (pooled variances); 1 intercept, letters: $t=-3.9, p<.001$; slope, letters: $t=-3.64, p<.01$. Memory scanning speed is thought to be a central part of information processing and is therefore more relevant to the speed of overall cognitive functioning. It is exactly this ability that appears most vulnerable to aging and to brain dysfunctioning. One might infer that a reduced speed of processing in middle-aged may eventually result in disorders of higher cognitive functions in elderly individuals.

The apparent decrease in the speed of information processing with age may help explain why elderly people who do not experience significant perceptual or intellectual deficits often do have difficulties with processing all information presented to them. Even without subjective memory complaints, older individuals report that they "can no longer keep up" with all the new impressions and issues relevant to their personal life. These worries may well originate from a general reduction in the speed of information processing. This reduction is already there in the fourth decade, but only becomes manifest after the sixth or seventh decade.

In those instances when it was possible to process the target information semiautomatically (digit subtasks), results showed that there was a small but systematic effect of age. This suggests that the older subjects were less apt to adopt an efficient, time-saving strategy like crossing-out only digits. However, in BLEaffected subjects, the increment of $\mathrm{Tt}$ with the memory set size in the digit subtasks was almost linear, as is normally the case in the letter subtasks. This can be taken as evidence that those individuals who experience some slowing of speeded processing of information, cope with this handicap by a shift to a strategy of controlled processing. Apparently, they confine themselves to the most elementary features of their task, unable to pay attention to other possibly useful aspects.

No significant change in the speed-accuracy trade-off (Fitts and Radford, 1966) was observed. On the contrary, apart from being much slower, older subjects tended to make more rather than fewer errors. This is inconsistent with Botwinick's notion (1977) notion that older people are more cautious, which also implies that accuracy should increase with age. A possible explanation for the absence of evidence for such a strategic shift might be found in the small number of errors and the large individual differences in the number of errors in all age groups. Another possibility is that speed and accuracy are dependent on the same or strongly related processing resources (see, for instance, Salthouse, 1988).

The poor correlations between the performance on the P\&P-MST and the CMST (presented in the previous chapter) suggest that at least one of these tests does 
not adequately measure what it is supposed to measure. Further research should bring clarity in the issue of construct validity of both tests. For the present discussion we may perhaps tentatively state that the P\&P-MST is the more reliable test, as the average linearity coefficient was considerably higher in the P\&P-MST: $r=0.96$ vs. $r=0.85$ in the CMST. Another reason why the P\&P-MST is probably the method of choice, is its shorter duration (an average of about 8 minutes as opposed to 15 minutes for the CMST; instruction time included for both tests). Finally, the high linearity of the response time $x$ set size functions that were found by Sternberg $(1969 ; 1975)$ were arrived at after prolonged practice trials (several hours). This is clearly not feasible in clinical assessment or experimental research with aging subjects. 
. 

TEST*

\subsection{Introduction}

In research into primary and secondary verbal memory processes and disorders thereof, multi-trial free recall tests offer a useful paradigm. The distinction between primary and secondary memory refers to acquisition and retention of new information (Poon, 1985). The Auditory Verbal Learning Test (AVLT; Lezak, 1983) is a much used example of this procedure. The procedure of the AVLT was derived from the work of Rey (1964). The test involves five presentations with free recall of a 15-word list followed by presentation with recall of a second word list. The main score is the number of items correctly recalled at each trial. Immediately after that, the first list is to be recalled (retention trial), followed by a recall without presentation of the first list after a 20 - or 30-minute delay.

Regarding delayed recall, Lezak (1983, p. 424) states that "although there are no norms for recall after such a lengthy delay, clinical experience suggests that few if any words recalled on trial VI are normally lost after half an hour". In a recent study (Geffen, Moar, O'Hanlon, Clark, and Geffen, 1990) normative data were presented for 153 16- to 86-year-old adults who were grouped for age and sex and matched for intelligence, education, and occupation. Over-all performance deteriorated with increased age, females performing better than males.

In the Netherlands, a comparable free recall test that is frequently used in clinical settings, differs to some extent from the procedure described above (Deelman et al., 1980). No second word list is used and there is no retention trial. Following the delayed recall trial, recognition is tested by offering a 30 -word list containing the initial 15-word list. The subject is requested to indicate with "yes" or "no" whether or not he recognizes the item as belonging to the initial list. This

*This chapter has been submitted for publication as journal article:

Houx, P. J., \& Jolles, J. Age-related decline in verbal memory performance: Physiological aging or biological life events? The Clinical Neuropsychologist (submitted).

A subset of the data presented here has been published elsewhere:

Houx, P. J., Vreeling, F. W., \& Jolles, J. (1990). Cognitieve veroudering wordt meer beïnvloed door 'biological life events' dan door fysiologische veroudering [Cognitive aging is more influenced by biological life events than by physiological aging]. In C. P. M. Knipscheer, J. J. M. Michels, \& M. W. Ribbe (Eds.), Ouder worden nu '90 [Aging now '90] (pp. 270-278). Almere, The Netherlands: Versluys.

Houx, P. J., Vreeling, F. W., \& Jolles, J. (1991). Age-associated cognitive decline is related to biological life events. In K. Iqbal, D. R. C. McLachlin, B. Winblad, \& H. M. Wisniewski (Eds.), Alzheimer's disease: Basic mechanisms, diagnosis and therapeutic strategies (pp. 353-358). Chichester, UK: Wiley. 
enables the distinction between active retrieval from secondary memory (as measured by the delayed recall) and the consolidation of new material into secondary memory (as assessed by the number of accurately recognized items; Jolles, 1985). In the 20-minute period between the learning trials and the delayed recall trials, no explicit memory test is administered in order to avoid interference with other newly learnt material.

Item presentation can be auditorily (preferably by tape recorder) or visually (on a computer screen), as Brand and Jolles (1985) have shown that mode of presentation has no differential effect on performance.

\subsection{Test description}

For the present study, the list of words was a slightly modified version of the list used by Deelman et al. (1980). The items for the learning and recognition lists are all monosyllabic dutch words that occur very frequently (Linschoten, 1963), are acquired early in life (Kohnstamm et al., 1981), and easily evoke a mental image (Van Loon-Vervoorn, 1989). Of this test, seven equivalent parallel versions are available.

All words were presented visually by means of a standard Apple II microcomputer and 33-cm monitor. The duration of each stimulus was $1 \mathrm{~s}$, and so was the length of the inter-stimulus interval. At the recognition trial, the duration of the stimuli was self-paced, that is, the item remained on the screen until the subject replied "yes" or "no" to indicate whether the item belonged to the learning list or not. The words were composed of ASCII-type capital letters, $0.6 \mathrm{~cm}$ in height. They were presented in green against a dark background in the center of the screen.

The test instructions were read aloud by the experimenter. The subject was asked to carefully watch the 15 words that were presented on the screen, and to mention as many words as possible as soon as the presentation stopped. There was explicitly no restriction on the order of recall. During the testing, the subject was requested to say nothing but the words to be recalled.

\subsection{Results}

Mean scores per trial, together with the standard deviations are given in table 8.1 and 8.2, for each age group, separated for the existence of BLE. The repeated measures ANOVA for learning trials 1 through 5 showed significant betweensubject effects of age group $(F(6,217)=15.24, p<.001)$ and level of education $(F(1,217)=8.14, p<.01)$. Sex difference was not significant $(F(1,217=2.43$, n.s. $)$. Most 

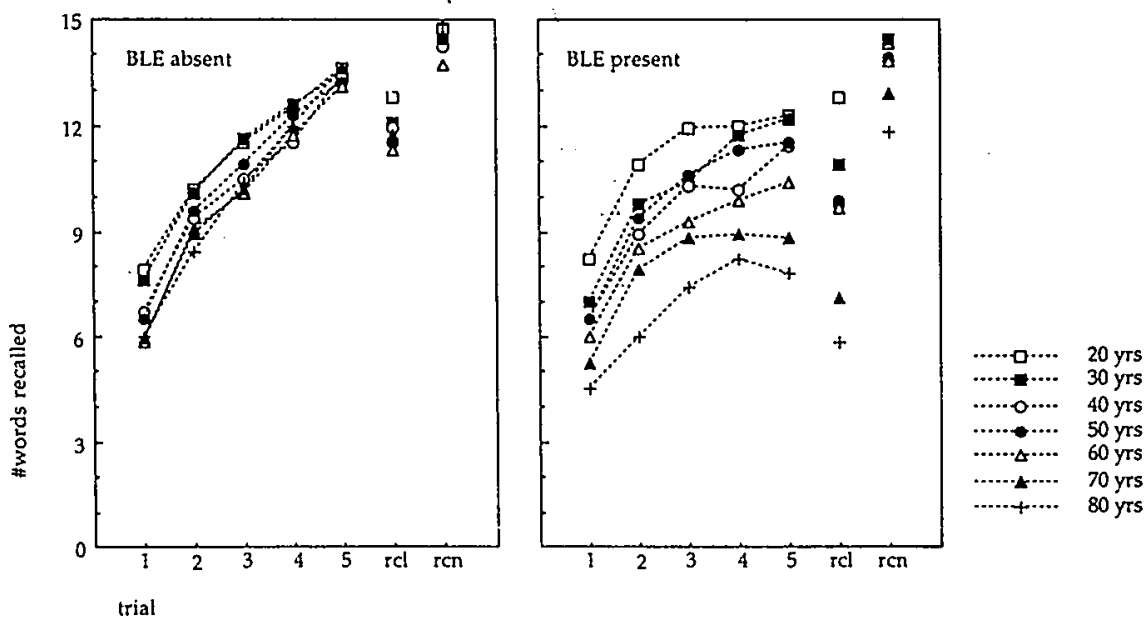

Figure 8.1 Learning curves and delayed recall/recognition scores on the Visual Verbal Learning Test, in seven age groups. Performance of subjects unaffected by biological life events, and of their affected age-peers.

importantly, the absence or presence of BLE yielded effects that were far larger than that of age as such (see table $8.1 \& 8.2 ; \mathrm{F}(1,217)=51.18, \mathrm{p}<.001$ ). Figure 8.1 depicts the age $x$ first trial and maximum recall plots for two levels of education and subjects with and without BLE. It can be seen that, although age is an important factor, level of education, and, especially the presence of BLE probably have greater impact.

Of the interactions between the between-subject factors, only the age $x$ BLE effect was significant $(F(1,217)=5.80, p<.001)$, indicating that the performance difference associated with BLE increases with age. The within-subject effect of repeated learning trials (main effect: $F(4,876)=664.69, \mathrm{p}<.001$ ) interacted with the BLE effect $(F(4,876)=30.78, p<.001)$, but not with age $(F(24,876)=1.03$, n.s. $)$ or education $(\mathrm{F}(4,876)<1)$. The trials $\mathrm{x}$ age $\mathrm{x}$ BLE interaction effect was significant, however $(\mathrm{F}(24,876)=1.56, \mathrm{p}<.05)$, which can be taken to indicate that older BLE-affected subjects profit the least from the repeated learning trials. None of the other interaction effects were significant.

Analysis of the delta scores (highest score minus the score at the first trial) revealed the same effects as did the analysis of the effect of repeated trials: no effect of age $(F(6,217)=1.44$, n.s.) or education $(F<1)$, but a large effect of BLE $(\mathrm{F}(1,217)=60.88, \mathrm{p}<.001)$ and age $\times$ BLE interaction $(\mathrm{F}(6,217)=2.30, \mathrm{p}<.05)$. 
Table 8.1 Mean scores per test parameter (SD): Biological life events absent

\begin{tabular}{|c|c|c|c|c|c|c|c|}
\hline & \multicolumn{7}{|c|}{ Age group (N) } \\
\hline & $\begin{array}{c}20 \\
(22)\end{array}$ & $\begin{array}{c}30 \\
(20)\end{array}$ & $\begin{array}{c}40 \\
(22)\end{array}$ & $\begin{array}{c}50 \\
(20)\end{array}$ & $\begin{array}{c}60 \\
(20)\end{array}$ & $\begin{array}{c}70 \\
(25)\end{array}$ & $\begin{array}{r}80 \\
(21)\end{array}$ \\
\hline recall trial 1 & $\begin{array}{c}7.9 \\
(1.7)\end{array}$ & $\begin{array}{c}7.6 \\
(1.2)\end{array}$ & $\begin{array}{c}6.7 \\
(1.6)\end{array}$ & $\begin{array}{c}6.5 \\
(1.5)\end{array}$ & $\begin{array}{c}5.8 \\
(1.0)\end{array}$ & $\begin{array}{c}5.9 \\
(1.3)\end{array}$ & $\begin{array}{c}6.0 \\
(1.5)\end{array}$ \\
\hline recall trial 2 & $\begin{array}{c}10.2 \\
(1.9)\end{array}$ & $\begin{array}{c}10.1 \\
(1.5)\end{array}$ & $\begin{array}{c}9.4 \\
(2.1)\end{array}$ & $\begin{array}{c}9.6 \\
(1.4)\end{array}$ & $\begin{array}{c}9.1 \\
(2.0)\end{array}$ & $\begin{array}{c}8.9 \\
(1.8)\end{array}$ & $\begin{array}{c}8.4 \\
(1.7)\end{array}$ \\
\hline recall trial 3 & $\begin{array}{l}11.5 \\
(1.7)\end{array}$ & $\begin{array}{l}11.6 \\
(2.1)\end{array}$ & $\begin{array}{l}10.5 \\
(1.6)\end{array}$ & $\begin{array}{l}10.9 \\
(1.8)\end{array}$ & $\begin{array}{c}10.1 \\
(1.4)\end{array}$ & $\begin{array}{l}10.2 \\
(1.9)\end{array}$ & $\begin{array}{l}10.4 \\
(2.0)\end{array}$ \\
\hline recall trial 4 & $\begin{array}{l}12.5 \\
(1.5)\end{array}$ & $\begin{array}{l}12.6 \\
(1.7)\end{array}$ & $\begin{array}{l}11.5 \\
(1.4)\end{array}$ & $\begin{array}{l}12.3 \\
(1.5)\end{array}$ & $\begin{array}{l}11.7 \\
(1.5)\end{array}$ & $\begin{array}{l}12.0 \\
(1.5)\end{array}$ & $\begin{array}{l}12.0 \\
(1.5)\end{array}$ \\
\hline recall trial 5 & $\begin{array}{l}13.6 \\
(1.4)\end{array}$ & $\begin{array}{l}13.4 \\
(1.5)\end{array}$ & $\begin{array}{c}13.4 \\
(0.9)\end{array}$ & $\begin{array}{c}13.2 \\
(1.2)\end{array}$ & $\begin{array}{l}13.1 \\
(1.0)\end{array}$ & $\begin{array}{c}13.6 \\
(0.9)\end{array}$ & $\begin{array}{l}13.6 \\
(1.0)\end{array}$ \\
\hline Total & $\begin{array}{l}55.7 \\
(5.8)\end{array}$ & $\begin{array}{l}55.2 \\
(6.6)\end{array}$ & $\begin{array}{l}51.4 \\
(5.2)\end{array}$ & $\begin{array}{l}52.5 \\
(5.4)\end{array}$ & $\begin{array}{l}49.6 \\
(5.4)\end{array}$ & $\begin{array}{l}50.6 \\
(5.5)\end{array}$ & $\begin{array}{l}50.5 \\
(6.3)\end{array}$ \\
\hline Maximum recall & $\begin{array}{l}13.7 \\
(1.3)\end{array}$ & $\begin{array}{l}13.7 \\
(1.4)\end{array}$ & $\begin{array}{c}13.4 \\
(0.9)\end{array}$ & $\begin{array}{l}13.3 \\
(1.2)\end{array}$ & $\begin{array}{c}13.2 \\
(0.9)\end{array}$ & $\begin{array}{l}13.6 \\
(0.9)\end{array}$ & $\begin{array}{l}13.8 \\
(0.9)\end{array}$ \\
\hline Delta & $\begin{array}{c}5.6 \\
(2.3)\end{array}$ & $\begin{array}{c}6.9 \\
(1.6)\end{array}$ & $\begin{array}{c}6.5 \\
(1.7)\end{array}$ & $\begin{array}{r}6.5 \\
(1.6)\end{array}$ & $\begin{array}{c}7.5 \\
(1.1)\end{array}$ & $\begin{array}{c}7.8 \\
(1.5)\end{array}$ & $\begin{array}{c}7.7 \\
(1.3)\end{array}$ \\
\hline Total repeats & $\begin{array}{c}1.1 \\
(1.6)\end{array}$ & $\begin{array}{c}4.0 \\
(5.5)\end{array}$ & $\begin{array}{c}3.1 \\
(3.8)\end{array}$ & $\begin{array}{c}2.4 \\
(3.8)\end{array}$ & $\begin{array}{c}2.3 \\
(2.8)\end{array}$ & $\begin{array}{c}1.0 \\
(1.9)\end{array}$ & $\begin{array}{r}1.6 \\
(2.3)\end{array}$ \\
\hline Total errors & $\begin{array}{c}0.4 \\
(0.6)\end{array}$ & $\begin{array}{c}0.8 \\
(0.9)\end{array}$ & $\begin{array}{c}0.8 \\
(1.0)\end{array}$ & $\begin{array}{c}0.9 \\
(1.3)\end{array}$ & $\begin{array}{c}0.7 \\
(0.9)\end{array}$ & $\begin{array}{c}0.4 \\
(1.1)\end{array}$ & $\begin{array}{c}0.8 \\
(1.9)\end{array}$ \\
\hline Delayed recall & $\begin{array}{l}12.8 \\
(1.7)\end{array}$ & $\begin{array}{l}12.1 \\
(1.5)\end{array}$ & $\begin{array}{l}11.9 \\
(1.3)\end{array}$ & $\begin{array}{l}11.5 \\
(1.4)\end{array}$ & $\begin{array}{l}11.3 \\
(1.4)\end{array}$ & $\begin{array}{l}11.7 \\
(1.8)\end{array}$ & $\begin{array}{l}11.5 \\
(2.1)\end{array}$ \\
\hline Retention & $\begin{array}{r}94.1 \% \\
(9.0)\end{array}$ & $\begin{array}{l}90.5 \% \\
(10.7)\end{array}$ & $\begin{array}{r}89.4 \% \\
(9.1)\end{array}$ & $\begin{array}{r}87.7 \% \\
(7.9)\end{array}$ & $\begin{array}{r}86.8 \% \\
(9.8)\end{array}$ & $\begin{array}{l}86.1 \% \\
(11.3)\end{array}$ & $\begin{array}{r}84.4 \% \\
(13.9)\end{array}$ \\
\hline Delayed repeats & $\begin{array}{c}0.3 \\
(0.6)\end{array}$ & $\begin{array}{c}0.8 \\
(1.5)\end{array}$ & $\begin{array}{c}1.2 \\
(2.0)\end{array}$ & $\begin{array}{c}0.4 \\
(0.6)\end{array}$ & $\begin{array}{c}0.5 \\
(0.8)\end{array}$ & $\begin{array}{c}0.4 \\
(0.9)\end{array}$ & $\begin{array}{c}0.3 \\
(0.7)\end{array}$ \\
\hline Delayed errors & $\begin{array}{c}0.5 \\
(0.9)\end{array}$ & $\begin{array}{c}0.4 \\
(0.8)\end{array}$ & $\begin{array}{c}0.7 \\
(1.1)\end{array}$ & $\begin{array}{c}0.4 \\
(0.7)\end{array}$ & $\begin{array}{c}0.7 \\
(1.0)\end{array}$ & $\begin{array}{c}0.3 \\
(0.6)\end{array}$ & $\begin{array}{c}0.2 \\
(0.5)\end{array}$ \\
\hline Recognition & $\begin{array}{l}14.7 \\
(0.6)\end{array}$ & $\begin{array}{c}14.5 \\
(0.9)\end{array}$ & $\begin{array}{c}14.2 \\
(1.2)\end{array}$ & $\begin{array}{l}14.5 \\
(0.8)\end{array}$ & $\begin{array}{l}13.7 \\
(1.6)\end{array}$ & $\begin{array}{l}14.5 \\
(1.2)\end{array}$ & $\begin{array}{l}14.8 \\
(0.4)\end{array}$ \\
\hline False-positives & $\begin{array}{c}2.8 \\
(3.5)\end{array}$ & $\begin{array}{c}3.0 \\
(3.4)\end{array}$ & $\begin{array}{c}3.5 \\
(3.3)\end{array}$ & $\begin{array}{r}2.2 \\
(4.3)\end{array}$ & $\begin{array}{c}1.4 \\
(1.8)\end{array}$ & $\begin{array}{c}0.2 \\
(0.6)\end{array}$ & $\begin{array}{r}0.1 \\
(0.3)\end{array}$ \\
\hline
\end{tabular}

Note: Retention percentage $=$ recall trial $5 /$ delayed recall $* 100 \%$ 
Table 8.2 Mean scores per test parameter (SD): Biological life events present

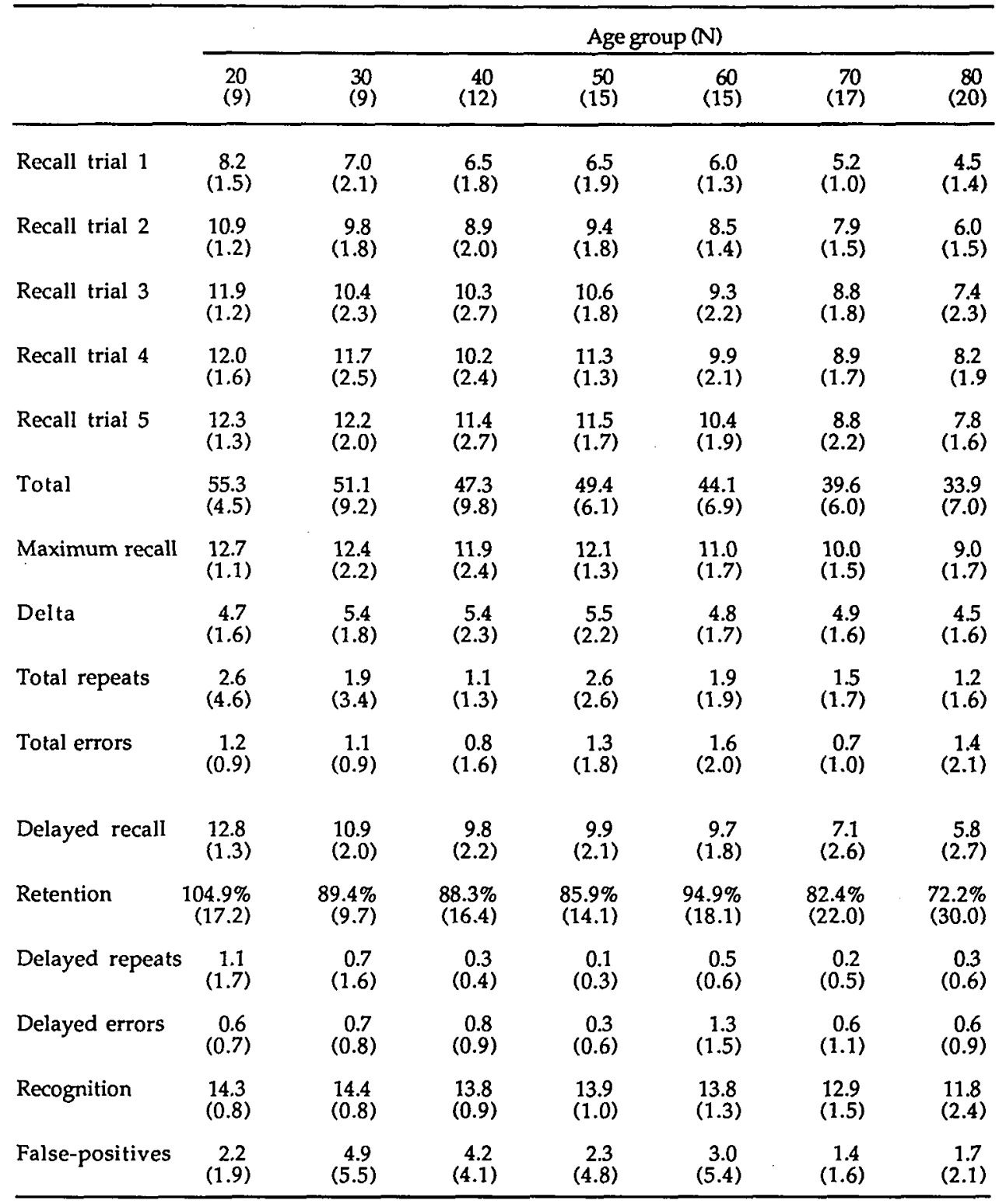


A very striking finding was the absence of age-associated decline of the highest score at the learning trials $(\mathrm{F}(6,143)<1)$ in the BLE-free subjects (see also fig. 8.1). The overall age effect on the maximum performance $(F(6,217)=6.38, p<.001)$ was entirely due to the BLE-affected group $(F(6,90)=8.87, p<.001)$. This is replicated by the significant age $x$ BLE interaction $(6,217)=8.27, \mathrm{p}<.001)$, indicating that ageassociated decline of the maximum capacity of primary memory does not seem to occur in rigorously health-selected subjects. Whereas education did not affect the extent to which subjects profit from repeated learning trials (as is apparent from the within-subject effect and the delta score), the maximum score was higher in the higher-educated subjects $(F(1,217)=6.25, \mathrm{p}<.01)$, irrespective of any other factor. There were no other interaction effects found for the maximum score.

Analyzing delta scores and maximum scores makes analysis of the summated performance of all five learning trials somewhat superfluous. As the total score is often discussed, however, the significant F-values are given here. All main between subject effects were significant: age $(F(6,217)=15.24, p<.001)$, BLE $(\mathrm{F}(1,217)=51.18, \mathrm{p}<.001)$, and education $(\mathrm{F}(1,217)=8.14, \mathrm{p}<.01)$. Only the age $\times$ BLE interaction was significant $(F(6,217)=5.80, p<.001)$.

Delayed recall was affected by age $(F(7,217)=13.32, p<.001)$ and very strongly by $\operatorname{BLE}(F(1,217)=80.00, p<.001)$, and even by $\operatorname{sex}(F(1,217)=6.32, p<.05)$, but not by education $(F(1,217)=2.23$, n.s. $)$. Women showed better recall than men. As there were no interactions with sex, this effect is taken to be consistent over all age groups. Again, there was an age $x$ BLE interaction $(F(6,217)=8.31, p<.001)$. Although BLE-free elderly subjects recalled less items after some 20 minutes, the average performance of 70- or 80-year-old subjects was close to that of patients with age-associated memory impairment (AAMI; Reyersen van Buuren et al., 1991), or general psychogeriatric patients (Ganzevles et al., 1991). A percentage measure of retention over a 20 -minute period is usually obtained by dividing the delayed recall score by the fifth immediate recall score. It appeared that age $(\mathrm{F}(6,217)=4.53, \mathrm{p}<.001)$ and $\operatorname{sex}(\mathrm{F}(1,217)=4.53, \mathrm{p}<.05)$ had a significant overall effect, but not $B L E(F<1)$. There were no other main effects, nor any interaction effect. However, if the percentage of retention was calculated by comparing delayed recall with the maximum trial score, there was a significant BLE effect $(\mathrm{F}(1,217)=79.96, \mathrm{p}<.001)$, and even age $\times \mathrm{BLE}$ interaction $(\mathrm{F}(6,217)=8.31, \mathrm{p}<.001)$.

In BLE-affected old subjects, even the delayed recognition was severely impaired. Although even in the BLE-free group there was some age-associated decline $(F(6,143)=2.63, p<.05)$, this effect was far larger (see tables 8.1 \& 8.2) in the BLEaffected group $(F(6,90)=5.36, p<.001)$. And so, the overall effects of age $(\mathrm{F}(6,217)=2.92, \mathrm{p}<.01)$ and $\mathrm{BLE}(\mathrm{F}(1,217)=20.65, \mathrm{p}<.001)$ interacted significantly $(F(6,217)=5.36, p<.001)$. No other interaction effects were observed for delayed recall or recognition. 
Each time a subject recalled an item correctly that had already been reported during the recall of a trial, this event was scored as a double response. Over all five learning trials, the average number of these events was low: $M=2.17$; $\mathrm{SD}=3.38$ in all BLE-free subjects, and $\mathrm{M}=1.75 ; \mathrm{SD}=2.49$ in BLE-affected subjects $(t=1.05, d f=245$, n.s.; pooled variances). As the variance was high, and group differences were low, no factor could significantly affect the number of items recalled twice.

The average number of words incorrectly recalled (not belonging to the set of words to be learned) at any of the five learning trials was even lower than that of double responses (overall mean: 0.86 ) and again, the variance was high. The only factor that could explain a significant proportion of the inter-individual differences was BLE $(F(1,217)=4.51, p<.05)$, the BLE-affected subjects making nearly twice as many errors as the BLE-free subjects.

The present study was not performed to assess the relative importance of individual BLE. Associations between test performance and BLE should therefore be interpreted very cautiously. Some correlative data can be discussed here, however. Table 8.3 shows Pearson's product-moment correlations between some core test parameters and age, number of experiences BLE, and three quantifiable BLE. Although most test scores showed moderate negative correlations with age, the number of BLE that subjects had experienced appeared to correlate to a comparable extent, in some instances (maximum score, e.g.) even stronger. That means that BLE were just as powerful in explaining interindividual differences in performance as age. No single BLE could account for a significant proportion of the variance, except the number of surgical operations under general anesthesia. Age and the number of experienced BLE appeared to correlate weakly $(r=0.12, p<.05)$, indicating that BLE are not a mere concomitant of age, and that both factors are largely independent.

Table 8.3 Correlations of test scores with Age and BLE

\begin{tabular}{llllll}
\hline & Age & $\#$ BLE & \#CHI & \#anest & \#alc/wk \\
\hline Maximum recall & $-.32^{* *}$ & $-.51^{* *}$ & -.12 & $-.25^{* *}$ & .11 \\
Delta score & .09 & $-.38^{* *}$ & -.01 & $-.23^{* *}$ & .02 \\
Total tr. 1-5 & $-.48^{* *}$ & $-.38^{* *}$ & -.11 & $-.15^{* *}$ & $.13^{*}$ \\
Delayed recall & $-.44^{* *}$ & $-.39^{* *}$ & -.10 & $-.14^{* *}$ & $.13^{*}$ \\
Delayed recognition & $-.26^{* *}$ & $-.22^{* *}$ & -.06 & -.04 & -.09 \\
\hline
\end{tabular}

Note: \#BLE: number of BLE experienced by a subject; \#contus: weighed number of closed head injuries; \#anest: weighed score of general anesthesia; \#alc/wk: \#weighed score of alcohol consumption per week. ${ }^{*} p<.05,{ }^{*} p<.01$, two-tailed. 


\subsection{Discussion}

Virtually all task parameters of the visual verbal learning test used in the present study showed age-related decline, with a remarkable exception for maximum recall and recognition in the group of subjects who had not experienced any biological life event (BLE) as defined for the present study. Sex differences were observed regarding delayed recall: delayed reproduction and retention percentage were somewhat better in women. Higher-educated subjects generally showed better recall at all trials. Most importantly, BLE accounted for a large -if not the largest- part of the inter-individual differences.

The finding that women consistently showed better retention of newly learnt material partly replicated the findings of Geffen et al. (1990). However, the absence of any other performance difference due to gender is not in accordance with her observations. As these authors do not report effects of education, IQ, or occupation, ability-related comparisons cannot be made.

As can be seen from table 8.2 , the recall score of elderly subjects at trial 1 was close to immediate memory span, measured by the Digit Span test (see section 5.3 and table 5.1). Only younger subjects seem to profit from what Geffen et al. (1990) term "information overload". This fact probably explains why the total performance of trials 1 to 5 was lower in older age groups, but not the maximum recall. Indeed, the learning rate, as expressed by the delta score, increased with age in the BLE-free group. By consequence, the maximum score did not decrease at all.

Retention after twenty minutes, as assessed by comparing delayed recall to the fifth trial score, showed an increase with age, irrespective of BLE. However, many BLE-affected subjects do not obtain their highest trial score at the fifth trial, but rather at the third or fourth. If retention was calculated with the highest trial score, instead of with the fifth, BLE had substantial impact. BLE-affected subjects did not only have inferior immediate recall, therefore, but also showed poorer active retrieval after twenty minutes. Only retrieval efficiency seems to deteriorate to a great extent, as is apparent from the almost perfect recognition in the older BLE-free subjects and a very much better recognition than delayed recall in BLE-affected subjects. Because the recognition score can be seen as a reflection of memory consolidation (Rey, 1964), it can be concluded that although active retrieval may be impaired in old age- storage of new material remains relatively intact throughout all age groups. The quality of delayed recognition in the BLE group is modified somewhat by the slightly larger number of false-positives, however.

The group differences due to education were small but consistent. Over all five learning trials, the higher-educated subjects recalled 50.8 words (averaged over all seven age groups), against 47.3 in the lower-educated subjects ( $=7.4 \%$ more). 
The average maximum recall scores were 12.9 and 12.1 (6.6\%), respectively, the delayed recall scores 11.1 vs. $10.3(3.9 \%)$, and recognition 14.1 vs. $14.0(0.7 \%)$. There were no interactions between the effects of education and age or BLE, indicating that the performance of lower-educated subjects does not suffer more from age or BLE.

From the fact that their subjects were matched according to IQ, education, and occupation, Geffen et al. (1990) inferred that all age group differences are true age differences as other cohort-specific factors were assumed to be negligible. We suggest however, that at least one factor, BLE, is far from negligible. As mentioned above, higher-educated subjects recalled a $7.4 \%$ more words over all five trials. For all subjects aged 20-40, the total recall amounted to 53.1 , which is $17.5 \%$ more than 45.1 , the average total recall of all subjects aged $60-80$. The overall average total recall of BLE-affected subjects was 44.1, of BLE-unaffected subjects 52.2 , which is $18.4 \%$ more. The size of group difference due to BLE is therefore entirely comparable to the effect of age.

Close inspection of the normative data of Lezak (1983) and Geffen et al., (1990) reveals that the average performance of their subjects with corresponding age lies roughly between the scores of our BLE-free and BLE-affected subjects, closer to the performance of BLE subjects however. For instance, the average recall score of the fifth trial subjects aged about 80 years is 9.2 as reported by Geffen et al., which is better than the score of our BLE subjects (7.8), but poorer than the score of their unaffected age-mates (13.6). Lezak reported an average recall of 10.2. For the other test parameters, similar comparisons can be made. 



\section{INTERFERENCE SUSCEPTIBILITY: STROOP COLOR WORD TEST*}

\subsection{Introduction}

The Stroop Color-Word Test (SCWT; Stroop, 1935) is a well-known test for the ease of shifting perceptual sets to conform to changing task requirements (Lezak, 1983). Several different versions are available, but the test typically consists of three subtests. In subtest I, 10 rows by 10 columns of color names (red, blue, green, and yellow) are printed in black on white cardboard. In subtest II, the same number of correspondingly colored patches are printed, whereas subtest III contains a number of color names, printed in incongruously colored ink. For instance, the word 'green' can be printed in red. There are some different ways of administering the test (see Lezak, 1983, pp. 523-525), but for the present study the protocol is as follows. For card I, the subject is requested to 'read the color names row by row, as fast as you can, without making mistakes'. The time needed to complete the whole card is recorded by stopwatch. At the second subtest (card II) the instruction is to 'name the colored patches'. The third trial (card III) involves naming the color of the ink the color words are printed in, without paying attention to the word itself. Often, a fourth trial is used to measure the time needed to read the color names from card III. Almost invariably, subtest I (reading) takes the least time (less than one minute). Color naming is a much less common activity than reading. Consequently, subtest II takes longer to complete (about one minute). Subtest III consists of this same uncommon activity, interfered by verbal information which is to be ignored. Conversely, reading color names, interfered by incompatibly colored ink (the fourth subtest) is much easier, as the color information is easily ignored. This trial does not take much more time, compared to subtest I (Cohn, Dustman, and Bradford, 1984) as a result of which it is not very informative. This is not the case for children, as

*This chapter has been submitted for publication as journal article:

Houx, P. J., Vreeling, F. W., \& Jolles, J. (submitted). Age effects assessed with the Stroop ColorWord Test. Perceptual and Motor Skills.

Part of the data presented here have been published elsewhere:

Houx, P. J., Vreeling, F. W., \& Jolles, J. (1990). Cognitieve veroudering wordt meer beïnvloed door 'biological life events' dan door fysiologische veroudering [Cognitive aging is more influenced by biological life events than by physiological aging]. In C. P. M. Knipscheer, J. J. M. Michels, \& M. W. Ribbe (Eds.), Ouder worden nu '90 [Aging now '90] (pp. 270-278). Almere, The Netherlands: Versluys.

Houx, P. J., Vreeling, F. W., \& Jolles, J. (1991). Age-associated cognitive decline is related to biological life events. In K. Iqbal, D. R. C. McLachlin, B. Winblad, \& H. M. Wisniewski (Eds.), Alzheimer's disease: Basic mechanisms, diagnosis and therapeutic strategies (pp. 353-358). Chichester, UK: Wiley. 
color naming is acquired earlier in childhood than reading, they also experience color-interference when reading.

The most interesting feature of the SCWT is that it enables a reliable estimate of the susceptibility to interference. By subtracting the average duration of trials I and II (basic speed) from that of subtest III, one obtains a measure of the delay caused by the interference of two activities. This delay can be expressed in a proportion, by dividing it by the average of trials I and II.

The SCWT is used for a wide variety of purposes. Neil and Westberry (1979) have studied the nature of selective attention and interference by cognitive noise with a computerized version of the test. It was concluded that selective inhibition is the time-consuming factor underlying the interference experienced in subtest III. To study prefrontal cortical functioning in reading-disabled children, Kelly, Best, and Kirk (1989) utilized the test to discriminate between frontal and posterior cognitive functions. It was found that selective and sustained attention were most impaired. Smith and Miles (1986) found that attention was impaired following eating lunch.

\subsection{Test procedure}

We used the version of three cards of $10 \times 10$ items (Nehemkis and Lewinsohn, 1972). No fourth trial involving reading while ignoring color interference was used. Two individual interference measures were calculated: 1 . the usual measure tIII-tII (where $t$ denotes total time needed to finish the card, and 2. (III -

$(\mathrm{I}+\mathrm{II})) / \mathrm{III})$, expressed as a percentage of extra time needed for part III, relative to the average of the first three parts.

\subsection{Results}

The mean total times to finish each subtest are summarized in figure 9.1. Mean performance per age $x$ BLE group is given table 9.1. As can readily be concluded from the graphs, substantial group differences were due to age and BLE. The ANOVA showed significant overall between-subject effects of age $(F(6,217)=23.28$, $\mathrm{p}<.001)$, BLE $(F(1,217)=34.72, p<.001$, and level of education $(F(1,217)=15.20$, $\mathrm{p}<.001$ ). None of the sex differences were significant ( $\mathrm{F}<1$ for all parameters). It can be concluded that older age groups are generally slower to finish the whole test. Also, the BLE-affected group was slower than the BLE-unaffected group. Finally, less educated subjects were slower than those in the more educated group. Only one interaction between two between-subject variables was significant: age $\times B L E(F(6,217)=4.82, p<.001)$, indicating that the performance gap 

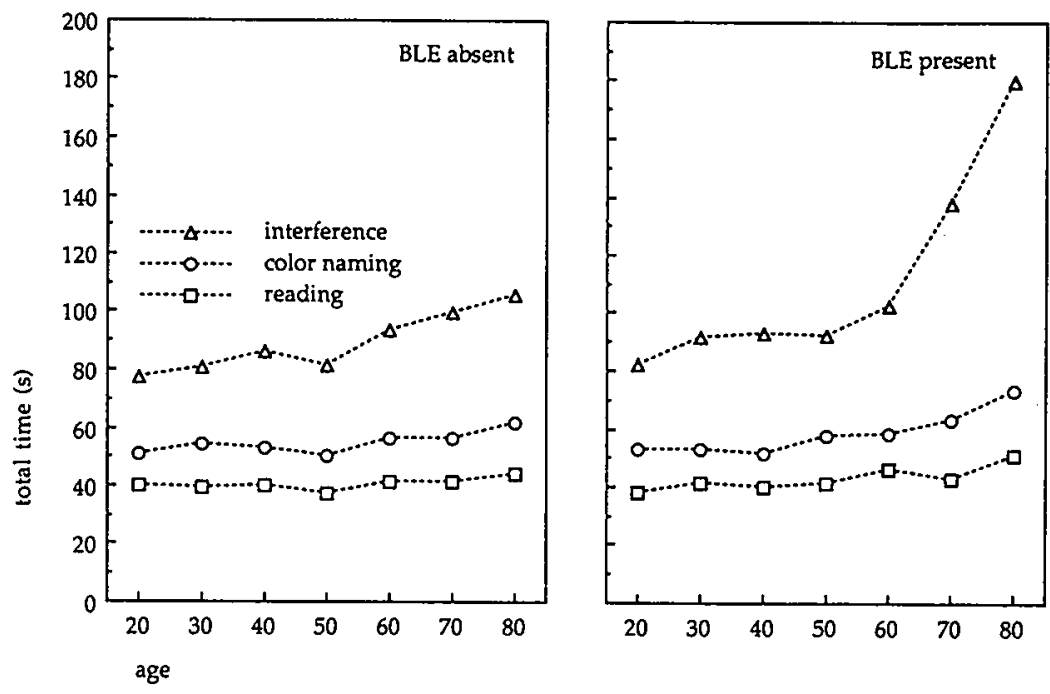

Figure 9.1 Mean performance on three test parts of the Stroop Color-Word test, by patients affected by biological life events (right), contrasted to the performance of their optimally healthy age peers.

between BLE-affected and BLE-unaffected subjects widens with increasing group age. Age and education did not interact $(F(6,217)=1.38$, n.s.), meaning that the less educated subjects did not show larger age effects than their more educated agemates. BLE and education did not significantly interact either $(F(1,217)=3.62, n . s$.$) ,$ which can be taken to indicate that the effect of BLE is not enhanced by little formal education. No set of three between-subject effects together showed interaction $(\mathrm{F}<1)$.

Regarding the within-subject variable (the three subtests I, II, and III), there was a large overall effect $(F(2,434)=1339.60, p<.001)$. In all subjects, subtest II takes longer to complete than subtest I, and III takes longer than II. As can be deduced from the interaction of this effect with age $(F(12,434)=21.05, p<.001)$, older subjects need more extra time for color naming, and more still when they experience colorword interference. The same interaction was found between repeated measures and $\operatorname{BLE}(\mathrm{F}(2,434)=36.71, \mathrm{p}<.001)$. There was an immense difference between the color-word interference effects in BLE-affected and BLE-unaffected subjects. The performance of less educated subjects suffers more from the increasing subtest difficulty than that of the more educated group, witness the interaction between 
Table 9.1 Mean performance (SD) on Stroop test in subjects with and without BLE

\begin{tabular}{|c|c|c|c|c|c|c|c|c|c|c|}
\hline \multirow[b]{2}{*}{ Age group } & \multicolumn{4}{|c|}{ total time } & \multicolumn{3}{|c|}{ Spont. corrections } & \multicolumn{3}{|c|}{ Uncorrected errors } \\
\hline & I & II & III & \%int. & I & II & $\overline{\text { III }}$ & I & $\overline{\text { II }}$ & III \\
\hline \multicolumn{11}{|c|}{ BLE absent } \\
\hline $20 \mathrm{yr}(\mathrm{N}=22)$ & $\begin{array}{l}40.1 \\
(7.6)\end{array}$ & $\begin{array}{c}51.1 \\
(10.1)\end{array}$ & $\begin{array}{r}77.3 \\
(11.7)\end{array}$ & $\begin{array}{c}71.1 \\
(14.4)\end{array}$ & $\begin{array}{c}0.2 \\
(0.5)\end{array}$ & $\begin{array}{r}0.5 \\
(0.8)\end{array}$ & $\begin{array}{r}1.6 \\
(1.2)\end{array}$ & $\begin{array}{c}0.1 \\
(0.3)\end{array}$ & $\begin{array}{c}0.0 \\
(0.2)\end{array}$ & $\begin{array}{r}0.4 \\
(1.0)\end{array}$ \\
\hline $30 \mathrm{yr}(\mathrm{N}=20)$ & $\begin{array}{l}39.6 \\
(6.1)\end{array}$ & $\begin{array}{l}54.0 \\
(8.1)\end{array}$ & $\begin{array}{r}80.8 \\
(14.5)\end{array}$ & $\begin{array}{r}72.6 \\
(17.7)\end{array}$ & $\begin{array}{c}0.2 \\
(0.4)\end{array}$ & $\begin{array}{c}0.9 \\
(1.0)\end{array}$ & $\begin{array}{r}1.2 \\
(1.0)\end{array}$ & $\begin{array}{c}0.1 \\
(0.3)\end{array}$ & $\begin{array}{c}0.2 \\
(0.4)\end{array}$ & $\begin{array}{r}0.3 \\
(0.8)\end{array}$ \\
\hline $40 \mathrm{yr}(\mathrm{N}=22)$ & $\begin{array}{l}39.9 \\
(4.9)\end{array}$ & $\begin{array}{l}52.7 \\
(9.6)\end{array}$ & $\begin{array}{c}86.4 \\
(21.4)\end{array}$ & $\begin{array}{r}85.3 \\
(28.2)\end{array}$ & $\begin{array}{c}0.0 \\
(0.2)\end{array}$ & $\begin{array}{c}0.6 \\
(0.7)\end{array}$ & $\begin{array}{r}1.3 \\
(1.5)\end{array}$ & $\begin{array}{c}0.0 \\
(0.0)\end{array}$ & $\begin{array}{c}0.2 \\
(0.5)\end{array}$ & $\begin{array}{r}0.3 \\
(0.6)\end{array}$ \\
\hline 50 yr $(\mathrm{N}=20)$ & $\begin{array}{l}37.0 \\
(4.9)\end{array}$ & $\begin{array}{l}50.1 \\
(9.3)\end{array}$ & $\begin{array}{c}81.3 \\
(12.0)\end{array}$ & $\begin{array}{c}88.1 \\
(21.9)\end{array}$ & $\begin{array}{c}0.2 \\
(0.4)\end{array}$ & $\begin{array}{c}1.2 \\
(1.1)\end{array}$ & $\begin{array}{r}1.5 \\
(1.4)\end{array}$ & $\begin{array}{c}0.1 \\
(0.3)\end{array}$ & $\begin{array}{c}0.3 \\
(0.6)\end{array}$ & $\begin{array}{r}0.3 \\
(0.7)\end{array}$ \\
\hline $60 \mathrm{yr}(\mathrm{N}=20)$ & $\begin{array}{l}41.5 \\
(4.4)\end{array}$ & $\begin{array}{l}56.1 \\
(6.9)\end{array}$ & $\begin{array}{r}93.6 \\
(16.9)\end{array}$ & $\begin{array}{r}92.5 \\
(31.9)\end{array}$ & $\begin{array}{c}0.1 \\
(0.3)\end{array}$ & $\begin{array}{c}1.5 \\
(1.0)\end{array}$ & $\begin{array}{c}1.4 \\
(1.6)\end{array}$ & $\begin{array}{c}0.1 \\
(0.4)\end{array}$ & $\begin{array}{c}0.5 \\
(0.4)\end{array}$ & $\begin{array}{r}0.4 \\
(0.8)\end{array}$ \\
\hline 70 yr $(\mathrm{N}=24)$ & $\begin{array}{l}41.3 \\
(4.2)\end{array}$ & $\begin{array}{l}56.4 \\
(5.9)\end{array}$ & $\begin{array}{r}99.5 \\
(21.2)\end{array}$ & $\begin{array}{r}98.5 \\
(33.7)\end{array}$ & $\begin{array}{c}0.3 \\
(0.7)\end{array}$ & $\begin{array}{c}1.5 \\
(1.6)\end{array}$ & $\begin{array}{r}1.6 \\
(2.0)\end{array}$ & $\begin{array}{c}0.3 \\
(0.6)\end{array}$ & $\begin{array}{c}0.3 \\
(0.7)\end{array}$ & $\begin{array}{r}1.8 \\
(2.7)\end{array}$ \\
\hline 80 yr $(\mathrm{N}=21)$ & $\begin{array}{l}44.1 \\
(5.6)\end{array}$ & $\begin{array}{l}61.6 \\
(8.5)\end{array}$ & $\begin{array}{c}105.5 \\
(14.9)\end{array}$ & $\begin{array}{c}100.3 \\
(18.5)\end{array}$ & $\begin{array}{c}0.3 \\
(0.6)\end{array}$ & $\begin{array}{c}1.3 \\
(1.0)\end{array}$ & $\begin{array}{c}2.5 \\
(2.4)\end{array}$ & $\begin{array}{c}0.3 \\
(0.6)\end{array}$ & $\begin{array}{c}0.5 \\
(0.8)\end{array}$ & $\begin{array}{r}0.8 \\
(1.4)\end{array}$ \\
\hline \multicolumn{11}{|c|}{ BLE present } \\
\hline $20 \mathrm{yr}(\mathrm{N}=9)$ & $\begin{array}{l}38.2 \\
(4.2)\end{array}$ & $\begin{array}{l}52.8 \\
(7.2)\end{array}$ & $\begin{array}{r}82.3 \\
(19.9)\end{array}$ & $\begin{array}{r}79.9 \\
(33.8)\end{array}$ & $\begin{array}{c}0.1 \\
(0.3)\end{array}$ & $\begin{array}{c}0.8 \\
(1.0)\end{array}$ & $\begin{array}{c}0.9 \\
(1.4)\end{array}$ & $\begin{array}{c}0.0 \\
(0.0)\end{array}$ & $\begin{array}{c}0.0 \\
(0.0)\end{array}$ & $\begin{array}{c}0.1 \\
(0.3)\end{array}$ \\
\hline $30 \mathrm{yr}(\mathrm{N}=9)$ & $\begin{array}{l}41.1 \\
(6.1)\end{array}$ & $\begin{array}{c}52.8 \\
(10.1)\end{array}$ & $\begin{array}{c}91.4 \\
(23.1)\end{array}$ & $\begin{array}{r}94.8 \\
(41.3)\end{array}$ & $\begin{array}{c}0.3 \\
(0.5)\end{array}$ & $\begin{array}{c}0.4 \\
(0.5)\end{array}$ & $\begin{array}{c}0.9 \\
(1.2)\end{array}$ & $\begin{array}{c}0.0 \\
(0.0)\end{array}$ & $\begin{array}{c}0.0 \\
(0.0)\end{array}$ & $\begin{array}{c}0.4 \\
(1.0)\end{array}$ \\
\hline $40 \mathrm{yr}(\mathrm{N}=12)$ & $\begin{array}{l}40.1 \\
(4.2)\end{array}$ & $\begin{array}{l}51.7 \\
(6.6)\end{array}$ & $\begin{array}{r}92.8 \\
(16.2)\end{array}$ & $\begin{array}{c}103.0 \\
(34.0)\end{array}$ & $\begin{array}{c}0.1 \\
(0.3)\end{array}$ & $\begin{array}{c}0.8 \\
(0.7)\end{array}$ & $\begin{array}{c}0.8 \\
(1.2)\end{array}$ & $\begin{array}{c}0.0 \\
(0.0)\end{array}$ & $\begin{array}{c}0.3 \\
(0.7)\end{array}$ & $\begin{array}{r}0.3 \\
(0.4)\end{array}$ \\
\hline 50 yr $(\mathrm{N}=15)$ & $\begin{array}{l}41.2 \\
(4.1)\end{array}$ & $\begin{array}{l}57.4 \\
(8.9)\end{array}$ & $\begin{array}{c}92.3 \\
(10.0)\end{array}$ & $\begin{array}{c}88.1 \\
(18.2)\end{array}$ & $\begin{array}{c}0.1 \\
(0.5)\end{array}$ & $\begin{array}{c}0.8 \\
(0.8)\end{array}$ & $\begin{array}{c}0.9 \\
(1.6)\end{array}$ & $\begin{array}{c}0.1 \\
(0.2)\end{array}$ & $\begin{array}{c}0.0 \\
(0.0)\end{array}$ & $\begin{array}{r}0.1 \\
(0.2)\end{array}$ \\
\hline $60 \mathrm{yr}(\mathrm{N}=15)$ & $\begin{array}{l}46.3 \\
(8.5)\end{array}$ & $\begin{array}{l}58.6 \\
(6.7)\end{array}$ & $\begin{array}{c}102.2 \\
(19.0)\end{array}$ & $\begin{array}{r}88.7 \\
(41.0)\end{array}$ & $\begin{array}{c}0.3 \\
(1.0)\end{array}$ & $\begin{array}{c}1.8 \\
(1.9)\end{array}$ & $\begin{array}{c}1.5 \\
(1.7)\end{array}$ & $\begin{array}{c}0.1 \\
(0.5)\end{array}$ & $\begin{array}{c}0.4 \\
(1.0)\end{array}$ & $\begin{array}{r}1.4 \\
(2.9)\end{array}$ \\
\hline 70 yr $(N=18)$ & $\begin{array}{l}43.1 \\
(4.9)\end{array}$ & $\begin{array}{c}63.2 \\
(11.4)\end{array}$ & $\begin{array}{c}138.1 \\
(36.2)\end{array}$ & $\begin{array}{c}164.5 \\
(87.2)\end{array}$ & $\begin{array}{c}0.2 \\
(0.5)\end{array}$ & $\begin{array}{c}2.2 \\
(2.0)\end{array}$ & $\begin{array}{c}3.5 \\
(3.7)\end{array}$ & $\begin{array}{c}0.9 \\
(1.3)\end{array}$ & $\begin{array}{c}0.6 \\
(0.9)\end{array}$ & $\begin{array}{r}3.4 \\
(5.2)\end{array}$ \\
\hline 80 yr $(N=19)$ & $\begin{array}{l}50.9 \\
(6.8)\end{array}$ & $\begin{array}{c}73.3 \\
(19.9)\end{array}$ & $\begin{array}{c}181.1 \\
(45.6)\end{array}$ & $\begin{array}{c}193.3 \\
(58.6)\end{array}$ & $\begin{array}{c}0.3 \\
(0.5)\end{array}$ & $\begin{array}{c}1.9 \\
(1.3)\end{array}$ & $\begin{array}{c}3.3 \\
(1.7)\end{array}$ & $\begin{array}{c}0.7 \\
(0.9)\end{array}$ & $\begin{array}{c}1.2 \\
(1.6)\end{array}$ & $\begin{array}{r}5.2 \\
(5.6)\end{array}$ \\
\hline
\end{tabular}

Note: \%int. = percentage of interference; extra time needed for part III relative to part I and II: (III (I + II)) / III * $100 \%$. 
the repeated measures and education $(F(2,434)=5.97, p<.01)$. Two complex interactions were also significant. Firstly, there was a marked age $x$ BLE $x$ repeated measures interaction $(F(12,434)=7.03, p<.001)$, as can be seen in figure 1 . Elderly BLE-affected subjects showed by far the largest effect of subtest difficulty. Secondly, the age $x$ education $x$ repeated measures interaction $(F(12,434)=1.83$, $\mathrm{p}<.05)$ showed that having received little education further enhances the age effect on the susceptibility of interference. There was no significant BLE $x$ education $x$ repeated measures interaction $(F(2,434)=2.20, n . s$.$) , or any other$ higher order interaction effects, other than mentioned above.

The color-word interference effect significantly increased with age $(F(6,217)=$ $20.82, \mathrm{p}<.001)$ and presence $\operatorname{BLE}(\mathrm{F}(1,217)=39.65, \mathrm{p}<.001)$, and decreased with education $(F(1,217)=6.71, p<.01$. These values confirm the conclusions from the ANOVAs just described. The only significant interaction effect was that between age and $\operatorname{BLE}(F(6,217)=7.37, p<.001)$, verifying that $B L E$-affected subjects experience by far the most color-word interference.

Accuracy roughly decreased in older age groups $(F(6,217)=7.80, p<.001)$ : in the BLEunaffected group, the average number of uncorrected color naming errors in subtest III increased from 0.4 in subjects aged 20-30 to 1.3 in subjects aged 70-80; in the BLE-affected group these values were 0.3 and 4.3 respectively (main effect of BLE: $F(1,217)=4.82, p<.05)$. Less educated subjects were also less accurate $(F(1,217)=5.70, p<.05)$. None of the interactions among the between-subject effects on numbers of errors were statistically significant.

In each successive subtest, more errors were made $(\mathrm{F}(2,434)=17.44, \mathrm{p}<.001)$. This increase interacted with age $(F(12,434)=3.50, p<.001)$, with $\operatorname{BLE}(F(2,343)=3.46$, $\mathrm{p}<.05)$, and with education $(\mathrm{F}(2,434)=3.87, \mathrm{p}<.05)$. None of the complex interactions with two or more between-subject variable were significant.

The number of corrected errors was only affected by age $(F(6,217)=5.87, p<.001)$. Other between-subject effects (main effects or interactions) were not significant. There was a repeated measurement effect of increasing task difficulty on the number of spontaneous corrections $(\mathrm{F}(2,434)=79.72, \mathrm{p}<.001)$, which also interacted with age $(F(12,434)=3.21, \mathrm{p}<.001)$ and education $(\mathrm{F}(2,434)=3.14, \mathrm{p}<.05$, but not with BLE.

Based on the data presently discussed, few conclusions can be drawn about the influence of separate BLE. The prevalence of most BLE was rarely higher than 2 or 3 in most age groups. Furthermore, as most BLE were scored either present or absent, little information is gained about their relative importance. Of those BLE that could be quantified (numbers of closed head injuries and narcoses sustained, and alcohol consumption per week) the correlations rarely exceeded .100 , which is not even statistically significant. However, a certain amount of individual variance in test performance could be explained by the number of BLE subjects had been exposed to. A Pearson's $r$ of .293 ( $p<.001$ ) was found for this variable 
with the time needed for part III; for subject age, this was $.553(\mathrm{p}<.001)$. The amount of extra time needed for part III relative to part I and II correlated .280 $(\mathrm{p}<.001)$ with number of BLE, and $.458(\mathrm{p}<.001)$ with subject age.

\subsection{Discussion}

The aim of the study was to assess whether BLE could account for a substantial amount of variance in performance on the Stroop test, in normally aging subjects. Evidence was found for the hypothesis that Biological Life Events (BLE) play a significant role in age-associated performance decline, comparable to that of physiological aging as such. Adults in a broad range of age categories were tested. After correction for BLE, the observed age effect was much smaller than in the whole sample. Conversely, the groups of subjects affected by BLE showed a much more pronounced age decline. This was especially the case in the test condition that involved color-word interference. Significant interactions were found between the effects of age, BLE and task requirements. No sex differences were found. A very slight decrement with age of basic reading speed was observed. Color naming was more slowed down, but a striking age effect was found as for word interference with color naming. Elderly subjects were very much delayed by the irrelevant verbal information that came with the color that was to be named. The most remarkable finding in this experiment however, was that the group of 80 year-old BLE-unaffected subjects needed half the amount of time for subtest III compared their BLE-affected age-peers.

Golden (1974) observed sex differences in Stroop performance, in favor of women. This was not replicated in the present study. Neither did we find any changes in the trade-off between speed and accuracy. Several authors (e.g., Botwinick, 1977) maintain that people, as they grow older, become more cautious, and therefore slower, but more accurate. In a number of studies of our own, these claims could not be affirmed (Houx et al., 1991a,b). It might be that in situations, not confined to the laboratory, e.g., driving a car, a strategic shift occurs to emphasizing accuracy rather than speed in the elderly.

The Stroop test appears to be very sensitive to age-related slowing or interference effects. Several authors have sought to detect the cognitive source of the 'Stroop phenomenon' (Doehrman, Landau, and O'Connel, 1978; Virzi and Egeth, 1985). Whatever the nature of the delay found in all subjects, it is apparent that focused attention is to some extent disrupted when some perceptually very salient, but irrelevant aspect is added to the stimulus. It was found that the amount of interference increased from some $70 \%$ in subjects aged 20 to a $100 \%$ in 80 -years old BLE-unaffected elderly. This increment is small, compared to the age trend observed in BLE-affected elderly subjects, some showing interference effects of well over $200 \%$. 


\section{CONCEPT SHIFTING ABILITY: REVISED TRAIL MAKING TEST AND CONCEPT SHIFTING TEST*}

\subsection{Introduction}

Since its introduction in 1944, as part of the Army Individual Test Battery (1944), the well-known Trail Making Test (TMT) has enjoyed wide use as an easily administered test of visual conceptual and visuomotor tracking. The test is given in two parts. In part $A$, the subject is requested to draw lines between consecutively numbered circles, in part B to alternate between numbered and lettered sequences. The TMT has been used for clinical diagnostic purposes, especially as part of the Halstead-Reitan Neuropsychological Test Battery (Reitan, 1958). The TMT is used either independently or in combination with a small battery of other more or less well-known tests (for instance, Stuss, Stethem, and Poirier, 1987).

TMT performance appears to be sensitive to the effects of brain injury (Armitage, 1946; Reitan, 1958; Spreen and Benton, 1965; Dye, Saxon, and Milby, 1981; Douma, 1987). Furthermore, the TMT has been used to test or identify a vast range of other disorders, such as sexual deviations (O'Carrol, 1989), juvenile delinquency (Pontius and Yudowitz, 1980), and dysfunctions associated with diabetes mellitus (Skenazy and Bigler, 1984).

The advantage of the TMT is that the test is very easy to administer and sensitive to any disorder involving a reduction in speed, visuomotor capacities, or planning. However, a drawback is that its use enables only limited insight to be gained into the origin or character of the neuropsychological dysfunction. Thus, the nature of the deficit that is measured with the TMT is not clear, as the test makes use of a whole range of functions and skills: attention, recognition of

*This chapter has been submitted for publication as journal article:

Houx, P. J., Vreeling, F. W., \& Jolles, J. (submitted). Age-related decline of concept-shifting ability: Revised Trail Making Test versus a new Concept-Shifting Test. Journal of Clinical and

Experimental Neuropsychology.

A subset of the data presented here has been published elsewhere:

Houx, P. J., Vreeling, F. W., \& Jolles, J. (1990). Cognitieve veroudering wordt meer beïnvloed door 'biological life events' dan door fysiologische veroudering [Cognitive aging is more influenced by biological life events than by physiological aging]. In C. P. M. Knipscheer, J. J. M. Michels, \& M. W. Ribbe (Eds.), Ouder worden nu '90 [Aging now '90] (pp. 270-278). Almere, The Netherlands: Versluys.

Houx, P. J., Vreeling, F. W., \& Jolles, J. (1991). Age-associated cognitive decline is related to biological life events. In K. Iqbal, D. R. C. McLachlin, B. Winblad, \& H. M. Wisniewski (Eds.), Alzheimer's disease: Basic mechanisms, diagnosis and therapeutic strategies (pp. 353-358). Chichester, UK: Wiley. 
digits and letters, counting, knowledge of the alphabet, visual scanning, motor skills, concept-shifting, and short term memory for keeping track of ongoing conduct. Vink and Jolles (1984) proposed the use of a revised TMT (R-TMT) in order to overcome this drawback and to enable a more precise interpretation of test performance in terms of psychological functions. The present report describes the R-TMT as well as a newly developed test -the Concept-shifting Test (CST)- in aging research and gives normative data for these tests.

The lay-out of the test parts A and B and the test procedure of the TMT has been unchanged for nearly five decades: recommendations by Armitage (1946) and Reitan (undated, quoted by Lezak, 1983, p.557) to change test administration procedures have not been followed. One of the more interesting aspects of the TMT is the possibility to assess the ability to make conceptual shifts in ongoing activity. Pontius and Yudowitz (1980), for instance, interpreted test outcomes (obtained from youthful offenders) in terms of an inability to make appropriate shifts during the commission of a crime. Vink and Jolles (1985) have further elaborated the notion of 'concept-shifting ability'. They reasoned that a higher time score for part $B$ can be ascribed to those functions that are necessary in part $\mathrm{B}$, but not in A.

Unfortunately, the interpretation of TMT data in terms of concept-shifting ability are not unequivocal. In the first place, by only testing the time needed to complete the number items (part A), no information is gained about the processing of the letter items, which is required in part B. This is of importance as knowledge about the order of the letters in the alphabet is likely to be less easily accessible than knowledge of the numbers 1-25. As a consequence, the increase in time needed to complete part $B$ (numbers and letters) cannot be ascribed merely to the factor 'concept-shifting' but has to be attributed to the processing of letters as well. In the second place, the trails to be tracked in the subtasks $A$ and $B$ are not of equal length and difficulty: task A contains 25 items, task $B$ 26. Furthermore, the trail sections between each item are, on average, longer in part $B$ than in part $A(t=2.352, d f=23, p<.05)$. In our copy of the test, the total trail length of part $A$ is $185.8 \mathrm{~cm}$ and $242.3 \mathrm{~cm}$ for part $B$. Thus, visual scanning is more difficult in part $B$ and time differences must be attributed partly to this.

Vink and Jolles (1985) have proposed a modified and extended version of the test (R-TMT), allowing for a more detailed interpretation of test outcomes. A third test part containing only letter items was added. For the present study, a fourth test part, an '0-task' was added. In this part, the trail is already drawn, making all activities but the visuomotor tracking superfluous. (See the materials and methods section for a more elaborated description of the R-TMT).

However, some problems still remain with the revised version of the TMT. First, the visual scanning needed for each subsequent item is not constant; 
sometimes, a considerable distance between two items has to be covered (between items 14 and 15, for instance), whereas other items are as near as 3.5 centimeters to the previous item (items 8 and 9). Second, after a subject has made an error, interconnecting lines can cross each other, which may confuse subjects even more. This can be an extra source of error. Third, as a consequence of the test lay-out, an item that is close to the edge of the paper may be covered by the hands of the subject. This may increase the search time for this particular item. Fourth, the visual search is made easy by the structure of the trail. Items cannot be too far away from the one that has just been found which may make the speed of visual scanning better than it is. Fifth, poorly educated elderly people may have an inadequate or inadequately available knowledge about the order of the alphabet. This is especially the case in the second half of the test. Finally, the number of possible parallel versions of the R-TMT is limited, since only eight geometrical manipulations are possible.

A completely new test -the 'Concept-Shifting Task' (CST)- was devised to compensate for the drawbacks outlined above. The main practical difference with the R-TMT is the lay-out of the test form in which lettered and numbered circles are arranged in a larger circle; these circles are to be crossed out, not connected by lines.

The present study was devised to provide age norms for the R-TMT and the CST. In addition, age-related and education-related differences in digit tracking, letter tracking and concept shifting ability were monitored. The study was motivated by findings that performance on the TMT slows down with every decade of adult life (Davies, 1968; Lindsey and Coppinger, 1969; Harley, Leuthold, Matthews, and Bergs, 1980; Stuss et al., 1987). Boll and Reitan (1973) found no slowing in subjects older than 45 who had received 15 years of scholastic education. Pointing out that intellectual ability apparently plays a role in this test, Kramer and Jarvik (1979) suggested that normative data for ability and age are needed for the TMT. To date, however, there is little such data (Charter, Adkins, Alekoumbides, and Seacat, 1987).

\subsection{Description of tests}

\subsubsection{Revised Trail Making Test (R-TMT)}

The R-TMT consists of four parts: Part A (numbers) was extended with one item (26) as the alphabet consists of 26 letters. A new part, R-TMT-B, was made, containing only the 26 letters of the alphabet. The former part $B$ was transformed into part R-TMT-C, containing the numbers $1-13$ and the letters A - M. All trails are exact copies of one another, and much like the original part $\mathrm{A}$. To prevent 
the subjects from learning the form of the trails by heart over the subsequent test trials, the trails were modified by mirroring them around the vertical or horizontal axis, or by rotating them over 180 . Thus, 8 permutations are possible, allowing for a complete parallel version of the whole test. The same procedure was followed for the practice samples preceding all test parts, containing only eight items. In order to be able to assess separately the contribution of motor processes in the completion of each single test part, a '0-task' (R-TMT) was added, in which the circles were empty, and connected with thick lines. The subjects had to follow the black line as quickly as possible.

The R-TMT has the important additional advantage that performance is now readily interpretable in terms of information processing (Vink and Jolles, 1985). Only one aspect of the task is varied in each successive trial, so that a difference in the time needed per test sheet can be taken to denote the time needed for the application of knowledge about the alphabet or, most importantly, conceptshifting ability: a quick alternation between the number and letter sequences requires a smooth shifting of concepts. Consequently, the R-TMT should be very suitable to assess disorders in the planning of ongoing activity. The relative contribution of the need to shift between two concepts to the total time needed for part R-TMT-C (percentage) can conveniently be computed with the formula: $(\mathrm{tC}-(\mathrm{Ta}+\mathrm{Tb})) /(\mathrm{Ta}+\mathrm{Tb}) \times 100 \%$, where $\mathrm{Ta}, \mathrm{Tb}$, and $\mathrm{Tc}$ denote the total time taken to complete the test part.

\subsubsection{Concept Shifting Task (CST)}

The CST consists of four parts analogous to the R-TMT with altered lay-out. Figure 10.1 depicts a copy of the test sheets from the CST. The weaknesses of the R-TMT mentioned above are eliminated largely. On each test sheet, 16 small circles (diameter: $15 \mathrm{~mm}$.) are grouped in a larger circle, with a radius of 8 centimeters. In the smaller circles, the test items (numbers (A), letters (B), or both (C)) appear in a fixed random order. Subjects are requested to cross out the items in the right order, in the same way as in the R-TMT. The experimenter must pay close attention that this be done in the right order, and has to register all errors and omissions. In a '0-task' all 16 empty circles are to be crossed out clockwise as quickly as possible. The whole procedure (four test parts) is repeated once.

\subsection{Results}

The mean values needed per test parameter of the R-TMT and first administration of the CST are summarized in tables 10.1 (BLE-unaffected subjects) and 10.2 (BLE-affected group). Figure 10.3 depicts the mean total times per age $\times$ BLE group needed for test parts $A$ through $C$ for both tests. 


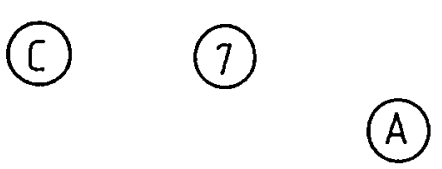

(8)

(6)

(4)

(2)

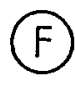

(E)

(G)

(B)

(H)

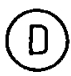

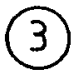

(1)

(5)

Figure 10.1. Test form of Concept-Shifting Test, part C. The subject is requested 'to cross out the circles in the correct order, as fast as he can, without making errors: first letter - first digit - second letter - second digit etc.'. The true diameter of the large circle is $16 \mathrm{~cm}$.

For the R-TMT, significant effects over all test parts were found for age $(F(6,221)=$ $38.62, \mathrm{p}<.001)$, the presence of $\operatorname{BLE}(\mathrm{F}(1,221)=47.24, \mathrm{p}<.001)$, and level of education $(F(1,221)=36.15, p<.001$. Furthermore, there was a significant interaction between age and BLE: $F(6,221)=5.97, p<.001$. Thus, in each successive age group, the average subject needed more time to complete each test part. BLE-affected subjects were also slower, and this effect became more pronounced in the older age groups. Less educated subjects were slower, especially in part C of the R-TMT and CST, which involved concept-shifting. There were no significant interactions with level of education $(\mathrm{F}<1)$. The repeated measures effect (main effect: $F(2,454)=324.64, p<.001)$ on the increasing difficulty of the successive test parts interacted significantly with all main effects: age $(F(12,442)=11.58, \mathrm{p}<.001)$, the 

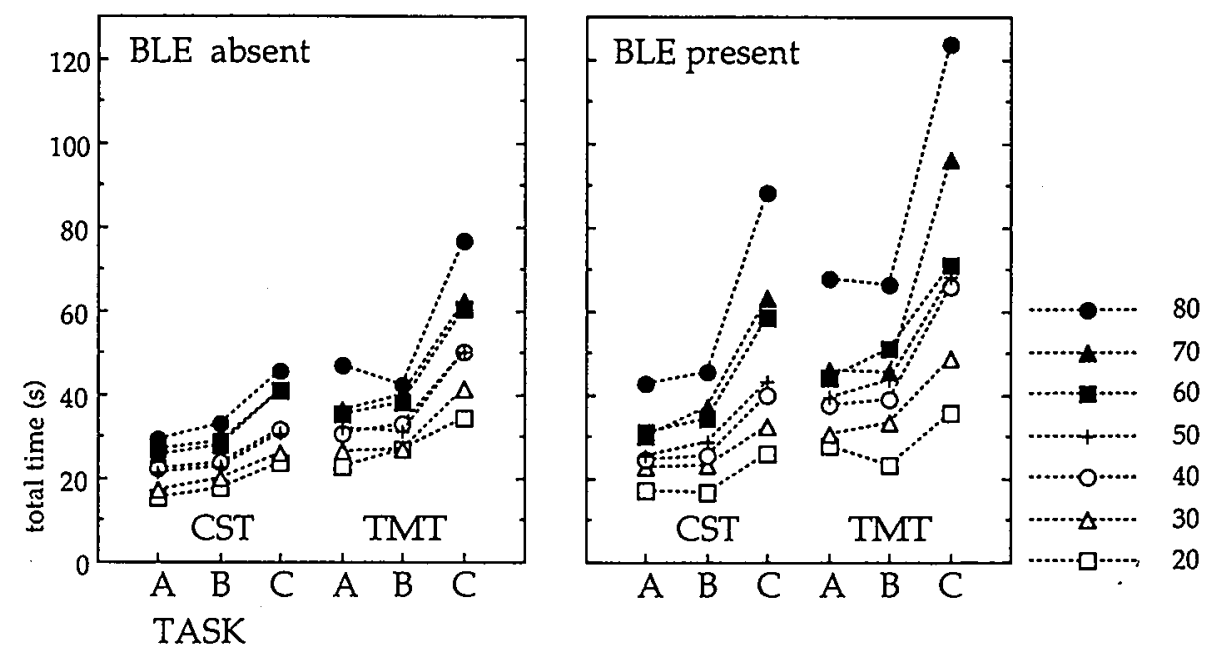

Figure 10.3. Mean total times needed by normal healthy subjects to complete each test sheet of the R-TMT and CST. The average of two parallel trials of the CST is depicted. On the left, the performance of healthy subjects of different ages who had not experienced any Biological Life Event (BLE) and on the right, the subjects who were affected by BLE.

presence of BLE $(\mathrm{F}(14.17), \mathrm{p}<.001$, and level of education $(\mathrm{F}(2,442)=13.58, \mathrm{p}<.001)$. This means that having to shift between concepts takes more time in the elderly, BLE-affected, and less educated subjects. The delay due to concept-shifting was greatest in the subjects who are both old and affected by BLE: $F(12,442)=3.78$, $\mathrm{p}<.001$ (age $\times$ BLE interaction). The basic speed of sensomotoric functions, as measured with the new 'part 0 ', showed the same effects, with the exception of the age $\times$ BLE interaction (age: $F(6,231)=14.34, p<.001$; BLE: $F(1,231)=22.48, p<.001$; educational level: $F(1,231)=232.01, p<.05)$.

The CST revealed the same pattern of results (fig. 10.3). Major effects were found for age $(F(6,227)=33.95, p<.001)$, $\operatorname{BLE}(F(1,227)=43.47, p<.001)$, and level of education $(F(1,227)=14.65, p<.001)$. Age and BLE also interacted: $F(6,227)=6.21$, $\mathrm{p}<.001$. The first within-subject effect (increasing task difficulty) was as pronounced as it was in the R-TMT: $F(2,454)=287.84, p<.001$. In addition, all between-subject effects interacted with this factor: age $(F(12,454)=13.42, p<.001)$, $\operatorname{BLE}(\mathrm{F}(2,454)=33.19, \mathrm{p}<.001)$, educational level $(\mathrm{F}(2,454)=5.28, \mathrm{p}<.01)$, and the age $x$ BLE interaction $(F(12,454)=5.36, p<.001)$. As in the R-TMT, the ' 0 tasks' showed effects of age $(F(6,231)=11.75, p<.001)$, BLE $(F(1,231)=28.74, p<.001)$ and educational level $(F(1,231)=42.32, p<.01)$. It appears that the CST reveals the same effects as the $\mathrm{R}$-TMT, and all interpretations are thus comparable. 
There was a very small practice effect in the CST, or rather, an effect of procedure learning. The subjects performed the test somewhat faster the second time it was administered (a parallel version): the overall mean time for the first part of the number subtask was 25.39 seconds and 24.79 seconds for the second part. Likewise, parts B ( 28.69 vs. 28.23$)$ and C (43.76 vs. 42.18$)$ were completed quicker the second time. This effect (over-all repeated measures) was consistent over all subgroups: $F(1,227)=6.36, p<.05$. There were interactions with age $(\mathrm{F}(6,227)=2.87, \mathrm{p}=.01)$ and with age $\times \mathrm{BLE}(\mathrm{F}(6,227)=4.38, \mathrm{p}<.001$. The mean practice effect was larger in the older age groups, and was greatest in older BLE subgroups.

The number of errors in both tasks was usually very low: the overall mean for the R-TMT was .391 per subtask and .106 for the CST. Invariably, the error rates were higher in the letter parts and were highest in the concept-shifting parts (TMT: $F(2,442)=4.05, p<.05$; CST: $F(2,454)=20.89, p<.001)$. Older subjects made more errors (R-TMT: $F(6,221)=4.21, \mathrm{p}<.001 ; \mathrm{CST}: \mathrm{F}(6,227)=10.04, \mathrm{p}<.001)$, as did the BLE-affected subjects (R-TMT: $F(2,221)=4.27, p<.05$; CST: $F(6,227)=7.54, p<.01$ ). Older BLE-affected subjects were the most accurate, with individual numbers of errors being as high as 8 in the R-TMT and 4 in the CST (age $\times$ BLE interaction in R-TMT: $F(6,221)=2.51, p<.05 ; \mathrm{CST}: \mathrm{F}(6,227)=2.10, \mathrm{p}=.055$, not significant).

The two tests appeared to consistently tap the same skills, as the correlations between the total time scores were quite high. For instance, part $C$ of the R-TMT showed an overall Pearson's $r$ of .72 with the first part $C$ of the CST $(t=16.24$, $\mathrm{df}=245, \mathrm{p}<.001)$ and of .81 with the second part $\mathrm{C}(\mathrm{t}=21.62, \mathrm{df}=245, \mathrm{p}<.001)$. For the A parts, these correlations were .70 and .72 , respectively, and for the $B$ parts .78 and .80. In addition, the reliability of the parallel versions of the CST was satisfactory: .84 (parts A), .80 (parts B), and .91 (parts C). As can be deduced from tables 10.1 and 10.2, the ratios of the total time to the standard deviation were somewhat smaller for performance in the CST than for performance in the RTMT, indicating that the CST has fewer inherent sources of error. 
Table 10.1 Mean scores per test parameter: Biological life events absent

Age group $(\mathbb{N})$

\begin{tabular}{ccccccc}
\hline 20 & 30 & 40 & 50 & 60 & 70 & 80 \\
$(22)$ & $(20)$ & $(22)$ & $(20)$ & $(20)$ & $(24)$ & $(20)$ \\
\hline
\end{tabular}

test part

Part A

Part B

27.1

(9.1)

22.7

(6.3)

Revised Trail Making Test

Part C

34.6

(9.9)

26.5

(5.4)

30.6

(8.4)

32.0

(7.4)

32.9

(8.6)

(6.1)

(8.6)

41.4

(13.9)

50.2

(16.8)

31.2

(8.9)

$58.2 \%$

Interference

$$
41.0 \%
$$

(28.1)

$53.6 \%$

(42.2)

(31.6)

11.6

(3.4)

13.9

(2.5)

0.4

(3.2)

(0.6)

1.0

(1.6)

\section{Concept Shifting Task}

Part A

$15.7 \quad 17.0$

(2.5)

(2.3)

22.0

(6.3)

50.0

(15.4)

$59.5 \%$

(40.0)

12.3

(3.1)

0.6

(1.0)

23.5

(5.8)

(3.2)

30.1

(8.1)

27.0
$(4.8)$

$32.9 \%$

(20.9)

21.8
$(5.6)$

\section{6}

(7.7)

26.4

29.4

21.6

30.1

(8.5)

29.2

(7.7)

33.9

(4.3)

(8.2)

Part C

Interference

$$
44.5 \%
$$

$46.2 \%$

(27.0)

\section{3}

(0.7)

$$
\text { (1.2) }
$$

0.1

(0.3)

$(0.0)$
5.0
$(0.9)$

(0.2)

42.4

43.7

29.0

(6.4)

(11.5)

(15.5)

47.2

(10.3)

$34.7 \% \quad 47.9 \% \quad 54.9 \% \quad 50.7 \%$

(19.0)

(23.4)

(32.9)

(21.0)

5.6
$(1.2)$

6.1

(1.5)

6.4

7.0

(1.2)

0.1

(1.0)

(1.3)

\begin{tabular}{cccc}
0.1 & 0.1 & 0.5 & 0.5 \\
$(0.2)$ & $(0.2)$ & $(0.9)$ & $(1.0)$ \\
\hline
\end{tabular}

Note: Interference $=(t C-(t A+t B) / t C) * 100 \%$ 
Table 10.2 Mean scores per test parameter: Biological life events present

\begin{tabular}{|c|c|c|c|c|c|c|c|}
\hline & \multicolumn{7}{|c|}{ Age group (N) } \\
\hline & $\begin{array}{l}20 \\
(9)\end{array}$ & $\begin{array}{l}30 \\
(9)\end{array}$ & $\begin{array}{r}40 \\
(12)\end{array}$ & $\begin{array}{c}50 \\
(15)\end{array}$ & $\begin{array}{c}60 \\
(15)\end{array}$ & $\begin{array}{c}70 \\
(17)\end{array}$ & $\begin{array}{r}80 \\
(20)\end{array}$ \\
\hline Test part & \multicolumn{3}{|c|}{ Revised Trail Making Test } & & & & \\
\hline Part A & $\begin{array}{l}27.8 \\
(8.5)\end{array}$ & $\begin{array}{c}30.6 \\
(9.9)\end{array}$ & $\begin{array}{l}37.8 \\
(8.8)\end{array}$ & $\begin{array}{c}39.6 \\
(12.8)\end{array}$ & $\begin{array}{c}44.2 \\
(15.4)\end{array}$ & $\begin{array}{c}49.0 \\
(12.7)\end{array}$ & $\begin{array}{r}67.7 \\
(23.6)\end{array}$ \\
\hline Part B & $\begin{array}{l}23.4 \\
(6.1)\end{array}$ & $\begin{array}{c}33.5 \\
(15.1)\end{array}$ & $\begin{array}{l}39.0 \\
(9.4)\end{array}$ & $\begin{array}{c}43.5 \\
(13.3)\end{array}$ & $\begin{array}{c}51.0 \\
(11.8)\end{array}$ & $\begin{array}{c}51.6 \\
(13.9)\end{array}$ & $\begin{array}{r}83.9 \\
(33.4)\end{array}$ \\
\hline Part C & $\begin{array}{l}35.7 \\
(9.3)\end{array}$ & $\begin{array}{c}48.8 \\
(25.6)\end{array}$ & $\begin{array}{c}65.9 \\
(23.1)\end{array}$ & $\begin{array}{c}68.1 \\
(23.1)\end{array}$ & $\begin{array}{c}76.4 \\
(14.2)\end{array}$ & $\begin{array}{c}102.2 \\
(67.8)\end{array}$ & $\begin{array}{c}137.1 \\
(54.0)\end{array}$ \\
\hline Interference & $\begin{array}{l}44.6 \% \\
(36.5)\end{array}$ & $\begin{array}{l}47.2 \% \\
(24.4)\end{array}$ & $\begin{array}{l}70.5 \% \\
(29.9)\end{array}$ & $\begin{array}{l}64.7 \% \\
(23.4)\end{array}$ & $\begin{array}{l}70.5 \% \\
(21.6)\end{array}$ & $\begin{array}{l}71.0 \% \\
(33.3)\end{array}$ & $\begin{array}{l}95.7 \% \\
(43.6)\end{array}$ \\
\hline Part 0 & $\begin{array}{l}10.7 \\
(2.1)\end{array}$ & $\begin{array}{c}14.7 \\
(4.4)\end{array}$ & $\begin{array}{c}15.4 \\
(5.0)\end{array}$ & $\begin{array}{c}18.3 \\
(6.4)\end{array}$ & $\begin{array}{l}22.2 \\
(6.3)\end{array}$ & $\begin{array}{c}20.2 \\
(6.7)\end{array}$ & $\begin{array}{r}26.4 \\
(11.3)\end{array}$ \\
\hline Total errors $(A-C)$ & $\begin{array}{c}0.2 \\
(0.4)\end{array}$ & $\begin{array}{c}0.9 \\
(1.4)\end{array}$ & $\begin{array}{c}0.9 \\
(1.4)\end{array}$ & $\begin{array}{c}1.1 \\
(1.3)\end{array}$ & $\begin{array}{c}0.5 \\
(1.0)\end{array}$ & $\begin{array}{c}1.6 \\
(2.2)\end{array}$ & $\begin{array}{c}2.7 \\
(4.3)\end{array}$ \\
\hline & & cept Shif & Task & & & & \\
\hline Part A & $\begin{array}{l}17.4 \\
(1.6)\end{array}$ & $\begin{array}{l}23.1 \\
(2.3)\end{array}$ & $\begin{array}{l}24.1 \\
(5.1)\end{array}$ & $\begin{array}{l}24.5 \\
(5.1)\end{array}$ & $\begin{array}{c}31.7 \\
(14.6)\end{array}$ & $\begin{array}{l}30.2 \\
(8.3)\end{array}$ & $\begin{array}{r}44.9 \\
(10.2)\end{array}$ \\
\hline Part B & $\begin{array}{c}16.8 \\
(4.2)\end{array}$ & $\begin{array}{c}23.9 \\
(5.0)\end{array}$ & $\begin{array}{l}26.2 \\
(6.3)\end{array}$ & $\begin{array}{l}29.6 \\
(5.3)\end{array}$ & $\begin{array}{c}33.4 \\
(11.3)\end{array}$ & $\begin{array}{c}37.3 \\
(21.6)\end{array}$ & $\begin{array}{r}55.4 \\
(23.6)\end{array}$ \\
\hline Part C & $\begin{array}{r}6.7 \\
(5.6)\end{array}$ & $\begin{array}{l}33.6 \\
(8.9)\end{array}$ & $\begin{array}{c}40.8 \\
(9.2)\end{array}$ & $\begin{array}{c}42.6 \\
(10.3)\end{array}$ & $\begin{array}{c}57.3 \\
(22.4)\end{array}$ & $\begin{array}{c}63.6 \\
(29.7)\end{array}$ & $\begin{array}{c}106.8 \\
(67.5)\end{array}$ \\
\hline Interference & $\begin{array}{l}55.0 \% \\
(17.7)\end{array}$ & $\begin{array}{l}42.1 \% \\
(23.1)\end{array}$ & $\begin{array}{l}63.3 \% \\
(19.1)\end{array}$ & $\begin{array}{l}57.6 \% \\
(30.0)\end{array}$ & $\begin{array}{l}77.2 \% \\
(21.0)\end{array}$ & $\begin{array}{l}97.4 \% \\
(61.6)\end{array}$ & $\begin{array}{r}101.7 \% \\
(69.4)\end{array}$ \\
\hline Part 0 & $\begin{array}{r}5.9 \\
(1.3)\end{array}$ & $\begin{array}{r}5.7 \\
(1.0)\end{array}$ & $\begin{array}{c}6.1 \\
(1.2)\end{array}$ & $\begin{array}{c}6.4 \\
(1.6)\end{array}$ & $\begin{array}{r}7.9 \\
(2.0)\end{array}$ & $\begin{array}{c}7.3 \\
(1.6)\end{array}$ & $\begin{array}{r}9.2 \\
(3.5)\end{array}$ \\
\hline Total errors $(A-C)$ & $\begin{array}{c}0.0 \\
(0.0)\end{array}$ & $\begin{array}{c}0.2 \\
(0.6)\end{array}$ & $\begin{array}{c}0.0 \\
(0.0)\end{array}$ & $\begin{array}{c}0.8 \\
(1.6)\end{array}$ & $\begin{array}{c}0.1 \\
(0.5)\end{array}$ & $\begin{array}{c}1.4 \\
(1.7)\end{array}$ & $\begin{array}{r}1.0 \\
(1.3)\end{array}$ \\
\hline
\end{tabular}




\subsection{Discussion}

An overall age-related slowing was found in the performance of healthy subjects for all test parts of the revised Trail Making Test (R-TMT) and Concept-shifting Task (CST). In addition, accuracy was somewhat poorer in the older age groups. However, these age effects were significantly more pronounced in those subjects who were affected by one or more biological life events (BLE). The greatest group difference due to BLE was found for the shift between number and letter sequences. The newly devised CST appeared to test the same skills as the R-TMT, as seen from the high correlations between the outcomes of the two tests.

In our opinion, the revisions of the R-TMT are useful. Almost invariably, part RTMT-B (containing only letter items) took longer to complete. This indicates that counting is a process that is less effort-demanding than applying the alphabetical order. It is evident, therefore, that part of the extra time needed for part $C$ (i.e., the former part B) must be explained by this fact alone. Furthermore, the contribution of sensomotoric processes can be estimated by subtracting the time needed for part 0 from the other total times, as the requirements of visual scanning and line-drawing remain constant over all test parts. Moreover, by applying the formula $(\mathrm{tC}-(\mathrm{t} A+\mathrm{tB})) /(\mathrm{t} A+\mathrm{tB}) \times 100 \%)$, a reliable measure of the speed of concept-shifting can be obtained.

During the past five years the R-TMT has received attention from several neuropsychologists, both clinical and experimental. In patients characterized by Age-Associated Memory Impairment (AAMI), Reyersen van Buuren, Jolles, Verhey, and Houx (in press) found an over-all group difference in speed but not in concept-shifting compared with normal controls. Bohnen, Houx, Jolles, and Janknegt (1989) found a significant difference in the performance of patients who had received an overnight isotonic fluid infusion compared to that of patients who had not. This was especially the case with R-TMT-C and concept-shifting. These authors concluded that the water metabolism of the brain could be involved in cognitive functions.

Each test part of the CST contains only 16 items, and usually the subjects needed less time (about 40\%) to complete the test parts. Although this can be an advantage over the R-TMT in its own right, the real advantage of a limited test size is that the influence of a limited knowledge about the alphabet is avoided. Indeed, it is our experience that many elderly subjects who had received only some years of primary education made errors when reproducing the second half of the alphabet. While this is not a problem in the new R-TMT part C, performance on part B can be affected. In part B of the CST, the last item is the letter $P$, and reproduction of the alphabet up to this item is usually quite easy. We think therefore that the CST is to be preferred over the R-TMT in clinical settings where time and patient compliance is usually limited. Another reason 
why the CST should be the test of choice is the very large number of possible parallel versions of the test. In experimental research, for instance, the two parallel versions of the R-TMT can be insufficient. In clinical assessment, however, repeated testing may be necessary. Especially with short time intervals, the patient can learn the trajectory by heart when given sufficient 'practice'. Furthermore, the effect of procedure learning can be distinguished adequately from the practice effect by using parallel versions. Six parallel versions have been developed and used up till now (Jolles, unpublished).

Aging appears to impair all aspects of performance in the R-TMT and CST. No evidence was found for a change in the speed-accuracy trade-off (Fitts and Radford, 1966), as proposed by Botwinick (1977). On the contrary, those elderly subjects who made most errors also tended to be slowest.

With respect to basic speed, it was found that every successive age group was slower than the preceding one. This age effect was further enhanced when subjects had been affected by one or more BLE. The speed of perceptual and motor processes is crucial to the ease with which many higher order cognitive processes (such as concept-shifting) are performed. Therefore, reduction of basic speed necessarily implies that other functions are also slowed down.

The interference effect of concept-shifting increased in each successive age group, especially in the R-TMT. The mean interference effect of concept-shifting was about $40 \%$ in 20 -years old, about $60 \%$ in 40 -years old, and about $70 \%$ in 80 -years old. Apparently, slowing of the kind of information processing that is involved in the planning of ongoing activity is already present at the age of 40 . This is consistent with the notion that frequent complaints by middle-aged and elderly persons concerning slowing of information processing find their origin in earlier decades, possibly as early as the mid-thirties. Reduction in basic speed combined with increasing susceptibility to interference can explain why many people experience 'difficulty keeping up'.

The R-TMT and CST may prove useful in research into dysfunctions associated with dysfunctions of the frontal cortex. As planning and evaluation of behavior are known to be represented in the frontal regions, tests of concept-shifting may be an important contribution to research into the age-associated decline in frontal functions. Morphometric evidence found by Haug (1985) can be taken to support this: age-related changes in frontal cortex -associated with planning of behavior-appear to begin very early in life (between the ages of 25 and 40 years). 


\section{PSYCHOMOTOR PERFORMANCE I: CONTINUOUS PERFORMANCE TAPPING TEST}

\subsection{Introduction}

Finger tapping speed is one of the more simple aspects of psychomotor performance and manual dexterity that are known to deteriorate with advancing age (Bag and Greene, 1980; Harley, Leuthold, Matthews, and Bergs, 1980; Welford, 1985). To test tapping speed in neuropsychological patients, Halstead (1947) devised a test that was originally named the Finger Oscillation Test, but is now better known as Finger Tapping Test (FTT), as part of the Halstead-Reitan Neuropsychological Test Battery (See Lezak, 1983, pp. 529 and 562-566, for a concise discussion). The FTT is now the most widely used test of simple manual motor speed. Also, it is often used to test performance differences between both hands in order to evaluate lateralized brain lesions, which often result in slowing of the tapping rate of the contralateral hand (Finlayson and Reitan, 1980; Haaland and Delaney, 1981).

Briefly, the test consists of a tapping key, attached to a tap-counting device, mounted on a small piece of board. Each hand makes five 10-seconds trials, with brief rest periods between the trials, by alternating the hands. The score for each hand is the average of all five trials. Dodrill (1979) described a group of 47 men and 47 women, the men averaging at almost 56 taps in ten seconds, the women 51 taps. This sex difference was significant. As yet, no age norms founded on sufficiently large groups of normal healthy controls are available.

Although the FTT is a handy, easy-to-administer test, is has some limitations. The tapping key is mounted to the counting-device in such a way, that many subjects experience trouble in speed finger oscillation. The wrist has to be placed on the board on which it mounted, whereas the key is situated some $4 \mathrm{~cm}$. higher. This is quite uncomfortable, so that low tapping rate may be due to this technical problem, especially in patients with small hands. More importantly however, the counting device merely registers the number of taps, not their timing. It was our clinical impression though, that the tapping rate slowed down during each ten-seconds trial. It has been our aim to devise a simple, clinically applicable test of manual motor proficiency, that would take into account the development of the performance over time.

For purposes of motor reaction timing, for NEUROPSYCH (Brand, 1987; section 2.3.4 a console was available, in which easy-to-press down keys were mounted, which could in turn be read out by an Apple-II microcomputer. This enabled the construction of a new test. The general advantages of computerizing neuropsychological tests were discussed in section 2.3.4. To these, two can be added regarding the newly developed tapping test: 1 . the period during which the subject is tapping can be much more accurately timed than by means of a stopwatch (at millisecond precision), and 2. the tapping period can be divided into successive blocks, in order to determine in which interval performance is at it's 
best, whether there is any decline in tapping speed, and, if so, at what rate this decline occurs. Regarding attention and reaction time, this procedure was described earlier by Gaillard and Varey (1979).

\subsection{Test description}

The technical aspects of the hardware of the test are discussed in chapter 2 (section 2.3.4), and in greater detail by Brand (1987). The procedure of the tapping test used in the present study, the Continuous Performance Tapping Test (CPTT) differed from the FTT. There were three 20-second trials for each hand. The time elapsed between two single taps was registered by the computer, at millisecond accuracy. For the purposes of this experiment, the 20-second trials were subdivided in four five-second intervals. The tapping rate during these blocks served as raw data for further analysis.

Analogous to the FTT, the average of the three corresponding intervals for the four trials were calculated, to yield four interval scores for each hand. These scores served as data for a linear regression analysis for every individual subject. Thus, apart from an over-all mean score, an intercept, slope, and linearity coefficient was calculated for each hand. Finally, the difference between the overall mean scores of the preferred hand minus the non-preferred hand was expressed in a personal delta-score.

\subsection{Results}

Figure 11.1 depicts the average interval performance of subjects with and without BLE. Tables 11.1 and 11.2 summarize the individual linear regression parameters. An ANOVA was carried out which had age ( 7 levels), BLE (2 levels), education (2 levels), and sex as main between subjects effects, and interval (4 levels) and hand as within subjects effects. Furthermore, three ANOVA's for individual parameters were performed: over-all mean, intercept, slope, and linearity coefficients, each of these with the same between subjects effects as the one mentioned above, and hand as within subjects effect.

Effects of interval, hand, and sex. With each successive interval, the number of taps declined $(\mathrm{F}(1,217)=183.88, \mathrm{p}<.001)$. The non-preferred hand was slower than the preferred hand $(F(3,651)=925.36, p<.001)$, and slowed down faster $(F(1,217)=$ 5.34, $\mathrm{p}<.05$; slopes). Women were slower than men $(\mathrm{F}(1,217)=30.95, \mathrm{p}<.001$; intercepts); $(F(1,217)=1,217=36.24, p<.001$; over-all means). There were no other sex effects or interactions with sex.

Age effects and interactions. Interval tapping rates declined with advancing age $(F(6,217)=21.93, p<.001)$. Age and interval showed interaction $(F(18,651)=3.53$, $\mathrm{p}<.001)$ : tapping rate declined less over the successive intervals in older subjects. This was replicated by an age effect regarding the individual slope $(F(6,217)=4.42$, 

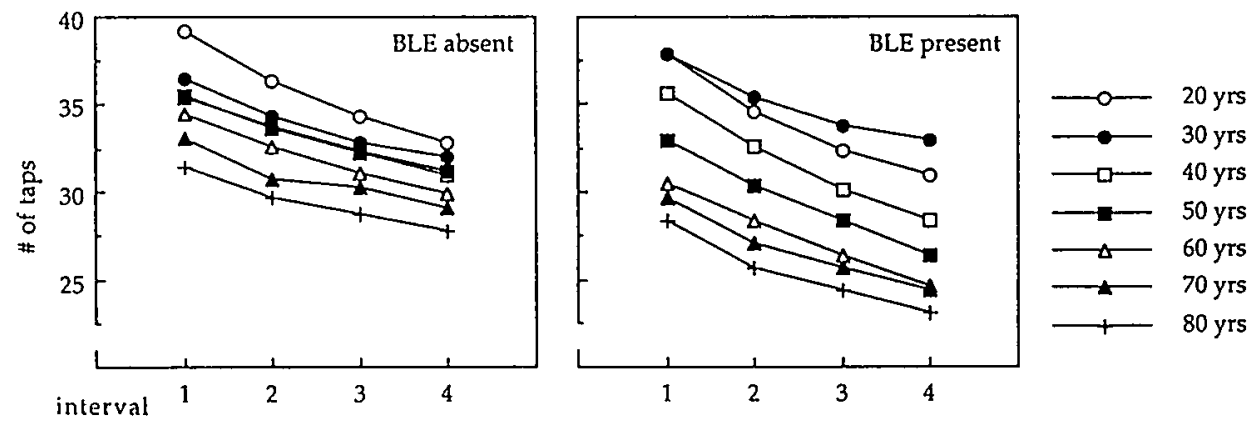

Figure 11.1 Mean number of taps of 3 successive 20-second trials with the preferred hand, divided in 5 -second intervals. The graph on the right summarizes the performance of subjects who had experienced biological life events (BLE).

$p<.001$. Older subjects showed no greater difference between both hands than younger subjects $(\mathrm{F}<1)$. Over-all means and intercepts were also lower in older subjects: $(F(6,217)=21.93, p<.001)$, and $(F(6,217)=24.36, p<.001)$, respectively. Sex differences were no greater in older subjects $(F<1)$.

Biological life events were associated with most aspects of performance. BLEaffected subjects had lower over-all means $(F(1,217)=17.14, p<.001)$, steeper slopes $(F(1,217)=14.64, p<.001)$, and larger hand differences $(F(1,217)=12.92, p<.001)$, but not significantly lower intercepts $(F(1,217)=2.77, p=.098)$. Older subjects who had experienced BLE performed most poorly, as appeared from age $\times$ BLE interactions regarding over-all means $(F(6,217)=2.48), p<.05)$. There were no other interactions.

There were two surprising effects of education: higher educated subjects started off faster $(F(1,217)=5.7, p<.05$; intercepts), but also slowed down faster $(F(1,217)=4.35, p<.05$; slopes $)$, which resulted in over-all means that showed no significant differences $(F(2,66), p=.10)$.

Linearity of performance decline over time. As can be seen from tables 11.1 and 11.2 , the average linearity of the decline over the successive intervals was quite high. In some age groups, means were negatively flattered because of high variance. Inspection of the raw data showed that this was mainly due to an occasional temporary lapse of the tapping which was otherwise quite high. Occasionally, a subject missed the tapping button. 
Table 11.1 Mean scores per test parameter: Biological life events absent

\begin{tabular}{|c|c|c|c|c|c|c|c|}
\hline & \multicolumn{7}{|c|}{ Age group (N) } \\
\hline & 20 & 30 & $\begin{array}{r}40 \\
(2 ?)\end{array}$ & 50 & 60 & $\begin{array}{r}70 \\
(25)\end{array}$ & 80 \\
\hline \multicolumn{8}{|c|}{ NON-preferred hand } \\
\hline Mean score & $\begin{array}{l}32.1 \\
(4.6)\end{array}$ & $\begin{array}{l}30.6 \\
(3.1)\end{array}$ & $\begin{array}{l}30.8 \\
(3.4)\end{array}$ & $\begin{array}{l}30.5 \\
(3.2)\end{array}$ & $\begin{array}{l}29.0 \\
(3.1)\end{array}$ & $\begin{array}{l}27.8 \\
(3.6)\end{array}$ & $\begin{array}{l}25.9 \\
(2.7)\end{array}$ \\
\hline Intercept & $\begin{array}{l}38.0 \\
(6.1)\end{array}$ & $\begin{array}{l}36.0 \\
(4.2)\end{array}$ & $\begin{array}{l}35.2 \\
(3.4)\end{array}$ & $\begin{array}{l}35.0 \\
(4.5)\end{array}$ & $\begin{array}{l}32.9 \\
(4.0)\end{array}$ & $\begin{array}{l}31.6 \\
(4.7)\end{array}$ & $\begin{array}{l}29.5 \\
(3.3)\end{array}$ \\
\hline Slope & $\begin{array}{l}-2.36 \\
(1.45)\end{array}$ & $\begin{array}{c}-2.13 \\
(1.03)\end{array}$ & $\begin{array}{l}-1.79 \\
(0.96)\end{array}$ & $\begin{array}{c}-1.79 \\
(0.89)\end{array}$ & $\begin{array}{l}-1.54 \\
(0.80)\end{array}$ & $\begin{array}{l}-1.50 \\
(0.72)\end{array}$ & $\begin{array}{l}-1.44 \\
(0.64)\end{array}$ \\
\hline Linearity & $\begin{array}{c}-0.90 \\
(0.14)\end{array}$ & $\begin{array}{c}-0.92 \\
(0.14)\end{array}$ & $\begin{array}{c}-0.95 \\
(0.08)\end{array}$ & $\begin{array}{c}-0.91 \\
(0.12)\end{array}$ & $\begin{array}{c}-0.89 \\
(0.25)\end{array}$ & $\begin{array}{c}-0.90 \\
(0.08)\end{array}$ & $\begin{array}{c}-0.90 \\
(0.12)\end{array}$ \\
\hline \multicolumn{8}{|c|}{ Preferred hand } \\
\hline Mean score & $\begin{array}{l}35.7 \\
(4.4)\end{array}$ & $\begin{array}{l}33.9 \\
(3.5)\end{array}$ & $\begin{array}{l}33.0 \\
(3.5)\end{array}$ & $\begin{array}{l}33.2 \\
(3.1)\end{array}$ & $\begin{array}{l}32.0 \\
(2.2)\end{array}$ & $\begin{array}{l}30.8 \\
(3.6)\end{array}$ & $\begin{array}{l}29.4 \\
(3.0)\end{array}$ \\
\hline Intercept & $\begin{array}{l}41.0 \\
(5.2)\end{array}$ & $\begin{array}{l}37.8 \\
(3.2)\end{array}$ & $\begin{array}{l}36.8 \\
(3.4)\end{array}$ & $\begin{array}{l}36.7 \\
(4.3)\end{array}$ & $\begin{array}{l}35.8 \\
(2.6)\end{array}$ & $\begin{array}{l}33.9 \\
(3.4)\end{array}$ & $\begin{array}{l}32.3 \\
(3.6)\end{array}$ \\
\hline Slope & $\begin{array}{c}-2.13 \\
(1.13)\end{array}$ & $\begin{array}{c}-1.53 \\
(0.72)\end{array}$ & $\begin{array}{c}-1.51 \\
(0.60)\end{array}$ & $\begin{array}{c}-1.42 \\
(0.85)\end{array}$ & $\begin{array}{c}-1.53 \\
(0.54)\end{array}$ & $\begin{array}{c}-1.26 \\
(0.74)\end{array}$ & $\begin{array}{c}-1.18 \\
(0.62)\end{array}$ \\
\hline Linearity & $\begin{array}{c}-0.89 \\
(0.18)\end{array}$ & $\begin{array}{c}-0.89 \\
(0.17)\end{array}$ & $\begin{array}{c}-0.92 \\
(0.17)\end{array}$ & $\begin{array}{l}-0.81 \\
(0.41)\end{array}$ & $\begin{array}{c}-0.96 \\
(0.04)\end{array}$ & $\begin{array}{c}-0.80 \\
(0.21)\end{array}$ & $\begin{array}{c}-0.85 \\
(0.17)\end{array}$ \\
\hline DELTA & $\begin{array}{c}-3.59 \\
(3.90)\end{array}$ & $\begin{array}{l}-3.27 \\
(2.11)\end{array}$ & $\begin{array}{l}-2.29 \\
(2.57)\end{array}$ & $\begin{array}{l}-2.68 \\
(2.00)\end{array}$ & $\begin{array}{l}-2.97 \\
(1.84)\end{array}$ & $\begin{array}{l}-2.95 \\
(2.13)\end{array}$ & $\begin{array}{c}-3.50 \\
(2.02)\end{array}$ \\
\hline
\end{tabular}

Note: Mean score: number of taps per 5 sec. of 3 successive trials of 4 intervals of 5 sec. each.

Interval, slope, and linearity: regression parameters of number of taps as a function of interval number, based on mean number of taps in all corresponding intervals of the 3 successive trials.

Delta: difference between overall interval scores of preferred hand - non-preferred hand.

The influence of separate BLE. As the study was not a prospective one, as to the impact of different BLE, only some separate correlations are given here with those factors that appeared to correlate significantly with test performance. Table 11.3 summarizes some of the relevant findings. Correlations that are not presented in the table were not significant. Of all the subject variables, age was most strongly related to tapping rate, but it was only weakly related to slope: older subjects tended to slow down less rapidly (or to start slower). Education was second best in explaining for the individual differences: there were moderate 
Table 11.2 Mean scores per test parameters: Biological life events present

\begin{tabular}{|c|c|c|c|c|c|c|c|}
\hline & \multicolumn{7}{|c|}{ Age group (N) } \\
\hline & 20 & 30 & 40 & 50 & 60 & 70 & 80 \\
\hline & (9) & (9) & (12) & (15) & (15) & (17) & (20) \\
\hline \multicolumn{8}{|c|}{ NON-preferred hand } \\
\hline Mean score & $\begin{array}{l}32.9 \\
(4.1)\end{array}$ & $\begin{array}{l}33.0 \\
(3.0)\end{array}$ & $\begin{array}{l}29.8 \\
(2.7)\end{array}$ & $\begin{array}{l}27.9 \\
(4.0)\end{array}$ & $\begin{array}{l}25.2 \\
(3.9)\end{array}$ & $\begin{array}{l}24.9 \\
(4.7)\end{array}$ & $\begin{array}{l}23.4 \\
(4.4)\end{array}$ \\
\hline Intercept & $\begin{array}{l}38.4 \\
(3.1)\end{array}$ & $\begin{array}{l}39.0 \\
(4.4)\end{array}$ & $\begin{array}{l}35.5 \\
(2.5)\end{array}$ & $\begin{array}{l}33.8 \\
(5.3)\end{array}$ & $\begin{array}{l}29.9 \\
(6.0)\end{array}$ & $\begin{array}{l}29.3 \\
(5.3)\end{array}$ & $\begin{array}{l}26.6 \\
(5.9)\end{array}$ \\
\hline Slope & $\begin{array}{c}-2.20 \\
(0.92)\end{array}$ & $\begin{array}{c}-2.40 \\
(0.99)\end{array}$ & $\begin{array}{l}-2.28 \\
(0.96)\end{array}$ & $\begin{array}{c}-2.35 \\
(1.00)\end{array}$ & $\begin{array}{c}-1.88 \\
(1.10)\end{array}$ & $\begin{array}{c}-1.74 \\
(0.84)\end{array}$ & $\begin{array}{c}-1.28 \\
(0.91)\end{array}$ \\
\hline Linearity & $\begin{array}{c}-0.98 \\
(0.01)\end{array}$ & $\begin{array}{c}-0.91 \\
(0.07)\end{array}$ & $\begin{array}{l}-0.93 \\
(0.17)\end{array}$ & $\begin{array}{l}-0.97 \\
(0.05)\end{array}$ & $\begin{array}{c}-0.82 \\
(0.34)\end{array}$ & $\begin{array}{l}-0.90 \\
(0.11)\end{array}$ & $\begin{array}{c}-0.78 \\
(0.34)\end{array}$ \\
\hline \multicolumn{8}{|c|}{ Preferred hand } \\
\hline Mean score & $\begin{array}{l}34.0 \\
(5.8)\end{array}$ & $\begin{array}{l}35.0 \\
(3.2)\end{array}$ & $\begin{array}{l}31.6 \\
(3.0)\end{array}$ & $\begin{array}{l}29.6 \\
(3.7)\end{array}$ & $\begin{array}{l}27.5 \\
(4.1)\end{array}$ & $\begin{array}{l}26.7 \\
(4.2)\end{array}$ & $\begin{array}{l}25.3 \\
(5.2)\end{array}$ \\
\hline Intercept & $\begin{array}{l}39.8 \\
(6.6)\end{array}$ & $\begin{array}{l}39.2 \\
(3.3)\end{array}$ & $\begin{array}{l}37.8 \\
(3.4)\end{array}$ & $\begin{array}{l}35.0 \\
(5.2)\end{array}$ & $\begin{array}{l}32.4 \\
(4.6)\end{array}$ & $\begin{array}{l}31.0 \\
(4.4)\end{array}$ & $\begin{array}{l}29.6 \\
(5.4)\end{array}$ \\
\hline Slope & $\begin{array}{c}-2.34 \\
(1.02)\end{array}$ & $\begin{array}{c}-1.66 \\
(0.60)\end{array}$ & $\begin{array}{c}-2.46 \\
(1.25)\end{array}$ & $\begin{array}{l}-2.17 \\
(1.13)\end{array}$ & $\begin{array}{l}-1.98 \\
(1.02)\end{array}$ & $\begin{array}{c}-1.75 \\
(0.71)\end{array}$ & $\begin{array}{c}-1.68 \\
(0.63)\end{array}$ \\
\hline Linearity & $\begin{array}{c}-0.93 \\
(0.05)\end{array}$ & $\begin{array}{c}-0.91 \\
(0.10)\end{array}$ & $\begin{array}{c}-0.97 \\
(0.02)\end{array}$ & $\begin{array}{c}-0.97 \\
(0.03)\end{array}$ & $\begin{array}{c}-0.93 \\
(0.15)\end{array}$ & $\begin{array}{c}-0.93 \\
(0.05)\end{array}$ & $\begin{array}{c}-0.91 \\
(0.10)\end{array}$ \\
\hline DELTA & $\begin{array}{c}-1.04 \\
(3.63)\end{array}$ & $\begin{array}{l}-2.07 \\
(2.45)\end{array}$ & $\begin{array}{l}-1.83 \\
(2.74)\end{array}$ & $\begin{array}{l}-1.67 \\
(1.48)\end{array}$ & $\begin{array}{c}-2.29 \\
(3.30)\end{array}$ & $\begin{array}{c}-1.75 \\
(2.36)\end{array}$ & $\begin{array}{l}-1.99 \\
(2.64)\end{array}$ \\
\hline
\end{tabular}

Note: See table 11.1 for explanation.

correlations with general speed. The number of BLE subjects had experienced was also related to all aspects of test performance: the higher the number of BLE, the steeper the slope. Of the separate BLE, only the number of different types of medication the subjects was taking regularly or had taken shortly before, could account for a substantial amount of variance. The number of closed head injuries was not related to any aspect of tapping performance; the number of anesthesias correlated only with the over-all mean. 
Table 11.3 Correlations of tapping rate (preferred hand) with Age and BLE

\begin{tabular}{lcccccc}
\hline & Age & Educ & \#BLE & \#CHI & \#anest & \#medic \\
\hline Mean & $-.569^{* *}$ & $.379^{* *}$ & $-.290^{* *}$ & -.029 & $-.173^{* *}$ & $-.389^{* *}$ \\
Intercept & $-.605^{* *}$ & $.375^{* *}$ & $-.173^{* *}$ & .012 & $-.139^{*}$ & $-.379^{* *}$ \\
Slope & $.198^{* *}$ & -.062 & $-.239^{* *}$ & -.095 & -.051 & .050 \\
\hline
\end{tabular}

Note: Educ: education, scored according to Verhagen (1964); \#BLE: number of BLE experienced by a subject; \#CHI: weighed score of the number of closed head injuries; \#anest: weighed score of general anesthesia; \#medic: number of different medications, taken regularly. ${ }^{*} p<.05,{ }^{* *} p<.01, t$-test, two-tailed.

\subsection{Discussion}

With a newly constructed tapping test, several aspects of manual motor performance could be studied. The were age differences as to the over-all number of taps, but also in the course of the performance. Younger subjects were faster 'starters' but also slowed down more rapidly. Healthy elderly subjects apparently performed at a more constant level. Elderly subjects who had experienced BLE however, showed faster decline. Furthermore, differences between young and old were larger in the BLE-affected group, irrespective of other factors. Subjects who had received more formal education performed somewhat better, but only in the first 5-second interval. In the other three intervals there was no significant difference. Of the separate BLE, the number of different medications taken regularly, correlated most strongly with test performance.

The finding of sex differences favoring men, supports Dodrill's (1979) findings. The size of the difference was roughly the same as found by Dodrill: nearly 3.0 in a five-second over-all means (Dodrill found women to be almost 5.0 taps slower in 10 seconds).

The absolute average tapping rate in the present study appeared to be somewhat (and in younger groups considerably) higher than in studies reported by Lezak (1983). She reports a maximum (in 10 seconds) of 55.9 for the preferred hand, and 51.1 for the other. The explanation is probably the better tapping device used in the present study.

The surprising differences due to education are difficult to account for. The size of the average difference between high- and low educated subjects regarding the intercepts was not very large: \pm 2 in the preferred hand, and $\pm 2,7$ in the nonpreferred hand. Possibly the high-educated subjects were somewhat more motivated to do their best. Perhaps, the tapping test may bear some sportive challenge, to which some people are attracted. 
The non-preferred hand was almost invariable slower than the preferred hand. Not only was it a slower starter (more than two point less), but also it appeared to fatigue somewhat faster (about 1.9 taps less every next interval, as opposed to 1.7 points in the right hand. See tables 11.1 and 11.2 for the distribution over the age groups.

The complex interactions between age, BLE and performance in successive intervals is not quite unequivocal. Young subjects were fast starters, irrespective of BLE, but slowed down quickly in the following intervals. Apparently, they can summon enough energy to make a quick, explosive start. Older subjects did not slow down that quickly, irrespective of BLE. Possibly they have learned to better distribute their energy.

The data suggest that it is worthwhile to develop this method further. The CPTT has proven to yield extra information that cannot be drawn from the original Halstead test. Given a microcomputer in the examination room, administration is as simple and quick as with the old version. For purposes of the present study, the raw data were not analyzed to search for small temporary lapses of the tapping rate. This is, however, still possible. It was our experience that especially older subjects show more of these lapses, as if they 'lose the rhythm'. To study this, however, it is probably required to use longer test trials, for instance 60 seconds, instead of 20. The CPTT would then be transformed into a 'sustained tapping test'. 


\section{PSYCHOMOTOR PERFORMANCE II: MOTOR CHOICE REACTION TEST*}

\subsection{Introduction}

Age-related decline of psychomotor speed is a very well-documented phenomenon (Welford, 1985; Salthouse, 1985; Jolles, 1986). Also, performance differences between age groups tend to increase as task complexity is raised (Simon and Pouraghabagher, 1978; Myerson, Hale, Hirschman, Hansen et al., 1990). Several authors have reported that a number of factors can interact with the effect of aging as such (Spirduso, 1975; Spirduso and Clifford, 1978). Among these factors are physical fitness (Milligan, Powell, Harley, and Furchtgott, 1984), brain damage (Hicks and Birren, 1970), education and perceived health (Era, Jokela, and Heikkinen, 1986). Spirduso (1980) has reviewed the evidence on the relation between physical fitness and psychomotor speed. She found that fitness was directly related to reaction time, and that by physical training reaction and movement time could be shortened. Conversely, performance is slower in subjects with hypertension and other forms of cardiovascular disease.

Disorders of several aspects of movement are an often-encountered phenomenon in a wide variety of disorders of the brain (Kolb and Whishaw, 1990, pp. 257-322). For instance, Parkinson's disease is associated with disturbances of movement initiation, rigidity, clumsiness, and movement amplitude (Bannister, 1981, pp. 290-296). Damage to the frontal lobes can result in disorders of movement ranging from disturbances in the fine motor control of lips or fingers, to disruption of the organization and planning of movement (Luria, 1973, pp. 169-186). It is clear therefore, that development of a simple test that enables the distinction between the speed of initiation and the actual carrying out of movements, would constitute an important contribution to the neuropsychological assessment techniques.

A simple choice-response task -involving different conditions with increasing

\footnotetext{
-This chapter is a condensed form of what has been submitted for publication as journal article:

Houx, P.J., \& Jolles, J. (submitted). Age-related decline in psychomotor speed: Effects of age, brain health, sex, and education. Perceptual and Motor Skills.

Part of the data presented here has been published elsewhere:

Houx, P. J. Vreeling, F. W. Vreeling, \& Jolles, J. (1990). Cognitieve veroudering wordt meer beinvloed door 'biological life events' dan door fysiologische veroudering [Cognitive aging is more influenced by biological life events than by physiological aging]. In C. P. M. Knipscheer, J. J. M. Michels, \& M. W. Ribbe (Eds.), Ouder worden nu '90 [Aging now '90] (pp. 270-278). Almere, The Netherlands: Versluys.

Houx, P. J., Vreeling, F. W., \& Jolles, J. (1991a). Age-associated cognitive decline is related to biological life events. In K. Iqbal, D. R. C. McLachlin, B. Winblad, \& H. M. Wisniewski (Eds.), Alzheimer's disease: Basic mechanisms, diagnosis and therapeutic strategies (pp. 353-358). Chichester, UK: Wiley.
} 
difficulty regarding the complexity of the motor initiation phase- appeared to be best suited for this aim. Several examples of this paradigm are known. Van Zomeren and Deelman (1978), for instance, used a 4-choice task to evaluate the recovery of closed-head injury. However, most available tests are too difficult with respect to the task instructions, the task requirements, or both. For clinical purposes, a test should be feasible for elderly and mildly demented subjects. In the next section a test is described that -in our opinion-adequately meets these criteria.

\subsection{Test description}

Analogous to the method presented by Frowein and Sanders (1978), a test was constructed in which many of the task conditions can be manipulated. Most importantly, the amount of motor planning, prior to the actual movement execution, can be controlled. This is achieved by adjusting the number of alternative stimuli, and introducing the element of stimulus-response incompatibility, meaning that stimulus and response do not coincide on the stimulus array. Neuropsychologically, this has the advantage that the delay due to the extra amount of motor planning can be studied. This is particularly of interest as slowing of motor planning and other aspects of behavioral organization might be indicative of frontal cortex involvement (Jolles, 1986). This, in turn, is of relevance as there are indications that loss of frontal neurones occurs as early as the fourth decade of life (Haug, 1985).

\subsubsection{Procedure and apparatus}

In the choice response task, there were three subsequent conditions of increasing task complexity. Briefly, a button was lit, in response of which this or another button, was to be pressed. The conditions involved:

1) Simple reaction time (SRT);

2) Choice reaction time (CRT): adding a response selection phase to the SRT condition;

3) Incompatible choice reaction time (CRTI): adding stimulus-response incompatibility to the CRT condition.

Measurements were obtained from a six-button panel (see fig. 12.1), containing one red button and five white target buttons, laid-out in a $180^{\circ}$ arc, all at $6 \mathrm{~cm}$ distance from the red button. The panel was connected to an Apple II microcomputer via an interface that was developed in our own laboratory. All buttons could be illuminated (stimulus onset) and button presses could be read out by the computer, both with $1 \mathrm{~ms}$ precision. Basically, the subject was requested to hold down the red button with the index finger of the preferred hand as long as no white button was lit. As soon as this happened, he/she was to release the red button and shortly press the lit button (or a button adjacent to it) with the same finger. After the target button had been pressed, the lit button went 


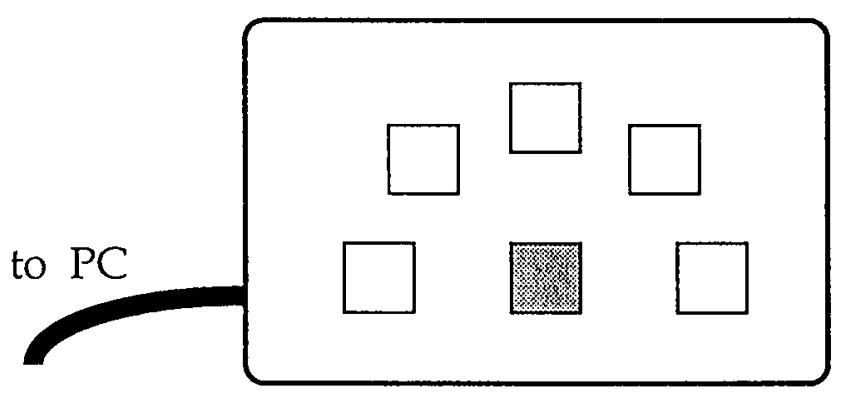

Figure 12.1 Schematic lay-out of the panel for the computerized Motor Choice Reaction Time Test. The subject is asked to hold down the central (red) button, until one of the other buttons lights up. See text for the required actions in the various task conditions.

out and the red button was again to be held down until the next white button was lit. Subjects were explicitly instructed not to release the red button until they were quite sure which white button they were going to press. Four millisecond time registrations per stimulus-response trial occurred:

1) initiation time (ms needed to release the red button);

2) movement time (ms needed to move from the red button to the target button);

3) duration of pressing the target button;

4) reset time (ms needed to move from the target button to the red button).

For the purposes of the present study, only the first two measurements were taken down as raw data.

SRT: only the upper button was lit and the subject was requested to press this button as quickly as possible;

CRT: one of the three upper buttons was lit and to be pressed;

CRTI: similar to CRT, however, the button immediately adjacent (clockwise) to the lit button was to be pressed, instead of the lit button itself.

In the CRT and the CRTI condition, the order of stimulus lights was semirandomly determined (no more than three times the same stimulus in succession), and the same for all subjects.

The instructions were given orally by the experimenter. In many instances, especially in older subjects, the instruction had to be repeated and rehearsed in detail in order to make sure that the subjects had understood the whole procedure. There was a set of at least 15 practice trials per condition immediately preceding the actual test trials. If, during these practice trials, a subject waited for 5 seconds or more to release the red button, or pressed the wrong white button, the trial was repeated before proceeding to the test trials. The subjects were unaware of the transition from practice to test trials. For each condition, the mean, 
median, and standard deviation of initiation and movement times were calculated of 20 test trials. Only the medians per condition were analyzed for the present study, thus allowing for an occasional extremely long initiation or movement time.

\subsection{Results}

Tables 12.1 and 12.2 summarize the mean scores per test parameter in all age groups of BLE-unaffected or BLE-affected subjects. In figure 12.2, mean reaction and movement times are plotted.

Different task conditions. In the vast majority of the subjects CRT was slower than SRT (see table 12.1 and 12.2; over all average: 16.2\%), and CRTI was slower than CRT (41.5\%). This was apparent from the effect of repeated measures (SRT, CRT, CRTI): $\mathrm{F}(2,406)=444.65, \mathrm{p}<.001$. To initiate a motor response appears to take longer when there are alternative responses, and even longer, when stimulus and response are incompatible. The same effect of condition was found regarding the movement times: $F(2,406)=30.60, p<.001$, movements in every successive
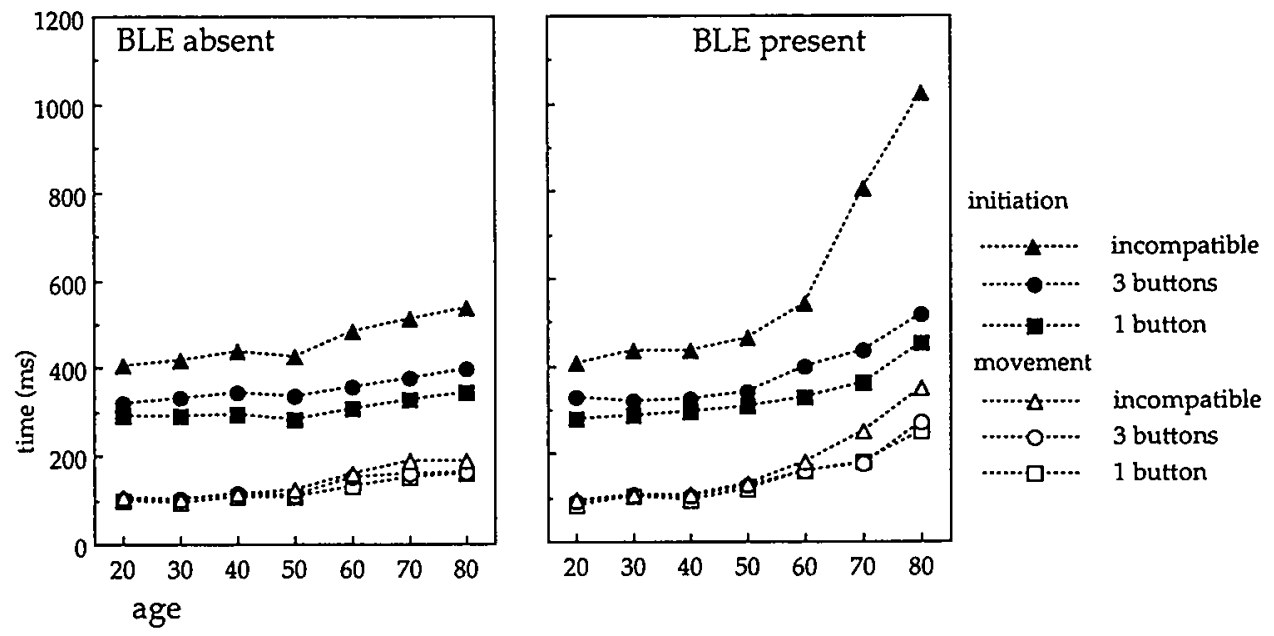

Figure 12.2 Mean reaction and movement times in three conditions of the choice response task, in subjects either without or with biological life events. 
condition taking more time (6.9\% and $10.9 \%$ respectively). As also illustrated by figure 12.2, both the preparation and the actual movement take significantly longer, when response requirements become more difficult, especially when the response is stimulus-incompatible. Errors occurred only in the CRTI condition.

Age effects and interactions. Age-dependent decrements in speed can be observed from figure 12.2. A significant age effect over all three conditions was found for the initiation time in $(F(6,216)=25.53)$, as well as movement time $(F(6,216)=16.03$, $p<.001)$. Age had no effect on the percentage of extra time needed for CRT, relative to SRT (see tables 12.1 and $12.2 ; \mathrm{F}<1$ ), but the amount of delay due to stimulus-response incompatibility was significantly larger in older subjects $(\mathrm{F}(6,216)=10.79, \mathrm{p}<.001)$. Also, there was interaction of age $\mathrm{x}$ repeated measurement of different conditions $(F(12,432)=18.99, p<.001)$. The same effects were found for the movement time (age: $F(6,216)=16.03$, $p<.001$; age $x$ condition interaction: $F(12,432)=5.34, p<.001)$, indicating that motor initiation and execution both took longer in older adults, especially when response requirements are more difficult. Regarding movement times, there was no age effect on the CRT-SRT difference $(\mathrm{F}<1)$, but older subjects showed a significantly increased CRTI-CRT delay. Older subjects made more errors $(F(6,216)=2.65, p<.05)$, but the number of errors was usually very low (mean number of errors 0.3 over $3 \times 20=60$ test trials, $\max .=6)$

Effects of biological life events (BLE). Subjects in the BLE groups were slower in initiating movement $(F(1,216)=23.69, p<.001)$ and carrying it out $(F(1,216)=5.08$, $\mathrm{p}<.05)$. Also, they made more errors $(\mathrm{F}(1,216)=4.99, \mathrm{p}<.05)$. BLE-affected subjects were much more slower than unaffected subjects in CRT and CRTI: $(\mathrm{F}(2,432)=30.40, \mathrm{p}<.001$ (initiation); $\mathrm{F}(2,432)=5.34, \mathrm{p}<.001$ (movement). There was significant age $x$ BLE interaction regarding overall speed in all three conditions $(F(6,216)=7.99, p<.001$; initiation only), and age $x$ BLE $\times$ condition interaction $(\mathrm{F}(12,432)=10.53, \mathrm{p}<.001$; initiation only). All BLE $\times$ age groups were slower in initiating movement, and the difference with BLE-unaffected subjects widened with increasing age. BLE-affected subjects made more errors (mean number of errors was 0.6 vs. 0.2 in the BLE-free group; $F(1,216)=4.99, p<.05$ ). There was no agerelated decline of accuracy in BLE-unaffected subjects.

Sex differences. Female subjects tended to be slower than male: the overall averaged slowing in female initiation time, relative to the males, was $6.9 \%$ $(\mathrm{F}(1,216)=5.40, \mathrm{p}<.05)$; and in movement time women were even $33.9 \%$ slower than men. There was no interaction with age $(\mathrm{F}<1$ for both initiation and movement times), indicating that the sex difference was independent of age. There was, however, interaction with BLE: $F(1,216)=7.69, p<.01$ (initiation) and $F(1,216)=5.78, p<.05$ (movement), the sex differences being larger in the BLEaffected subjects. BLE-unaffected women were even somewhat faster in initiating movements $(3.1 \%)$, but slower in the execution (12.5\%). BLE-affected women however, needed $19.5 \%$ more time to initiate, and $61.6 \%$ more time to execute a movement. It would appear that motor performance in women suffers more from BLE than it does in men. No differences in accuracy due to sex were observed. 
Table 12.1 Mean scores (SD) per test parameter: Biological life events absent

\begin{tabular}{|c|c|c|c|c|c|c|c|}
\hline \multirow[b]{2}{*}{ Condition } & \multicolumn{7}{|c|}{ Age group (N) } \\
\hline & $\begin{array}{r}20 \\
(22)\end{array}$ & $\begin{array}{r}30 \\
(20)\end{array}$ & $\begin{array}{r}40 \\
(22)\end{array}$ & $\begin{array}{r}50 \\
(20)\end{array}$ & $\begin{array}{r}60 \\
(20)\end{array}$ & $\begin{array}{c}70 \\
(25)\end{array}$ & $\begin{array}{r}80 \\
(21)\end{array}$ \\
\hline $\begin{array}{l}\text { SRT } \\
\text { initiation }\end{array}$ & $\begin{array}{l}289.4 \\
(35.7)\end{array}$ & $\begin{array}{l}289.1 \\
(26.8)\end{array}$ & $\begin{array}{l}294.6 \\
(35.3)\end{array}$ & $\begin{array}{l}283.6 \\
(20.4)\end{array}$ & $\begin{array}{l}307.9 \\
(57.7)\end{array}$ & $\begin{array}{l}326.0 \\
(37.9)\end{array}$ & $\begin{array}{l}343.3 \\
(48.7)\end{array}$ \\
\hline $\begin{array}{l}\text { movement } \\
\mathrm{CRT}\end{array}$ & $\begin{array}{c}96.6 \\
(25.3)\end{array}$ & $\begin{array}{c}94.7 \\
(24.4)\end{array}$ & $\begin{array}{l}107.1 \\
(24.4)\end{array}$ & $\begin{array}{l}105.5 \\
(23.3)\end{array}$ & $\begin{array}{l}132.1 \\
(37.3)\end{array}$ & $\begin{array}{l}152.4 \\
(62.5)\end{array}$ & $\begin{array}{c}160.0 \\
(38.4)\end{array}$ \\
\hline initiation & $\begin{array}{l}317.9 \\
(39.4)\end{array}$ & $\begin{array}{l}331.6 \\
(22.7)\end{array}$ & $\begin{array}{l}341.5 \\
(35.1)\end{array}$ & $\begin{array}{l}333.8 \\
(26.4)\end{array}$ & $\begin{array}{l}357.8 \\
(49.0)\end{array}$ & $\begin{array}{l}376.9 \\
(43.1)\end{array}$ & $\begin{array}{c}397.5 \\
(47.6)\end{array}$ \\
\hline $\begin{array}{l}\text { movement } \\
\text { CRTI }\end{array}$ & $\begin{array}{l}103.2 \\
(24.6)\end{array}$ & $\begin{array}{l}100.7 \\
(20.5)\end{array}$ & $\begin{array}{l}113.1 \\
(25.6)\end{array}$ & $\begin{array}{l}112.0 \\
(27.6)\end{array}$ & $\begin{array}{l}149.8 \\
(69.0)\end{array}$ & $\begin{array}{l}159.1 \\
(54.9)\end{array}$ & $\begin{array}{l}163.3 \\
(34.4)\end{array}$ \\
\hline initiation & $\begin{array}{l}405.9 \\
(52.8)\end{array}$ & $\begin{array}{l}418.8 \\
(48.7)\end{array}$ & $\begin{array}{l}437.9 \\
(67.7)\end{array}$ & $\begin{array}{l}426.4 \\
(48.1)\end{array}$ & $\begin{array}{r}483.6 \\
(102.1)\end{array}$ & $\begin{array}{l}512.2 \\
(80.4)\end{array}$ & $\begin{array}{l}538.4 \\
(81.0)\end{array}$ \\
\hline movement & $\begin{array}{l}105.8 \\
(29.2)\end{array}$ & $\begin{array}{l}101.4 \\
(29.7)\end{array}$ & $\begin{array}{l}115.0 \\
(29.5)\end{array}$ & $\begin{array}{l}123.0 \\
(41.9)\end{array}$ & $\begin{array}{l}159.1 \\
(90.0)\end{array}$ & $\begin{array}{l}187.0 \\
(82.2)\end{array}$ & $\begin{array}{c}190.2 \\
(38.3)\end{array}$ \\
\hline Errors & $\begin{array}{c}0.2 \\
(0.4)\end{array}$ & $\begin{array}{c}0.1 \\
(0.3)\end{array}$ & $\begin{array}{c}0.3 \\
(0.7)\end{array}$ & $\begin{array}{c}0.1 \\
(0.2)\end{array}$ & $\begin{array}{c}0.3 \\
(0.4)\end{array}$ & $\begin{array}{c}0.0 \\
(0.2)\end{array}$ & $\begin{array}{c}0.3 \\
(0.5)\end{array}$ \\
\hline
\end{tabular}

Note: SRT: simple reaction time; CRT: choice reaction time; CRTI: choice reaction time with stimulus-response incompatibility. Initiation and movement times in milliseconds.

Education. Education had no significant effect on initiation times (highereducated subjects were $13.4 \%$ faster; $F(1,216)=2.88$, n.s.), but rather surprisingly, it did affect the movement times (higher-educated subjects were $26.2 \%$ faster; $\mathrm{F}(1,216)=4.66, \mathrm{p}<.05)$. None of the interaction terms with education were significant. Thus, irrespective of age, BLE, or sex, subjects who had more schooling, moved substantially faster. Education did not affect the number of errors.

The influence of separate BLE. The present study was not planned to investigate prospectively the effects of individual BLE on motor performance. By consequence, the prevalence of BLE can differ widely over the different age groups. However, correlations between test performance and age, level of education, and BLE can be compared. Spearman's rank order correlations between several measures of performance and age were usually about 0.60 .

Table 12.3 gives correlations between test performance and age, education, number of experienced BLE, and those BLE that yielded at least one significant correlation. Although these values are statistically significant, both age and education leave a considerable amount of variation unaccounted for. The number of BLE the subjects had experienced during their lives appeared to 
Table 12.2 Mean scores (SD) per test parameter: Biological life events present

\begin{tabular}{lccccccr}
\hline & \multicolumn{7}{c}{ Age group (N) } \\
\cline { 2 - 7 } & 20 & 30 & 40 & 50 & 60 & 70 & 80 \\
Condition & $(9)$ & $(9)$ & $(12)$ & $(15)$ & $(15)$ & $(17)$ & $(20)$ \\
\hline SRT & & & & & & & \\
initiation & 281.1 & 288.1 & 294.1 & 307.1 & 330.0 & 360.7 & 451.6 \\
& $(28.0)$ & $(45.7)$ & $(31.7)$ & $(32.6)$ & $(38.1)$ & $(108.7)$ & $(164.7)$ \\
movement & 83.8 & 103.2 & 95.7 & 121.0 & 158.7 & 180.4 & 249.8 \\
CRT & $(18.6)$ & $(24.2)$ & $(21.5)$ & $(29.7)$ & $(61.1)$ & $(98.0)$ & $(140.4)$ \\
initiation & 329.6 & 320.3 & 325.9 & 341.3 & 397.7 & 435.2 & 515.8 \\
& $(37.0)$ & $(48.0)$ & $(29.3)$ & $(37.7)$ & $(45.0)$ & $(140.9)$ & $(173.8)$ \\
movement & 91.8 & 105.4 & 101.6 & 129.5 & 161.3 & 176.4 & 270.9 \\
CRTI & $(23.3)$ & $(26.2)$ & $(17.5)$ & $(27.4)$ & $(52.3)$ & $(85.4)$ & $(179.5)$ \\
initiation & 405.9 & 435.8 & 434.3 & 464.2 & 543.4 & 803.8 & 1023.8 \\
movement & $(38.3)$ & $(68.7)$ & $(35.0)$ & $(66.0)$ & $(71.3)$ & $(332.6)$ & $(356.3)$ \\
& 93.6 & 108.0 & 104.8 & 132.9 & 182.3 & 251.2 & 348.1 \\
Errors & $(25.6)$ & $(29.3)$ & $(21.3)$ & $(26.9)$ & $(70.1)$ & $(213.4)$ & $(228.7)$ \\
& 0.1 & 0.1 & 0.3 & 0.1 & 0.5 & 1.0 & 1.4 \\
& $(0.3)$ & $(0.3)$ & $(0.6)$ & $(0.2)$ & $(1.1)$ & $(2.1)$ & $(1.7)$ \\
\hline
\end{tabular}

correlate even weaker. Correlations between performance and other BLE than given in table 12.3 seldom exceeded .10, and did not reach significance.

\subsection{Discussion}

Overall age-related slowing was found in all conditions of a new choice reaction test. This slowing was greatest in motor execution times, whereas slowing in initiation was mainly present in the condition involving stimulus-response incompatibility. Apart from age, sex, education, and most importantly, biological life events (BLE) accounted for a substantial and significant amount of interindividual variance. The finding of slowing of motor preparation processes that is more marked in difficult task conditions is in line with the notion of Spirduso (1980), Welford (1977; 1985), and many others, that motor initiation is a central process and as such vulnerable to the effects of aging.

Much less in line with Welford's reasoning, however, is the finding that the motor execution stage in the choice reaction test presently under discussion, actually shows more age-related slowing than the preparation stage. The average 
Table 12.3 Spearman's rank order correlations of test scores with Age, education, number of experience BLE, and two separate BLE

\begin{tabular}{|c|c|c|c|c|c|}
\hline & Age & Educ & \#BLE & \#anest & \#medic \\
\hline \multicolumn{6}{|l|}{ SRT } \\
\hline initiation & $.501^{* *}$ & $-.277^{*}$ & $.190^{*}$ & $.221^{*}$ & $.349^{*}$ \\
\hline movement & $.628^{* *}$ & $-.330^{* *}$ & $.159^{* *}$ & $.243^{* *}$ & $.365^{* *}$ \\
\hline \multicolumn{6}{|l|}{ CRT } \\
\hline initiation & $.613^{* *}$ & $-.272^{* *}$ & $.171^{* *}$ & $.183^{* *}$ & $.376^{4 *}$ \\
\hline movement & $.625^{* *}$ & $-.374^{* *}$ & $.138^{*}$ & $.263^{* *}$ & $.340^{* *}$ \\
\hline \multicolumn{6}{|l|}{ CRTI } \\
\hline initiation & $.664^{* *}$ & $-.215^{* *}$ & $.283^{* *}$ & $.261^{* *}$ & $.418^{* *}$ \\
\hline movement & $.676^{* *}$ & $-.350^{* *}$ & $.134^{* *}$ & $.191^{* *}$ & $.389^{* *}$ \\
\hline
\end{tabular}

Note: Educ: education, scored according to Verhagen (1964); \#BLE: number of BLE experienced by a subject; \#anest: weighed score of general anesthesia; \#medic: number of different medications, taken regularly. ${ }^{*} p<.05,{ }^{* *} p<.01$, t-test, two-tailed.

initiation times of subjects aged 70-80 compared to those of subjects aged 20-30 were $28 \%$ slower in the SRT condition, $32 \%$ slower in the CRT condition, and 70\% slower in CRTI condition (see the method section for description). By contrast the corresponding percentages for the movement times were $93 \%, 89 \%$, and $134 \%$, respectively. Close inspection of the data of Spirduso and Clifford (1978) reveals that movement times in old men are also more slowed down than reaction times, although the age differences were less marked than those found in the present study. A study by Era et al. (1986) reveals roughly the same pattern: age-related slowing in movement times was at least as large as the slowing in reaction times, depending on the task conditions. The most likely explanation seems that part of the response preparation takes place during the actual movement from the button-to-be-held-down to the target button. This would also explain why the movement time is also affected by the condition, a finding that is also inconsistent with the notion of Frowein and Sanders (1978), that the initiation time reflects all of the response preparation, as expressed by Fitts (1954). Although the subjects were instructed not to respond until they were sure about which button they were going to press, many subjects seemed to hesitate during both preparation and movement. This indecisiveness was particularly apparent in older subjects, especially women. This, in turn, is in line with Botwinick's (1977) notion that elderly subjects tend to be more cautious and therefore take longer to respond.

Another explanation for the greater proportion of delay in movement time might be that movement of untrained elderly subjects are generally much slower than young, often trained subjects. Era et al. (1986) found significant slowing of tapping and knee-extension speed in a population study. Spirduso and Clifford (1978) replicated Spirduso's (1975) finding that reaction and movement times 
were directly related to the level of physical activity their subjects engaged in. Old racketball players were only $7 \%$ slower in reacting, and $5 \%$ slower in moving than young racketball players. Taking the absence of BLE as a rough indication of physical health, correcting for BLE markedly reduces the age-related slowing of reaction times to $15 \%, 19 \%$, and $27 \%$, and of movements to $63 \%, 58 \%$, and $81 \%$ for the three successive conditions. Subjects for the present study were not selected for physical training. It is supposed that rigorously selecting subjects based on physical activity, will further reduce the age differences. An extensive study to test this hypothesis is currently being prepared.

Landauer (1981) reported that women were faster in decision times, but slower in movement times. Interaction with age was not evaluated. Lahtela, Niemi, and Kuusela (1985) found men to be faster across all age levels, but no sex $x$ age interaction. Sex differences seem to be rarely observed in relation with age in reaction time studies. Spirduso and Clifford (1978), and Era et al. (1986) only investigated performance in men. In a study involving factor analysis, Vrtunski, Patterson, and Hill did not mention sex as an important subject variable. We found that men were generally faster in reaction and movement times in all task conditions. This was only apparent in the older age groups, although the age $x$ sex interaction was not significant. There was, however, substantial BLE $x$ sex interaction, both in reaction times and in movement times. At the CRTI condition, BLE-unaffected women reacted $4 \%$ faster, but moved $17 \%$ slower than men, consistent with Landauer's findings. In the BLE-affected group however, women reacted $26 \%$ and moved $86 \%$ slower than men. Further research will be aimed at the nature of this BLE $x$ sex interaction.

Subjects who had received more schooling consistently were faster in reaction and movement times. At the SRT, CRT, and CRTI conditions respectively, they reacted $11 \%, 9 \%$, and $16 \%$ faster, and moved $22 \%, 24 \%$, and $30 \%$ faster. As there were no interactions, it is concluded that this education effect is independent of age, sex, or BLE. In the study by Era et al. (1986), education was one of the most important covariants, the highest correlation being -.328 , with movement in a visual CRT condition. In our study, the highest correlation was -.396 (also movement time in the CRT condition). There seems to be no intrinsic reason why education should be related to speed of movement. It might be that higher educated people adopt a 'life style' enabling them to be more physically fit. Another possibility is that higher educated subjects are better motivated to perform well in an experimental setting, instead of needing monetary incentives.

The MCRT appeared to be easy to administer and very sensitive to a number of subject variables. Moreover, the instructions are generally well understood, even by neuropsychological patients with severe disorders. It has already proven its value in clinical settings (Brand, Van Wijk, and Hijman, 1990). Curran, Wattis, and Hindmarch (1989), and Mahurin and Pirozollo (1986) have used a similar test (without the S-R element of incompatibility, however) with demented patients. Thus, choice reaction tests seem to constitute a useful paradigm in assessing dysfunctions in neuropsychological patients, and in studying age-related decline of planning and execution of motor responses. 



\section{Age-DifferenCes IN TEST PERFORMANCE: BeyOND THE Single TEST PARADIGM}

\subsection{Introduction and method}

In chapters 5 through 12, a large amount of data was presented, gathered with a variety of tests. These tests are thought to evaluate specific cognitive functions. Therefore, they were dealt with separately: in each chapter a specific aspect of cognitive functioning was discussed as it is affected by age, biological life events, or other personal variables. However, it is likely that different tests draw upon the same cognitive functions, or that one test taps an array of different abilities. It has been stated in chapter 1 that analyzing these complex relationships is beyond the scope of this thesis. However, some issues can be considered in this chapter without much further analysis. Furthermore, some group differences based on background variables (see section 3.2) can be presented.

The major purpose of the present chapter was to arrive at some preliminary approach of particular functions that can be regarded as the common denominator of different tests or test parts that have been used in the present thesis. For this purpose, a drastic reduction of the amount of data was required to compare different cognitive functions. This was achieved by composite scores of test performance. Four main areas of cognitive functioning were identified: 1 . memory; 2 . cognitive speed; 3 . sensomotoric speed; 4 . accuracy. Other functions were only evaluated by one single test, and therefore need no further discussion than their treatment in the experimental chapters 5-12.

For each of the areas of cognitive functioning, some core variables were used (see table 13.1). It is not our claim that the present reduction into these four main areas of cognitive functions is the only possible, or even the single best one. First of all, large and important areas of cognition have not been taken into consideration in the present thesis. Secondly, the taxonomy of cognitive functions is far from unequivocal. Some aspects of test performance could be categorized under two main areas. For instance, the speed of the memory scanning process (chapters 6 and 7) can be said to belong to 'cognitive speed', but the scanning of the short-term memory is clearly also a memory-related activity. Finally, it could be argued that other test parameters should be included in the four sets that comprise the four function domains sketched above, or that some of them should be left out. However, within the limits of the present thesis we have found our present choice the most practical. Its rationale will now be shortly addressed to. There was only one reliable measure of memory used for the present research: Digit and Block Span tests (chapter 5) appeared not very reliable. Therefore, the first main area -memory- contained three parameters of one complex learning test, the Auditory Verbal Learning Test (chapter 8). Nevertheless, the three parameters were thought to represent different aspects of secondary memory functioning: maximum capacity, average immediate recall, and retrieval 
Table 13.1 Composite performance scores and core variables

\begin{tabular}{ll}
\hline Composite score & Core test variable \\
\hline Memory & Auditory Verbal Learning Test (ch. 8): \\
& 1. maximum recall \\
2. total recall & 3. delayed recall \\
Cognitive speed & 1. Slope of Memory Scanning test (letters; ch. 7) \\
& 2. Stroop interference (ch. 9) \\
3. Concept-shifting interference (ch. 10) \\
4. Complex reaction time (ch. 12) \\
Sensomotoric speed \\
1. Basic speed of P\&P memory scanning test (ch. 7) \\
2. Reading speed in Stroop test (ch. 9) \\
3. 0-task of Concept-Shifting test (ch. 10) \\
4. Mean intercept of tapping test (ch. 11) \\
5. Simple reaction time (ch. 12) \\
6. Movement speed (ch. 12). \\
Numbers of error in simple parts of: \\
1. Memory Scanning Test (ch. 7) \\
3. Stroop I (ch. 9). \\
2. Concept-Shifting Test part A (ch. 9)
\end{tabular}

of consolidated material.

Cognitive speed, the second main area of cognition, consisted of four essentially different processes. These had in common that the amount of extra time they required was measured, relative to some more simple condition of the test with which it is evaluated. The slope of the Paper-and-Pencil Memory Scanning Test (chapter 7) reflects the effect of memory load on the speed with which primary memory is searched. Stroop interference (chapter 9) is the amount of extra time needed to suppress obtrusive but irrelevant information. Concept-Shifting interference (chapter 10) denotes the additional time needed when the subjects is to alternate between two familiar patterns, instead of following just one. Finally, the time difference between simple and complex reaction time conditions (chapter 12) reflects the amount of extra time spent initiating a response that is incompatible with the stimulus. These four test parameters were thought to best reflect the speed of cognitive operations as evaluated with the present set of neuropsychological tests.

Sensomotoric speed was comprised of those test variables that were thought to require the least or the simplest cognitive operations. Yet, these test variables all reflect aspects of sensomotoric functioning. The '\%-part' of the Paper-and-Pencil 
Memory Scanning Test (chapter 7) was devised to provide a baseline of sensomotoric processes like visual scanning, to compare this with subsequent part requiring much more cognitive processing. The same goes for the '0-task' of the Concept-Shifting Test (chapter 10). Reading was assumed to be the most automatized of all functions the speed of which was tested with the Stroop Color-Word Test, and requiring the least cognitive effort. The average of both hands' intercept of the tapping slope in the Continuous Performance Tapping Test (chapter 11) was taken as the maximum speed of hand movement, a subject could arrive at. Arm movement and basic reaction speed were tested with the Motor Choice Reaction Time test, in the condition that required the least cognitive effort, thus avoiding possible slowing due to the cognitively complex task requirements.

For the compound accuracy score, three error rates in the Concept-Shifting test (chapter 10), Paper \& Pencil Memory Scanning Test (chapter 7), and Stroop ColorWord Test were compiled. The most simple parts of these tests were used to ensure that a possible high error rate could not be attributed to factors other than lack of pure accuracy. For instance, omitting some targets in the Memory Scanning Test can be caused by faulty recall of the memory set, instead of overlooking the targets. In older subjects, it often happens that one target out of a set of four is forgotten.

To be able to compare the relative performance on this variety of test outcomes, the individual scores on these parameters had to be standardized. For this purpose, $\mathrm{Z}$-scores were calculated relative to the performance of the healthy young adults aged 20-30, who had not experienced any BLE. For each of the abovementioned areas of cognitive functioning, an average Z-score was calculated: a compound function score. The four resulting scores were used as compound representations of the four areas. These variables were used for further analysis.

\subsection{Results}

Means and standard deviations per age group are given in table 13.2, for all subjects in the sample, and with subdivision for BLE and education in table 13.3.

\subsubsection{Memory}

The test scores of which the memory score was assembled, were highly interrelated. Table 13.4 gives the correlations, irrespective of age, BLE, or any other variable, for all 247 subjects. For the sake of completeness, the compound memory score is included. As the test scores showed high correlations, it is not surprising that the memory score is closely related to any of them. All correlations were significant beyond the $p<.001$ level ( $t$-test).

An ANOVA on the memory score (with age, BLE, education, and sex as main effects) showed the results that are familiar from chapter 8 . Older subjects showed poorer performance $(\mathrm{F}(6,217)=14.10, \mathrm{p}<.001)$. This was also true for BLE-affected subjects $(F(1,217)=107.28, p<.001)$, and less-educated subjects $(F(1,217)=6.43, p<.05)$. 
The only significant interaction was between age and $\operatorname{BLE}(F(6,217)=9.30, p<.001)$, indicating that older BLE-affected subjects showed poorer performance than their unaffected age peers. The standard deviation of the memory score in BLE-free subjects aged $20-30$ was 0.88 (by definition, the mean is zero). Of all BLE-unaffected subjects aged 50 , there were 7 out of 20 who had a Z-score of less than -1 . Nine out of $15 \mathrm{BLE}$-affected subjects fell into this range, and three of them even scored below $Z=-2$. The difference between the distribution of $Z$-scores within the BLEfree and the BLE-affected group was not significant by Pearson's Chi-square test. For the older age groups, the differences between the groups of subjects with and without BLE were larger. Of the subjects aged 60, nine subjects without BLE scored below $Z=-1$ (none below $Z=-2$ ), whereas $14 / 15$ of the other group did, and five scored below $\mathrm{Z}=-2\left(\mathrm{Chi}^{2}=22.07, \mathrm{df}=5, \mathrm{p}<.001\right)$. In BLE-free subjects aged 70 and 80 , $11 / 25$ and $8 / 21$ subjects respectively scored below $Z=-1$, and two subjects aged 80 below $Z=-2$. Sharply contrasted to this, 36 out of 37 BLE-affected subjects showed $\mathrm{Z}$-scores below -1 , and all but two below $\mathrm{Z}=-2$ (two of them as low as -7). Some subjects aged over \pm 50 scored above the mean of young adults: 22/86 BLE-free subjects and 3/67 BLE-affected subjects.

Crook et al. (1986) have proposed some diagnostic criteria for what they termed 'Age-Associated Memory Impairment' (AAMI; see chapter 1, section 1.2). One of these criteria was: a score on some well-known memory test, that falls beyond one standard deviation of the average of young healthy adults*. It can be seen that the 'memory score', being a Z-score relative to the performance of health young adults, is applicable for the AAMI-criterion. It could serve to assess how

Table 13.2 Mean Z-scores (SD) of compound measures of cognition, relative to normal young adults, who had not experienced BLE.

\begin{tabular}{lccccccc}
\hline & \multicolumn{7}{c}{ Age group } \\
\cline { 2 - 8 } & 20 & 30 & 40 & 50 & 60 & 70 & 80 \\
\hline$N$ & 31 & 29 & 34 & 35 & 35 & 42 & 41 \\
Memory & 0.0 & -0.4 & -0.9 & -0.9 & -1.4 & -1.6 & -2.4 \\
& $(1.0)$ & $(1.3)$ & $(1.3)$ & $(1.1)$ & $(1.2)$ & $(1.7)$ & $(2.3)$ \\
Cognitive speed & 0.1 & -0.6 & -1.1 & -1.3 & -1.6 & -4.1 & -5.1 \\
\multirow{3}{*}{ Sensomot. speed } & $(1.2)$ & $(1.6)$ & $(1.6)$ & $(1.6)$ & $(1.8)$ & $(4.5)$ & $(4.1)$ \\
& 0.1 & -0.2 & -0.6 & -0.8 & -2.2 & -2.6 & -4.4 \\
Accuracy & $(0.9)$ & $(1.0)$ & $(0.8)$ & $(1.1)$ & $(1.6)$ & $(2.2)$ & $(3.6)$ \\
& -0.2 & -0.1 & -0.2 & -2.5 & -2.3 & -8.4 & -8.9 \\
& $(1.8)$ & $(1.7)$ & $(1.3)$ & $(4.9)$ & $(3.7)$ & $(10.3)$ & $(8.9)$ \\
\hline
\end{tabular}

*Three important other criteria are: 1 . Subjective memory complaints; 2 . Age over $50 ; 3$. No major pathology regarding the brain or psychopathology. 
Table 13.3 Z-scores (see table 13.2), subdivided for level of education and BLE.

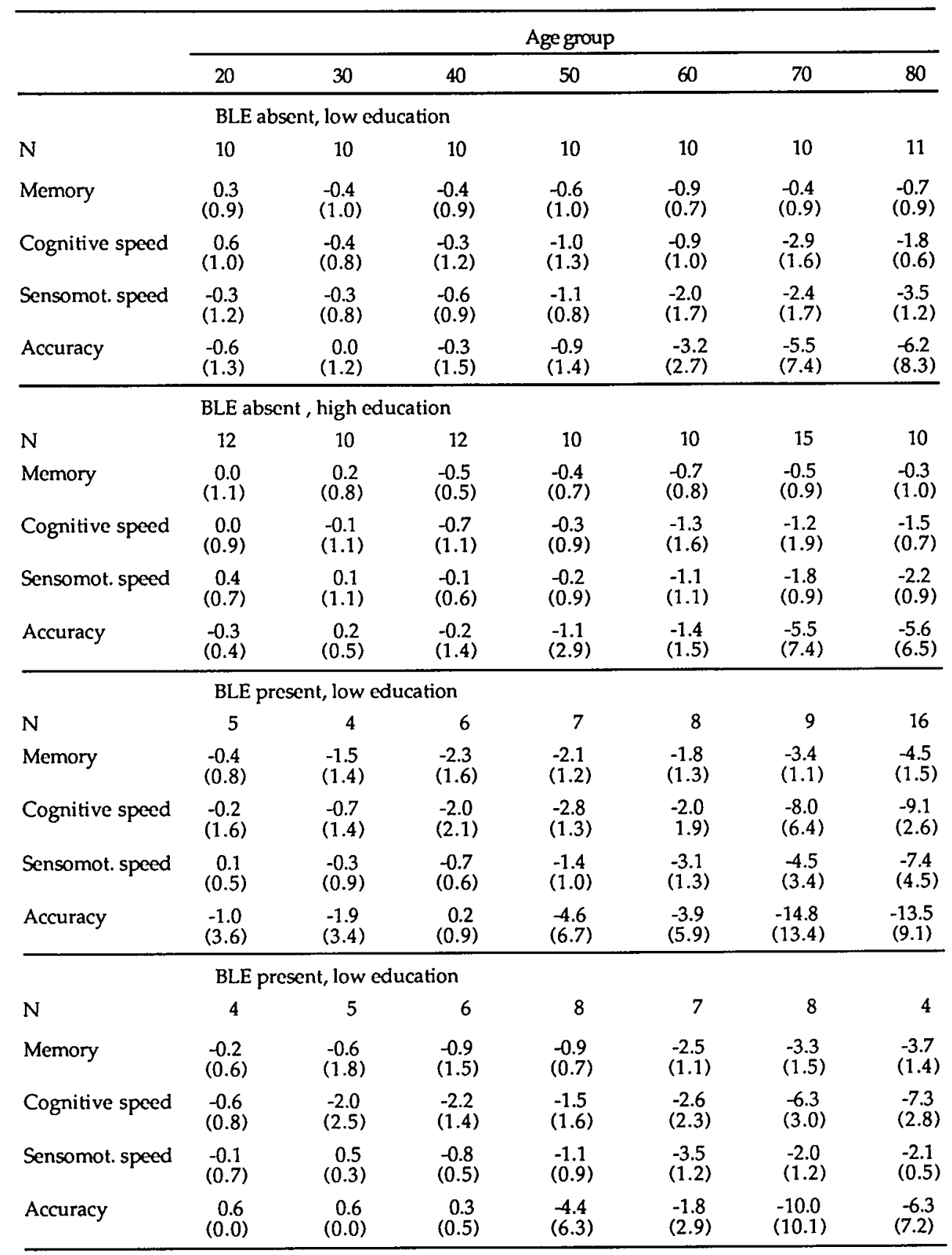


Table 13.4 Correlations among memory measures

\begin{tabular}{lccc}
\hline & Max.Rcl & Tot.Rcl & Del.Rcl \\
\hline Maximum recall & & & \\
Total recall & .904 & & \\
Delayed recall & .838 & .829 & \\
Compound score & .958 & .951 & .943 \\
\hline
\end{tabular}

many of the subjects would fall into the AAMI-range. The cut-off value of minus one Z-score has met some criticism as being too rigorous: too many normal subjects would fall into the AAMI-range. Within the present sample, 59 out of 67 BLE-affected subjects aged about 50 and over, would be judged impaired, and also 35 out of 86 BLE-unaffected subjects. However, this cut-off value can be lowered to, for instance, $Z<-2$. In that case $48 / 67$ BLE-affected subjects are impaired, and only 3/86 BLE-free subjects. It would appear that this adjustment of the cut-off score enhances the feasibility of the AAMI-criteria.

In chapter 3, some individual background variables have been discussed: the amount of time spent participating in each of six activities: reading, brain teasers and other puzzles, club membership, watching TV, sports, and other hobbies. These variables were recorded in the $60-80$ years old. Significantly more subjects who obtained a high memory score, spent much time reading (Chi2 $=59.82, \mathrm{df}=24$, $\mathrm{p}<.001)$, with puzzles $\left(\mathrm{Chi}^{2}=51.17, \mathrm{p}<.001\right)$, or sport $\left(\mathrm{Chi}^{2}=37.58, \mathrm{p}<.05\right)$. Participating in other hobbies or clubs, or watching TV was not associated with differences in test performance.

\subsubsection{Speed of cognitive processing}

Several aspects of test performance are dependent on the central information processing rate, i.e., those aspects of performance that do not rely on sensomotoric processes. As was discussed in section 2.2.2, these processes can be inferred from the difference in time needed for different conditions of some otherwise identical task. Correlations between some of these measures are given in table 13.5. With $n=247$, correlations greater than .194 are significant beyond the $p<.001$ level. The

Table 13.5 Correlations among measures of cognitive speed

\begin{tabular}{lcccc}
\hline & Stroop Int & CST Int & CRT Int & MST Slope \\
\hline Stroop Interference & & & & \\
Concept Shift Interf & .387 & & & \\
Choice Reaction Interf & .687 & .367 & & \\
Memory Scan Slope & .482 & .298 & .440 & \\
Compound Score & -.891 & -.586 & -.844 & -.704 \\
\hline
\end{tabular}


different scores were not so closely related as the memory scores obtained from the Auditory Verbal Learning Test.

A similar ANOVA as described in the previous section was performed. The compound cognitive speed score was lower in older subjects $(F(6,216)=26.36$, $\mathrm{p}<.001)$ and BLE-affected subjects $(\mathrm{F}(6,216)=78.35, \mathrm{p}<.001)$. No other main effects were observed. Age and BLE interacted $(F(6,216)=10.34, p<.001)$, which can be taken to indicate that cognitive slowing with increasing age was more pronounced in the BLE group.

In subjects aged 50 or 60 , the number of individuals performing worse than one standard deviation below the mean of young adults $(\mathrm{sd}=.533)$ was greater in the BLE-affected groups (9/15 vs. $3 / 20$ and $10 / 15$ vs. $7 / 20$, respectively), but not significantly so (Chi2). This was the case in the groups aged 70 ( $16 / 17$ vs. $14 / 25$; $\left.\mathrm{Chi}^{2}=23.81, \mathrm{df}=12, \mathrm{p}<.05\right)$ and $80\left(20 / 20\right.$ vs. $14 / 21$; $\left.\mathrm{Chi}^{2}=39.29, \mathrm{df}=12, \mathrm{p}<.001\right)$. Very great deviations from the young adult's mean occurred in the BLE groups: some as large as $Z=-15$, or even $Z=-25$.

In theory, the finding of lower correlations between the different measures of cognitive speed means that the tests draw upon different aspects of information processing. In any event, low correlations between test outcomes can be said to justify the use of all of these tests: if they would show near perfect correlation, they would be interchangeable. It may prove fruitful to evaluate the merits of such compound scores for research or clinical practice.

Central processing speed was very much impaired in older BLE-affected subjects. This replicates observations done with single tests. Inability to process information adequately quickly, can be seriously invalidating. Central slowing may constitute as much a serious threat to cognitive validity as memory impairment. It means missing most of the information that is presented to the individual.

The same background variables as observed in the memory score, appeared to be differentially distributed over the subjects whose cognitive speed fell in different classes: reading ( $\left.\mathrm{Chi}^{2}=35.94, \mathrm{df}=15, \mathrm{p}<.01\right)$, puzzles $\left(\mathrm{Chi}^{2}=26.49, \mathrm{p}<.05\right)$, and sports $\left(\mathrm{Chi}^{2}=33, \mathrm{p}<.01\right)$.

\subsubsection{Measures of sensomotoric speed}

Peripheral slowing (that is, slowing of movements and sensory processes) is also a well-described concomitant of old age. The compound measure used here consists of tests of: reading, reaction and movement, and visual scanning speed (see table 13.6 for correlations between the elements). This was found to be impaired in older subjects $(F(6,214)=28.65, p<.001)$, and BLE-affected subjects $(F(1,214)=19.35, p<.001)$. Women were slower than men $(F(1,214)=14.18, p<.001)$, and lower educated subjects were slower than higher educated $(F(1,214)=11.35$, $\mathrm{p}<.01)$. There was age $x$ BLE interaction $(F(6,214)=3.16, p<.01)$, indicating that subjects who experienced BLE suffered more as to their behavioral speed, than their optimally healthy age mates. 
In subjects aged 50, the number of individuals performing worse than one standard deviation below the mean of young adults $(\mathrm{sd}=.533)$ was greater in the BLE-affected groups $\left(12 / 15\right.$ vs. $\left.7 / 20 ; \mathrm{Chi}^{2}=12.68, \mathrm{df}=4, \mathrm{p}<.05\right)$. This was not significantly the case in the older groups. Out of 20 healthy subjects aged 60,10 performed at a level lower than $Z=-1$; for the BLE-affected 60tyears old this number was $12 / 15$. In the groups of subjects of 70 and 80 years old, the ratios were $15 / 25$ vs. $13 / 17$, and $19 / 21$ vs. $17 / 20$ respectively.

Table 13.6 Correlations among measures of sensomotoric speed

\begin{tabular}{lcccccc}
\hline & StroopI & React & Move & CST-0 & MST\% & Tapping \\
\hline Stroop part I & .424 & & & & & \\
Simple reaction time & .479 & .828 & & & & \\
Simple movement time & .578 & .614 & .603 & & & \\
Concept-Shift part 0 & .511 & .536 & .516 & .569 & & \\
Memory Scan part '\% & -.563 & -.481 & -.553 & -.469 & -.485 & \\
Tapping intercept & -.649 & -.892 & -.905 & -.800 & -.736 & .664 \\
Compound score & & & & & & \\
\hline
\end{tabular}

The separate test scores which comprise the compound variable, are more interrelated than those constituting the central speed score. This can be explained by the less complex processes than those occurring in cognitive operations. Although there were differences due to BLE, these were smaller than in the central speed score. Also, the proportion of subjects performing poorly relative to young adults was no greater in older age groups. It is likely that degradation of peripheral processing is much more uniformly present in the aging, than impairments of central processing. It is evident that many old people can function at high levels cognitively, although their physical performance may have much declined. None of the background variables showed any difference regarding sensomotoric speed.

\subsubsection{Accuracy}

It is often thought that people not only become slower as they grow older, but also more cautious, perhaps to compensate for the reduced sensomotoric agility (Botwinick, 1984). This is an intuitively appealing notion. In some of the preceding chapters evidence was found, that, if this increased cautiousness exists at all, it is not replicated by an increased accuracy. On the contrary, on most tests, the average number of errors increased with age.

Table 13.7 gives the correlations among the numbers of errors on the three simple task conditions described above. The resulting compound accuracy score only showed effects of age $(F(6,217)=13.42, p<.001)$ and $\operatorname{BLE}(F(1,217)=8.27, p<.01)$. 
Table 13.7 Correlations among accuracy measures

\begin{tabular}{lccc}
\hline & CST Omissions & MST Omissions & Stroop Errors \\
\hline Concept-Shifting Task omissions & & & \\
Memory Scanning Task omissions & .176 & & \\
Stroop errors & .423 & .187 & \\
Compound score & -.729 & -.742 & -.625 \\
\hline
\end{tabular}

Older and BLE-affected subjects made more errors than younger and BLE-free subjects respectively. There were no significant interaction effects.

Age-associated decline of cognitive and sensomotoric processes did not appear to be positively related to an increased accuracy. Rather, these three variables were all negatively related to age. Furthermore, accuracy was positively related to both cognitive and sensomotoric speed (see table 13.8), also after correction for age and education: in subjects aged 20-30, correlations were .230 and .320, respectively, and in subjects aged 70-80, these values were .469 and .352 ; in less educated subjects .599 and .589 , in more educated subjects .452 and .299 . As was found for sensomotoric speed, none of the background variables showed any difference regarding accuracy.

Table 13.8 Correlations among personal and composite variables

\begin{tabular}{lcccccc}
\hline & Age & Educ & \#BLE & Memory & Cogn.Sp Sensomot. Sp \\
\hline Memory & -.442 & .319 & -.467 & & & \\
Cognitive speed & -.511 & .251 & -.392 & .601 & & \\
Sensomotoric speed & -.598 & .443 & -.256 & .530 & .470 & \\
Accuracy & -.485 & .308 & -.191 & .446 & .564 & .528 \\
\hline
\end{tabular}

\subsection{Discussion}

All four compound variables (memory, cognitive speed, sensomotoric speed, and accuracy) were significantly affected by age: $Z$-scores relative to the performance of normal subjects, free of biological life events (BLE), showed consistent decline as the subjects' age increased. As can be observed from the average Z-scores in tables 13.2 and 13.3, and from figure 13.1, this age-associated decline was gradual for all functions but accuracy, which declined sharply in subjects aged over 60 . Memory appeared to be the least vulnerable to age: irrespective of BLE, the oldest ( 80 years) 

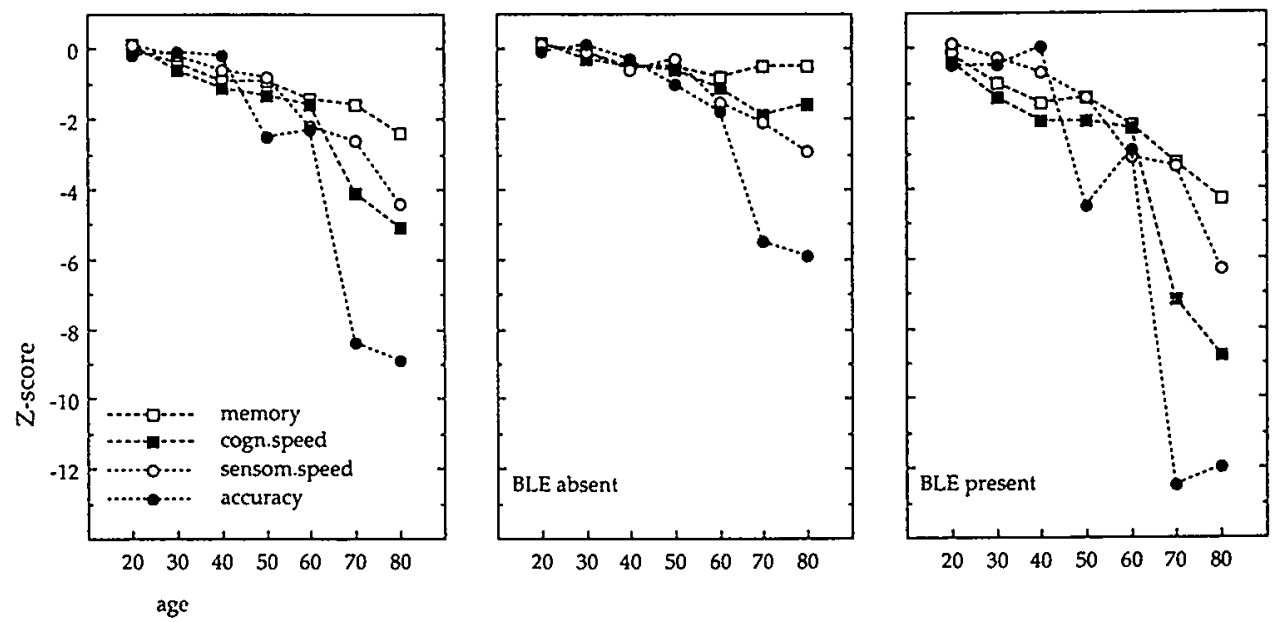

Figure 13.1 Average Z-scores of four compound variables per age group, in all subjects (left), with (middle), and without (right) biological tife events.

subjects' average performance lay 2.4 standard deviations below the mean of BLEunaffected subjects aged 20-30. The average Z-score of the sensomotoric speed was -4.4 , of cognitive speed -5.1 , and of accuracy -8.9. As the latter general area of cognition showed very much inter-individual variability, cognitive speed can be said to have shown itself most vulnerable to age. As age increased, so did the variability of test performance. Again, memory showed the least increment of the standard deviation, followed by sensomotoric speed, cognitive speed, and accuracy.

After correction for BLE, the extent of this decline was greatly reduced, and so was the variability. This was especially the case with the memory score, the average Z-score of which in subjects aged 70-80 was only half a standard deviation below the mean of healthy subjects aged 20-30. Likewise, the individual variability, which increased with age in the whole sample population, was much smaller in subjects who had not experienced BLE. This confirms the findings done with single tests. At the same time, the moderate to high correlations within and among different areas of functioning can be taken to indicate that subjects performing poorly in one test, are likely to do so in another. This, however, remains to be worked-out in detail by further analyses.

In the previous chapters, an effect of education was often found, favoring the higher educated subjects. Also many age $x$ education interactions were observed. 
Of the four compound scores, only memory and sensomotoric speed were found to be affected by education. As for memory, this can be understood by a higher degree of practice in learning new material, or, conversely, by assuming that subjects who learn easily, also have had access to higher forms of education. For the speed of perceptual and motor processes, the effect of education is somewhat more difficult to explain. It was suggested in chapter 11, that higher-educated subjects are perhaps more motivated to perform optimally, or regard speeded tapping performance like a sportive challenge. Another hypothesis might be added: higher educated subjects are probably the more experienced, the better and faster readers. The sensomotoric speed score consisted of, among others, three subtests involving visual scanning (which is likely to be related to reading), and one directly measuring reading speed.

From table 13.3, it can be seen that education cannot explain for all, or even the larger part of the group differences due to BLE: these differences are much larger than the effects of education, or in some instances even calendar age. It can be concluded therefore, that BLE themselves are associated with very substantial differences in cognitive performance, irrespective of age, education, or gender.

It might be hypothesized that BLE-affected normal adults without any major brain damage or disease are the ones that fall within the definition of ageassociated memory decline by Crook et al. (1986). Other evidence for this hypothesis was presented by Reyersen van Buuren et al. (in press). The only objection to this is that subjects in our sample had no subjective complaints about any aspect of their cognitive functioning, that they mentioned spontaneously. Thus, the subjects aged 50 and over from the present sample, meet all but one AAMI-criterion. Within this group, the great majority of the subjects meeting the $Z<-1$ criterion for a well-known memory test, had experienced BLE. In the next chapter, this issue will be discussed further.

The most widely-heard complaint about cognitive functions expressed by the elderly is about secondary memory. However, these complaints may well be secondary to other impairments. Several other functions are needed for adequate memory storage and retrieval. At least two of the other three areas of functioning can, if impaired, result in a memory deficit. To remember what has just been said, hearing must be unimpaired, as too much energy has to be invested in detecting the meaning of the perceptual input. If resources for cognitive processing are much reduced, a subject may still be processing the most recent input, when new material requires resources. Finally, attentional deficits may cause memory complaints, or even impaired test performance on a Verbal Learning Test: if there are lapses of attention during the presentation of a whole array of items, recall is bound to be impaired. Possibly, therefore, the notion of age-associated memory impairment (AAMI) may have to be supplemented by new notions such as an age-associated resource deficit (AARD) or cognitive slowing (AACS), and attentional deficit (AAAD). For the first two age-associated impairment measures, compound measures such as have been proposed above, may serve their purpose. Incidentally, subcategories of AAMI have been proposed (Blackford and LaRue, 1989): age-consistent memory impairment (ACMI) and late life 
forgetfulness (LLF), which would be analogous to benign senescent forgetfulness (BSF; Kral, 1962)

Slow subjects were not more accurate or vice versa. Although the accuracy on one test was a poor predictor for the number of errors in another, the compound accuracy scores indicated a consistent decrease of accuracy with age, coupled by a decreased sensomotoric speed. Therefore, it appears that, given the tests used presently, there is little evidence for a shift in the trade-off between speed and accuracy in cognitive functioning (Botwinick, 1984), if such a trade-off can be observed at all outside the experimental laboratory. We, in any case, found no evidence at all for such a phenomenon.

Salthouse et al. (1988) did not find any association between any background variable and test performance. Our findings did not replicate this. In elderly and old subjects, three background variables (reading, mental exercise, and sports) appeared to be associated with performance on two compound cognitive scores: memory and cognitive speed. Whether there is any causal relationship between these variables, and in which direction this would be, remains unclear. It can be said, that 'mind jogging' may constitute a 'protective factor'. These protective factors have to be interpreted with caution: for example, smoking seems to 'protect' against dementia (Hofman et al., 1991), but it is very probable that some healthy survivor effect must be applicable. The three other variables (watching TV and participating in clubs and other hobbies) showed no difference as to any of the compound variables. For TV and clubs, this is not surprising, as they need not require much cognitive activity of the participant. Even the most impaired patients watch TV nowadays, and being present at a social meeting of the local elderly society can be maintained until very late in life. It would be expected that having hobbies would be associated with adequate cognitive functioning. This was not the case in our sample. Perhaps our way of scoring this variable was too crude. Another possibility is that many elderly subjects called relatively undemanding activities such as embroidering or playing billiard a hobby. This would make hobbies a 'wastebasket' of activities that could not be categorized under one of the other five background variables. 


\section{GENERAL DISCUSSION AND CONCLUDING REMARKS}

In the preceding chapters, a cross-sectional study into several aspects of cognitive aging was described. A large sample of normal healthy subjects was studied. In each of seven age groups from 20 through 80 years, at least ten males and ten females were tested. Significant age-associated decline was observed in all aspects of cognitive functioning that have been studied. Of the four main areas of cognition that were identified, memory showed the least decline, and cognitive speed the greatest. The same was true regarding the age-related increase in variability of test performance. Taking biological life events (BLE) into account much attenuated this decline, however. Subdivision of the total sample of subjects -all regarding themselves normal and healthy- into BLE-free and BLEaffected showed large group differences. Compared to the over-all averaged performance, age differences were much smaller when BLE were absent, and greatly enhanced when they were present. This confirms the data of Haxby et al. (1986) on differences between the visual memory of normal, healthy aging subjects and that of aging groups with health problems. Very few of the separate health-related factors which comprised these BLE could account for a substantial part of the individual differences in test performance. The suggestion made by Salthouse et al. (1988) to record a number of other background variables, such as 'hours spent on reading per day', and 'hobbies', was followed in an adapted version. It appeared that reading, mind games, and sports were associated with both BLE and test performance in old subjects: those subjects who spent considerable time in any of these activities, were less likely to have experienced $\mathrm{BLE}$, or to show extensive age-related cognitive deficits.

\subsection{Age-associated memory impairment}

In the previous chapter, it was suggested that the BLE-affected subjects in the present sample, are characterized by age-associated memory impairment, a condition that was recently defined by Crook et al. (1986). These authors proposed their criteria to bring more clarity in the diagnostic terminology. If many or all researchers would adhere to these well-defined criteria, the measurement of clinical change and the assignment of patients and subjects to various experimental groups for research aims would be greatly facilitated. The summary of most important criteria for the diagnosis of AAMI is given in table 14.1. The reader is referred to the original article for the full list of inclusion and exclusion criteria.

Some of the exclusion criteria mentioned under (6) in table 14.1 are close to our criteria for BLE in the present study, but they are less rigorously formulated. For instance, as to the history of head injury 'repeated' injuries are mentioned, but not how many injuries should be sustained. Furthermore, the cut-off value of 
Table 14.1 Summary of criteria for AAMI (Crook et al., 1986).

1. Age at least 50

2. Subjective complaints about everyday memory with gradual onset

3. Memory test performance at least one standard deviation below the mean of normal young adults

4. Adequate intellectual functioning

5. Absence of neurological or psychiatric pathology that could produce cognitive deterioration.

6. Absence of a number of less well established health factors such as repeated minor head injury or single major injury; history of alcoholism or drug dependence; medical disorders that could produce cognitive disorders; recent history of psychotropic drug usage.

unconsciousness of more than one hour was used for the single injury exclusion criterion. We used a less conservative criterion of post-traumatic amnesia of more than one hour (see section 3.1.4). However, it seems that the exclusion criteria for AAMI were formulated to prevent inclusion of subjects with brain dysfunction that could possibly lead to cognitive dysfunction.

As was shown in the previous chapter, most subjects (and almost all elderly subjects) affected by BLE met the inclusion criteria of AAMI, with the exception that they were not complaining about memory dysfunction. Subjects meeting the exclusion criteria for AAMI should be categorized for the larger part under pathological or even tertiary aging. Although some exclusion criteria for AAMI can overlap some of the criteria used for inclusion in the BLE group, it can safely be stated that most individuals whose pathology is not severe enough to be beyond the AAMI exclusion criteria, but who show evidence of subtle healthrelated factors, would fall into the BLE group as defined in chapter 3 . This suggests that, apart from the subjective complaints, AAMI and BLE may coincide to some extent. Evidence for exactly this hypothesis was published by Reyersen van Buuren et al. (in press), who showed that in subjects meeting the AAMI criteria, the number of BLE-affected subjects was higher than in a randomly selected sample of controls.

\subsection{Implications}

Health care and prevention. As was stated above, the danger of documenting how most people age, instead of how people can age successfully, is that processes that are not intrinsic to age are accepted as 'natural' and in any case inevitable. Confusing the effects of age-extrinsic conditions with aging itself yields an overly pessimistic picture of aging. Not all the conditions can be prevented or cured, but some of them can, to a considerable extent. Conditions involving the brain that are thought to have disappeared or be cured completely when the patient no 
longer complains, or the CT-scan no longer shows any anomalies, could form the substrate of the long-term effects of BLE.

One very important area of where age-extrinsic factors could be circumvented is anesthetics. The number of operations under general anesthesia was the BLE that was most closely associated with age-related decline of several cognitive performance in the present study. If it can be reproduced, this finding should, in our view, have impact on the policy regarding anesthetics. Surgeons and patients should not imprudently favor general anesthesia over local anesthesia. Every narcosis counts.

Another area of health care that can profit from findings like these is medication. If future research confirms the present finding of association between certain types of medication and behavior, clinicians should be more cautious in their prescription of medication, sleeping pills for instance. The role of medication that can affect consciousness in cognition, their long-term effects and the interaction of these effects with aging are insufficiently understood (Hartman, 1988). It is possible that old people are more vulnerable to the effects of benzodiazepines, and that its dosage should be adapted, or preferably, if possible, abolished completely. Every sleeping pill counts.

Repeated mild head injuries are yet another category of BLE the frequency or severity of which could be reduced. It is now more or less agreed upon, that head injury cannot be assumed to go by without any repercussion to brain functioning (Binder, 1986; Bohnen et al., 1991). Certain sports should be restrained by tighter safety measures and regulations. Boxing should be abolished, in any case punches 'above the collar'. Every knock-out counts.

Exposure to neurotoxic agents in individuals' profession for instance, is a factor that has fortunately gained interest of many researchers (Ganzevles and Jolles, 1989; see Hartman, 1988, for an extensive survey of the issue). However, much remains to be done to increase safety for craftsmen such as roofers or carpet-layers who can -more often than not- be observed without any protection against inhalation of organic solvents or other toxic substances. Even for do-ityourselfers, this matter can be of importance. Anyone who has ever varnished a parquet floor will have experienced some 'lightness in the head', after having spent some hours above vaporizing solvents. As this dizziness disappears after some time in the open air, and nothing is known about the impact of exposure of such short duration, little attention is paid to this phenomenon by the individual and researchers.

\subsubsection{Research of aging and dementia}

The present findings may have serious implications for virtually all cognitive aging research (Houx et al., 1991b, c). In the vast majority of studies on cognitive aging, normal subjects are not explicitly screened for factors related to physical or mental health. It seems likely, therefore, that many of the effects of aging reported in the literature result from age-extrinsic factors, of which BLE, as investigated in the present study, may be a good example. It is very probable that all aging studies 
will have included BLE subjects in their groups of nondiseased, usually aging subjects, when the subjects were not thoroughly screened for health as they were in the study of Haxby et al. (1986) or in the present study.

In future research on aging and cognitive functions, a rigorous health screening of subjects for any factor that is known or likely to be associated with changes in brain functioning, should be part of the experimental procedure. This is also the case for neuropsychological studies. After all, as brain-behavior relationships constitute the basis of neuropsychology, it is important to have information about the condition of the brain, the complex functions of which are being studied.

It might be argued that by discarding the secondarily aging subjects, no insight is gained into the actual distributions of the variables under investigation. Whether this argument applies, depends on the research question. For most purposes, however, the implicit or explicit aim is to study primary, that is cognitive aging, unaffected by any other factors. In those cases, the actual demographic distributions are irrelevant since all BLE-affected subjects should be excluded. Whether the result of these studies is representative for the whole aging population, is quite another matter.

The generalizability to the whole aging population of such research is probably low. However, research of this kind may constitute an important step in gaining knowledge about the nature of primary and -if subjects selection is based on separate BLE- of secondary aging, especially when carried out on a prospective basis. Most of the BLE are also accepted as risk factors for dementia, when they are more severe than defined in chapter 3. The work of Amaducci et al. (e.g., 1986) is relevant in this respect: these authors found a significant relationship between clinically diagnosed Alzheimer's disease and a number of the factors that we identified as BLE. If indeed BLE are mild forms of conditions that can actually produce severe disorders of cognition, or even dementia, then it can be envisaged that the presence of one or more BLE is a risk factor for pathological or tertiary aging per se (type 3 and 4).

The question regarding determinants of age-related memory dysfunctions and possible determinants of further deterioration into dementia-like conditions is of great importance because of the complete lack of information on this topic and its implications for health care via early detection and early intervention.

BLE might be thought of as bruises or marks on the brain. The effect on brain functioning of a single BLE may be minimal, as the bruises are too slight. Only severe single brain damage can have perceivable effects on cognitive functioning. However, if the number of bruises increases with age, so does their combined effect. If the effects of BLE are indeed additive, then their impacts on cognition will become perceivable beyond some threshold value. Consistent with the notion of increased vulnerability (Rabbitt, 1990), this threshold probably declines with age, as an age-intrinsic process of primary aging. This would explain why the effect of BLE on the average cognition scores was found to be larger in older subjects, and why in many cases the number of experienced BLE could equally well predict cognitive performance as age per se. 
It is sometimes suggested that the outcomes of the present study are trivial, as it is very obvious that aging is the combined effect of all noxious influences on the individual. This is an interesting viewpoint, avowed by some, but lived up to by hardly anyone: it was observed above that only very few researchers pay more than superficial attention to the health status of their supposedly normal and healthy subjects.

Another criticism that is sometimes expressed is that we did not pay enough attention to the 'nosological entities' of the conditions from which our subjects suffered. This argument would be valid if it was not for the fact that all our subjects (also those in the BLE-affected group) regarded themselves as healthy, normal, and were free of complaints. Moreover, by any standard used in the experimental aging literature, our subjects would be assigned to a normal, healthy group. Our subjects did not suffer from anything. The reply to this criticism is at the same time the crux of the present thesis: after a subdivision of normal subjects based on subtle health-related factors, clear differences in cognitive performance can be observed, and these differences increase with age.

Finally, we have often been reproached for not having controlled for general intelligence. The basis for this argument is that poor cognitive performance and BLE share some common cause: lower intelligence, for example, might also explain performance differences, and at the same time render individuals more likely to experience some BLE. This cannot be excluded, but can hardly be the only explanation, since the average level of education did not differ significantly between the groups of BLE-unaffected and BLE-affected subjects in any age group (see table 3.1).

\subsection{Background variables}

It was found that poorly performing elderly subjects were over-represented in those groups of individuals who did not spend any time (or not much) in the following activities: reading, sports, and mind puzzles. No definite conclusions can be drawn from this finding, as the possibility of it being an artefact of the method of subject selection can not be ruled out. At best, it can be regarded as circumstantial evidence. It remains possible that elderly individuals who spend little or no time with cognitively demanding activities, do not do so because of their inabilities. Most likely, both possibilities have some validity. Conceivably, engaging in much mental activities ('mind jogging') is the opposite of a risk factor: a 'protective' factor against age-associated cognitive decline: 'use it or lose it'. Much further research can and should be addressed at this topic. 


\subsection{Longitudinal follow-up}

Early 1992, the first subjects who were tested in the present study will be re-tested. Only by this longitudinal approach, several issues can be further investigated in the same subjects:

1. Does the poorer average test performance observed in BLE-affected subjects represent an enhanced effect of aging, in that the presence of BLE portends a more rapid decline over time?

2. Are there different individual patterns of cognitive aging to be discerned (cf. Rabbitt's (1990) notion of individual trajectories)?

3. Can risk factors and protective factors for age-associated cognitive impairments be established?

4. What part of the age effects found in the present study can be attributed to age as such, and what part should be ascribed to cohort effects?

A follow-up study with a very large number of subjects $(\mathrm{N}=3360$, in 14 discrete age groups of 240 subjects from age 20 to 85 ) is being planned in order to study possible differential interactions of cognitive aging with BLE and other variables. Among other things, this research will be aimed at determining the prevalence of BLE in the aging population. This study is called 'The Netherlands Memory and Aging Programme 1991-1995'. It will serve as a basis for longitudinal (crosssequential) study that will end in the year 2006 (Jolles, 1991). Important topics will be:

1. The nature and prevalence of subjective problems with memory and other cognitive functions, in relation to compensatory behavior. Measures to evaluate subjective complaints about cognitive functions and coping behavior will have to be developed or translated, and validated.

2. The mechanisms of age-associated cognitive decline (global or specific deterioration).

3. The relevance of minor health-related factors in their relation to complaints and objective dysfunctions in memory and memory-related functions.

4. Information concerning the prevalence of the various health-related factors in relation to age and normal/subnormal cognitive functioning.

5. Establishing a large corpus of information on subject variables (healthrelated factors and psychosocial factors), cognition and age in order to be publicly used.

6. Foundation of a basis for longitudinal research into "predictors for pathological cognitive aging" and "predictors for healthy cognitive aging".

Experimental research into cognitive gerontology has traditionally made use of a cross-sectional design in which different age-cohorts were compared in their performance on cognitive tests. The use of the cross-sectional design is usually motivated by the fact that they are the most practical and least expensive. Nesselroade and Labouvie (1985) in their discussion of experimental designs on cognitive aging, compare cross-sectional designs to longitudinal designs. Longitudinal designs allow the study of intra-individual changes. They are, 
however, not insensitive to confounding variables such as time-of-measurement effects or what might be termed Zeitgeist. The cross-sequential design combines both approaches. It is attractive to developmentalists because it allows the experimental study of intra-individual change in reference to a wide age span over a relative short time period. Regrettably, this approach of the crosssequential design has yielded very little data on cognitive aging. Rabbitt's (1986, 1990) research, that of Zappala (1990) and the Maastricht Memory Project (Houx et al., 1989; 1991) have set out to be followed-up, as are probably more cross-sectional studies. However, attending many workshops and symposia on longitudinal research learns us that the status of large-scale cross-sequentially gathered knowledge has seldom gone beyond good intentions.

\subsection{Normality}

The finding of large individual differences in a group of subjects, who can be regarded as normal by any standard used in the experimental literature, raises the issue of normality. Recently, this matter has gained some interest. Rowe and Kahn (1987) published an influential review regarding normality in biological, psychological and social aging. They stated that in a wide range of scientific disciplines, it is tacitly assumed that individuals who are not diseased, are therefore normal and healthy. In their opinion, too little attention is being paid to the increase with age of the variability of the parameter of interest, not only in the area of cognition*. Howe, Stones, and Brainerd (1990) edited a book on the subject of atypical aging. Atypical aging is the result of conditions that not all aging subjects experience, but are secondary rather than primary. Characteristics of aging that are essential to the aging are regarded as primary (Birren and Cunningham, 1985; Salthouse, 1990). Secondary conditions are all too often closely associated with aging, because their effects are greater in old age (due to increased vulnerability, longer exposure, or reduced resistance). Understanding secondary aging can eventually lead to understanding primary aging, i.e., those processes that are unavoidably concomitant of aging. As was stated in chapter 1 , distinguishing secondary from primary processes can be of great importance, both to the individual and to society. Conceivably, a number of age-extrinsic conditions can be prevented, diminished, or even eliminated (Rabbitt, 1990).

What can be regarded as normal? Salthouse (1990) employs an operational definition: observations or entities can be regarded as typical if they fall within some fixed boundaries, for instance, inside the middle $90 \%$ of their distributions. Anything outside these boundaries would be irregular, out-of-the-ordinary. In fact, all terms like usual, regular, or ordinary imply some reference to a distribution of values. Of course, such an operational definition is only practical. It does not help us in theorizing about the nature of the processes to which such

*Recently, this view was once again confirmed by Ligthart (1989) with respect to the immune system. He found less disorders of the immune system in a subpopulation of healthy elderly subjects, who met very strict inclusion criteria. 
typicality or a-typicality should be ascribed. Moreover, it could be an invitation to accept the actual distribution as normal.

Rowe and Kahn (1987), and more recently, Stones, Kozma, and Hannah (1990) advocate a clear distinction between usual and successful aging. These are two types of primary aging, that is, disease-free. The notions of usual and unsuccessful resemble that of (a-)typicality as advocated by Howe et al. (1990) and Salthouse (1990), but with the important difference that the judgement of success depends on the parameter by which this success is being measured. According to Rowe and Kahn (1987) and Stones et al. (1990) merely distinguishing between nondiseased and diseased aging has serious limitations. Most importantly, the heterogeneity in the non-diseased elderly group is neglected. Furthermore, this notion of the normality of usual aging implies the harmlessness of several possibly health-threatening factors, such as BLE. Finally, normality implies that what is usual is also natural, and cannot -or even should not- be modified. This notion of 'normality' puts too large an emphasis on studying the level of functioning of most old individuals, instead of attempting to explain for the increased heterogeneity. "It tends to create a gerontology of the usual" (Rowe and Kahn, 1987). Stones et al. (1990) identify four different types of aging:

1. Primary aging (=successful) aging: functional changes that are intrinsic to age;

2. Usual aging: nonpathological deficiencies added to the age-intrinsic processes of successful aging;

3. Secondary aging: pathology-related decrements added to nonpathological aging;

4. Tertiary aging: pathological aging plus the effects of terminal illness. Tertiary aging can thus be roughly equated to the 'terminal drop' phenomenon as described by Riegel and Riegel (1972).

Usual aging is subsumed under primary aging by Rowe and Kahn (1987). With this model of multiple types of aging, it becomes understandable why ageassociated decline can accelerate and why the variability increases with age, two often observed trends in aging research. The frequency of aging types 2-4 must increase with age, as these age-linked conditions and processes are irreversible in most cases, and any brain dysfunction that is caused by them is likely to be permanent. The onset of these age-extrinsic conditions can be assumed to vary between individuals. The aggregated deleterious effects of pathology or life style on the average performance in a random sample of subjects is therefore expected to accumulate with age. Many an age-related decline observed in the test outcomes in the present thesis fit into this line of thinking. Conversely, processes that are age-intrinsic (primary aging) are more likely to cause a linear decline of cognition with age, if a given function is to decline at all as a result of primary aging.

It is hypothesized here that BLE constitute a biological substrate for nonpathological deficiencies that are associated with usual aging (type 2). Our difficulty to obtain a sample of BLE-free subjects aged 80 , and even 70, illustrates this point nicely: BLE and pathology (type 3) were more frequent then their complete absence. Setting aside pathology and terminal drop, if aging as it is 
affected by BLE or nonpathological deficiencies is the most frequent type, then it is regarded as the normative pattern, in Salthouse's (1990) operational definition. Aging types 1 and 3-4 both are then to be regarded as atypical. Defining true age effects depends heavily on the extent to which deficiencies are still accepted as nonpathological. The issue that was discussed at the end of chapter 8 , may serve to illustrate this. Geffen et al. (1990) stated that the age effects they found with the Auditory Verbal Learning Test were due to "true age effects" (italics by Geffen et al.), because 1. cohort-specific factors such as education could be regarded as negligible; 2 . subjects were matched for IQ; and 3. they were free of neurological symptoms (self-report). Few authors put it this explicitly, but this notion of aging is probably very common in cognitive gerontology. Geffen et al. did not take the nonpathological deficiencies associated with type 2 aging into consideration. Consistent with our thinking about the occurrence BLE as a predictor of less than successful aging, the average performance of their subjects lay between the means of the BLE-free and the BLE-affected group in our sample, and showed a larger variability than both separate groups. We hypothesize therefore, that subdivision of subjects based on BLE equals the distinction between usual and successful aging, between aging type 1 and 2 . This hypothesis should be further investigated in the light of the fundamental issue about when age-associated changes can be regarded as age-intrinsic, that is, physiological, and when the aging process is usual but non-diseased.

In conclusion, our notion of what is normal may be about to be radically changed: from what is average into what is optimal. As for aging this means that we should vigorously seek for every conceivable age-extrinsic factor. Whatever the nature of aging research -be it biological or cognitive, be it cross-sectional or longitudinal-, if these factors are not controlled for, true age effects will never be found. More importantly however, there are many age-extrinsic factors we can do something about. 


\section{REFERENCES}

Abbenhuis, M. A., Raaijmakers, W. G. M., Raaijmakers, J. G. W., \& Van Woerden, G. J. M. (1990). Episodic memory in dementia of the Alzheimer type and in normal ageing: similar impairment in automatic processing. The Quarterly Journal of Experimental Psychology, 42 (3), 569-583.

Amaducci, L. A., Fratiglioni, L., \& Rocca, W. A. (1986). Risk factors for clinically diagnosed Alzheimer's disease: A case-control study of an Italian population. Neurology, 36, 922-931.

Arbuckle, T. Y., Gold, D., \& Andres, D. (1986). Cognitive functioning of older people in relation to social and personality variables. Psychology and Aging, 1(1), 55-62.

Baddeley, A. D. (1976). The psychology of memory. New York: Basic Books.

Bannister, R. (1981). Brain's clinical neurology (5th ed.). Oxford: Oxford University Press.

Binder, L. M. (1986). Persisting symptoms after mild head injury: a review of the postconcussive syndrome. Journal of Clinical and Experimental Neuropsychology, 8, 323-346.

Birren, J. E., \& Cunningham, W. (1985). Research on the psychology of aging: Principles, concepts and theory. In J. E. Birren, \& K. W. Schaie (Eds.), Handbook of the psychology of aging (2nd ed.) (pp. 3-34). New York: Van Nostrand Reinhold.

Birren, J. E., \& Schaie, K. W. (Eds.). (1985). Handbook of the Psychology of Aging (2nd ed.). New York: Van Nostrand Reinhold.

Birren, J. E., \& Schaie, K. W. (Eds.). (1990). Handbook of the Psychology of Aging (3rd ed.). New York: Van Nostrand Reinhold.

Blackford, P., and LaRue, T. S. (1989). Developmental Neuropsychology, 5, 295-306.

Bohnen, N., Houx, P., Jolles, J., \& Janknegt, R. (1989). Effects of an overnight fluid infusion on cognitive functions in preoperative patients. International Journal of Neuroscience, 48, 233-241.

Botwinick, J. (1967). Cognitive processes in maturity and old age. New York: Springer.

Botwinick, J. (1977). Intellectual abilities. In J. E. Birren \& K. W. Schaie (Eds.), Handbook of the Psychology of Aging (pp. 580-605). New York: Van Nostrand Reinhold.

Botwinick, J. (1984). Aging and Behavior (3rd ed.). New York: Springer.

Botwinick, J., \& Storandt, M. (1974). Memory, related functions, and age. Springfield, Ill.: C. C. Thomas.

Branconnier, R. J., DeVitt, D. R. (1984). Early detection of incipient Alzheimer's disease. In B. Reisberg (Ed.), Alzheimer's Disease (pp. 214-227). New York: The Free Press.

Brand, N., \& Jolles, J. (1985). Learning and retrieval rate of words presented auditorily and visually. The Journal of General Psychology, 112 (2), 201-210.

Brand, N., V. d. Wijk, A., \& Hijman, R. (1990). Motor planning in neurological and psychiatric patients. In P. J. D. Drenth, J. A. Sergeant, \& N. R. J. Takens (Eds.), European Perspectives in Psychology (Vol. 2) (pp. 321-334). Chichester, UK: Wiley.

Brand, N., \& Jolles, J. (1987). NEUROPSYCH: computer-assisted neuropsychological assessment. In F. J. Maarse, L. J. M. Mulder, W. P. B. Sjouw, \& A. E. Akkerman (Eds.), Computers in Psychology: Methods, instrumentation and psychodiagnostics. Lisse (The Netherlands): Swetz \& Zeitlinger. and psychodiagnostics.

Broadbent, D. E. (1958). Perception and communication. London: Pergamom.

Cattell, R. B. (1963). Theory of fluid and cristallized intelligence: A critical experiment. Journal of Educational Psychology, 54, 1-22.

CBS (1991). Jaarverslag 1990.

Charness, N. (Ed.). (1985). Aging and human performance. Chichester, UK: Wiley.

Christensen, A. L. (1979). Luria's neuropsychological investigation. Text (2nd ed.). Copenhagen: Munksgaard.

Chung, F., Seyone, C., Dyck, B., Chung, A., Ong, D., Taylor, A., \& Stone, R. (1990). Age-related cognitive recovery after general anaesthesia. Anaesthesiology and Analgesiology, 17, 217-224.

Cook, T. D., \& Campbell, D. T. (1979). Quasi-experimentation: Design \& analysis issues for field settings. Boston: Houghton Mifflin.

Craik, F. I. M., Byrd, M., \& Swanson, J. M. (1987). Patterns of memory loss in three elderly samples. Psychology and Aging, 2(1), 87-86. 
Crook, T., Bartus, R. T., Ferris, S. H., Whitehouse, P., Cohen, G. D., \& Gershon, S. (1986). Ageassociated memory impairment: Proposed diagnostic criteria and measures of clinical change report of a national institute of mental health work group. Developmental Neuropsychology, 2(4), 261-276.

Curran, S., Wattis, J. P., Hindmarch, I. (1989). Psychometric assessment of patients with primary degenerative dementia: Results using choice reaction time: A preliminary report. Medical Science Research, 17 (21), 893-894.

Deelman, B. G., Brouwer, W. H., van Zomeren, A. H., \& Saan, R. J. (1980). Functiestoornissen na trauma capitis. In A. Jennekens-Schinkel, J. J. Diamant, H. F. A. Diesfeldt, R. Haaxma (Eds.), Neuropsychologie in Nederland. Deventer, The Netherlands: Van Loghum Slaterus.

Dodrill, C. A. (1979). Sex differences on the Halstead-Reitan Neuropsychological Battery and on other neuropsychological measures. Journal of Clinical Psychology, 35, 236-241.

Donders, F. C. (1969). Over de snelheid van psychische processen [On the speed of psychological processes]. In W. Koster (Ed.), Attention and performance: $I I$ (original work published in 1868). Amsterdam: North Holland.

Douma, M. (1987). De onderkenning van prefrontaal hersenletsel [Identification of prefrontal brain injury]. Tijdschrift voor Psychiatrie, 29 (9), 570-584.

Dye, O. A., Saxon, S. A., \& Milby, J. B. (1981). Long-term neuropsychological deficits after traumatic head injury with comatosis. Journal of Clinical Psychology, 37(3), 472-477.

Elias, M. F., Robbins, M. A., Schultz, N. R., \& Pierce, T. W. (1990). Is blood pressure an important variable in research on aging and neuropsychological test performance? Journal of Gerontology. 45 (4), P128-135.

Elias, W. F., Schultz, N. R., Jr., Robbins, M. A., \& Elias, P. K. (1989). A longitudinal study of neuropsychological performance by hypertensives and normotensives: A third measurement point. Journal of Gerontology: Psychological Sciences, 44(1), P25-P28.

Era, P., Jokela, J., \& Heikkinen, E. (1986). Reaction and movement times in men of different ages: A population study. Perceptual and Motor Skills, 63(1), 111-130.

Eskelinen, L., Luisto, M., Tenkanen, L., \& Mattei, O. (1986). Neuropsychological methods in the differentiation of organic solvent intoxication from certain neurological conditions. Journal of Clinical and Experimental Neuropsychology, 8, 239-256.

Finlayson, M. A. J., \& Reitan, R. M. (1980). Effect of lateralized lesions on ipsilateral and contralateral motor functioning. Journal of Clinical Neuropsychology, 39, 33-36.

Fitts, P. M. (1954). The information capacity of the human motor system in controlling the amplitude of movement. Journal of Experimental Psychology, 47(6), 381-391.

Fitts, P. M., \& Radford, B. K. (1966). Information capacity of discrete motor responses under diferent cognitive sets. Journal of Experimental Psychology, 71, 465-482.

Folstein, M. F., Folstein, S. E., \& McHugh, P. R. (1975). "Mini-Mental State". Journal of Psychiatric Research, 12, 189-198.

Fozard, J. L., Thomas, J. C. (1975). Psychology of aging. In J. G. Howcll (Ed.), Modern perspectives in the psychiatry of old age. New York: Bruner/Mazel.

Fozard, J. L., Metter, E. J., \& Brant, L. J. (1990). Next steps in describing aging and disease in longitudinal studies. Journal of Gerontology: Psychological Sciences, 43(4), P116-P127.

Frowein, H. W., Sanders, A. F. (1978). Effects of visual stimulus degradation, S-R compatibility, and foreperiod duration on choice reaction time and movement time. Bulletin of the Psychonomic Society, 12(2), 106-108.

Gaillard, A. W. K., \& Varey, C. A. (1979). Some effects of an ACTH 4-9 analog (ORG 2766) on human performance. Physiology and Behavior, 23, 79-84.

Ganzevles, P. G., \& Jolles, J. (1989). Psychological dysfunctions as a result of long-term exposure to organic solvents. Paper presented at the 12th European conference of the International Neuropsychological Society, Antwerpen, Belgium.

Geffen, G., Moar, K. J., O'Hanlon, A. P., Clark, C. R., \& Geffen, L. B. (1990). Performance measures of 16- to 86-year-old males and females on the auditory verbal learning test. The Clinical Neuropsychologist, 4 (1), 45-63.

Gerhard, U., \& Hobi, V. (1984). Cognitive psychomotor functions with regard to fitness for driving 
of psychiatric patients treated with neuroleptics and antidepressants. Neuropsychobiology, 12 (1), 39-47.

Giambra, L. M., \& Quilter, R. (1988). Sustained attention in adulthood: A unique, large sample, longitudinal and multicohort analysis using the Mackworth-Clock-Test. Psychology and Aging, $3(1), 75-83$.

Golden, C. J. (1981). A standardized version of Luria's neuropsychological tests. In S. Filskov, \& T. J. Boll (Eds.), Handbook of clinical neuropsychology. New York: Wiley.

Goldstein, K. (1959). Functional disturbances in brain damage. In S. Arieti (Ed.), American Handbook of Psychiatry (Vol. 1) (pp. 182-207). New York: Basic Books.

Goodrich, S., Henderson, L., \& Kennard, C. (1989). On the existence of an attention-demanding process peculiar to simple reaction time: Converging evidence for Parkinson's disease. Cognitive Neuropsychology, 6(3), 309-331.

Haaland, K. Y., \& Delaney, H. D. (1981). Motor deficits after left or right hemisphere damage due to stroke or tumor. Neuropsychologia, 19, 17-27.

Halstead, W. C. (1947). Brain and intelligence. Chicago: University of Chicago Press.

Hamsher, K. de S, Benton, A. L., \& Digre, K. (1980). Serial digit learning: Normative and clinical aspects. Journal of Clinical Neuropsychology, 2, 39-50.

Harley, J. P., Leuthold, C. A., Matthews, C. G., \& Bergs, L. E. (1980). Wisconsin Neuropsychological Test Battery T-score norms for older Veterans Administration Medical Center patients. Madison, Wis.: C. G. Matthews.

Hart, R. P., \& Kwentus, J. A. (1987). Psychomotor slowing and subcortical-type dysfunction in depression. Journal of Neurology, Neurosurgery, and Psychiatry, 50, 1263-1266.

Hartman, D. E. (1988). Neuropsychological toxicology: Identification and assessment of human neurotoxic syndromes. New York: Pergamom Press.

Hasher, L., \& Zacks, R. T. (1979). Automatic and effortful processes in memory. Journal of Experimental Psychology: General, 108, 356-388.

Haug, $H$. (1985). Are neurons of the human cerebral cortex really lost during aging? In J. Traber \&W. H. Gispen (Eds.), Senile dementia of the Alzheimer type (pp. 150-163). Berlin: Springer.

Haxby, J. V., Grady, C. L., Duara, R., Robertson-Tchabo, E. A., Koziarz, B., Cutler, N. R., \& Rapoport, S. I. (1986). Relations among age, visual memory, and resting cerebral metabolism in 40 healthy men. Brain and Cognition, 5, 412-427.

Hebb, D. O. (1972). Textbook of psychology. Toronto: Saunders.

Hicks, L. H., \& Birren, J. E. (1970). Aging, brain damage and psychomotor slowing. Psychological bulletin, 74, 377-396.

Houx, P. J., Brand, N., \& Jolles, J. (1987). Use of a XY-tablet for paper and pencil tests in neuropsychological assessment. In F. J. Maarse, L. J. M. Mulder, W. P. B. Sjouw, \& A. E. Akkerman (Eds.), Computers in Psychology: Methods, instrumentation and psychodiagnostics. Lisse (The Netherlands): Swetz \& Zeitlinger.

Houx, P. J., \& Jolles, J. (1988). De microcomputer in the neuropsychologie: Een middel, geen doel [The microcomputer in neuropsychology: means, not aim]. Proceedings of the Third Workshop Computers in Psychology (pp. 103-104). Groningen, the Netherlands: GCOP.

Houx, P. J., Vreeling, F. W., \& Jolles, J. (1989). Cognitive aging and risk factors for dementia. In R. J. Wurtman, S. H. Corkin, \& J. H. Growdon (Eds.), Alzheimer's Disease: Proceedings of the 5th meeting of the international study group on the Pharmacology of Memory disorders associated with aging (pp. 413-417). Center for Brain Sciences and Metabolism Charitable Trust.

Houx, P. J., Vreeling, F. W., \& Jolles, J. (1990). Cognitieve veroudering wordt meer beïnvloed door "biological life events" dan door fysiologische veroudering [Cognitive aging is more influenced by biological life events than by physiological agingl. In C. P. M. Knipscheer, J. J. M. Michels, \& M. W. Ribbe (Eds.), Ouder worden nu '90 [Aging now '90] (pp. 270-278). Almere, The Netherlands: Versluys.

Houx, P. J., Vreeling, F. W., \& Jolles, J. (1991a). Risk factors for age-associated cognitive decline. In C. F. A. van Bezooijen, R. Ravid, \& A. A. J. Verhofstad (Eds.), From gene to man: Gerontological research in The Netherlands (pp. 190-193). The Hague, The Netherlands: Pasmans.

Houx, P. J., Vreeling, F. W., \& Jolles, J. (1991b). Age-associated cognitive decline is related to 
biological life events. In K. Iqbal, D. R. C. McLachlin, B. Winblad, \& H. M. Wisniewski (Eds.), Alzheimer's disease: Basic mechanisms, diagnosis and therapeutic strategies (pp. 353-358). Chichester, UK: Wiley.

Houx, P. J., Vreeling, F. W., \& Jolles, J. (1991c). Rigorous health screening reduces age effect on Memory Scanning Task. Brain and Cognition, 15, 246-260.

Howe, M. L., Stones, M. J., \& Brainerd, C. J. (Eds.). (1990). Cognitive and behavioral performance fatcors in atypical aging. New York: Springer.

James, W. (1890). The principals of psychology. New York: Henry Holt.

James, W. (1892). Psychology. New York: Henry Holt.

Jennett, B. (1976). Assessment of the severity of head injury. Journal of Neurology, Neurosurgery and Psychiatry, 39, 647-655.

Jensen, A. R. (1982). Reaction time and psychometric ' $\mathrm{g}$ '. In H. J. Eysenck (Ed.), A model for intelligence (pp. 93-132). Berlin: Springer.

Jolles, J., \& Hijman, R. (1983). The neuropsychology of aging and dementia. In W. H. Gispen, \& J. Traber (Eds.), Developments in Neurology: Vol. 7. Aging of the Brain (pp. 227-250). Amsterdam: Elsevier Science Publishers.

Jolles, J. (1985). Early diagnosis of dementia: Possible contributions from neuropsychology. In W. H. Gispen, \& J. Traber (Eds.), Aging of the brain (pp. 84-100). Berlin: Springer.

Jolles, J. (1986). Neuropeptides and cognitive disorders. In J. M. van Ree, \& S. Matthyse (Eds.), Progress in Brain Research (Vol. 65, pp. 177-192). Amsterdam: Elsevier Science Publishers.

Jolles, J. (1986). Cognitive, emotional and behavioral dysfunctions in aging and dementia. In D. F. Swaab, E. Fliers, M. Mirmirian, W. A. Van Gool, \& F. Van Haaren (Eds.), Progress in Brain Research (Vol. 70, pp. 15-39). Amsterdam: Elsevier Science.

Jolles, J. (1991). The Netherlands memory and aging programme 1991-1995. NESTOR.

Jones, M. J. T., Piggott, S. E., Vaughan, R. S., Bayer, A. J., Newcombe, R. G., Twining, T. C., Pathy, J., \& Rosen, M. (1990). Cognitive and functional competence after anaesthesia in patients aged over 60: controlled trial of general and regional anaesthesia for elective hip or knee replacement. British Medical Journal, 300, 1683-1687.

Kahneman, D. (1973). Attention and effort. Englewood Cliffs, NJ: Prentice Hall.

Kalverboer, A. (1988). Follow-up of biological high-risk groups. In M. Rutter (Ed.), Studies of psychosocial risk: The power of longitudinal data. Cambridge, UK: Cambridge University Press.

Kausler, D. H. (1985). Episodic memory: Memorizing performance. In N. Charness (Ed.), Aging and human performance (pp. 101-142). Chichester, UK: Wiley.

Knoefel, J. E., \& Albert, M. L. (1985). Secondary dementias. In J. A. M. Frederiks (Ed.), Handbook of clinical neurology: Vol. 46. Neurobehavioral disorders (pp. 385-411). Amsterdam: Elsevier Science Publishers.

Kolb, B., \& Whishaw, I. Q. (1990). Fundamentals of human neuropsychology (3rd ed.). New York: Freeman.

Koh, S. D., \& Wolpert, E. A. (1983). Memory scanning and retrieval in affective disorders. Psychiatry Research, 8, 289-297.

Kohnstamm, G. A., Schaerlakens, A. M., De Vries, A. K., Akkerhuis, G. W., \& Froonincksx, M. (1981). Nieuwe streeflijst woordenschat zes-jarigen [New target list of vocabulary in the sixyear old]. Lisse, The Netherlands: Swets \& Zeitlinger.

Kral, V. A. (1962). Senescent forgetfulness: Benign and malignant. Canadian Medical Association Journal, 86, 257-260.

Kramer, N. A., \& Jarvik, L. (1979). Assessment of intellectual changes in the elderly. In A. Raskin \& L. Jarvik (Eds.), Psychiatric symptoms and cognitive loss in the elderly (pp. 221-271). Washington, D.C.: Hemisphere.

LaBerge, D. (1981). Automatic information processing: A review. In J. Long, and A. Baddely (Eds.), Attention and Performance IX (pp. 173-186). Hillsdale, NJ: Erlbaum.

Labouvie-Vief, G. (1985). Intelligence and cognition. In J. E. Birren, \& K. W. Schaie (Eds.), Handbook of the psychology of aging (2nd ed.) (pp. 500-530). New York: Van Nostrand Reinhold.

Lahtela, K., Niemi, P., \& Kuusela, V. (1985). Adult visual choice reaction time, age, sex and 
preparedness: A test of Welford's problem in a large population sample. Scandinavian Journal of Psychology, 26(4), 357-362.

Landauer, A. A. (1981). Sex differences in decision and movement time. Perceptual and Motor Skills, $52(1), 90$.

Letourneau, J. E. (1990). Choice reaction time as a measure of recovery from general anesthesia. Perceptual and Motor Skills, 70(1), 256-258.

Levin, H. S., Goldstein, F. C., High, W. M., \& Williams, D. (1988). Automatic and effortful processing after severe closed head injury. Brain and Cognition, 7, 283-297.

Lezak, M. D. (1983). Neuropsychological assessment (2nd ed.). New York: Oxford University Press.

Ligthart, G. J. (1989). The immune system in human ageing: Necessity of the assessment of health status in gerontological studies. Leiden, The Netherlands: doctoral dissertation.

Lindsey, B. A., \& Coppinger, N. W. (1969). Age-related deficits in simple capabilities and their consequences for Trail Making performance. Journal of Clinical Psychology, 25, 156-159.

Linschoten, J. (1963). De la Court's frequentietellingen van Nederlandse woorden [De la Court's frequency counts of Dutch words]. (Report 6301). Utrecht, The Netherlands: University of Utrecht, Psychologisch Laboratorium.

Logan, G. D. (1978). Attention in character-classification tasks: Evidence for the automaticity of component stages. Journal of Experimental Psychology: General, 107, 32-63.

Luria, A. R. (1973). The working brain: An introduction to neuropsychology. Middlesex, UK: Penguin Books.

Luria, A. R. (1980). Higher cortical functions in man (2nd ed.). New York: Basic Books.

MacFlynn, G., Montgomery, E. A., Fenton, G. W., Rutherford, W. (1984). Measurement of reaction time following minor head injury. Journal of Neurology, Neurosurgery and Psychiatry, 47(12), 1326-1331.

MacLeod, C. M., \& Dunbar, K. (1988). Training and Stroop-like interference: Evidence for a continuum of automaticity. Journal of Experimental Psychology: Learning, Memory and Cognition, 14 (1), 126-135.

Madden, D. J. (1990). Adult age differences in the time course of visual attention. Journals of Gerontology, 45 (1), P9-P16.

Measso, G., Romani, L., Martini, E., \& Zappalà, G. (1990). Preliminary analysis of effects of "normal" aging on different memory processes and abilities. Perceptual and Motor Skills, 71, 395401.

Medical Pharmaceutical Committee (1988). Farmacotherapeutisch kompas [Pharmacotherapeutic Compass]. Amstelveen, The Netherlands: Dutch National Health Council.

Miller, G. A. (1956). The magical number seven, plus or minus two: some limits on our capacity for processing information. Psychological Review, 63, 81-97.

Milligan, W. L., Powell, D. A., Harley, C., Furchtgott, E. (1984). A comparison of physical health and psychosocial variables as predictors of reaction time and serial learning performance in elderly men. Journal of Gerontology, 39(6), 704-710.

Milner, B. (1971). Interhemispheric difference in the localization of psychological processes in man. British Medical Bulletin, 27, 272-277.

Múller, G., \& Pilzecker, A. (1900). Experimentelle Beiträge zur Lehre vom Gedächtniss [Experimental contributions to the study of thinking]. Zeitschrift für Psychology [Journal of Psychologyl, 1.

Myerson, J., Hale, S., Hirschman, R., Hansen, C. et al. (1989). Global increase in response latencies by early middle age: Complexity effects in individual performances. Special Issue: Experimental analysis of cognition. Journal of the Experimental Analysis of Behavior, 52(3), 353-362.

National Centre for Health Statistics. (1976). Plan and operation of the Health and Nutrition Examination Survey, United States, 1971-1973. Vital and Health Statistics, Series 1, No. 10a. DHEW publications (HRA) 76-1210. Rockville. MD: U.S. Department of Health, Education and Welfare.

National Centre for Health Statistics. (1987). Cohen, B. B., Barbano, H., Cox, E. S., et al. Plan and operation of NHANES I Epidemiological Follow-up Study 1982-84. Series 1, No. 22, DHHS Publication (PHS) 87-1324. Vital Health Statistics, Washington, DC: Public Health Service. 
Nehemkis, A.M., \& Lewinsohn, P.M. (1972). Effect of left and right cerebral lesions in the naming process. Perceptual and Motor Skills, 35, 787-798.

Neil, W. T., \& Westberry, R. L. (1987). Selective attention and the suppression of cognitive noise. Journal of Experimental Psychology: Learning, Memory and Cognition, 13(2), 327-334.

Neisser, U. (1967). Cognitive psychology. New York: Appleton.

Neisser, U. (1988). New vistas in the study of memory. In U. Neisser, \& E. Winograd (Eds.), Remembering reconsidered: Ecological and traditional approaches to the study of memory (pp. 110). Cambridge, UK: Cambridge University Press.

Nesselroade, J. R., \& Labouvie, E. W. (1985). Experimental design in research on aging. In J. E. Birren, \& K. W. Schaie (Eds.), Handbook of the psychology of aging (2nd ed.) (pp. 35-60). New York: Van Nostrand Reinhold.

Offenbach, S. I., Chodzko-Zajko, W. J., \& Ringel, R. L. (1990). Relationship between physiological status, cognition, and age in adult men. Bulletin of the Psychonomic Society, 28(2), 112-114

Perlmutter, M., \& Nyquist, L. (1990). Relationships between self-reported physical and mental health and intelligence performance across adulthood. Journal of Gerontology: Psychological Sciences, 45(4), P145-155.

Plude, D. J., \& Hoyer, W. J. (1985). Attention and performance: Identifying and localizing age deficits. In N. Charness (Ed.), Aging and human performance (pp. 47-99). Chichester, UK: Wiley.

Pontius, A. A., \& Yudowitz, B. S. (1980). Frontal lobe system dysfunction in some criminal actions as shown in the Narratives Test. Journal of Nervous and Mental Disease, 168, 111-117.

Poole, L., McNiff, M., \& Cook, S. (1981). Apple II: User's guide. Berkeley: Osborne-McGraw-Hill.

Poon, L. W. (1983). Application of information-processing techniques in psychological assesment. In T. Crook, S. Ferris, \& B. Reisberg (Eds.), Assessment in geriatric psychopharmacology (pp. 187201). New Canaan, CT: Powly.

Poon, L. W. (1985). Differences in human memory with aging: Nature, causes, and clinical problems. In J. E. Birren, \& K. W. Schaie (Eds.), Handbook of the psychology of aging (2nd ed.) (pp. 427463). New York: Van Nostrand Reinhold.

Raaijmakers, J. G. W. (1984). De psychologie van het geheugen [The psychology of memory]. Deventer, The Netherlands: Van Loghum Slaterus.

Rabbitt, P. M. A. (1967). Learning to ignore irrelevant information. American Journal of Psychology, 80, 1-13.

Rabbitt, P. M. A. (1986). Memory impairment in the elderly. In P. E. Bebbington \& R. Jacoby (Eds.), Psychiatric disorders in the elderly. London: Mental Health Foundation.

Rabbitt, P. M. A. (1990). Applied cognitive gerontology: some problems, methodologies and data. Applied Cognitive Psychology, 4, 225-246.

Reese, H. W., \& Rodeheaver, D. (1985). Problem solving and decision making. In J. E. Birren, \& K. W. Schaie (Eds.), Handbook of the psychology of aging (2nd ed.) (pp. 474-499). New York: Van Nostrand Reinhold.

Reitan, R. M. (1958). Validity of the Trail Making Test as an indication of organic brain damage. Perceptual and Motor Skills, 8, 271-276.

Rey, A. (1964). L'examen psychologique dans les cas d'encéphalopathie traumatique. Paris: Presses Universitaires de France.

Reyersen van Buuren, E. J., Houx, P. J., \& Jolles, J. (1991). Age-associated memory impairment (AAMI): Results form a controlled study into memory dysfunction. In C. F. A. van Bezooijen, R. Ravid, \& A. A. J. Verhofstad (Eds.), From gene to man: Gerontological research in The Netherlands (pp. 194-198). The Hague, The Netherlands: Pasmans.

Reyersen van Buuren, E. J., Jolles, J. (submitted). Age-associated memory impairment (AAMI): Evaluation of diagnostic criteria. Developmental Neuropsychology.

Riegel, K. F., \& Riegel, R. M. (1967). A study of the drop-out rates in longitudinal research on aging and the prediction of death. Journal of Personality and Social Psychology, 4, 342-348.

Riegel, K. F., \& Riegel, R. M. (1972). Development, drop, and death. Developmental Psychology, 6, 309-316.

Rowe, J. W., \& Kahn, R. L. (1987). Human aging: Usual and successful. Science, 237, 143-149. 
In J. E. Birren, \& K. W. Schaie (Eds.), Handbook of the psychology of aging (2nd ed.) (pp. 427463). New York: Van Nostrand Reinhold.

Raaymakers, J. G. W. (1984). De psychologie van het geheugen [The psychology of memory]. Deventer, The Netherlands: Van Loghum Slaterus.

Rabbitt, P. M. A. (1967). Learning to ignore irrelevant information. American Journal of Psychology, 80, 1-13.

Rabbitt, P. M. A. (1978). Hand dominance, attention, and the choice between responses. Quarterly Journal of Experimental Psychology, 30(3), 407-416.

Rabbitt, P. M. A. (1979). How old and young subjects monitor and control responses for accuracy and speed. British Journal of Psychology, 70(2), 305-311.

Rabbitt, P. M. A. (1982). Development of methods to measure changes in activities of daily living in the elderly. In S. Corkin, K. L. Davis, J. H. Growdon, E. Usdin, \& R. J. Wurtman (Eds.), Alzheimer's disease: A report of progress in research (pp. 127-131). New York: Raven Press.

Rabbitt, P. M. A. (1986). Memory impairment in the elderly. In P. E. Bebbington \& R. Jacoby (Eds.), Psychiatric disorders in the elderly. London: Mental Health Foundation.

Rabbitt, P. M. A. (in press). Secondary central effects on memory and attention of mild hearing loss in the elderly. Acta Psychologica Scandinavica.

Rabbitt, P. M. A. (1990). Applied cognitive gerontology: some problems, methodologies and data. Applied Cognitive Psychology, 4, 225-246.

Rabbitt, P. M. A., \& Banerji, N. (1989). How does very prolonged practice improve decision speed? Journal of Experimental Psychology: General, 118(4), 338-345.

Rabbitt, P. M. A., \& Goward, L. M. (1986). Effects of age and raw IQ test scores on mean correct and mean error reaction times in serial choice tasks: A reply to Smith \& Brewer. British Journal of Psychology, 77(1), 69-73.

Reese, H. W., \& Rodeheaver, D. (1985). Problem solving and decision making. In J. E. Birren, \& K. W. Schaie (Eds.), Handbook of the psychology of aging (2nd ed.) (pp. 474-499). New York: Van Nostrand Reinhold.

Reitan, R. M. (1958). Validity of the Trail Making Test as an indication of organic brain damage. Perceptual and Motor Skills, 8, 271-276.

Rey, A. (1964). L'examen psychologique dans les cas d'encéphalopathie traumatique. Paris: Presses Universitaires de France.

Reyersen van Buuren, E. J., Houx, P. J., \& Jolles, J. (1991). Age-associated memory impairment (AAMI): Results from a controlied study into memory dysfunction. In C. F. A. van Bezooijen, R. Ravid, \& A. A. J. Verhofstad (Eds.), From gene to man: Gerontological research in The Netherlands (pp. 194-198). The Hague, The Netherlands: Pasmans.

Reyersen van Buuren, E. J., Jolles, J. (submitted). Age-associated memory impairment (AAMI): Evaluation of diagnostic criteria. Developmental Neuropsychology.

Riegel, K. F., \& Riegel, R. M. (1967). A study of the drop-out rates in longitudinal research on aging and the prediction of death. Journal of Personality and Social Psychology, 4, 342-348.

Riegel, K. F., \& Riegel, R. M. (1972). Development, drop, and death. Developmental Psychology, 6, 309-316.

Rowe, J. W., \& Kahn, R. L. (1987). Human aging: Usual and successful. Science, 237, 143-149.

Salthouse, T. A. (1985). Speed of behavior and its implications for cognition. In J. E. Birren, \& K. W. Schaie (eds.), Handbook of the psychology of aging (pp. 400-426). New York: Van Nostrand Reinhold.

Salthouse, T. A. (1988). Resource reduction interpretations of cognitive aging. Brain and Cognition, 7, 238-272.

Salthouse, T. A. (1990). Cognition, motor behavior, and the assesment of atypical aging. In M. L. Howe, M. J. Stones, \& C. J. Brainerd (Eds.), Cognitive and behavioral performance factors in atypical aging (pp. 221-234). New York: Springer.

Salthouse, T. A., Kausler, D. H., \& Saults J. S. (1988). Investigation of student status, background variables, and the feasibility of standard tasks in cognitive aging research. Psychology and Aging, 3(1), 29-37.

Salthouse, T. A., Kausler, D. H., \& Saults J. S. (1990). Age, self-assessed health status, and 
Psychologica, 30, 276-315.

Sternberg, S. (1975). Memory scanning: new findings and current controversies. Quarterly journal of Experimental Psychology, 27, 1-32.

Sterling, N. (1979). Stroop interference: An input and an output phenomenon. Quarterly Journal of Experimental Psychology, 31(1), 121-132.

Stokx, L. C., Gaillard, A. W. (1986). Task and driving performance of patients with a severe concussion of the brain. Journal of Clinical and Experimental Neuropsychology, 8(4), 421-436.

Stoloff, M. L., \& Couch, J. V. (Eds.). (1988). Computers in psychology: A directory of software (2nd. ed.). Washington, DC: American Psychological Association.

Stones, M. J., \& Kozma, A. (1985). Physical performance. In N. Charness (Ed.), Aging and human performance (pp. 261-291). Chichester, UK: Wiley.

Stones, M. J., Kozma, A., \& Hannah, T. E. (1990). The measurement of individual differences in aging: The distinction between usual and successful aging. In M. L. Howe, M. J. Stones, \& C. J. Brainerd (Eds.), Cognitive and behavioral performance factors in atypical aging (pp. 181-218). New York: Springer.

Strayer, D. L., Wickens, C. D., \& Cannon, C. J. (1987). Adult age differences in the speed of information processing: II. An electrophysiological approach. Psychology and Aging, 2, 99-110.

Subhan, Z., \& Hindmarch, I. (1984). Effects of zopiclone and benzodiazepine hypnotics on search in short-term memory. Neuropsychobiology, 12, 244-248.

Thomassen, A. J. W. M., \& Kempen, G. A. M. (1976). Geheugen [Memory]. In J. A. Michon, E. G. J. Eijkman, \& L. F. W. de Klerk (Eds.), Handboek der psychonomie [Handbook of psychonomy] (pp. 354-387). Deventer, The Netherlands: Van Loghum Slaterus.

Tulving, E. (1972). Episodic and semantic memory. In E. Tulving, \& W. Donaldson (Eds.), Organization of memory. New York: Academic Press.

Van Bezooijen, C. F. A., Ravid, R., \& Verhofstad, A. A. J. (Eds.). (1990). From gene to man: Gerontological research in The Netherlands. The Hague, The Netherlands: Pasmans.

Van der Maas, P. (1988). Aging and public health. In J. J. F. Schroots, J. E. Birren, \& A. Svanborg, (Eds.), Health and aging: Perspectives and prospects (pp. 95-115). New York: Springer - Lisse, The Netherlands: Swets.

Van Loon-Vervoorn, W. A. (1989). Voorstelbaarheidswaarden van Nederlandse woorden [Imageability ratings of Dutch words]. Lisse, The Netherlands: Swets \& Zeitlinger.

Van Zomeren, A. H., \& Deelman, B. G. (1976). Reaction time measurement in clinical neuropsychology. Nederlands Tijdschrift voor de Psychologie en haar Grensgebieden, 31(7), 377-391.

Van Zomeren, A. H., \& Deelman, B. G. (1978). Long-term recovery of visual reaction time after closed head injury. Journal of Neurology, Neurosurgery and Psychiatry, 41(5), 462-475.

Verhage, F. (1964). Intelligentie en leefijd [Intelligence and Age]. Assen, The Netherlands: doctoral dissertation.

Verhey, F. R. J., Houx, P. J., Vreeling, F. W., \& Jolles, J. (in preparation). Biological aspects in patients with memory complaints.

Verillo, R. T., \& Verillo, V. (1985). Sensory and perceptual performance. In N. Charness (Ed.), Aging and human performance (pp. 1-46). Chichester, UK: Wiley.

Vreeling, F. W., Verhey, F. R. J., Houx, P. J., \& Jolles, J. (1988). Methodological problems in the assessment of neurological signs, i.e. primitive reflexes, in aging and dementia. In Proceedings of the 2nd International Symposium on Alzheimer Disease. Kuopio, Finland.

Vroon, P. A. (1980) Intelligentie. Baarn, The Netherlands: Ambo.

Vrtunski, P. B., Patterson, M. B., \& Hill, G. O. (1984). Factor analysis of choice reaction time in young and elderly subjects. Perceptual and Motor Skills, 59(2), 659-676.

Wechsler, D. (1945). A standardized memory scale for clinical use. Journal of Psychology, 19, 87-95.

Wechsler, D. (1955). Wechsler Adult Intelligence Scale. Manual. New York: Psychological Corporation.

Weingartner, H. (1986). Automatic and effort-demanding cognitive processes in depression. In L. W. Poon (Ed.), Handbook for Clinical Memory Assessment of Older Adults. American Psychological Association. 
Welford, A. T. (1977). Motor performance. In J. E. Birren \& K. W. Schaie (Eds.), Handbook of the psychology of aging (pp. 450-496). New York: Van Nostrand Reinhold.

Welford, A. T. (1983). Comment on the paper "Preprogramming, programming, and reprogramming of aimed hand movements as a function of age" by D. D. Larish and G. E. Stelmach (1982). Joumal of Motor Behavior, 15(4), 383-385.

Welford, A. T. (1985). Changes of performance with age: An overview. In N. Charness (Ed.), Aging and human performance (pp. 333-369). Chichester, UK: Wiley.

Welford, A. T. (1989). Effects of concentration in relation to sex and age. Developmental Neuropsychology, 5(2-3), 261-265.

White, N., \& Cunningham, W. R. (1988). Is terminal drop pervasive or specific? Journal of Gerontology, 43(6), P141-P144.

Wickens, C. D. (1980). The structure of attentional recources. In R. Nickerson (Ed.), Attention and performance (VIII) (pp. 239-258). Hillsdale, NJ: Erlbaum.

Wickens, C. D., Braune, R., \& Stokes, A. (1987). Adult age differences in the speed of information processing: I. A dual task approach. Psychology and Aging, 2, 70-78.

Winograd, E. (1988). Memory for randomly sampled autobiographical events. In U. Neisser, \& E. Winograd (Eds.), Remembering reconsidered: Ecological and traditional approaches to the study of memory (pp. 11-21). Cambridge, UK: Cambridge University Press.

World Health Organization (1980). Problems related to alcohol consumption - Report of a W.H.O. expert committee. Geneva: World Health Organization.

Woodruff, D. S. (1985). Arousal, sleep, and aging. In J. E. Birren, \& K. W. Schaie (eds.), Handbook of the psychology of aging (pp. 261-295). New York: Van Nostrand Reinhold.

Zappala, G. (1990). Progetto Memoria: Study Plan Abano Terme. Padua, Italy: Memory Research Centre.

Zappalà, G., Martini, E., Crook, T., \& Amaducci, L. (1989). Ecological memory assessment in normal aging. Clinics in Geriatric Medicine, 5 (3), 583-593. 



\section{LIST OF PUBLICATIONS}

Bohnen, N. I. L. J., Houx, P. J., Jolles, J., \& Janknegt, R. (1989). Effects of an overnight fluid infusion on cognitive functions in preoperative patients. International Journal of Neuroscience, 48, 233-241.

Bohnen, N. I. L. J., Houx, P. J., Nicolson, N., \& Jolles, J. (1990). Cortisol reactivity and cognitive performance in a continuous mental task paradigm. Journal of Psychosomatic Research, 31, 107-116.

Brand, N., \& Houx, P. J. (1988). Bericht van de neuropsychologen [Message of the neuropsychologists]. Psychologie en Computers, 4, 30-32.

Houx, P. J., Brand, N., \& Jolles, J. (1987). Use of a XY-tablet for paper and pencil tests in neuropsychological assessment. In F. J. Maarse, L. J. M. Mulder, W. P. B. Sjouw, \& A. E. Akkerman (Eds.), Computers in Psychology: Methods, instrumentation and psychodiagnostics (pp. 177-184). Lisse (The Netherlands): Swetz \& Zeitlinger.

Houx, P. J., \& Jolles, J. (1988). De microcomputer in the neuropsychologie: Een middel, geen doel [The microcomputer in neuropsychology: Means, not aim]. Proceedings of the Third Workshop Computers in Psychology (pp. 103-104). Groningen, the Netherlands: GCOP.

Houx, P. J., \& Jolles, J. (submitted). Age-related decline of verbal memory performance: Physiological aging of biological life events? The Clinical Neuropsychologist.

Houx, P. J., Vreeling, F. W., \& Jolles, J. (1988). Cognitieve veroudering en risicofactoren [Cognitive aging and risk factors]. De Psycholoog, 22 (9) pp. 498499.

Houx, P. J., Vreeling, F. W., \& Jolles, J. (1989). Cognitive aging and risk factors for dementia. In R. J. Wurtman, S. H. Corkin, \& J. H. Growdon (Eds.), Alzheimer's Disease: Proceedings of the 5th meeting of the international study group on the Pharmacology of Memory disorders associated with aging (pp. 413-417). Center for Brain Sciences and Metabolism Charitable Trust.

Houx, P. J., Vreeling, F. W., \& Jolles, J. (1990). Cognitieve veroudering wordt meer be nvloed door biological life events dan door fysiologische veroudering [Cognitive aging is more influenced by biological life events than by physiological aging]. In C. P. M. Knipscheer, J. J. M. Michels, \& M. W. Ribbe (Eds.), Ouder worden nu '90 [Aging now '90] (pp. 270-278). Almere, The Netherlands: Versluys.

Houx, P. J., Vreeling, F. W., \& Jolles, J. (1990). Experimental evidence for a relation between accelerated cognitive aging and brain dysfunction: Aging and risk factors. European Journal of Clinical Investigation, 20 (2-II), A62.

Houx, P. J., Vreeling, F. W., \& Jolles, J. (1991). Age-associated cognitive decline is related to biological life events. In K. Iqbal, D. R. C. McLachlin, B. Winblad, \& 
H. M. Wisniewski (Eds.), Alzheimer's disease: Basic mechanisms, diagnosis and therapeutic strategies (pp. 353-358). Chichester, UK: Wiley.

Houx, P. J., Vreeling, F. W., \& Jolles, J. (1991). Rigorous health screening reduces age effect on Memory Scanning Task. Brain and Cognition, 15, 246-260.

Houx, P. J., Vreeling, F. W., \& Jolles, J. (1991). Risk factors for age-associated cognitive decline. In C. F. A. van Bezooijen, R. Ravid, \& A. A. J. Verhofstad (Eds.), From gene to man: Gerontological research in The Netherlands (pp. 190193). The Hague, The Netherlands: Pasmans.

Houx, P. J., Vreeling, F. W., \& Jolles, J. (submitted). Age-related decline of conceptshifting ability: Revised Trail Making Test versus a new concept-shifting test. Journal of Clinical and Experimental Neuropsychology.

Houx, P. J., Vreeling, F. W., \& Jolles, J. (submitted). Biological life events accentuate age effects on performance in a paper \& pencil memory scanning task. Psychology and Aging.

Houx, P. J., Vreeling, F. W., \& Jolles, J. (submitted). Performance decline on the Stroop Color-Word Test: Effects of age and health screening. Neuropsychologia.

Hijman, R., Mauser, H., Houx, P. J., \& Jolles, J. (1986). Neuropsychological Dysfunctions after Surgery of Anterior Communicating Artery Aneuryms. Journal of Clinical and Experimental Neuropsychology, 8, 131.

Jolles, J., Houx, P., Vreeling, F. W., Reyersen van Buuren, E. J. (1990). Biological risk factors for accelerated cognitive aging and dementia: Findings from a multiple cohort study. Neurobiology of Aging, 11, 293.

Jolles, J., Reyersen van Buuren, E. J., Houx, P. J., Plugge, L. A., \& Verhey, F. R. J. jr. (1990). Early diagnosis of Alzheimer's disease and the differentiation from normal aging. European Journal of Clinical Investigation, 20 (2-II), A61.

Reyersen van Buuren, E. J., Jolles, J., \& Houx, P. J. (1990). Neuropsychological evaluation of patients suspected of early Alzheimer's disease: Experimental studies with age-associated memory impairment and dysthymia. Neurobiology of Aging, 11(3), p. 256.

Reyersen van Buuren, E. J., Houx, P. J., \& Jolles, J. (1991). Age-associated memory impairment (AAMI): Results from a controlled study into memory dysfunction. In C. F. A. van Bezooijen, R. Ravid, \& A. A. J. Verhofstad (Eds.), From gene to man: Gerontological research in The Netherlands (pp. 194-198). The Hague, The Netherlands: Pasmans.

Vreeling, F. W., Verhey, F. R. J., Houx, P. J., \& Jolles, J. (1988). Methodological problems in the assessment of neurological signs, i.e., primitive reflexes, in aging and dementia. In Proceedings of the 2 nd International Symposium on Alzheimer's Disease. Kuopio, Finland. 


\section{SUMMARY}

Probably all researchers in the field of aging agree that many -if not all-cognitive functions decline with age. This widely held belief, that is based upon an evergrowing body of empirical evidence, is mirrored by subjective complaints by many elderly individuals about failing memory or concentration, slowness of thinking, or the disability to do more than one thing at a time. The study of cognitive aging has been termed cognitive gerontology, for which four main research questions have been formulated: 1 . When in a human lifetime do cognitive changes first become apparent? 2. At what rate do cognitive functions then decline? 3. Which functions are most sensitive to age? 4 . Which individuals are most vulnerable to age-related cognitive decline? These important questions are discussed in chapter 1, along with a number of methodological problems that are specific to aging research. A major problem is that the effect of age always has to be inferred from differences in some parameter, within the same individuals (as in longitudinal research) or between individuals of different ages (as in crosssectional designs). Serious problems of inferring cause and effect can arise from both approaches, and experimental designs that combine the two (sequential or cross-sequential), also have to cope with the limitations of both techniques.

There are still other problems. Probably the most important of these is the elimination of confounding variables whose effects can mimic or enhance that of age per se. Information about the interaction of aging and mild health-related factors that are associated with brain dysfunction (biological life events; BLE) is strangely lacking in the literature on cognitive aging. Following some suggestions and evidence from other disciplines however, it was anticipated at the outset of the study present in this thesis that health-related factors can interact with age regarding cognitive performance as measured with cognitive tests: individuals affected by such health-related factors may show poorer performance than unaffected subjects and these difference may become larger with advancing age.

Nine categories of BLE were identified, each of them based on empirical evidence that they are associated with brain dysfunction, and hence with impaired cognitive performance. Examples of BLE are: repeated mild head injury, repeated operations under general anesthesia, perinatal complications, or excessive drinking. In a large-scale cross-sectional study into cognitive aging, all subjects who had experienced at least one BLE were assigned to a separate group. Their performance in cognitive tests was then compared with that of their age peers who were entirely unaffected by BLE. The tests, whose theoretical backgrounds are discussed in chapter 2, were selected to cover a broad range of cognitive functions, including several aspects of memory, speed of information processing in memory and initiation of movements, sensomotoric speed, attention, and the ability to shift between concepts in ongoing behavior. Although the main reason for the selection of these tests was their theoretical framework, the second important reason was their common use in neuropsychological practice. Also, normative data based on age, gender, education, and -most importantly- health factors, were badly needed for these tests. 
Chapter 3 describes the procedure of subject selection and experimental setup. A minimum number of healthy subjects who had not experienced any BLE was set at twenty. There were seven discontinuous age groups (20 years 3, 30 3, through 80 3). Subject selection was balanced for gender and education. The minimum number of subjects per age $\mathrm{x}$ education (high or low) $\mathrm{x}$ gender cell was set at five. The screening for health factors involved two steps. Community-dwelling subjects who regarded themselves as normal and healthy had been asked to volunteer. At a pre-screening more than a hundred applicants appeared to have sustained a condition associated with major brain damage. These individuals mostly elderly- were not admitted to the study. Two hundred and fifty-six subjects were eventually pre-selected and tested. Prior to the actual examination, the subjects were once again screened for evidence of brain damage. Nine additional subjects did not pass this screening, six of them because they were mildly demented. Thus, we had a large group of selected subjects $(n=247)$ without any a priori likelihood of brain dysfunction or cognitive dysfunctions attributable to a major neurological or psychiatric illness. The average physical and mental condition of the subjects can therefore be said to have been at least as good as that in any experiment reported in the literature.

At the time of the actual testing all subjects were individually interviewed about BLE in their personal history by an experienced neurologist. For the age groups of 70 and 80 years, the number of BLE-affected volunteers exceeded our testing capacity, so that an initial interview over the telephone about BLE had to take place prior to the testing. About another fifty volunteers were excluded at this stage. Subjects aged over 60 were also asked about some of their social and cognitive activities: background variables. Scoring of BLE and background variables is discussed in detail in chapter 3 . Recruitment of subjects continued until the minimum number of BLE-free subjects per age group was reached.

Chapter 4 presents the prevalence of BLE and distribution of background variables in the sample described above. The proportion of BLE-affected individuals roughly increased in each successive age group (from nearly $30 \%$ in subjects aged 20 to nearly $50 \%$ in subjects aged 80 ), although age was poor in predicting quantitative measures of separate BLE. No conclusions about the prevalence of BLE in the whole population can be drawn from these data. The sample for the present study cannot be regarded as representative due to the procedure of subject recruitment. However, in view of the number of excluded elderly volunteers - with brain damage or BLE- it seems likely that the proportion of BLE-affected subjects in the present sample underestimated the actual prevalence in the whole population. It was concluded that the importance of health-related factors has been unduly underestimated in aging research. In elderly subjects, BLE were associated with less participation in cognitively demanding activities (reading or 'mind games' such as crosswords) and sports, but not with watching television.

Chapter 5 describes the findings on primary memory capacity, as measured with the Digit and Block Span Tests. Auditory verbal and visual memory span both declined with age. Also, in both tests, performance was poorer in subjects affected 
by BLE. Regarding visual span, the age-related performance decrement was stronger in BLE-affected individuals. Higher-educated subjects consistently performed better in both tests.

Findings done with an abbreviated version of Sternberg's computerized Memory Scanning Task are presented in chapter 6 . For practical reasons, subjects aged over 60 were not tested with this task. Response time was longer in older and BLEaffected subjects. Moreover, the slopes of the response time as a function of the number of items to remember, increased with age and BLE. These effects also showed interaction, in that the older BLE-affected subjects showed the steepest slope.

Very similar findings were done with a paper-and-pencil version of the Sternberg task, which at the same time allowed for the distinction between automatic and effortful processing (chapter 7). When effortful scanning of the short term memory was unnecessary, the steepness of the slope was much reduced. However, elderly subjects -especially those affected by BLE- appeared less proficient in selecting a strategy that allows for effortless processing. Apparently, they were not able to perceive possibly useful aspects of the task, and confined themselves to the usual and more burdensome way of finishing it.

Chapter 8 discusses the results obtained with a multi-trial free-recall visual verbal learning test, which was an adaptation of a procedure proposed by Rey. The most striking finding was that the maximum performance in BLE-unaffected subjects aged 80 was as good as that of individuals aged 20 or 30 , whereas in those subjects who had experienced BLE performance was markedly poorer. Delayed recall of newly learned material roughly decreased in every successive age group, but BLEunaffected elderly subjects recalled many more items than their affected age mates. In the BLE-affected elderly subjects even the delayed recognition was impaired. Memory performance of women and higher-educated subjects was better than that of men and lower-educated subjects, respectively. Finally, the number of experienced BLE could equally well predict test performance as age, and even correlations with separate BLE (especially anesthesia) were significant. Comparison of the present findings with other recent evidence showed that the average performance found in other studies tends to lie between that of BLEunaffected and BLE-affected subjects.

Chapter 9 presents data from the Stroop Color-Word Test. Older subjects were slower in all subtests of this task, as were BLE-affected and lower-educated subjects. There were no differences due to gender. Again, there were age $\times$ BLE interactions. In the subtest that involved language interference with color naming, the performance of elderly BLE-affected subjects decreased dramatically.

A revision of the Trail Making Test (TMT) and the newly devised Concept Shifting Test (CST) are discussed in chapter 10, along with the experimental findings. The revision of the TMT mainly consisted of adding a test part that contains only letters, which allowed for the calculation of the amount of extra time needed to shift between two concepts. The same was true for the CST, which has some additional advantages. Although virtually all subtests of both tasks showed performance decline that was associated with age, BLE, and education, 
the effects were greatest in the conditions involving concept shifting.

A new tapping test was designed to allow for the registration of the development of simple psychomotor performance over time (chapter 11). By implementing the test on a computer, extending its duration, and dividing the total tapping duration into a number of blocks, the slowing of movements during a test trial can be registered. Tapping performance decreased with age and BLE. A large part of the age effect was due to the fact that elderly subjects appeared to be slower starters but they also showed less decline over time. BLE-affected subjects slowed down more than their BLE-free age-peers.

Chapter 12 presents data obtained with a motor choice reaction test involving three conditions with increasing task complexity. The speed of motor initiation and movements were measured. Age affected all aspects of psychomotor speed, but in the most difficult condition, the slowing that was associated with BLE was by far the largest. Women -especially when BLE-affected- were slower than men, both in reaction times and in movement times.

In chapter 13, four major constructs were identified: memory, cognitive speed, sensomotoric speed, and accuracy. For each of these constructs, a composite score consisting of standardized scores of different test outcomes was proposed. The standardized (Z-)scores had been calculated relative to the performance of BLEunaffected subjects aged 20 and 30 , a procedure that was suggested in the criteria for Age-Associated Memory Impairment (AAMI). The average of all four composite scores declined markedly in the successive age groups, irrespective of BLE: accuracy deteriorated most (the average Z-score in 80-year old subjects was about -9), followed by cognitive speed and sensomotoric speed. The memory score showed only little decline with age. For all scores the variability increased markedly with age. However, in BLE-free subjects there was no increase in variance of the memory en speed scores, only in the accuracy score. Moreover, in BLE-affected subjects, the age-associated decline was much more pronounced than in unaffected individuals. The cognitive speed score in BLE-affected elderly was four or five times lower than in their unaffected age-mates. It was proposed that the AAMI criterion of a memory Z-score lower than -1 is too rigorous, and should be lowered to -2: too many normal subjects would fall into the AAMIrange. The finding that the other composite scores also declined with age, suggested that the concept of AAMI should be supplemented with criteria for ageassociated impairments of other functions.

Elderly subjects who spent much time in reading, sports, and puzzles generally showed better performance. It can be hypothesized that such 'mind jogging' constitutes some 'protective factor' against age-associated cognitive decline. 'Use it or lose it' seems to be a appropriate slogan in this respect. No conclusions about the effects of separate BLE can be drawn, as the number of subjects affected by one single BLE was too small, and the procedure of subject recruitment was not representative for the whole population. However, the number of operations under general anaesthesia appeared to be most closely inversely related to test performance.

In chapter 14 the outcomes of the present study are discussed in the light of 
current thinking about cognitive aging and normality. Recently, it was suggested that normal -that is non-diseased- aging should be subdivided into successful and usual aging. Usual aging would be the result of age-intrinsic changes (as encountered in successful aging) plus non-pathologic changes that are often encountered in old age, but that are not inherent to age. In the present thesis it is hypothesized that BLE constitute a biological substrate for usual aging. BLEunaffected individuals are probably a minority in the whole aging population, that also includes pathological aging. Also, it was hypothesized that subjects who can be characterized by AAMI are over-represented in BLE-affected elderly. The implications of the finding that BLE were associated with enhanced age-related decline are twofold: In the area of health care and safety, some regulations should be more strict. In research on aging and dementia, subjects who are supposedly normal, should be subjected to a much more rigorous health screening than is the case in the great majority of studies. If a thorough health screening is not part of the experimental procedure, it is not clear whether the age-associated decline that is observed, is the effect of aging per se, or a consequence of age-extrinsic health factors.

The present study will serve as basis for a longitudinal project, in which all subjects will be tested again with the same methods five years after the first examination. Early 1992, the first individuals will be re-examined. Furthermore, a very large-scale project is being planned: The Netherlands Memory and Aging Project (NMAP). In the NMAP, involving at least 3360 subjects, the effect of separate BLE will be studied in a prospective manner. The NMAP is planned as a cross-sequential study and shares much of it's methodology with other large-scale studies that are currently being carried out. 


\section{SAMENVATTING}

De onderzoekers op het gebied van veroudering zijn het er wel over eens dat veel -zo niet alle- cognitieve functies achteruitgaan met het klimmen der jaren. Deze algemene overtuiging, die onderbouwd wordt door een nog steeds groeiende hoeveelheid onderzoeksevidentie, wordt weerspiegeld door subjectieve klachten van veel ouderen over geheugen-achteruitgang, verminderde concentratie, traagheid van denken, of onvermogen meerdere dingen tegelijk te doen. De studie van cognitieve veroudering is wel genoemd cognitieve gerontologie, waarvoor vier hoofdvragen zijn geformuleerd: 1 . Wanneer worden cognitieve veranderingen voor het eerst duidelijk in een mensenleven? 2. Hoe snel gaan cognitieve functies dan achteruit? 3 . Welke functies zijn het meest gevoelig voor veroudering? 4. Welke individuen zijn het meest kwetsbaar voor leeftijd-gerelateerde cognitieve achteruitgang? Deze belangrijke vragen worden besproken in hoofdstuk 1, samen met een aantal methodologische problemen die specifiek zijn voor verouderings-onderzoek. Het belangrijkste probleem is dat leeftijdseffecten altijd moeten worden afgeleid uit verschillen in de een of andere parameter, binnen dezelfde individuen (zoals in longitudinaal onderzoek), of tussen individuen van verschillende leeftijden (zoals in cross-sectioneel onderzoek). Moeilijkheden bij het afleiden van oorzaak en gevolg kunnen voortkomen uit beide benaderingen, en binnen een onderzoek dat die twee verenigt (sequentieel of cross-sequentieel) moet rekening worden gehouden met de beperkingen van beide technieken.

Er zijn nog meer methodologische problemen. Het belangrijkste daarvan is waarschijnlijk het elimineren van factoren waarvan de gevolgen op die van veroudering op zich kunnen lijken, of die de achteruitgang kunnen versterken. Merkwaardig genoeg ontbreekt in de literatuur over veroudering informatie over de interactie tussen veroudering en lichte, gezondheid-gerelateerde factoren die in verband gebracht kunnen worden met gestoorde hersenfuncties (biologische 'life events'; BLE). Echter, naar aanleiding van enkele suggesties terzake en onderzoeksgegevens afkomstig uit andere disciplines, gingen wij er bij de aanvang van het hier besproken onderzoek van uit, dat gezondheidsfactoren kunnen interacteren met leeftijd wat betreft cognitieve prestaties, zoals gemeten met cognitieve tests: mensen die zulke gezondheidsfactoren achter de rug hebben, kunnen slechtere prestaties laten zien dan proefpersonen bij wie dat niet het geval is geweest. Die verschillen kunnen steeds groter worden met toenemende leeftijd.

Negen categorieen BLE werden onderscheiden, elk gebaseerd op onderzoeksgegevens waaruit bleek dat ze verband hielden met hersendysfuncties, en daarmee met cognitieve functiestoornissen. Voorbeelden van BLE zijn: herhaald licht hersentrauma, herhaalde operaties onder algehele narcose, complicaties bij de geboorte of overmatig alcoholgebruik. Bij een grootschalig cross-sectioneel onderzoek naar cognitieve veroudering werden alle proefpersonen die tenminste één BLE achter de rug hadden, ingedeeld in een aparte groep. Hun testprestaties werden vergeleken met die van hun leeftijdgenoten die geen enkele BLE hadden 


\section{SAMENVATTING}

De onderzoekers op het gebied van veroudering zijn het er wel over eens dat veel -zo niet alle- cognitieve functies achteruitgaan met het klimmen der jaren. Deze algemene overtuiging, die onderbouwd wordt door een nog steeds groeiende hoeveelheid onderzoeksevidentie, wordt weerspiegeld door subjectieve klachten van veel ouderen over geheugen-achteruitgang, verminderde concentratie, traagheid van denken, of onvermogen meerdere dingen tegelijk te doen. De studie van cognitieve veroudering is wel genoemd cognitieve gerontologie, waarvoor vier hoofdvragen zijn geformuleerd: 1 . Wanneer worden cognitieve veranderingen voor het eerst duidelijk in een mensenleven? 2. Hoe snel gaan cognitieve functies dan achteruit? 3. Welke functies zijn het meest gevoelig voor veroudering? 4. Welke individuën zijn het meest kwetsbaar voor leeftijd-gerelateerde cognitieve achteruitgang? Deze belangrijke vragen worden besproken in hoofdstuk 1, samen met een aantal methodologische problemen die specifiek zijn voor verouderingsonderzoek. Het belangrijkste probleem is dat leeftijdseffecten altijd moeten worden afgeleid uit verschillen in de een of andere parameter, binnen dezelfde individuën (zoals in longitudinaal onderzoek), of tussen individuën van verschillende leeftijden (zoals in cross-sectioneel onderzoek). Moeilijkheden bij het afleiden van oorzaak en gevolg kunnen voortkomen uit beide benaderingen, en binnen een onderzoek dat die twee verenigt (sequentieel of cross-sequentieel) moet rekening worden gehouden met de beperkingen van beide technieken.

Er zijn nog meer methodologische problemen. Het belangrijkste daarvan is waarschijnlijk het elimineren van factoren waarvan de gevolgen op die van veroudering op zich kunnen lijken, of die de achteruitgang kunnen versterken. Merkwaardig genoeg ontbreekt in de literatuur over veroudering informatie over de interactie tussen veroudering en lichte, gezondheid-gerelateerde factoren die in verband gebracht kunnen worden met gestoorde hersenfuncties (biologische 'life events'; BLE). Echter, naar aanleiding van enkele suggesties terzake en onderzoeksgegevens afkomstig uit andere disciplines, gingen wij er bij de aanvang van het hier besproken onderzoek van uit, dat gezondheidsfactoren kunnen interacteren met leeftijd wat betreft cognitieve prestaties, zoals gemeten met cognitieve tests: mensen die zulke gezondheidsfactoren achter de rug hebben, kunnen slechtere prestaties laten zien dan proefpersonen bij wie dat niet het geval is geweest. Die verschillen kunnen steeds groter worden met toenemende leeftijd.

Negen categorieën BLE werden onderscheiden, elk gebaseerd op onderzoeksgegevens waaruit bleek dat ze verband hielden met hersendysfuncties, en daarmee met cognitieve functiestoornissen. Voorbeelden van BLE zijn: herhaald licht hersentrauma, herhaalde operaties onder algehele narcose, complicaties bij de geboorte of overmatig alcoholgebruik. Bij een grootschalig cross-sectioneel onderzoek naar cognitieve veroudering werden alle proefpersonen die tenminste eén BLE achter de rug hadden, ingedeeld in een aparte groep. Hun testprestaties werden vergeleken met die van hun leeftijdgenoten die geen enkele BLE hadden 
gehad. De tests, waarvan de theoretische achtergrond besproken wordt in hoofdstuk 2, waren gekozen om een breed scala van cognitieve functies te bestrijken: verscheidene aspecten van het geheugen, snelheid van informatieverwerking, sensomotorische snelheid, aandacht en het vermogen om snel tussen twee bezigheden te wisselen. Hoewel hun theoretisch kader de hoofdreden was om juist deze tests te kiezen, was een andere belangrijke reden het feit dat zij vaak gebruikt worden in de neuropsychologische praktijk. Voor dit doel was er een grote behoefte aan normgegevens die gebaseerd zijn op leeftijd, geslacht, opleidingsniveau en, vooral, gezondheidsfactoren.

Hoofdstuk 3 beschrijft de procedure van de proefpersoon-selectie en de onderzoeksopzet. Het minimum aantal gezonde proefpersonen die geen BLE hadden gehad, werd vastgesteld op twintig. Er waren zeven discontinuë leeftijdsgroepen (20 jaar, 30 jaar, etc. tot en met 80 jaar, met een maximale afwijking van 3 jaar per groep). De proefpersoon-selectie was gebalanceerd qua geslacht en opleidingsniveau. Er waren tenminste vijf personen per cel (leeftijd $x$ opleiding (hoog of laag) $x$ geslacht). De selectie op grond van gezondheidsfactoren bestond uit twee stappen. Alleen zelfstandig wonende vrijwilligers die zichzelf als normaal en gezond beschouwden, waren opgeroepen. Echter, bij een voorselectie bleken meer dan honderd geïnteresseerden toch een aandoening gehad te hebben die hersenschade tot gevolg kan hebben. Deze mensen -vooral ouderen- vielen af. Uiteindelijk werden 256 mensen onderzocht. Voorafgaand aan het eigenlijke onderzoek werden de proefpersonen nog eens ondervraagd over eventuele hersenschade. Nog eens negen mensen vielen hierbij af; zes van hen waren licht dement. Zo werd een grote groep van proefpersonen samengesteld $(n=247)$ van wie er niet a priori hoefde worden aangenomen dat er sprake was van hersendysfunctie of cognitieve stoornissen als gevolg van een neurologische of psychiatrische aandoening. Er kan dus gesteld worden dat de gemiddelde fysieke en mentale conditie van de proefpersonen minstens even goed was als die in enig ander gerapporteerd verouderingsonderzoek.

Voor het onderzoek werden alle proefpersonen door een ervaren neuroloog individueel ondervraagd over BLE in hun medische voorgeschiedenis. Wat betreft de vrijwilligers van 70 en 80 jaar overtrof het aantal mensen met een BLE onze test-capaciteit. Daarom moest er een eerste telefonisch gesprek over BLE plaatsvinden. Nog eens ongeveer 50 mensen werden daarna niet onderzocht. Mensen ouder dan 60 werden ook ondervraagd over enkele van hun sociale en cognitieve bezigheden: deze worden wel achtergrond-variabelen genoemd. Scoring daarvan, en van BLE, wordt ook in hoofdstuk 3 besproken. De werving van proefpersonen ging door totdat het minimum aantal van BLE-vrije individuën per leeftijdsgroep was bereikt.

Hoofdstuk 4 laat de prevalentie van BLE zien en de verdeling van de achtergrondvariabelen in de bovenbeschreven steekproef. De proportie van mensen met een BLE nam grofweg toe in elke opeenvolgende leeftijdsgroep (van bijna $30 \%$ bij de 20 -jarigen tot bijna $50 \%$ bij de 80 -jarigen), hoewel leeftijd een slechte voorspeller was van kwantitatieve maten voor afzonderlijke BLE. Er kunnen, op grond van deze gegevens, geen conclusies worden getrokken over de prevalentie van BLE in 
de hele bevolking. De steekproef-populatie voor dit onderzoek kan niet als representatief worden beschouwd als gevolg van de procedure van proefpersoonwerving. Echter, gezien het aantal uitgesloten vrijwilligers -met hersenschade of BLE- lijkt het waarschijnlijk dat de proportie van mensen met een BLE in de huidige steekproef een onderschatting betekent van de werkelijke prevalentie. Er werd geconcludeerd dat het belang van gezondheidsfactoren onderschat is geweest in verouderingsonderzoek. Ouderen met BLE deden minder mee aan cognitief veeleisende activiteiten (lezen of denksport zoals kruiswoord-raadsels) en sport, maar er werd geen verband gevonden met niet-inspannende zaken als TV-kijken.

Hoofdstuk 5 beschrijft de bevindingen aangaande de capaciteit van het kortetermijngeheugen, zoals dat onderzocht werd met de Digit - en Block Span Tests. De auditief-verbale en visuele geheugenspanne namen beide af met leeftijd. Voorts was bij beide tests de prestatie slechter bij mensen met BLE. Wat betreft de visuele spanne was de leeftijd-gerelateerde achteruitgang sterker bij mensen met een BLE. Hoger-opgeleide proefpersonen deden het beter in beide tests.

Bevindingen met een ingekorte versie van Sternbergs Geheugen-Vergelijkingstaak worden besproken in hoofdstuk 6 . Om praktische redenen zijn de proefpersonen die ouder waren dan 60 niet met deze taak onderzocht. De responstijd was langer in oudere en door BLE getroffen proefpersonen. Bovendien nam de hellingshoek van de responstijd als functie van het aantal te onthouden items toe. Deze effecten lieten ook interactie zien: oudere mensen met BLE vertoonden de grootste hellingshoek.

Sterk daarop lijkende resultaten werden gevonden met een papier-en-potloodversie van de Sternberg-taak, die tegelijkertijd ook nog het onderscheid toelaat tussen automatische en bewuste cognitieve verwerking (hoofdstuk 7). Wanneer bewust zoeken in het korte-termijn-geheugen niet nodig was, waren de hellingshoeken veel kleiner. Maar ouderen -vooral die met BLE- bleken zich minder makkelijk een strategie te kunnen aanmeten die automatische verwerking toelaat. Blijkbaar waren zij niet in staat om handige kenmerken van de test waar te nemen en bepaalden zij zich tot de gebruikelijke en dus moeizamere wijze om hem af te maken.

Hoofdstuk 8 bespreekt de bevindingen gedaan met de 'Vijftien-Woorden-Test'. Het meest opvallende resultaat was dat de maximale prestatie bij mensen van 80 jaar zonder BLE net zo goed was als die van proefpersonen van 20 of 30, terwijl bij die mensen die BLE doorgemaakt hadden de prestatie wèl veel slechter was. Uitgestelde herinnering van nieuw-geleerd materiaal nam -grofweg- af in elke opeenvolgende leeftijdsgroep, maar mensen zonder BLE reproduceerden veel meer items dan hun leeftijdgenoten mèt. In oudere proefpersonen met BLE was zelfs de uitgestelde herkenning gestoord. De geheugenprestaties van vrouwen en hoog-opgeleide mensen waren beter dan die van respectievelijk mannen en lageropgeleiden. Tenslotte was het aantal doorgemaakte BLE een even goede voorspeller van testprestaties als leeftijd, en zelfs correlaties met afzonderlijke BLE (vooral anaesthesie) waren significant.

Hoofdstuk 9 laat de resultaten zien die zijn verkregen met de Stroop-test. Oudere 
mensen waren trager in alle onderdelen van deze taak, net als mensen met BLE en lager-opgeleide mensen. Er waren geen prestatie-verschillen tussen mannen en vrouwen. Opnieuw waren er interacties tussen leeftijd en BLE. In het testdeel met taal-interferentie bij het kleur-benoemen nam vooral de prestatie van oudere mensen met BLE dramatisch af.

Een herziene versie van de Trail Making Test (TMT) en de nieuw-ontworpen Concept Shifting Test (CST) worden besproken in hoofdstuk 10, samen met de onderzoeksresultaten. De herziening van de TMT bestond hoofdzakelijk in het toevoegen van een deeltaak die alleen maar letters bevat en daarmee de berekening mogelijk maakt van de hoeveelheid extra tijd die nodig is voor het wisselen tussen twee concepten. Dat geldt ook voor de CST, die nog enkele andere voordelen heeft. Hoewel bijna alle deeltaken van beide tests achteruitgang van prestaties lieten zien, die gerelateerd was aan leeftijd, BLE en opleiding, waren de verschillen toch het grootst in díe condities die een beroep deden op het wisselen tussen concepten.

Een nieuwe tapping-test werd ontworpen om de registratie mogelijk te maken van de ontwikkeling van eenvoudige psychomotore prestaties gedurende de testtijd (hoofdstuk 11). Door de test via een computer af te nemen, de duur te verlengen en die onder te verdelen in deel-intervallen, werd het mogelijk vertraging van de bewegingen tijdens een testonderdeel te bestuderen. De prestaties liepen terug met leeftijd en BLE. Het leeftijdseffect kon goeddeels worden verklaard met het feit dat de ouderen tragere starters waren, maar wel minder vertraagden tijdens het tappen. Mensen met BLE vertraagden daarentegen weer meer dan hun leeftijdgenoten zonder BLE.

Hoofdstuk 12 laat gegevens zien die verkregen zijn met een motorische reactiekeuze-taak met drie verschillende condities die opliepen qua complexiteit. Snelheid van bewegingsvoorbereiding en -uitvoering werd gemeten. Leeftijd had effect op alle aspecten van psychomotore snelheid, maar in de moeilijkste conditie was de BLE-geassocieerde vertraging verreweg het sterkst. Vrouwen waren trager dan mannen, zowel qua reactie- als bewegingssnelheid, vooral wanneer zij een BLE hadden doorgemaakt.

In hoofdstuk 13 worden vier belangrijke constructen vastgesteld: geheugen, cognitieve snelheid, sensomotorische snelheid en nauwkeurigheid. Voor elk van deze constructen werd een samengestelde score voorgesteld, die bestond uit gestandaardiseerde scores van verschillende testresultaten. De gestandaardiseerde (Z-)scores werden berekend ten opzichte van de prestaties van gezonde mensen van 20 en 30 jaar, zoals dat ook wordt voorgesteld in de criteria voor 'AgeAssociated Memory Impairment (AAMI)'. De gemiddelde Z-score van alle samengestelde scores vertoonde achteruitgang met leeftijd, BLE buiten beschouwing gelaten: nauwkeurigheid nam het sterkst af (de gemiddelde Z-score van 80-jarigen was -9), gevolgd door cognitieve en sensomotorische snelheid. De geheugen-score vertoonde slechts lichte achteruitgang. Voor alle scores nam de spreiding sterk toe met leeftijd. Bij mensen zonder BLE was er echter géén toename van de spreiding wat betreft geheugen en de beide snelheidsmaten, alleen wat betreft nauwkeurigheid. Bovendien was bij individuën die BLE 
hadden doorgemaakt de achteruitgang veel meer uitgesproken dan bij hun optimaal gezonde leeftijdgenoten. De score voor cognitieve snelheid was bij ouderen vier tot vijf maal lager wanneer er sprake was van BLE. Er werd gesteld dat het AAMI-criterium van een Z-score voor geheugen lager dan -1 te rigoureus is, en dat deze waarde tot -2 verlaagd moet worden: anders vallen er te veel volkomen normale mensen in de AAMI-range. De bevinding dat andere samengestelde scores ook achteruit gingen, leidde tot de suggestie dat de notie van AAMI aangevuld zou moeten worden met criteria voor andere leeftijdgeassocieerde stoornissen.

Ouderen die veel tijd doorbrachten met lezen, sport of denksport, lieten doorgaans betere testprestaties zien. De hypothese kan worden opgeworpen dat zulke 'hersengymnastiek' een zgn. beschermingsfactor kan betekenen tegen cognitieve achteruitgang. 'Use it or lose it' lijkt in dit verband een toepasselijke uitspraak. Aan het huidige onderzoek kunnen geen conclusies worden verbonden aangaande het effect van afzonderlijke BLE, aangezien de aantallen proefpersonen met één enkele BLE te gering waren, en de procedure van proefpersoon-werving niet representatief was voor de hele bevolking. Het aantal doorgemaakte operaties onder algehele narcose bleek echter het sterkst negatief verband te houden met testprestaties.

In hoofdstuk 14 worden de bevindingen van dit onderzoek besproken in het licht van vigerende opvattingen over cognitieve veroudering en normaliteit. Recentelijk is naar voren gebracht dat normale, dat wil zeggen niet door ziekte bepaalde, veroudering zou moeten worden onderverdeeld in succesvolle en gangbare veroudering. Gangbare veroudering is dan het resultaat van processen die intrinsiek zijn aan fysiologische (=succesvolle) veroudering, plus de nietpathologische veranderingen die wèl vaak voorkomen bij ouderen, maar die toch niet inherent zijn aan kalenderleeftijd. In dit proefschrift wordt de hypothese geformuleerd dat BLE een biologisch substraat vormen voor gangbare veroudering. Mensen zonder BLE vormen waarschijnlijk een minderheid binnen de verouderende bevolking, waar ook nog eens de pathologische veroudering onder valt. Voorts werd er gesteld dat mensen die gekenmerkt worden door AAMI over-vertegenwoordigd zijn in de groep van individuën met BLE. De implicaties van de bevinding dat BLE verband houden met een sterkere leeftijd-geassocieerde achteruitgang zijn tweeërlei: Op het gebied van de gezondheidszorg en veiligheid zouden sommige regels moeten worden aangescherpt en zou het beleid, bijvoorbeeld inzake anaesthesie of medicatie, moeten worden gewijzigd. In alle onderzoek naar cognitieve veroudering met proefpersonen die geacht worden normaal te zijn, behoort een grondige gezondheidsscreening deel uit te maken van de procedure. Als dat niet het geval is, is het onduidelijk of de eventueel gevonden leeftijdseffecten toe te schrijven zijn aan de leeftijd als zodanig, of aan andere, niet leeftijd-intrinsieke factoren zoals BLE.

Het hier beschreven onderzoek zal dienen als basis voor een longitudinaal project, waarin alle proefpersonen vijf jaar na dato opnieuw getest zullen worden met dezelfde methoden. Begin 1992 worden de eerste proefpersonen onderzocht. Voorts wordt er momenteel een zeer grootschalig project voorbereid: het 
Netherlands Memory and Aging Project (NMAP). In dit onderzoek, waaraan meer dan drieduizend proefpersonen zullen deelnemen, kan het effect van afzonderlijke BLE prospectief onderzocht worden. Het NMAP wordt gepland als een cross-sequentieel onderzoek en komt in methodologisch opzicht sterk overeen met andere, in het buitenland reeds lopende, longitudinale projecten. 


\section{WOORDEN VAN DANK}

Veel mensen zijn bij de totstandkoming van dit proefschrift betrokken geweest. Van hen wil ik er een aantal in dankbaarheid noemen.

Jelle Jolles was een goed en geestdriftig promotor: hij heeft mij goed begeleid, waar nodig aangespoord, afgeremd of richting gegeven, en steeds prompt mijn schrijfsels van commentaar voorzien. En nu mogen we weer gaan fietsen.

Alle twee honderd en tweeenzestig proefpersonen ben ik dank verschuldigd. Bij dezen. Speciaal genoemd moeten worden: Mr. D. Tripels en de leden van fanfare St. Joezep, de directie en bewoners van het verzorgingshuis Campagne, en het Gilde Maastricht.

Helma de Veth heeft talloze proefpersonen te woord gestaan, afspraken gemaakt en weer afgezegd. Dianne van de Ven en Colette Verbeek hebben veel van het testwerk gedaan. Germa Wijnen heeft mij een hoop werk uit handen genomen. Elsa Misdom heeft mij geduldig verdragen op haar secretariaat terwijl ik met de materie worstelde.

Met Paul Ganzevles en Leo Plugge heb ik veel stimulerende gedachtenwisselingen gehad.

Samen met Fred Vreeling je onderzoek doen maakte het twee maal leuker, ook al omdat Corinne, Vreneli en Kiki hun huis welhaast tot het mijne maakten.

Meryan Broeren en Maurice Wolfhagen boden mij vriendschap, onderdak en whisky tijdens mijn dienstreizen.

Door de inspanning en het gastvrij onthaal van de familie Kersten werd voor mij het autorijden -of het betalen van een promotie- haalbaar gemaakt. Voorts leerde ik dat een uitlaat aan de goede kant van de mof doorgezaagd dient te worden.

Zonder Anja Jansens inzet was het boekje niet op tijd afgeweest, en zeker niet in deze vorm. 


\section{CURRICULUM VITAE}

De schrijver van dit proefschrift werd geboren op 9 maart 1958 te 's-Gravenhage. In 1977 werd het diploma gymnasium- $\alpha$ behaald, aan het St. Bonifatius-college te Utrecht. Daar ter stede werd de propaedeuse Nederlandse Taal- en Letterkunde doorlopen. Zijn militaire dienstplicht vervulde hij als kanonnier. In Utrecht studeerde hij psychologie, met als hoofdrichting functieleer, nevenrichting klinische psychologie, en als bijvakken filosofie, musicologie en biologie (kandidaats), neurologie, informatica en psychopathologie (doctoraal). Het afstudeeronderwerp betrof de neuropsychologie en menselijke informatieverwerking. De bul werd in 1986 behaald. In dat jaar trad hij tevens in tijdelijke dienst bij de Rijkuniversiteit Limburg, bij prof. dr. J. Jolles, leider van het Deelproject 'Hersenen en Gedrag (Hoofdproject Veroudering). Daar werd het onderzoek verricht waarvan dit proefschrift de weerslag is. De auteur zal zich de komende jaren bezighouden met onderzoek naar cognitieve veroudering en (biologische) determinanten daarvan. 

Appendix I:

On the following pages, instructions for administration and scoring are given for new and revised tests presented in this thesis:

1 - Paper and Pencil Memory Scanning Task (chapter 6)

2 - Revised Trail Making Test (chapter 10)

3 - Concept Shifting Test (chapter 10)

4 - Continuous Performance Tapping Test (chapter 11)

5 - Motor Choice Reaction Test (chapter 12)

See the text in chapters $6,10,11$, and 12, for information about the theoretical background, purpose and general procedure. 


\section{1 - Paper and Pencil Memory Scanning Task (P\&P-MST)}

Prerequisites: stopwatch, pencil, nine test sheets, nine corresponding example sheets with memory sets.

First \% part

Put the first test sheet, and next to it, the example sheet (with only the $\%$-sign) facing upward in front of the subject.

On this sheet you see the percentage sign. I want you to remember this, for on this sheet (point) you will see a number of these signs. You have to find them between all the letters and cross them out, as fast as you can, but without making any mistakes. You must proceed line by line. Did you understand all this? Go ahead. Press the stopwatch. Watch closely that the subject is working line by line, instead of screening all of the stimulus matrix. Stop the stopwatch when the subject has crossed out the last item on the last line, and remove the test sheet. The subject is not allowed to re-scan the paper for omitted items.

Digit parts

Put the test sheet, and, on top of that, the example sheet (with only the memory set) in front of the subject. Now you have to remember this digit (do not say: seven) and cross it out, each time you see it on this paper, as fast as you can, but without making any mistakes. The subject is allowed to look at the example sheets for 5 seconds per item in the memory set. Go ahead. Remove the example sheet and press the stopwatch. See \% -part.

Ok. This time you have to remember twolfour digits.

Letters parts

This task is a little different. This time you have to remember one/two/three/ four letters. You still have to work as fast as you can, without making mistakes. See $\%$ - and digits parts.

Second \% -part

Finally, I want you to once again cross out this sign.

Raw data per test sheet are time and number of positive and negative errors, every error is taken down on the score form. A number of calculations can be made. 
Calculation of slope (Sl), 1-intercept (B1), and linearity ( $\mathrm{Ln}$ ) for digits (D) and letters (L) subtests of the P\&P-MST. The following notation is suitable for most computer software, but can also be followed for manual computation. $D_{1,2,4}$ denote the time needed for the three digits test parts, $\mathrm{L}_{1-4}$ for the four letter test parts; ${ }^{\wedge}$ : squared; $S Q R(X)$ : square root of $X$.

$$
\begin{aligned}
\mathrm{DSl}= & \left(7^{*}(\mathrm{D} 1+\mathrm{D} 2+\mathrm{D} 4) / 3-\left(\mathrm{D} 1+2^{*} \mathrm{D} 2+4^{*} \mathrm{D} 4\right)\right) /(49 / 3-21) \\
\mathrm{CB} 1= & ((\mathrm{D} 1+\mathrm{D} 2+\mathrm{D} 4) / 3-\mathrm{DTg} 7 / 3)+\mathrm{DSl} \\
\mathrm{CLn}= & \left(3^{*}\left(\mathrm{D} 1+2^{*} \mathrm{D} 2+4^{*} \mathrm{D} 4\right)-7^{*}(\mathrm{D} 1+\mathrm{D} 2+\mathrm{D} 4)\right) / \\
& \left(\mathrm{SQR}\left(14^{*}\left(3^{*}\left(\mathrm{D} 1^{\wedge} 2+\mathrm{D} 2^{\wedge} 2+\mathrm{D} 4^{\wedge} 2\right)-(\mathrm{D} 1+\mathrm{D} 2+\mathrm{D} 4)^{\wedge} 2\right)\right)\right) \\
\mathrm{LS}= & \left(10^{*}(\mathrm{~L} 1+\mathrm{L} 2+\mathrm{L} 3+\mathrm{L} 4) / 4-\left(\mathrm{L} 1+2^{*} \mathrm{~L} 2+3^{*} \mathrm{~L} 3+4^{*} \mathrm{~L} 4\right)\right) /-5 \\
\mathrm{LB} 1= & \left((\mathrm{L} 1+\mathrm{L} 2+\mathrm{L} 3+\mathrm{L} 4) / 4-\mathrm{LT}{ }^{*} 2.5\right)+\mathrm{LS} 1 \\
\mathrm{LLn}= & \left(4^{*}\left(\mathrm{~L} 1+2^{*} \mathrm{~L} 2+3^{*} \mathrm{~L} 3+4^{*} \mathrm{~L} 4\right)-10^{*}(\mathrm{~L} 1+\mathrm{L} 2+\mathrm{L} 3+\mathrm{L} 4)\right) / \\
& \left(\mathrm{SQR}\left(20^{*}\left(4^{*}\left(\mathrm{~L} 1^{\wedge} 2+\mathrm{L} 2^{\wedge} 2+\mathrm{L} 3^{\wedge} 2+\mathrm{L} 4^{\wedge} 2\right)-(\mathrm{L} 1+\mathrm{L} 2+\mathrm{L} 3+\mathrm{L} 4)^{\wedge} 2\right)\right)\right)
\end{aligned}
$$


2 - Revised Trail Making Task (R-TMT)

Prerequisites: stopwatch, pencil, four test sheets. All test sheets are printed at both sides: on the one side is the practice trial, on the other the test trial. Give the subject the pencil en put all sheets with the practice samples facing upwards in front of him/her, before starting the test instruction.

Part A

Here you see some digits, in these small circles. This task is only for practice. I want you to draw a line through all the digits in the right order, starting at 1 and ending at 8 (point at the digits). You must not take the pencil from the paper.

(Take another test sheet if the subject has made more than one error.) Turn the sheet.

Ok, now we do the real task. This task is the same as the practice task, only much longer. Again, you draw a line from begin to end. I want you to do it as fast as you can. I am recording the time you need for this task. Go ahead.

Press the stopwatch as soon as the subject puts the pencil at the first digit, or starts scanning the test sheet. Correct any errors at once, without resetting the stopwatch.

\section{Part B}

Ok, here is another practice task, this time with letters. You draw the line from $A$ to $H$.

Turn the sheet.

Now you are to start with $A$ and to stop at Z. Again, you must work as fast as you can, without taking the pencil from the paper. Go ahead.

\section{Part C}

This task is a little different. As you draw the line, you have to keep switching between digits and letters. Like this: from 1, you go to $A$, and then the next digit, and then the next letter, and so on. (Do not say 1-A-2-B-etc.)

Turn the sheet.

Ok. Remember, you have to switch between digits and letters, and work as fast as you can.

Correct all errors (e.g., connecting E to F) at once: No, you have to go to the next digit. If the subject is lost in intersecting lines: You were here (point) and now you have to go to the next digit/letter.

Some prefer to administer the original part B (B) at this stage. The instructions are identical as for part $C$. The practice trial can be omitted.

\section{Part 0}

This is the last part of this test. Now we have already drawn the line between the circles. I want you to follow the line as fast as you can. You don $t$ have to be careful, just follow the line very fast. 
Raw data per test sheet are time and number of errors. A number of calculations can be made. A-B-C denote the time needed per test sheet.

B - A ....................... Extra time needed for letters

$((B-A) / A) * 100 \% \ldots \ldots \ldots \ldots \ldots$.

$C-.5^{*}(A+B) \ldots \ldots \ldots \ldots \ldots \ldots \ldots$ Extra time needed for concept shifting

$\left(\left(C-.5^{*}(A+B)\right) / .5^{*}(A+B)\right) * 100 \% \quad$.. Slowing due to concept shifting

$(B-C) / C * 100 \% \ldots \ldots \ldots \ldots$. $\ldots$. $\ldots$ lowing due to increased difficulty of $B$ 
3 - Concept Shifting Task

Prerequisites: stopwatch, pencil, eleven test sheets. Show every test sheet at the moment the instruction is given.

\section{Practice trial}

Part A: Here you see some small circles with digits in them, from 1 to 6 (point from 1 to 6). You see? I want you to cross out all digits as fast as you can, in the right order.

Part B: This task is similar, but this time you have to cross out letters, from $A$ to $F$. Part C: This task is a little different. You have to keep switching between digits and letters. Like this: from 1, you go to $A$, and then the next digit, end then the next letter, and so on. (Do not say 1-A-2-B-etc.)

\section{Trial 1}

Part A: This is the real test. Again, you are to cross out all digits, in the right order, only there are more of them. Remember to work as fast as you can. Go ahead.

Press the stopwatch as soon as the subject puts the pencil at the first digit, or starts scanning the test sheet. Do not correct any errors, but write down where the subject made the error. Observe carefully.

Part B-C: Again, you have to ... See practice trial.

\section{Trial 2}

Part A: Now we do all tasks once again, but the digits and letters are in different places. You have to cross out al digits in the right order and as fast as you can.

Part B-C: Again, you have to ... See practice trial.

\section{Trial 0}

Now I want to see how fast you can cross out these empty circles, clockwise. You see? Go ahead. Record the time as accurately as possible. Repeat this once.

Raw data per test sheet are time and number of errors. A number of calculations can be made. A-B-C denote the time needed per test sheet.

B - A ...................... Extra time needed for letters

$((B-A) / A) * 100 \% \ldots \ldots \ldots \ldots \ldots$ Slowing due to letters

$C-.5^{*}(A+B) \ldots \ldots \ldots \ldots \ldots \ldots$ Extra time needed for concept shifting

$\left(\left(C-.5^{*}(A+B)\right) / .5^{*}(A+B)\right) * 100 \%$. Slowing due to concept shifting

$A_{1}-A_{2} \ldots \ldots \ldots \ldots \ldots \ldots$ Practice effect

$\mathrm{B}_{1}-\mathrm{B}_{2} \ldots \ldots \ldots \ldots \ldots \ldots \ldots \ldots$ Practice effect

$C_{1}-C_{2} \ldots \ldots \ldots \ldots \ldots \ldots \ldots$ Practice effect 
4 - Continuous Performance Tapping Test (chapter 11)

Prerequisites: Computer, special keyboard, console.

Put your right (left) hand on this shelf and your index finger on this red button here. In a moment, I want you to tap this button for twenty seconds as fast as you can. Now try tapping the button. Keep your wrist on the shelf. Now with the other hand. Ok, you can start tapping with your right hand whenever you are ready. I will tell you when the twenty seconds are over.

There are three trials for each hand. The subject is to change hands between each trial.

Intervals between taps are saved on disk as raw data. A screen or printout is generated automatically, which gives per trial:

- the number of taps per 5-second interval and overall tapping rate;

- slope, 1-intercept, and linearity of tapping rate as a function of interval number.

Also, for each hand, mean, slope, 1-intercept, and linearity are given. 
5 - Motor Choice Reaction Test (chapter 12)

Prerequisites: Computer, special keyboard, console.

Simple reaction time condition

I want you to hold down this red button, until this upper button is lit. As that happens, you have to press that button immediately, and then press the red button again. Hold the red button down until the upper button is lit again.

Demonstrate a few trials. There are a number of practice trials for the subject, during which errors must be corrected. If the subject tends to release the red button during the response-stimulus interval, repeat the instruction that the red button must be kept down.

\section{Choice reaction time condition}

The next task is very similar to the one before, only this time one of these upper three buttons can be lit (point). You have to press the lit button immediately, and then press the red button again.

Demonstrate a few trials.

Incompatible choice reaction time condition

In the next task, one of these three buttons can be lit, just as in the previous task. But this time, instead of that button itself, you press the one next to it, clockwise. For instance, if this button is lit (point), you have to press this one (point), and then press the red button again. Do not release the red button until you are sure which of these buttons you should press.

Demonstrate a few trials.

Usually, this procedure is repeated once at this stage, depending on the experimental paradigm. A screen or printout is generated automatically, giving, per condition: mean, standard deviation, and median of reaction time, movement time, 'press' time, reset time, and number of errors. 


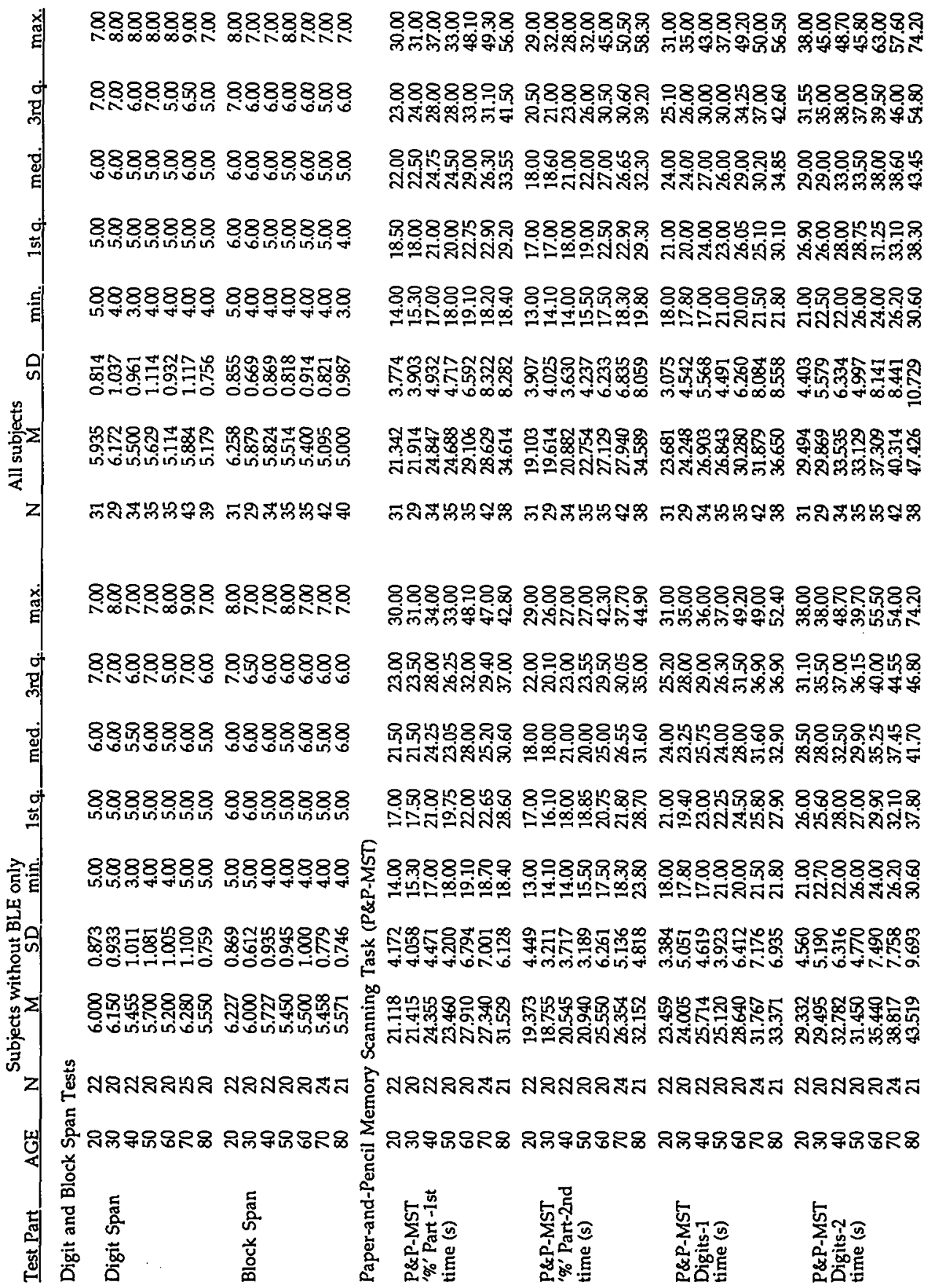




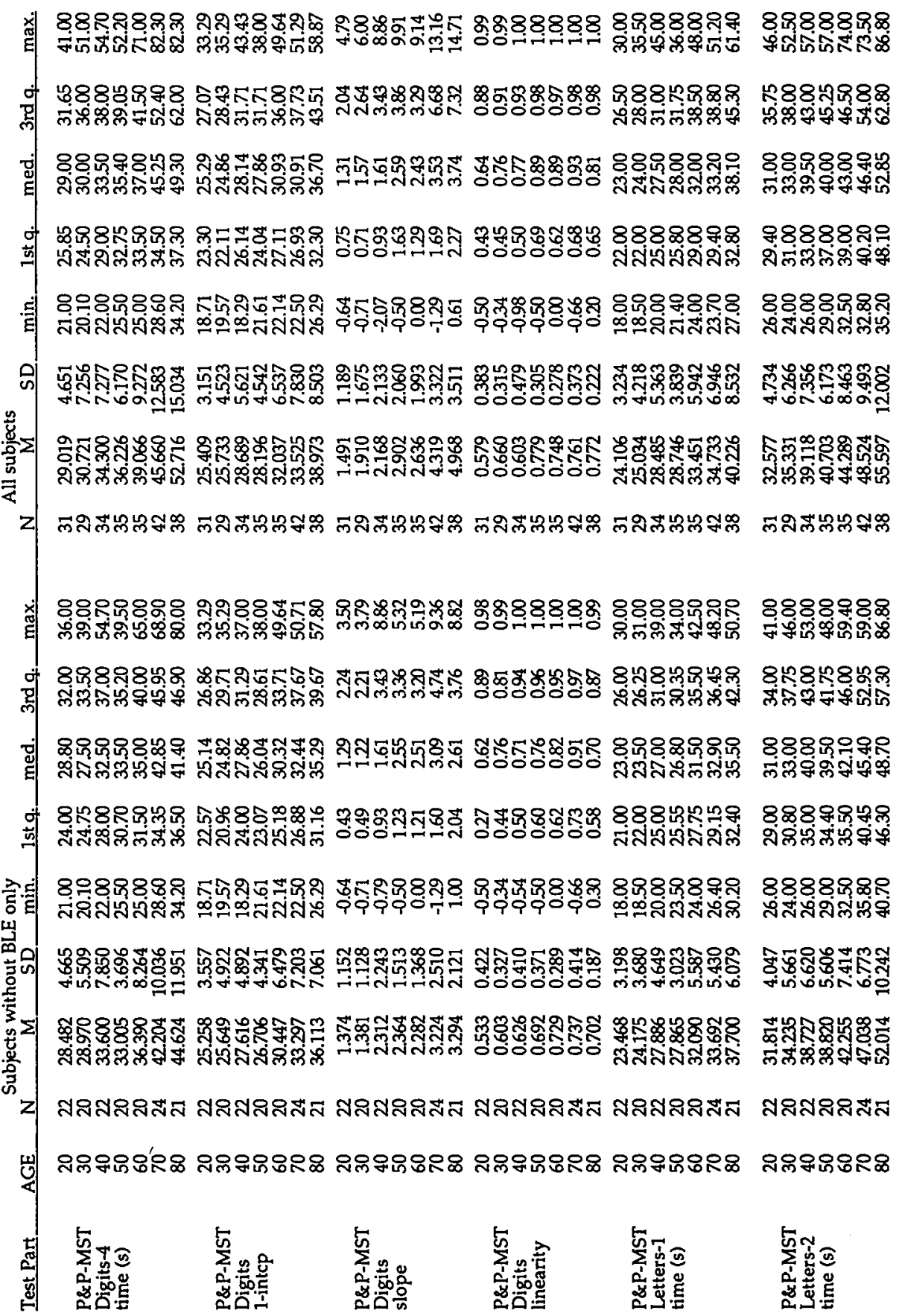




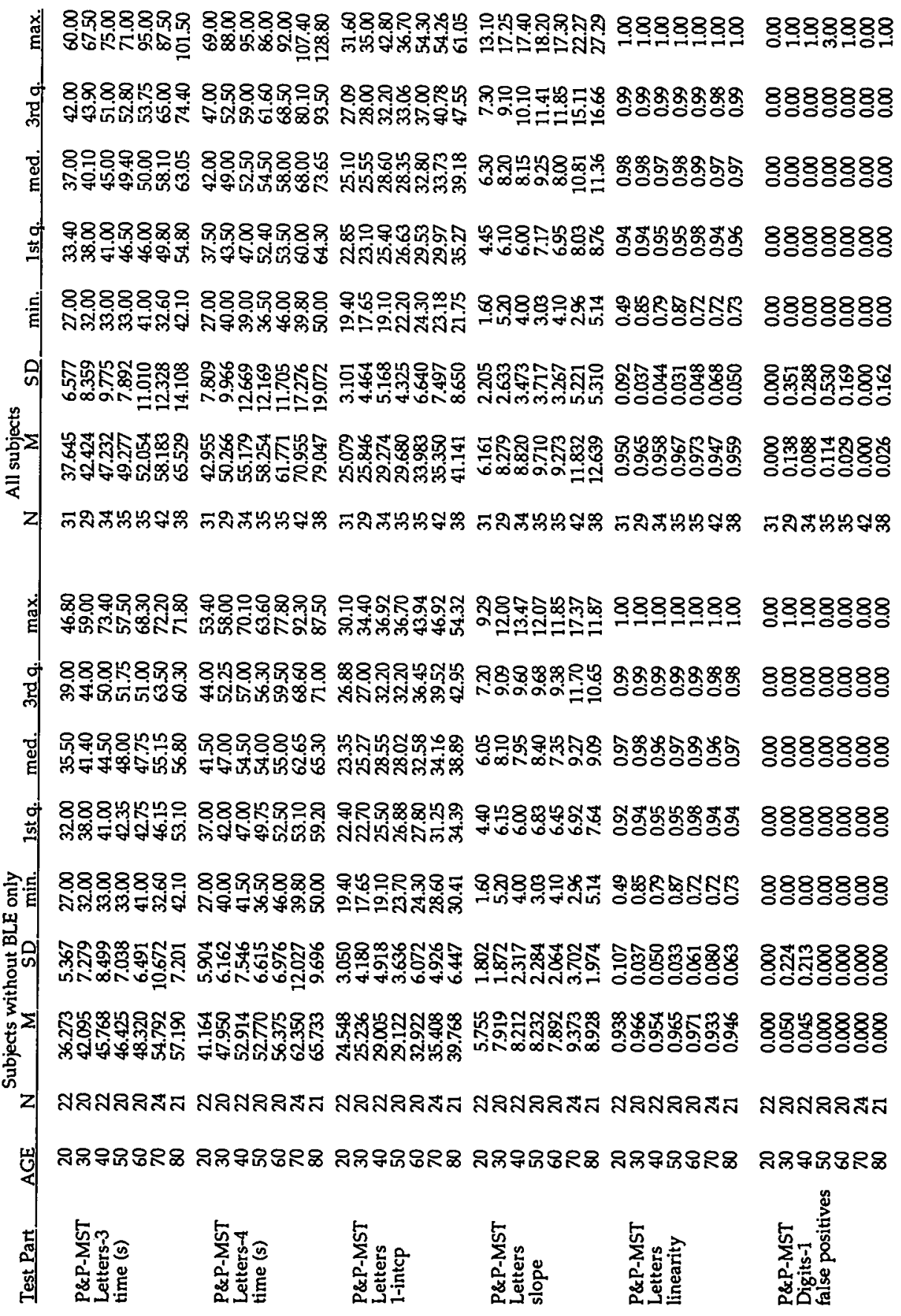




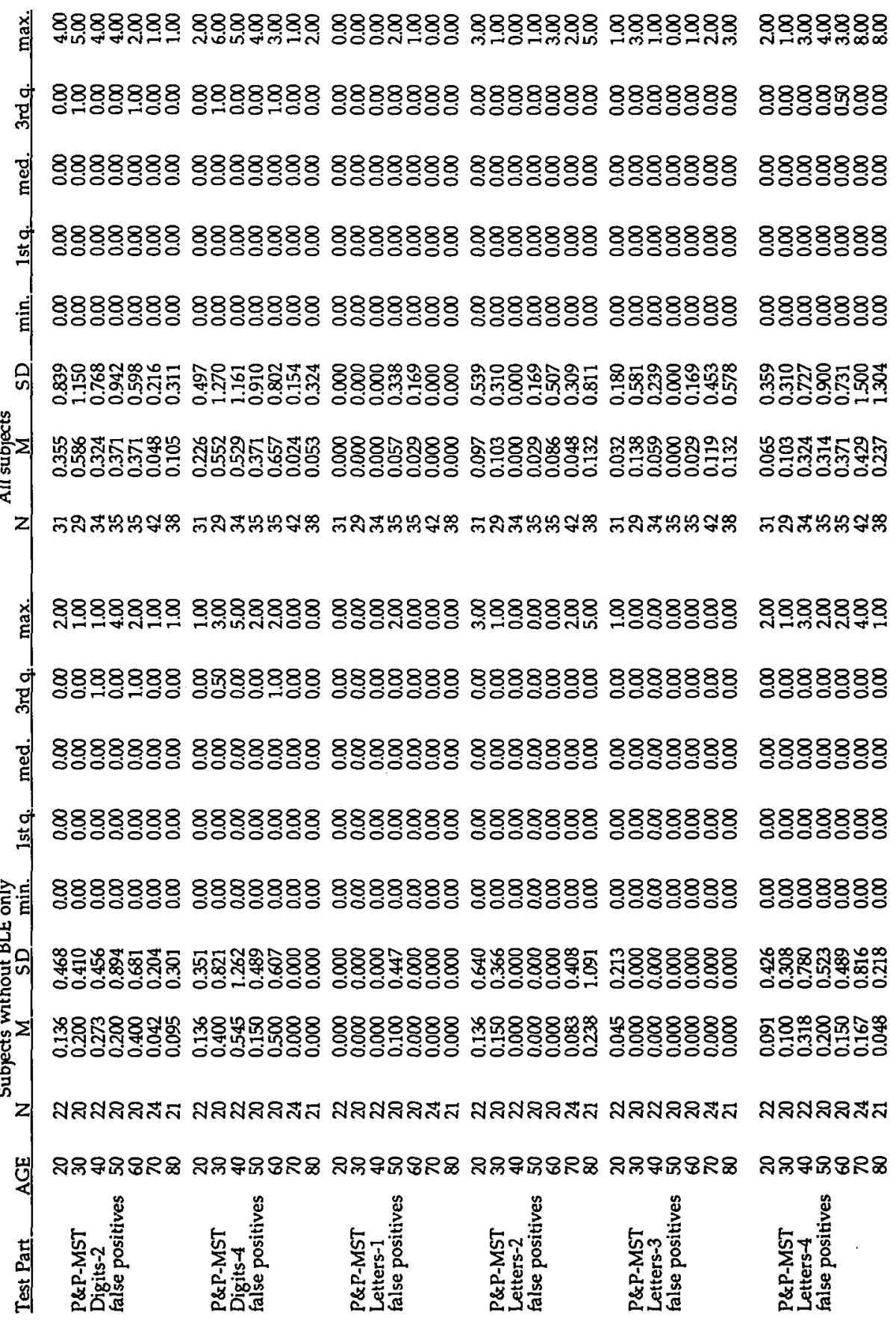




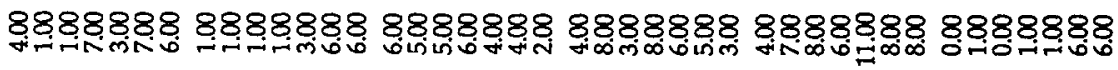

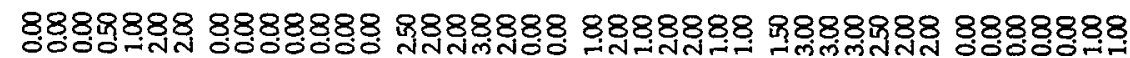
88888888888888888888888888880888888888888888

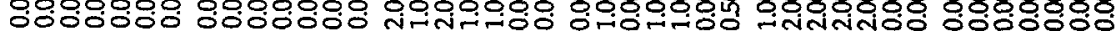

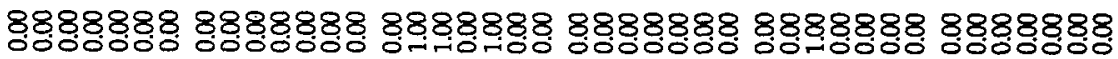

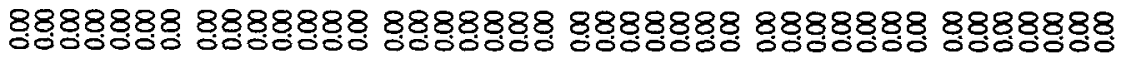

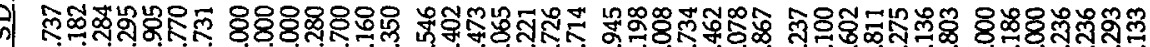
范

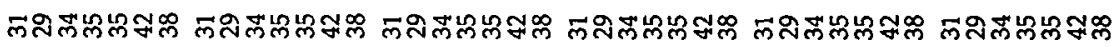

8888888 8888888 8888888 8888888 8888888 8888888

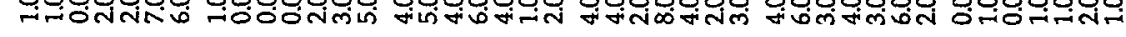

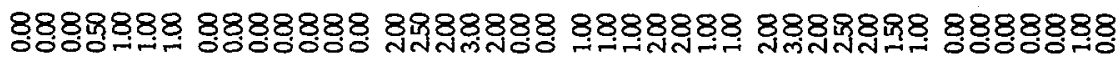

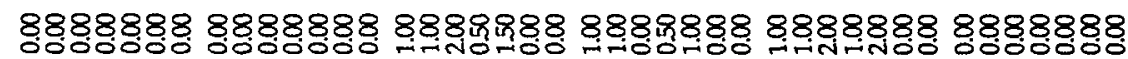

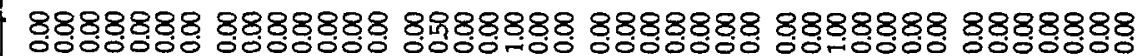

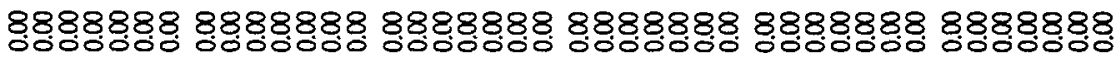
(4) |ิ

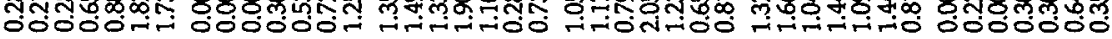

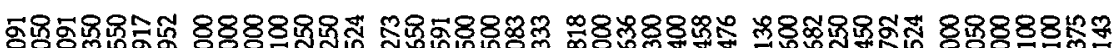

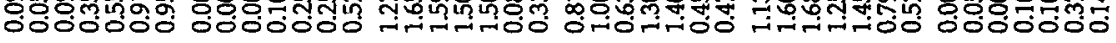

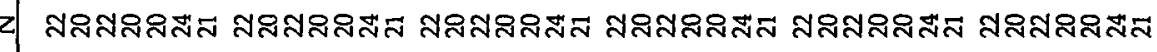

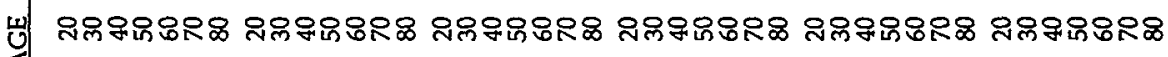
\& 


\section{放

8888888.8888888 .888888

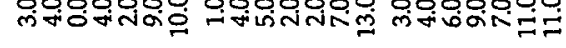

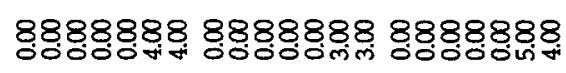

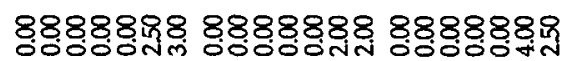

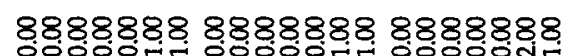
8888888.8888888 .8888888 .08

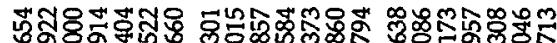

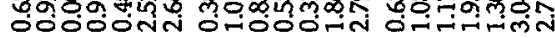

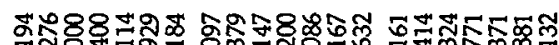

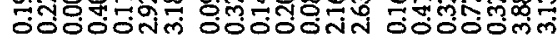

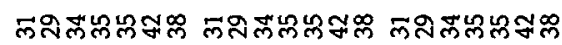

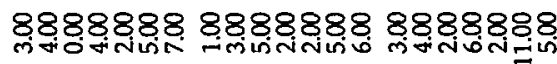
888888888888888888888

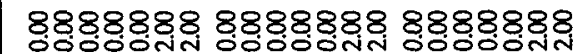

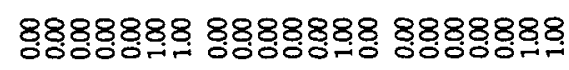
888888888.88888888 .88888888 䆠

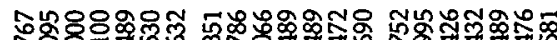
5id

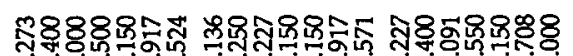

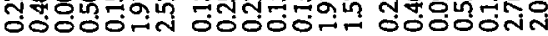

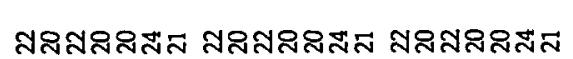

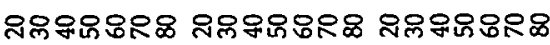
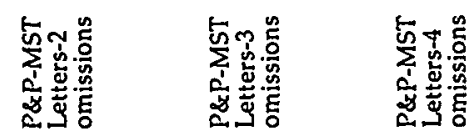

田
$88888888888888 \quad 8888888$

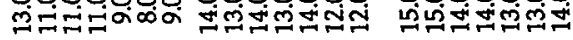

8888888 888 888 8 888880

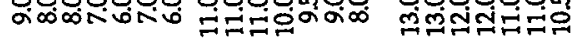

88888888888888.88888

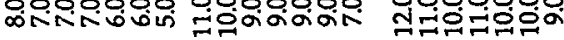

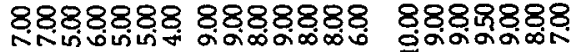

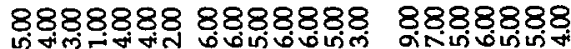

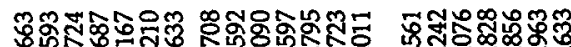

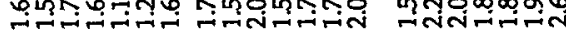

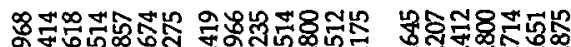

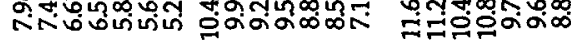

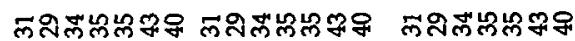

88888888888888

8888888

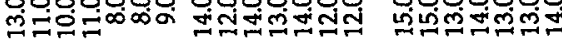

$88888888888888 \quad 8888888$

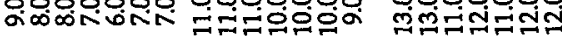

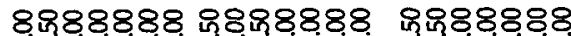

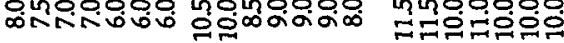

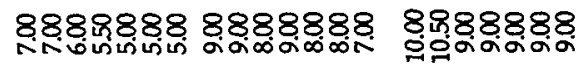
$88888888888888 \quad 8888888$

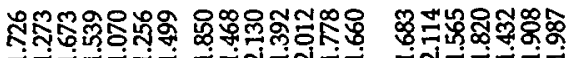

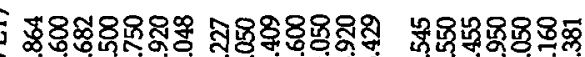

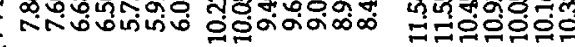
蕊

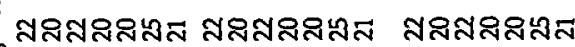
蛋

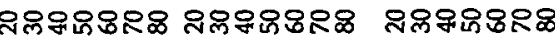

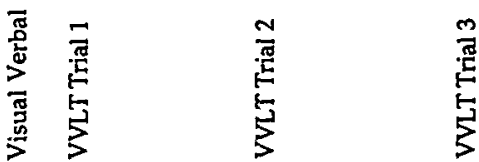


है

ज)

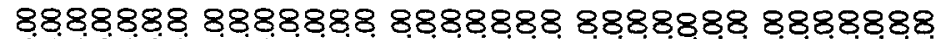

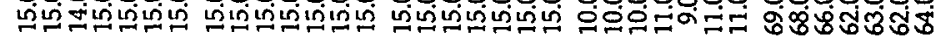

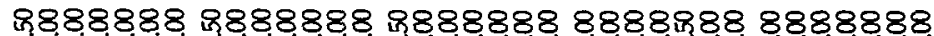

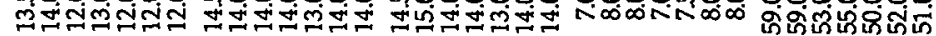

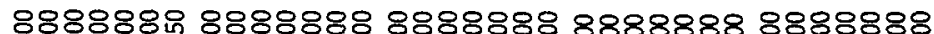

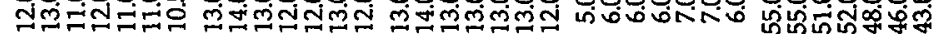
గ

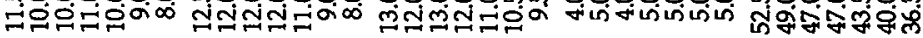
88888888888888888888888888888888888

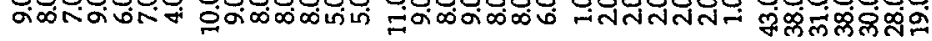

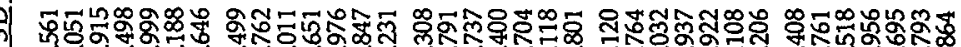

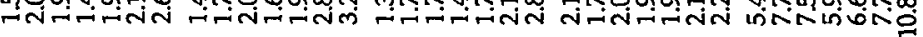

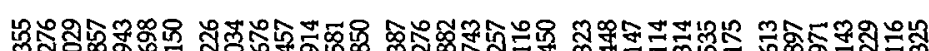

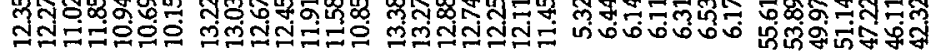

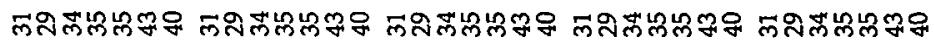

888888888888888888888 8888888 8888888

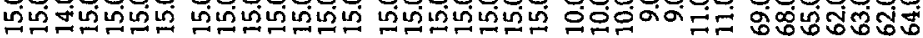

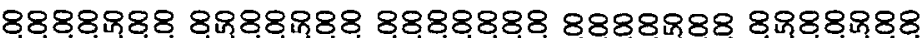

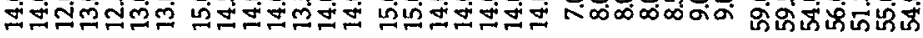

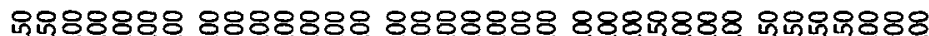

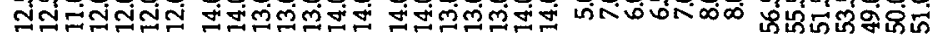

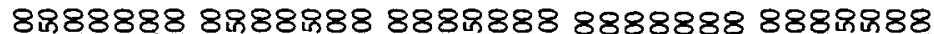

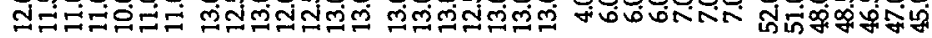

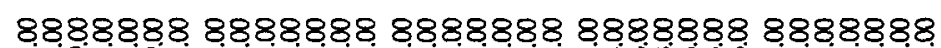

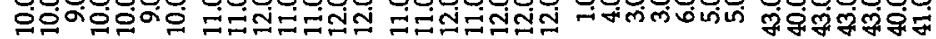

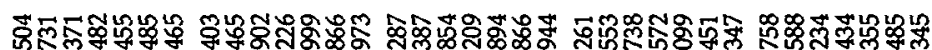
-

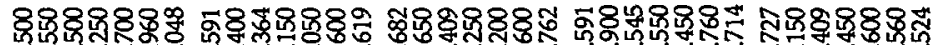

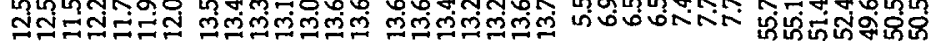

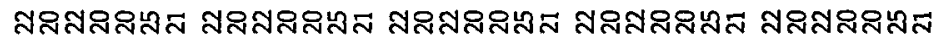

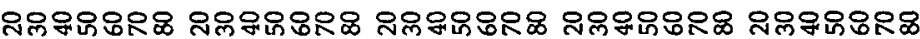
蛋

蛋

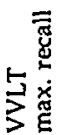

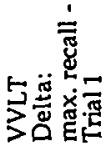

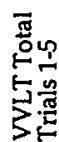

8888888

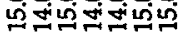

8888888

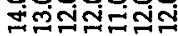

8888880

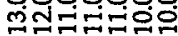

888888 . 붕ㅇํำ 8888888

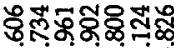
निन्नलिल

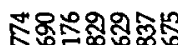
걸유유

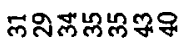

8888888 nivingivin 8880808

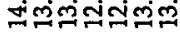

8808888 ตำสสมสำ 8888888 검ำㅇำ:

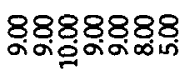

무요요 ํㅜㅇㅝำ T-IITA

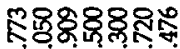

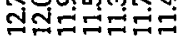

สลสสกำลส 주유유모요

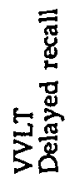




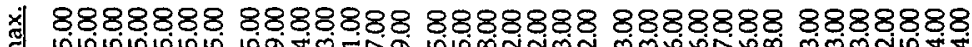

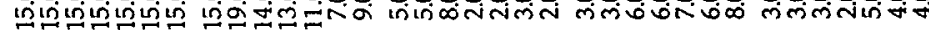

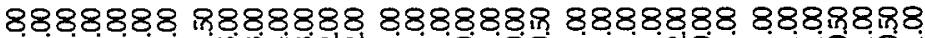

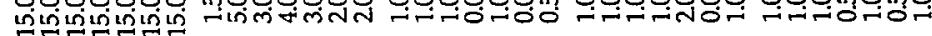

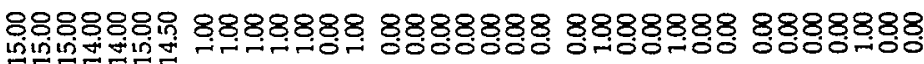

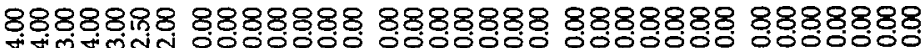

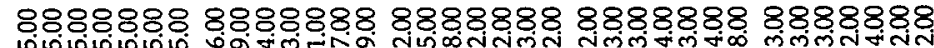

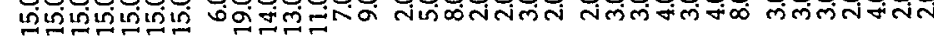

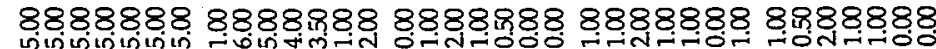

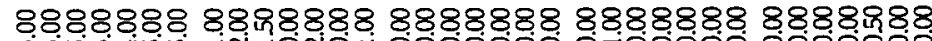
inininininin

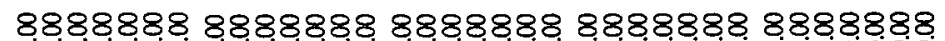
ษ๋minnin

\section{8888888888888888888888888888}

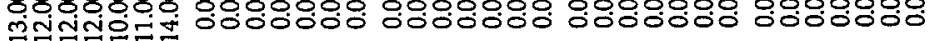

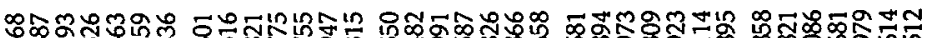

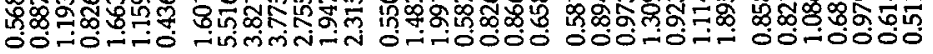

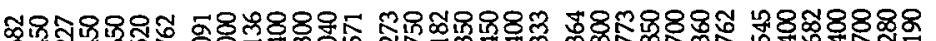

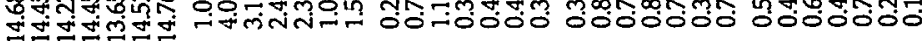

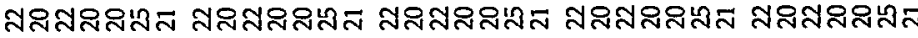

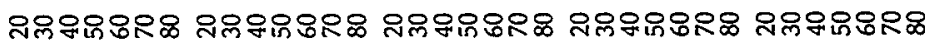

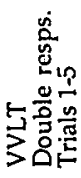

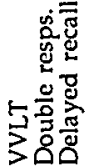

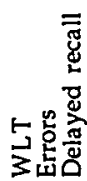

$888 \% 888$ หิ่

$888 \operatorname{lng} 8$ सुㅎํㅇำ

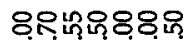

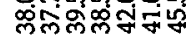

8గ్రి

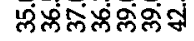

웅이웅애묵 क्लिंक्लिख्ले

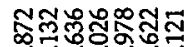

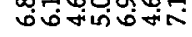

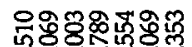

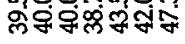

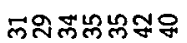

8ㅇำำํํำ

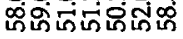

8.? 8 గి 88 अं भुजे

గำ लिलिलिज标

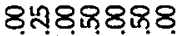
लिलिल्लिं

88,8 우ㅇㅛㅛ लेंस्लंज्लिख

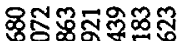

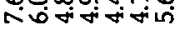

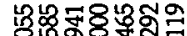

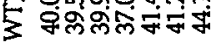

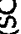

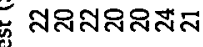
자유뮴요 훙 号 总产总 


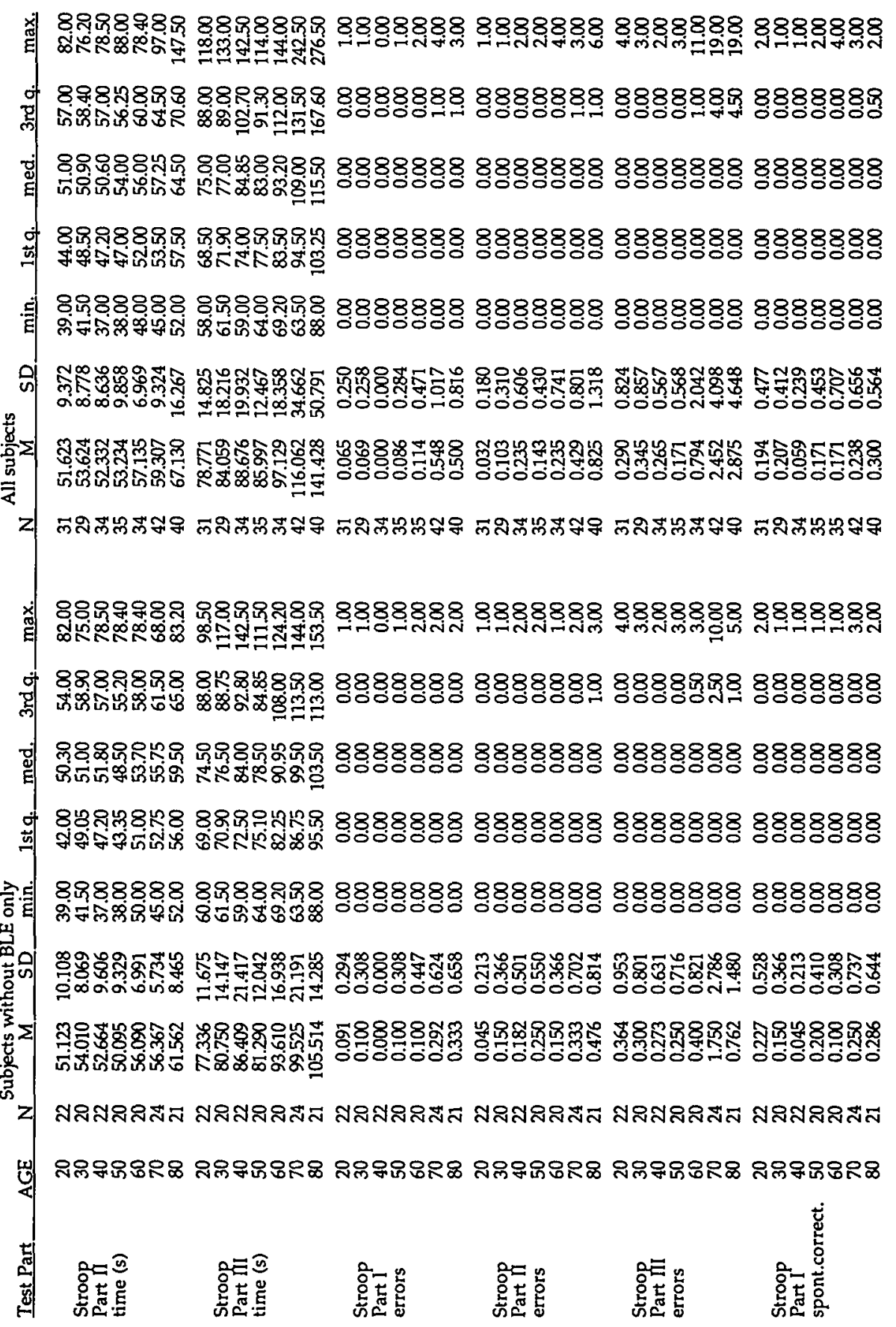




\begin{tabular}{|c|c|}
\hline 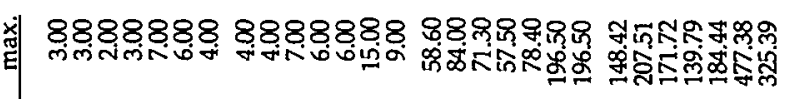 & 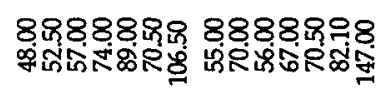 \\
\hline 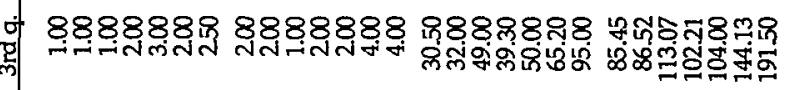 & 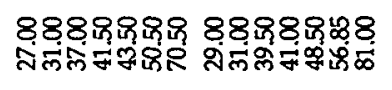 \\
\hline 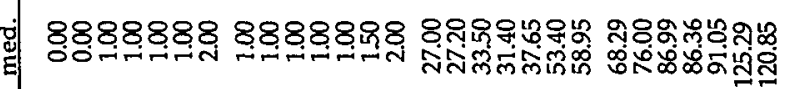 & 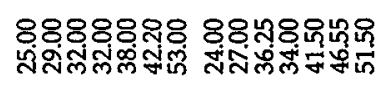 \\
\hline 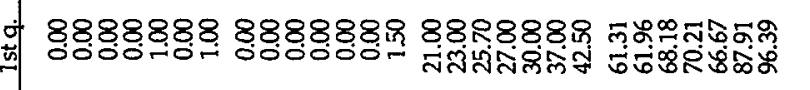 & हृष्रुष \\
\hline 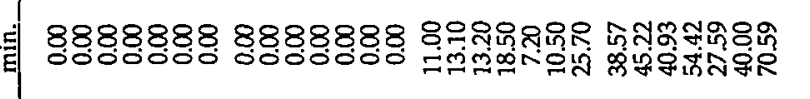 & 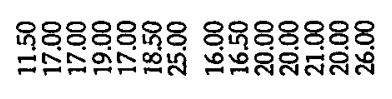 \\
\hline 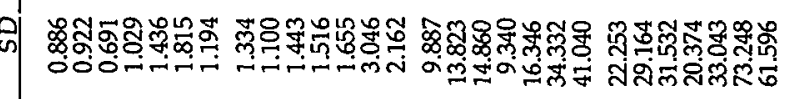 & 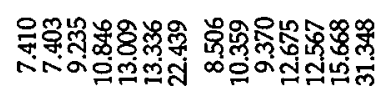 \\
\hline 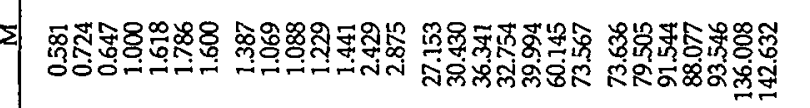 & 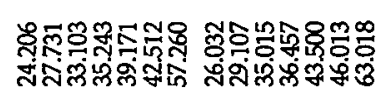 \\
\hline 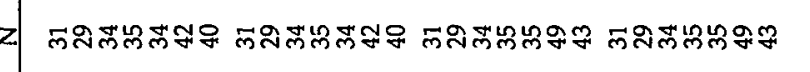 & 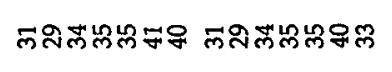 \\
\hline 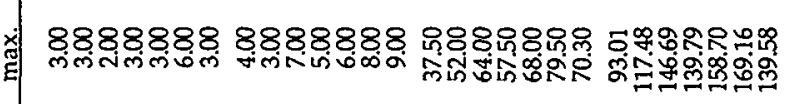 & 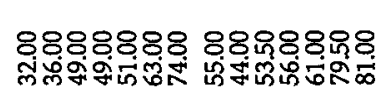 \\
\hline 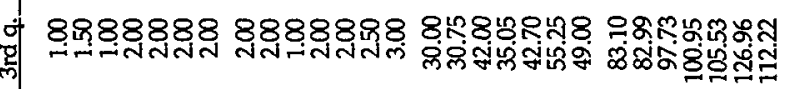 & 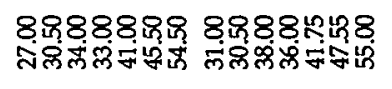 \\
\hline 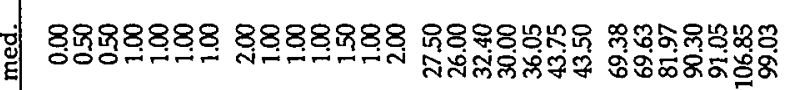 & (2) \\
\hline 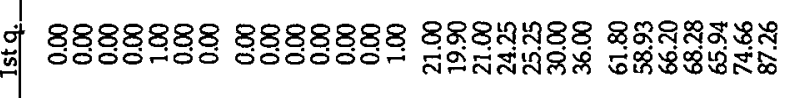 & nim \\
\hline 8.88 .8 & $\pi$ \\
\hline 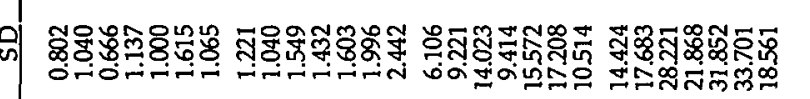 & 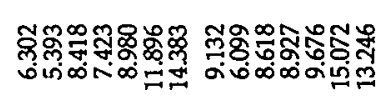 \\
\hline 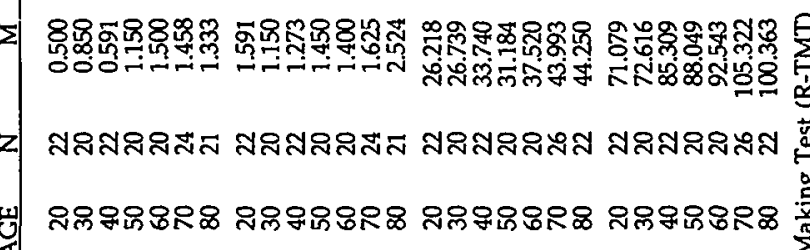 & 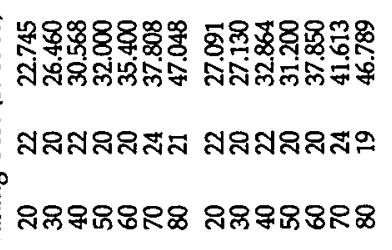 \\
\hline 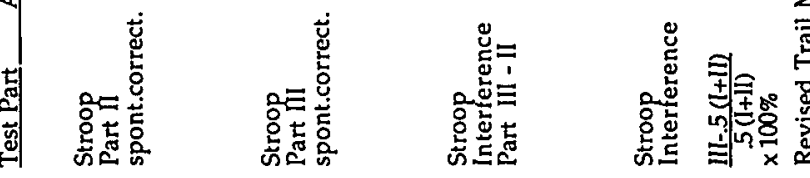 & 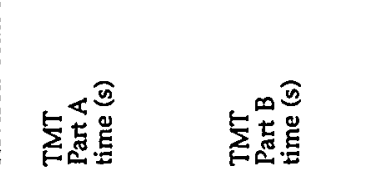 \\
\hline
\end{tabular}




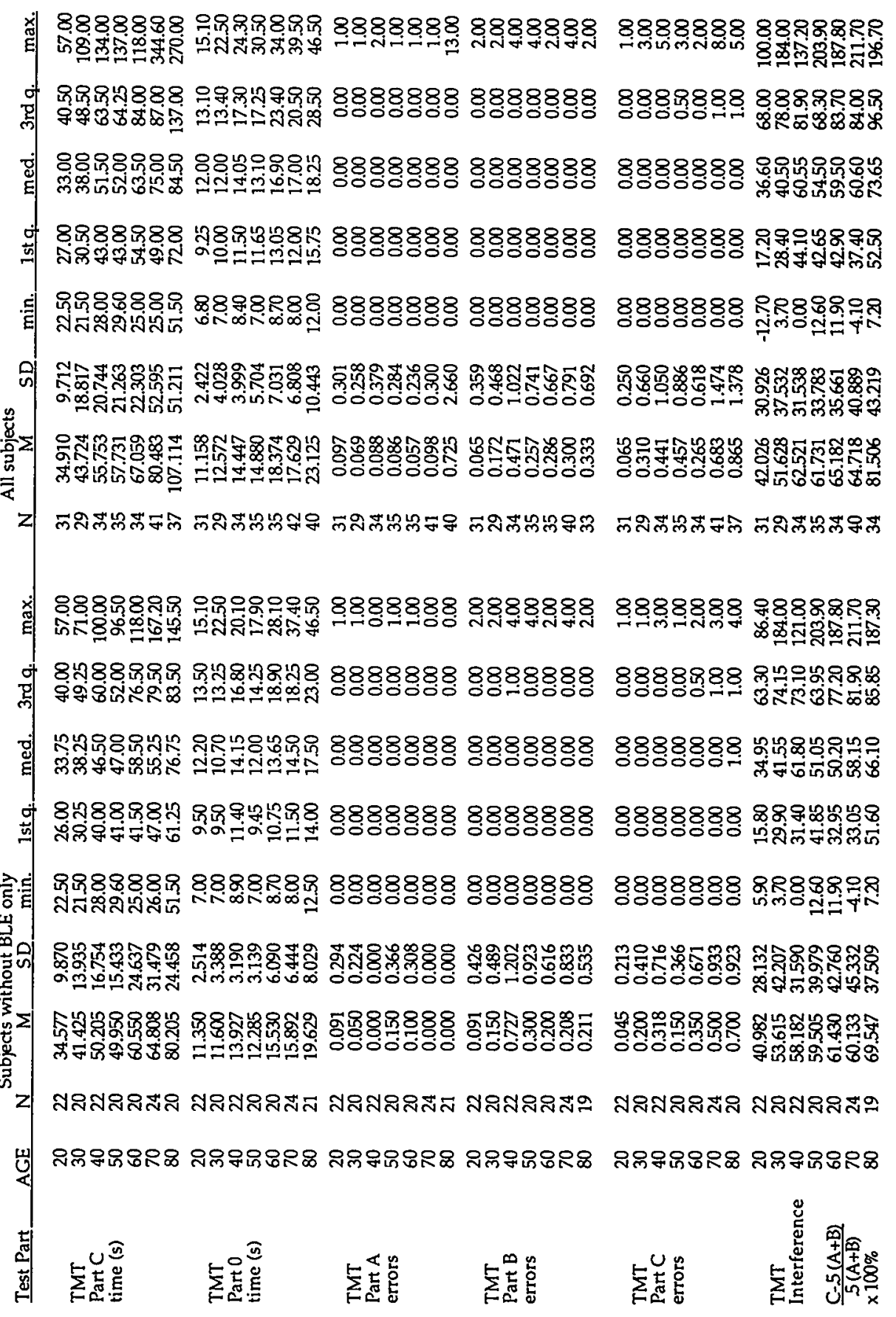




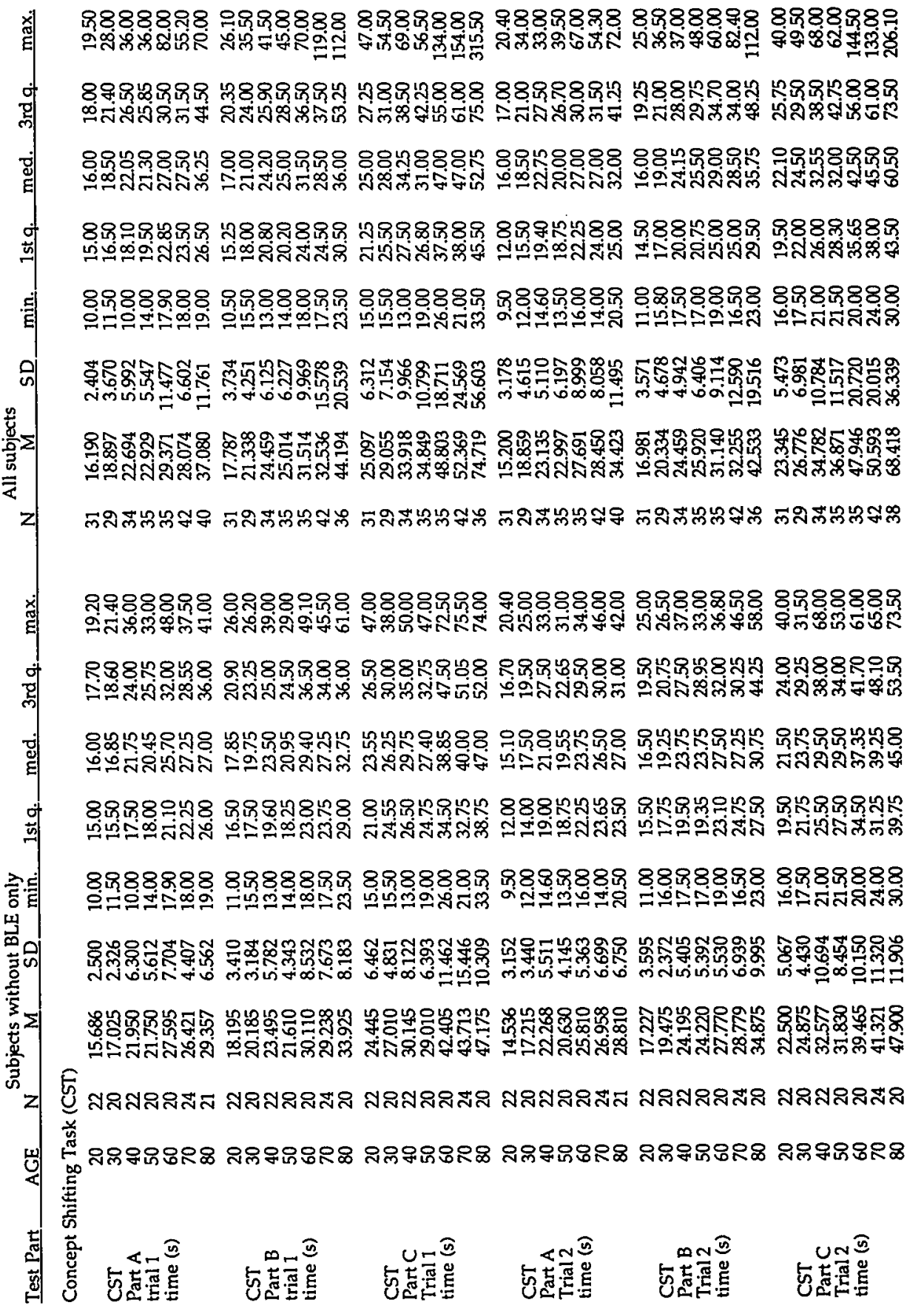




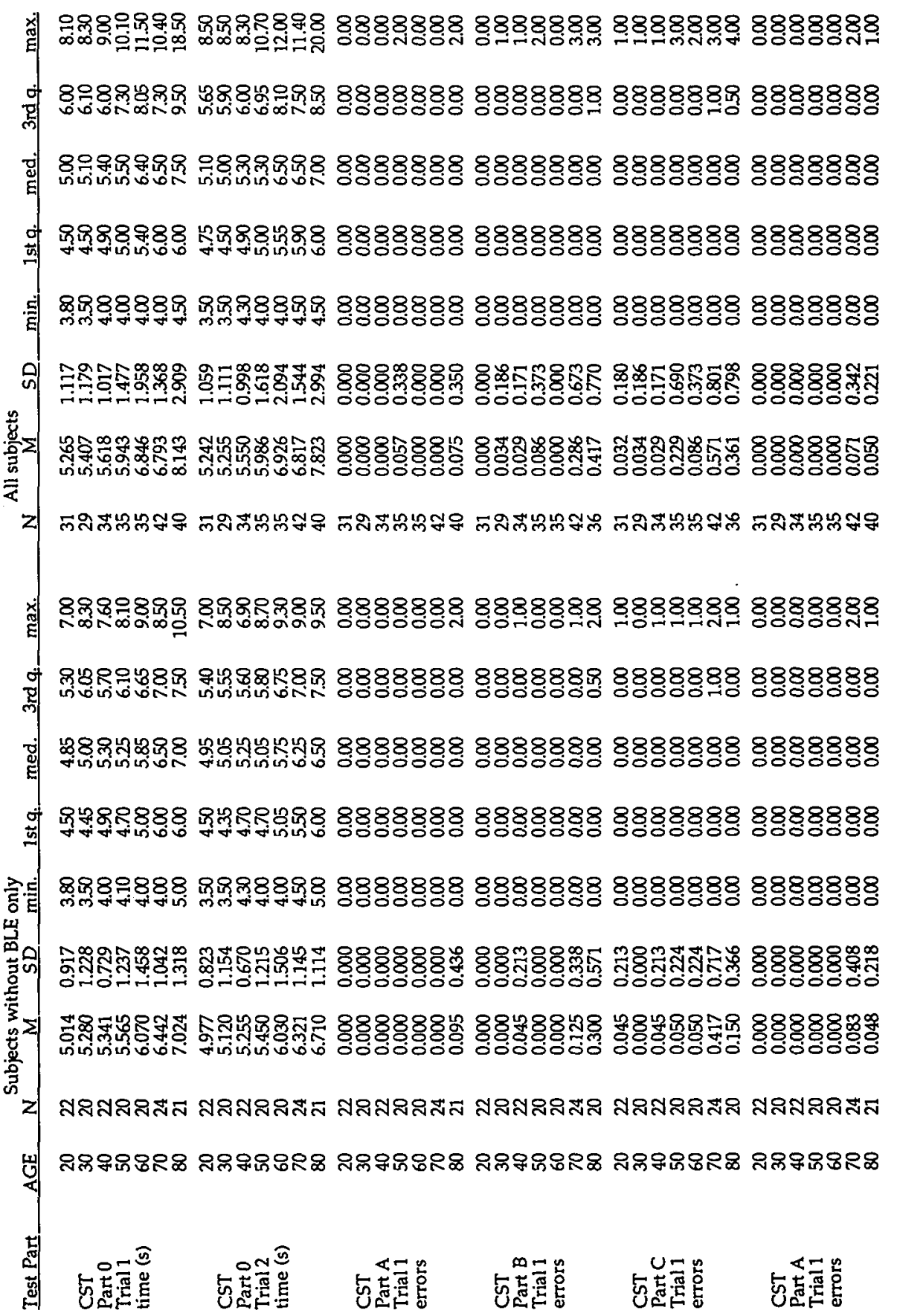




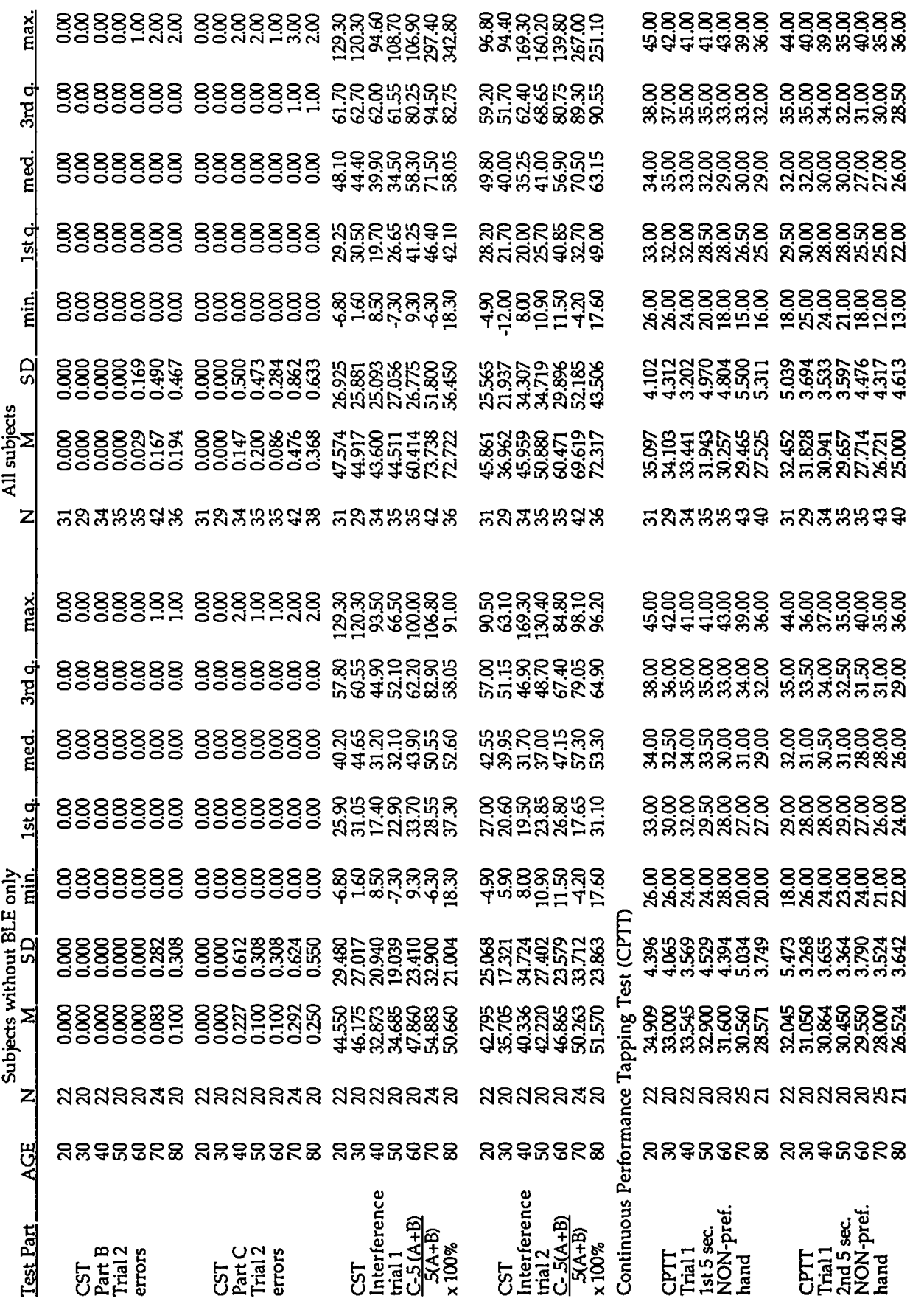




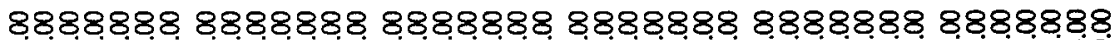

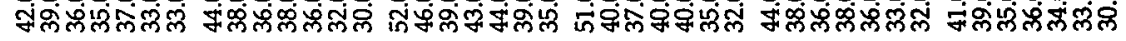

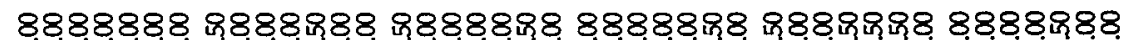

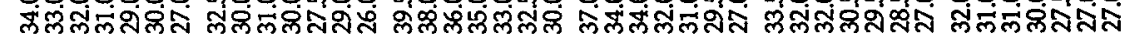

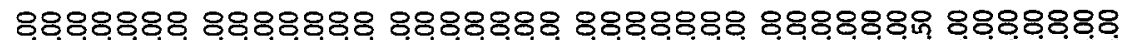

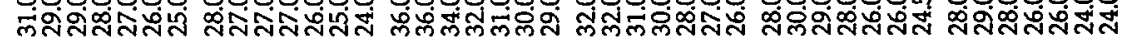

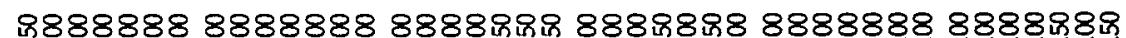

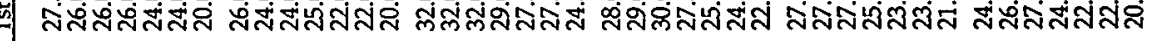
८888888 8888888 8888888 88888888888888 8888888

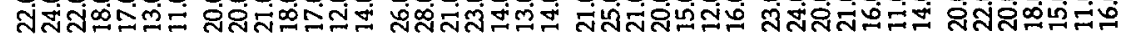

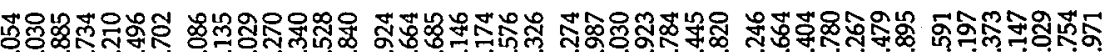

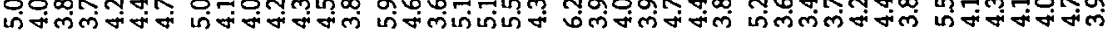

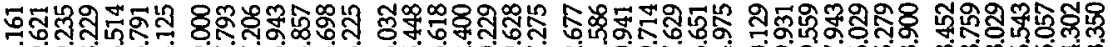

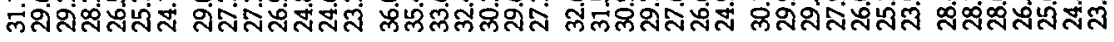

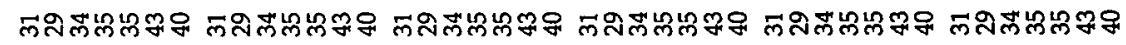

888888888888888888888888888888888888888888

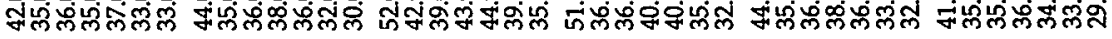

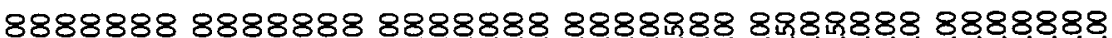

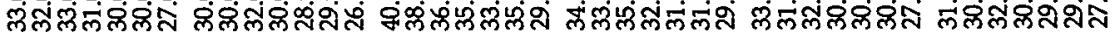

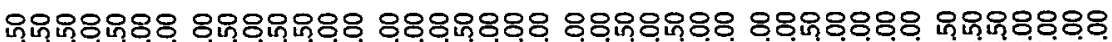

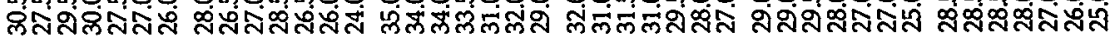

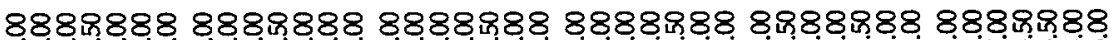

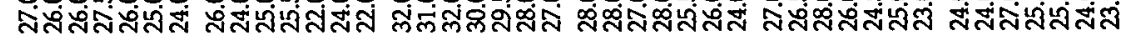
888888888888888888888888888888888888888888 状

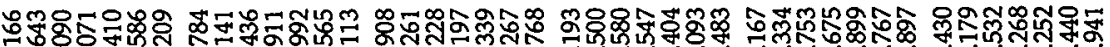

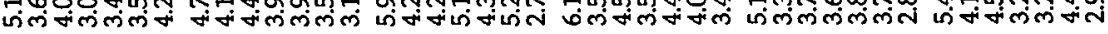

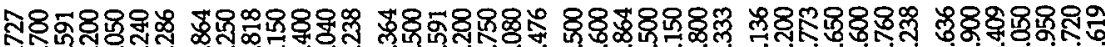

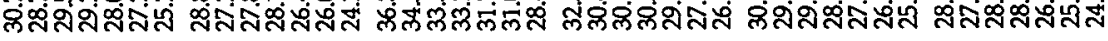

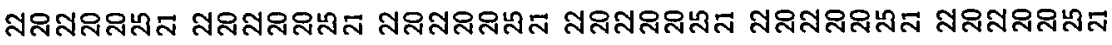

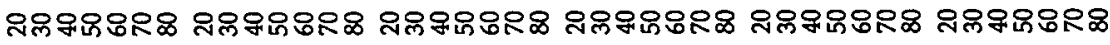




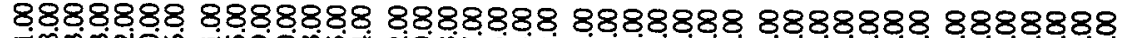

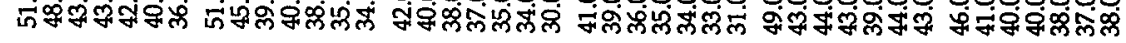

8888 .

m

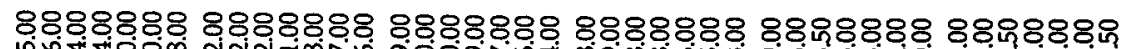

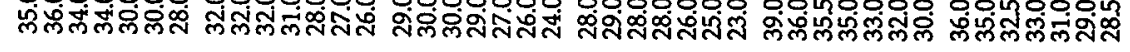

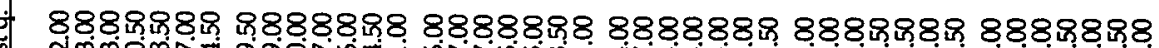

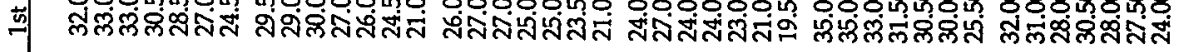

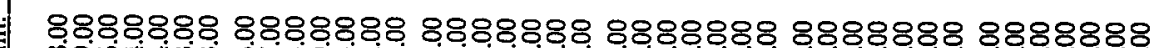

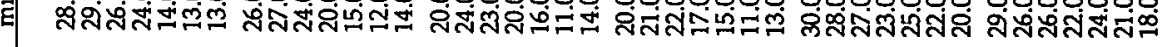

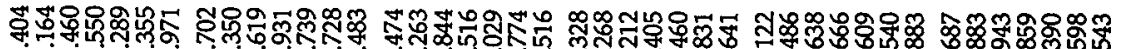

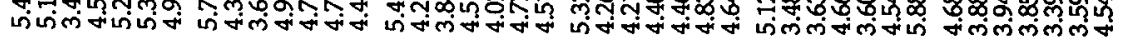

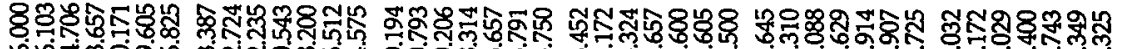

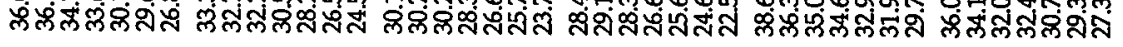

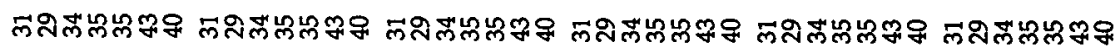

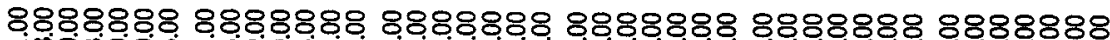

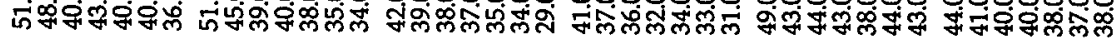
8.

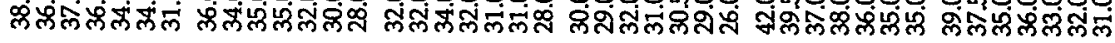

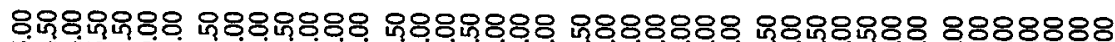

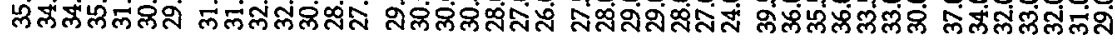

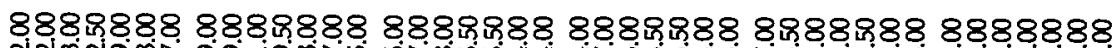

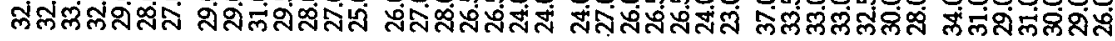

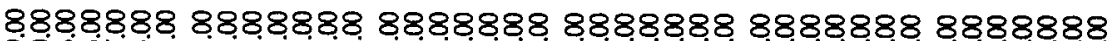

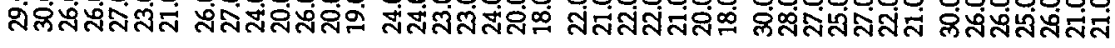

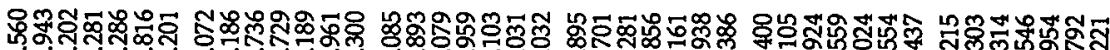

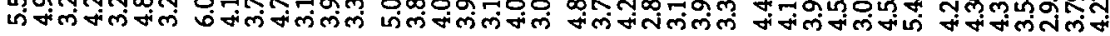

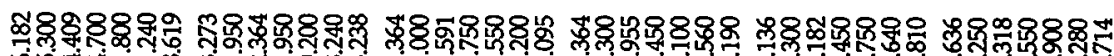

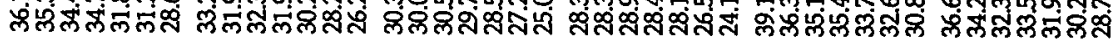

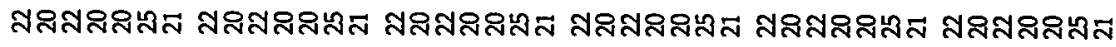

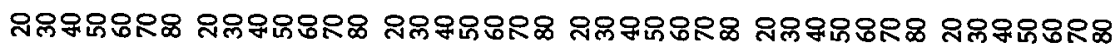

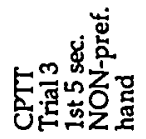

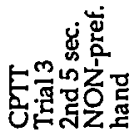

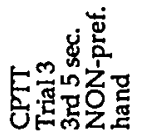

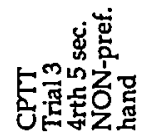

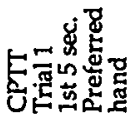

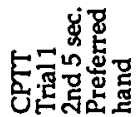




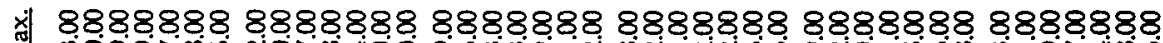

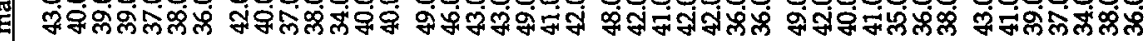

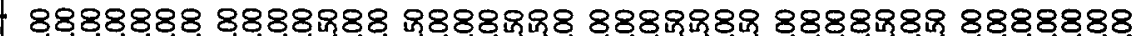

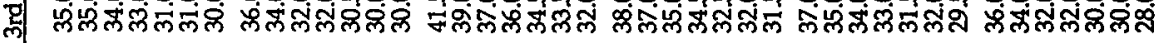
8888888 8888888 888888. 8888880.88888888888888

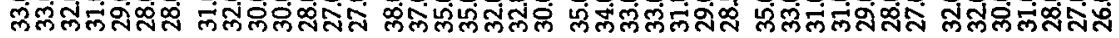

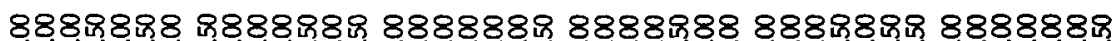

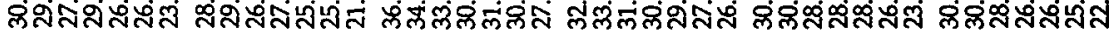
888888888888888888888888888888888888888888

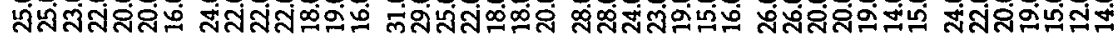

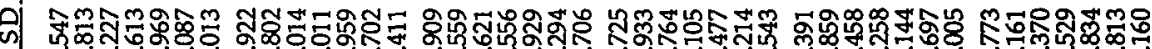

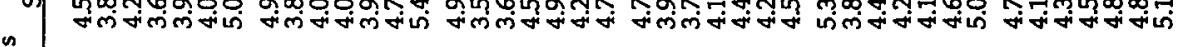
荧

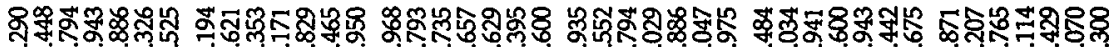

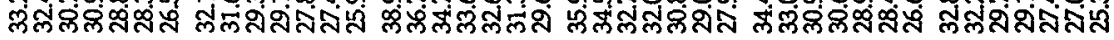

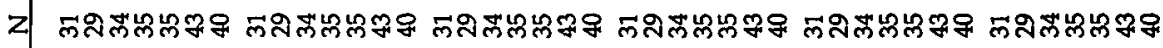

888888888888888888888888888888888888888888

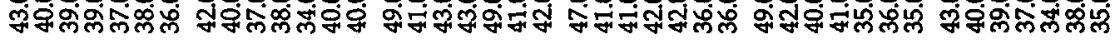

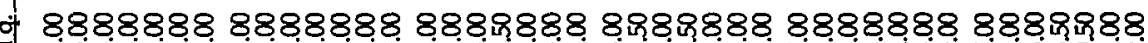

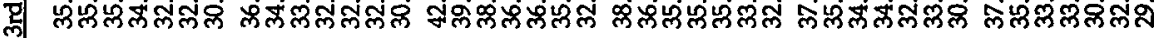

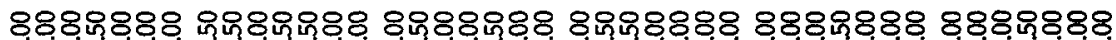

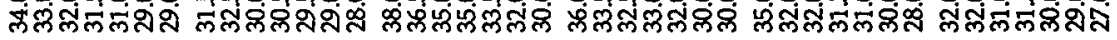

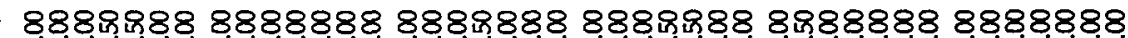
4 लंखี่ 888888888888888888888888888888888888888888

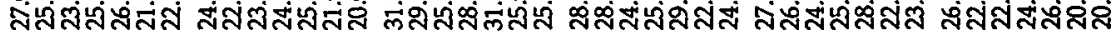

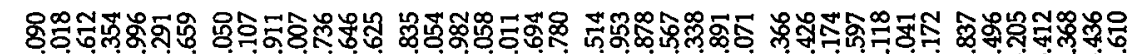

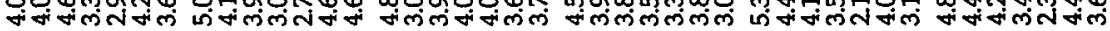

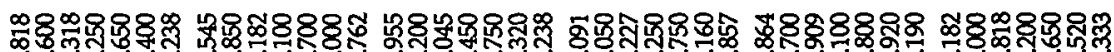

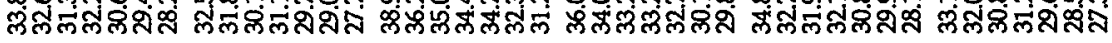

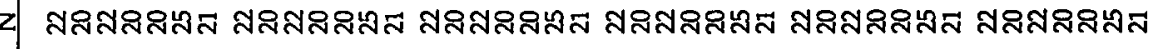

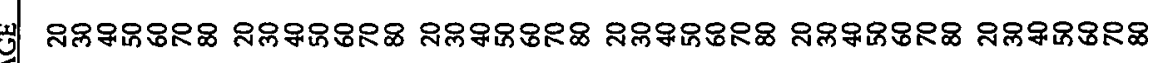




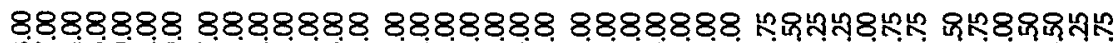

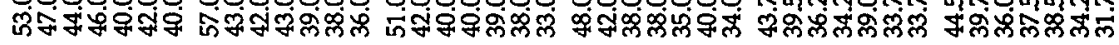

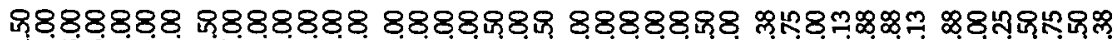

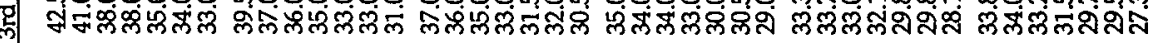

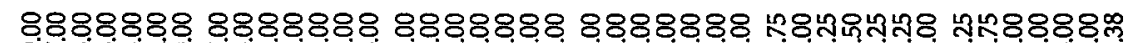

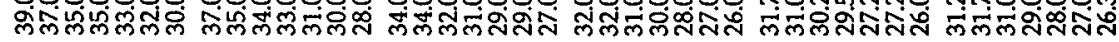

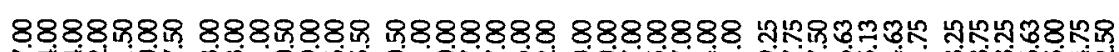

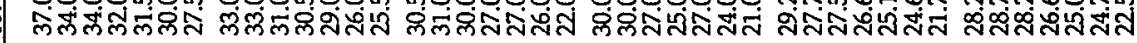

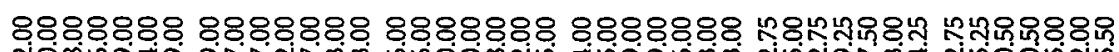

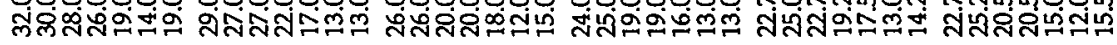

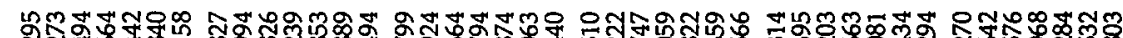

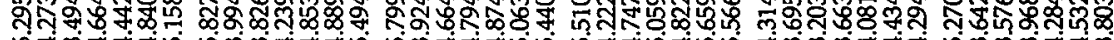

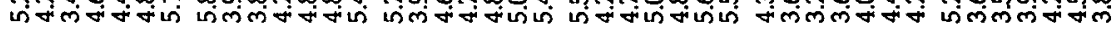

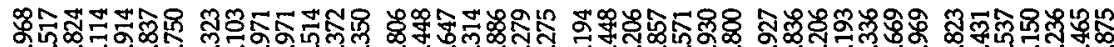

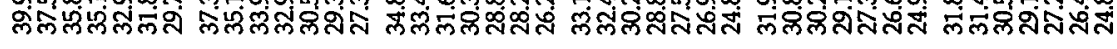

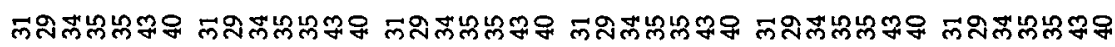

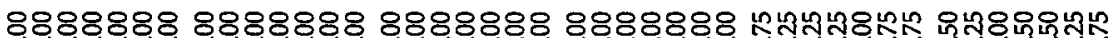

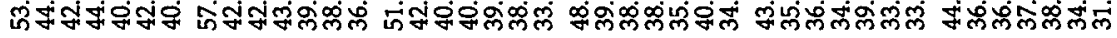

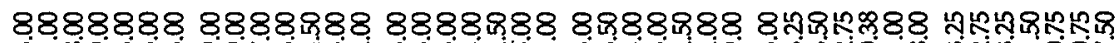

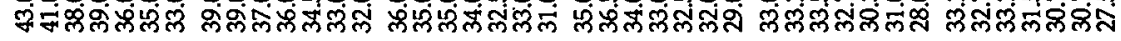

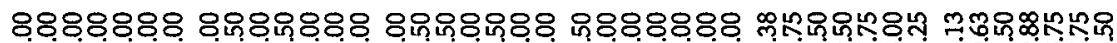

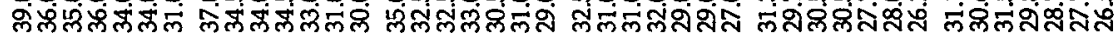

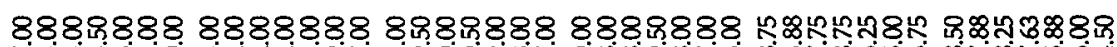

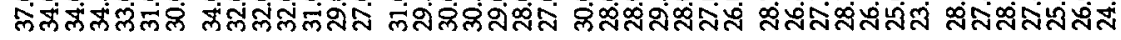
8888888888888888888888888888 k8ณ

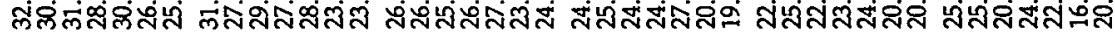

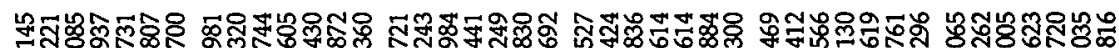

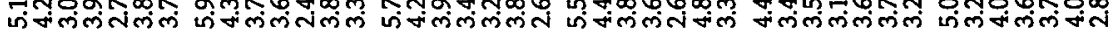

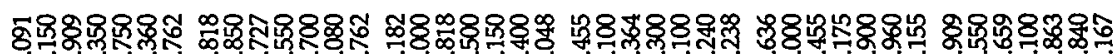

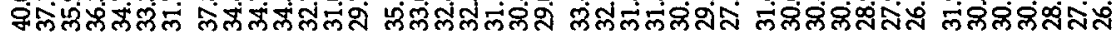

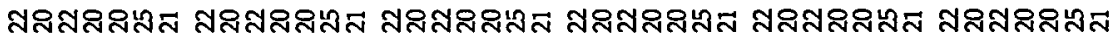

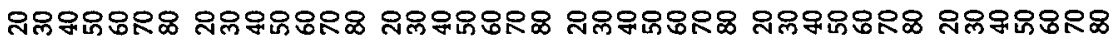




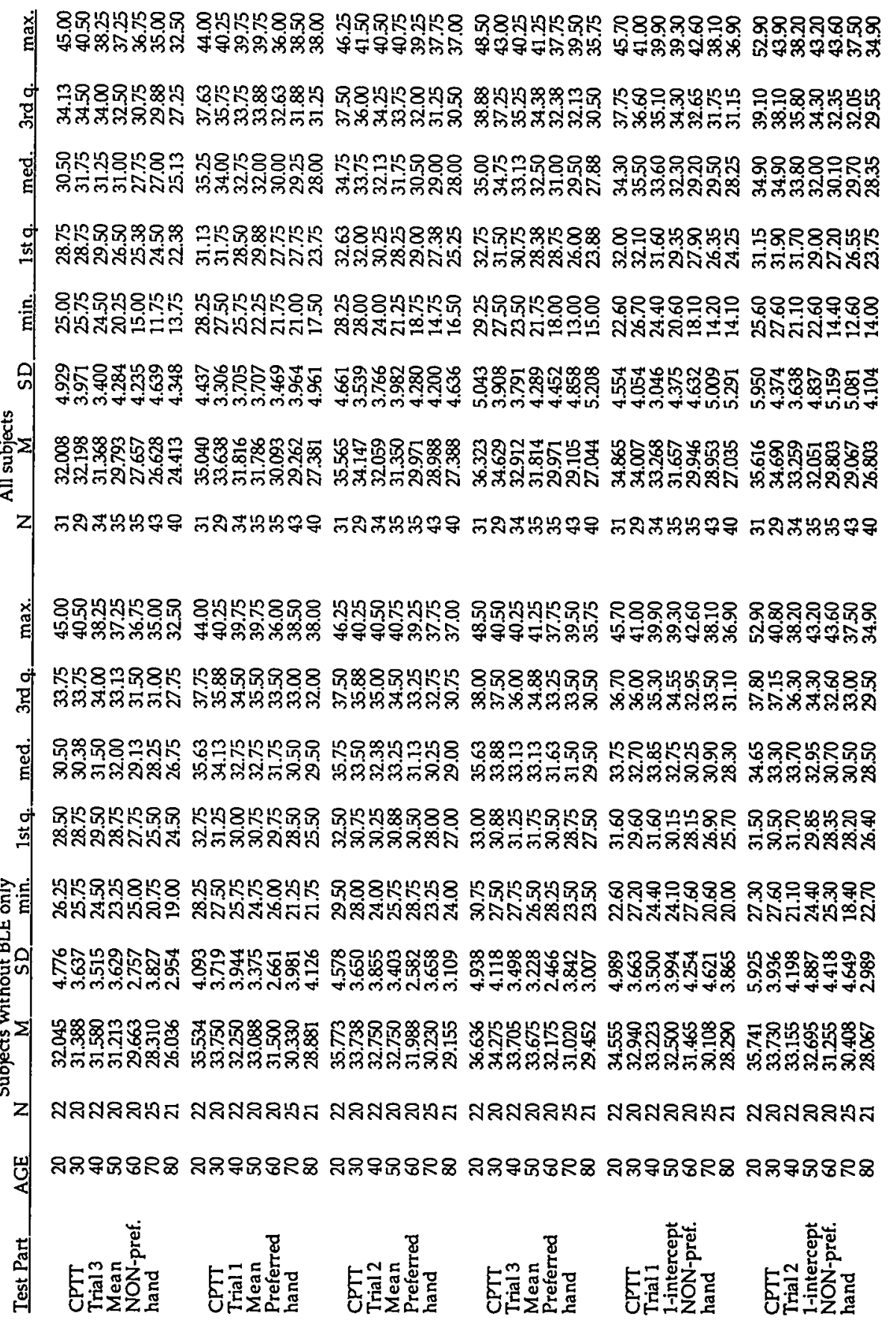




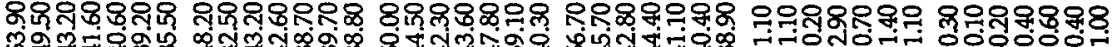

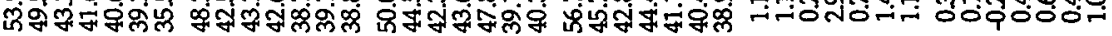

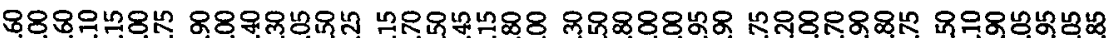

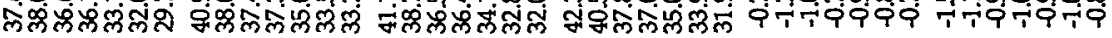

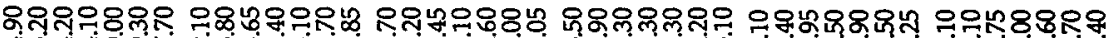

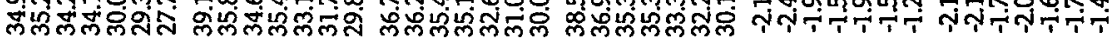

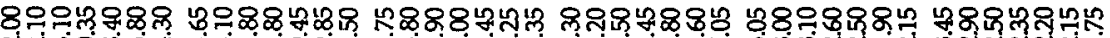

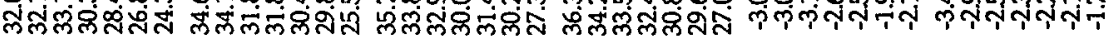

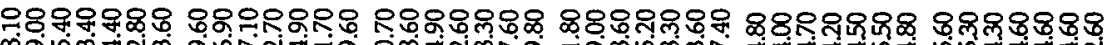

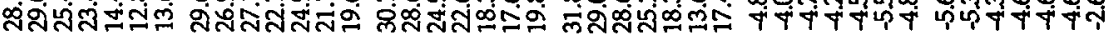

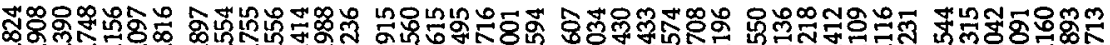

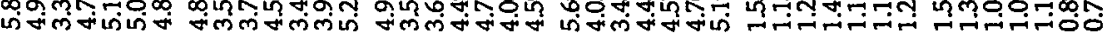

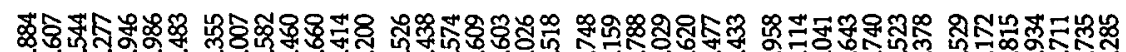

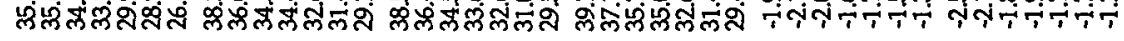

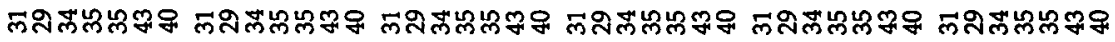

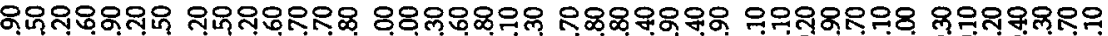

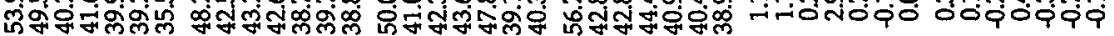

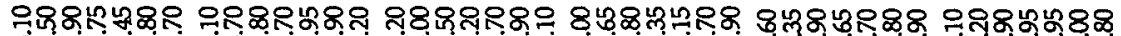

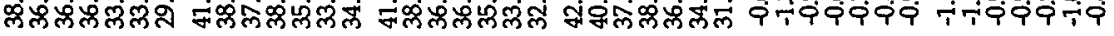

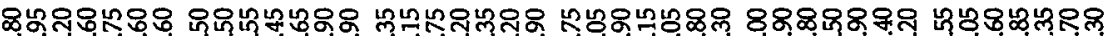

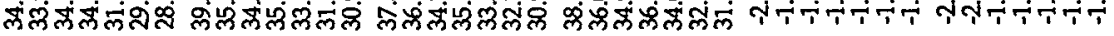

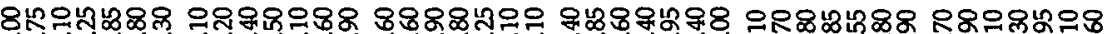

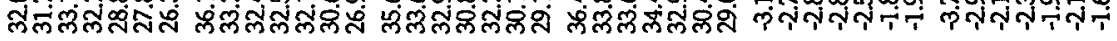

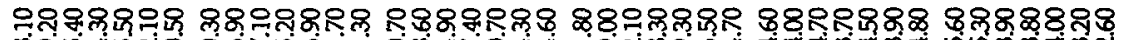

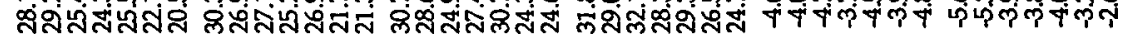

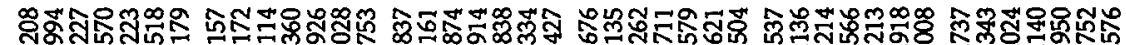

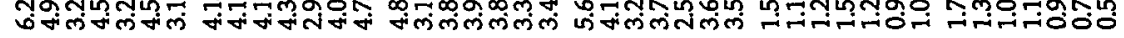

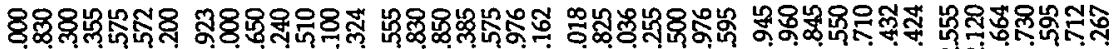

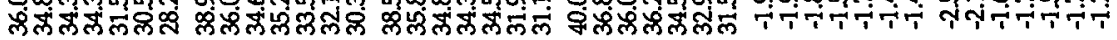

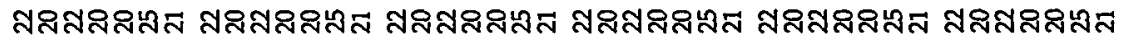

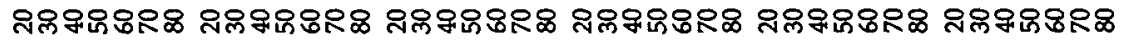

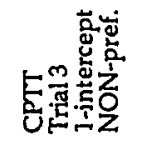

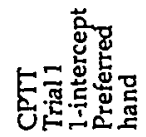

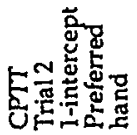

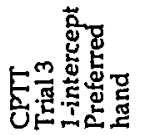

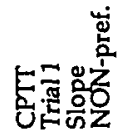

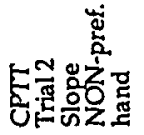




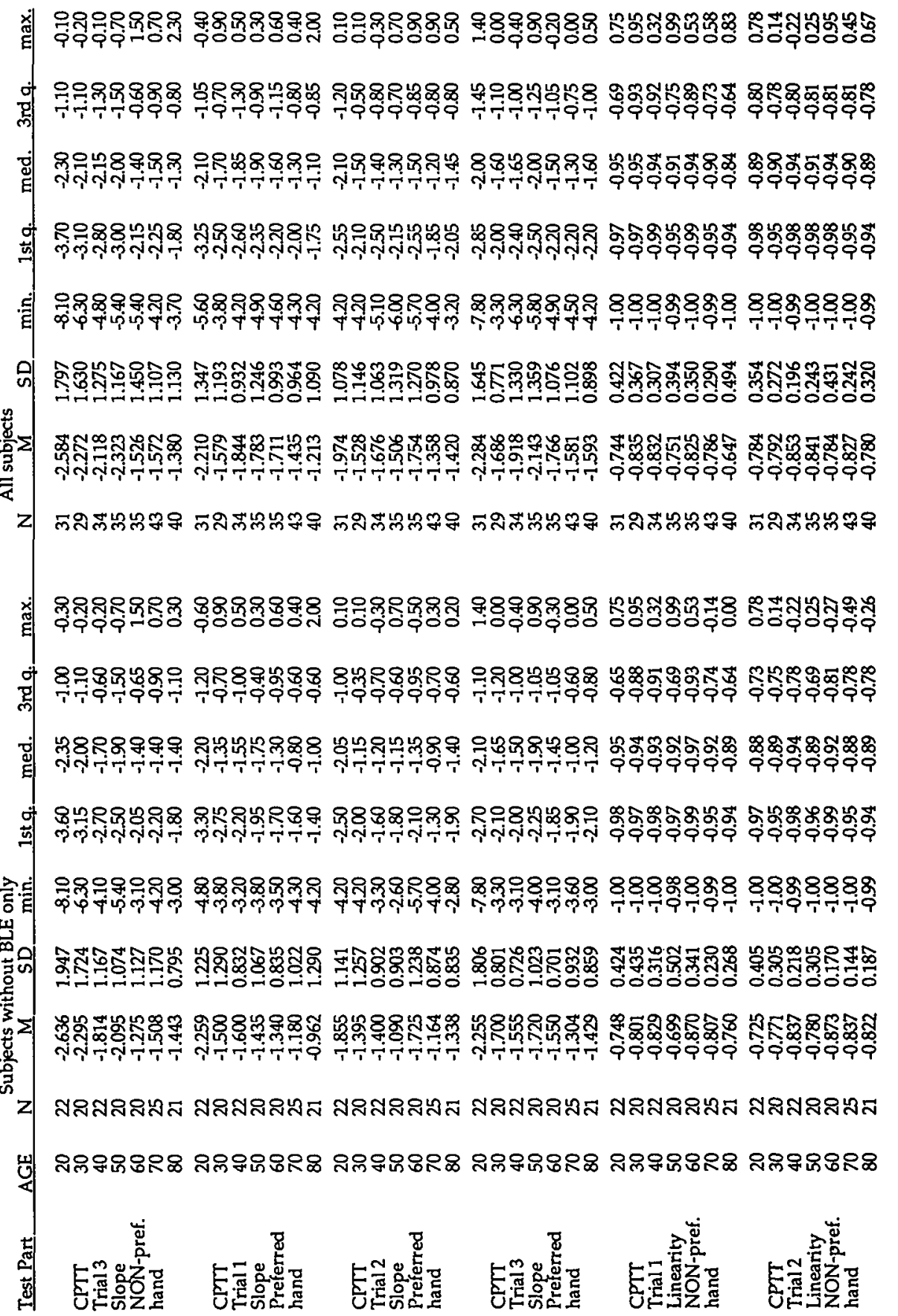




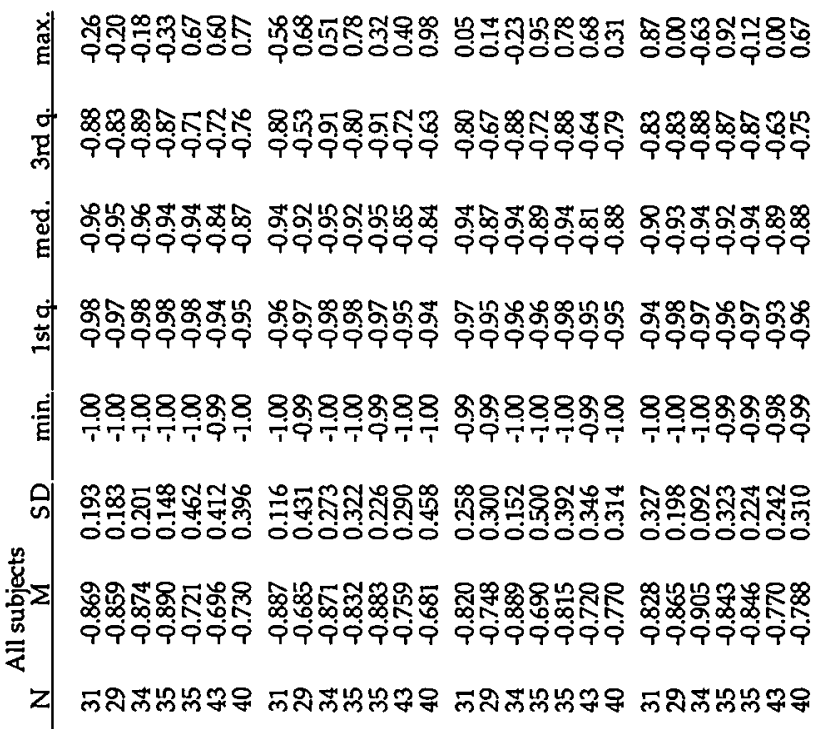

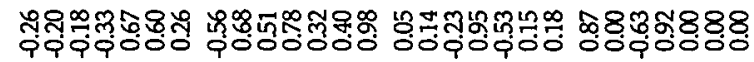

\%

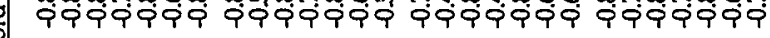

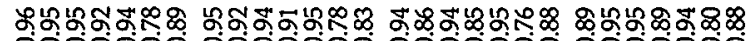

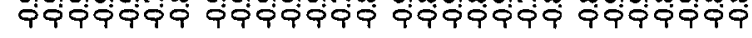

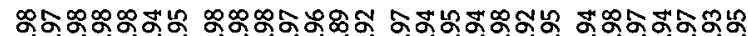

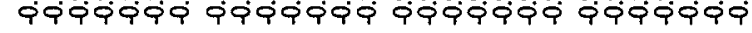

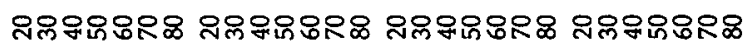

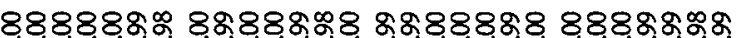

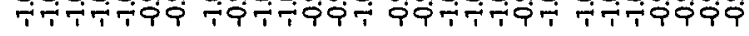

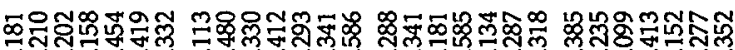

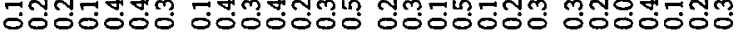

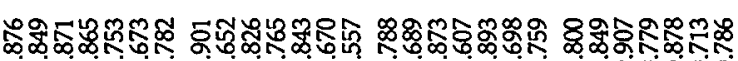

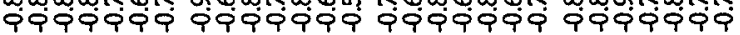
สลสスลヘন

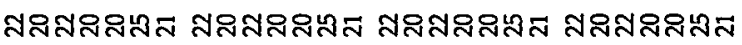

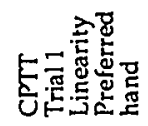

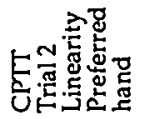

8,888888888888

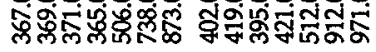

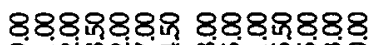

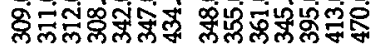

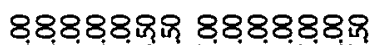

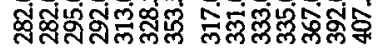
888 గํ

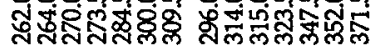

8888888888888

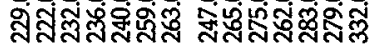

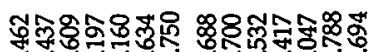
में సं तิ

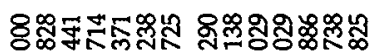

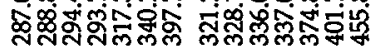

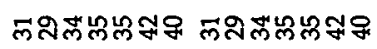

8888888.888888 般

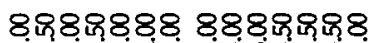

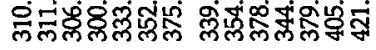

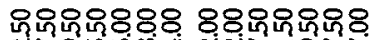

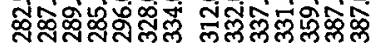

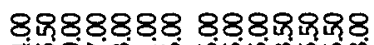

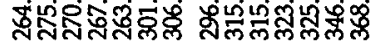
8.88 8.88 8888888

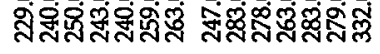

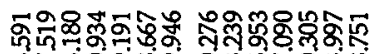

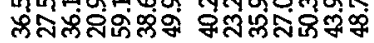

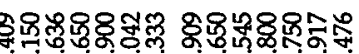

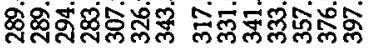
岁

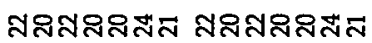
:

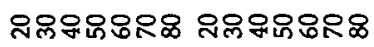

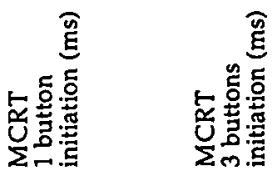




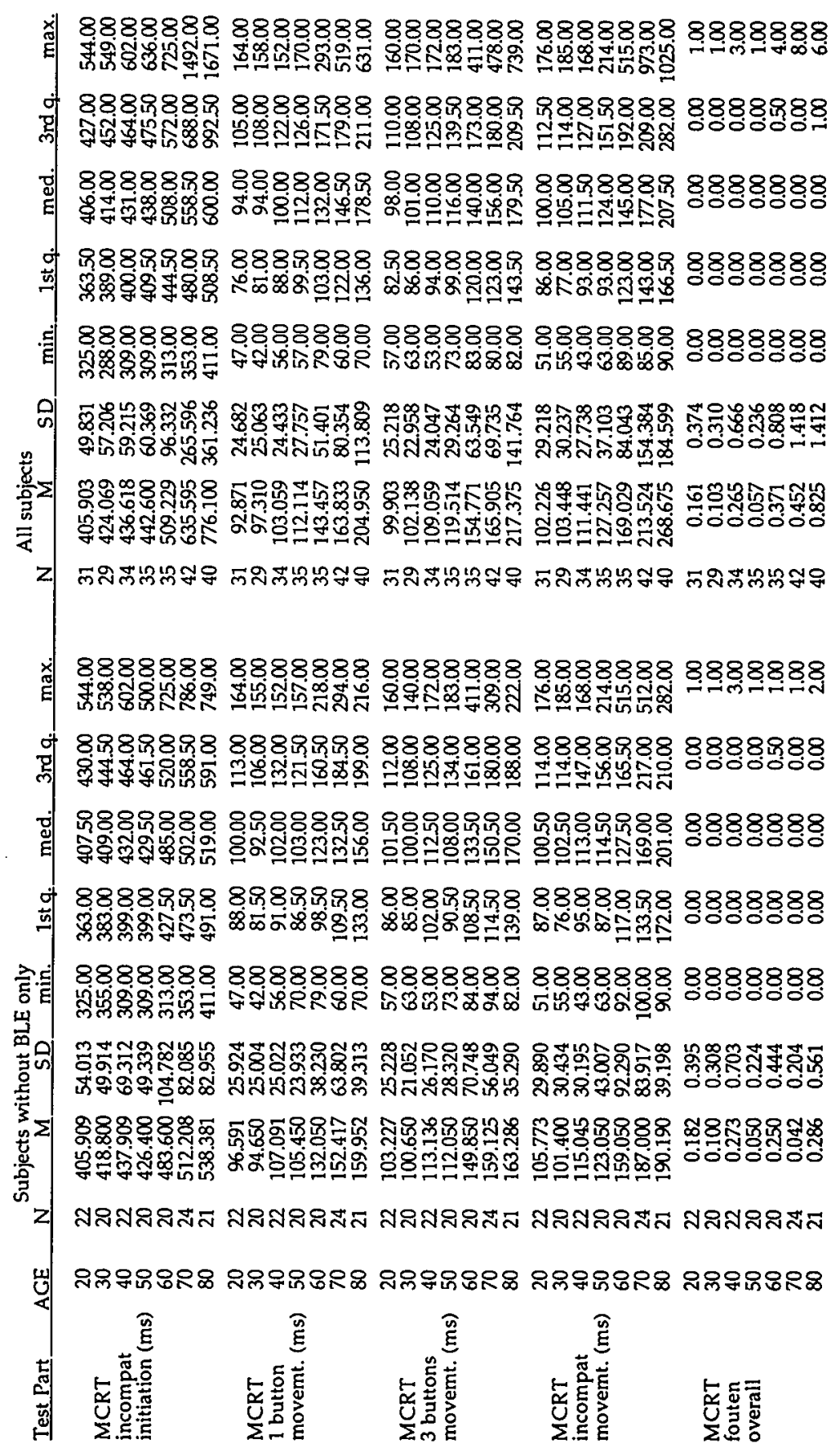

